\title{
Validation Tests of Fiber Optic Strain-Based Operational Shape and Load Measurements
}

\author{
John Bakalyar ${ }^{1}$ and Dr. Christine Jutte ${ }^{2}$ \\ NASA Dryden Flight Research Center \\ Edwards, $C A$
}

\begin{abstract}
Aircraft design has been progressing toward reduced structural weight to improve fuel efficiency, increase performance, and reduce cost. Lightweight aircraft structures are more flexible than conventional designs and require new design considerations. Intelligent sensing allows for enhanced control and monitoring of aircraft, which enables increased structurally efficiency. The NASA Dryden Flight Research Center (DFRC) has developed an instrumentation system and analysis techniques that combine to make distributed structural measurements practical for lightweight vehicles. Dryden's Fiber Optic Strain Sensing (FOSS) technology enables a multitude of lightweight, distributed surface strain measurements. The analysis techniques, referred to as the Displacement Transfer Functions (DTF) and Load Transfer Functions (LTF), use surface strain values to calculate structural deflections and operational loads. The combined system is useful for real-time monitoring of aeroelastic structures, along with many other applications. This paper describes how the capabilities of the measurement system were demonstrated using subscale test articles that represent simple aircraft structures. Empirical FOSS strain data were used within the DTF to calculate the displacement of the article and within the LTF to calculate bending moments due to loads acting on the article. The results of the tests, accuracy of the measurements, and a sensitivity analysis are presented.
\end{abstract}

\section{Introduction}

\section{A. Value of Structural Shape and Load Measurement}

Knowledge of the operational shape and loading of a structure is valuable for a variety of aerospace applications, such as aeroelastic monitoring, improved control surface effectiveness, drag reduction, sonic boom reduction and stores pointing. ${ }^{1}$ Existing camera-based methods are effective, ${ }^{2}$ but often impractical for use as permanent installations for real-time data display on large, lightweight aircraft.

The in-flight failure of Helios (Aerovironment, Inc., Monrovia, California), an extremely lightweight and flexible unmanned aircraft shown in Fig. 1, called attention to the need for a lightweight real-time deflection measurement system suitable for such an aircraft. Following the incident, the NASA Dryden Flight Research Center (Edwards, California) began investigating the use of distributed surface strain measurements as a means to calculate structural shape. ${ }^{3}$

In addition to deflection measurement, the surface strain measurements of Fiber Optic Strain Sensing (FOSS) can be used to calculate the loads acting on a structure. ${ }^{4}$ Current techniques use conventional metallic foil strain gages wired into shear, bending, and torsion bridges to measure loads at a few discrete points. ${ }^{5,6}$ Fiber Optic Strain Sensing and the Load Transfer Functions (LTF) enable load measurements

\footnotetext{
${ }^{1}$ Research Engineer, Aerostructures (RS) Branch, PO Box 273 M/S 48202A, and Member AIAA

${ }^{2}$ Research Engineer, Aerostructures (RS) Branch, PO Box 273 M/S 48202A, and Member AIAA 
distributed over the entire structure, often at a fraction of the weight of a conventional strain bridge arrangement.

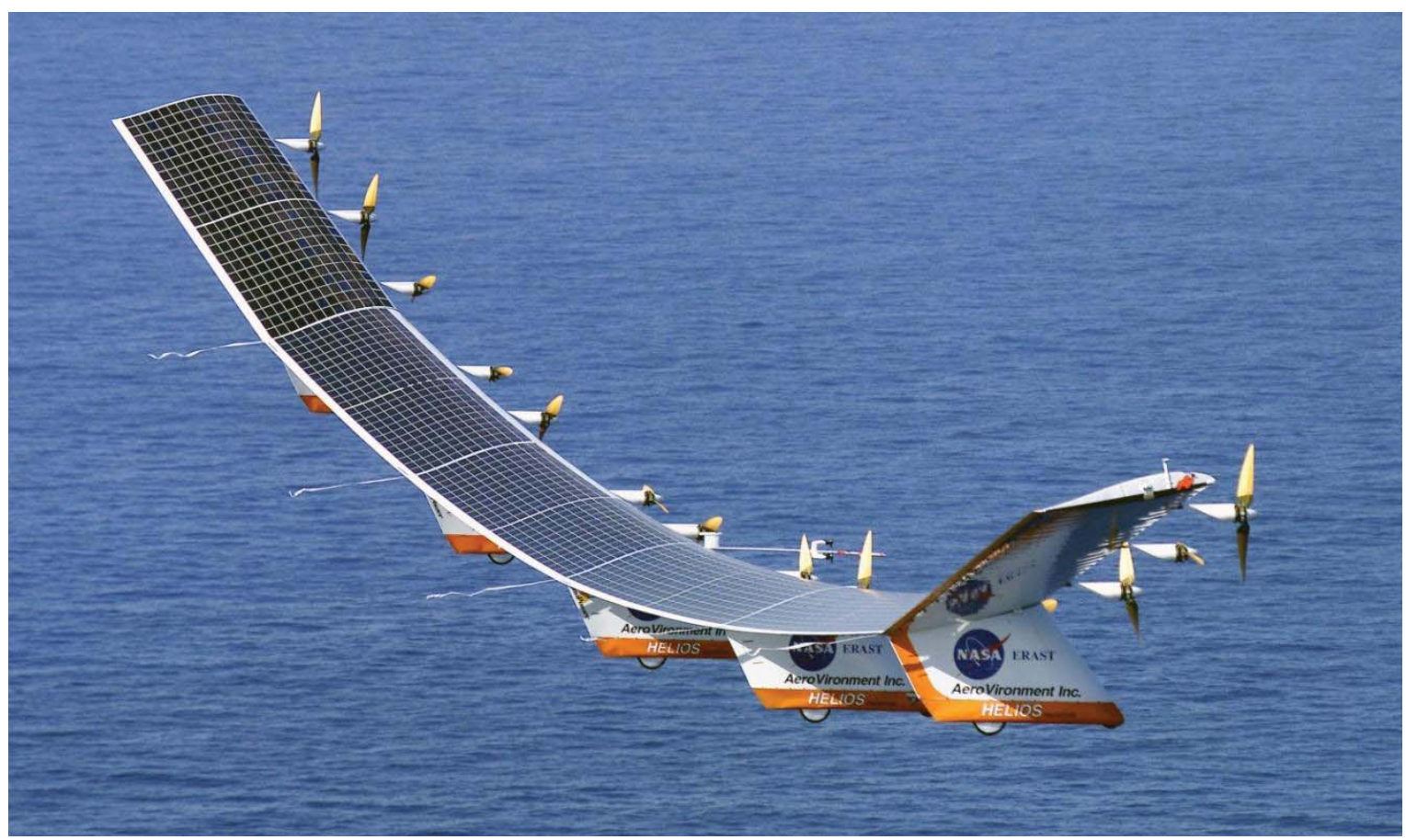

Figure 1. Helios (Aerovironment, Inc., Monrovia, California) aircraft; Note large operational wing deflections. 


\section{B. Equations}

A system of equations known as the Displacement Transfer Functions (DTF, also known as the Ko Displacement Theory) was developed at NASA Dryden. These equations use distributed surface strain values to calculate structural slopes and displacements. The DTF were formulated by integrating the curvature equation for the deformed-beam elastic curve. The structure is first discretized into multiple domains, so that the surface strain distribution within each domain can be described with a linear function. This piecewise linear approach enables integration of the beam curvature equation to yield slope and deflection equations in recursive formats. The slope and deflection equations were then combined into a single equation called the Displacement Transfer Function (Eq. 1). Furthermore, by calculating the deflection along a forward and aft fiber, the chord-wise angle of twist can be determined along the entire span. The formulation of the DTF is detailed in reference 7.

$$
y_{i}=\frac{(\Delta l)_{i}^{2}}{6 c_{i-1}}\left[\left(3-\frac{c_{i}}{c_{i-1}}\right) \varepsilon_{i-1}+\varepsilon_{i}\right]+y_{i-1}+(\Delta l)_{i} \tan \theta_{i-1}
$$

where,

$$
\tan \theta_{i}=\frac{(\Delta l)_{i}}{2 c_{i-1}}\left[\left(2-\frac{c_{i}}{c_{i-1}}\right) \varepsilon_{i-1}+\varepsilon_{i}\right]+\tan \theta_{i-1}
$$

Similar to the DTF, a new method was developed at NASA Dryden to use distributed strain measurements to calculate operational loads using the LTF. This process requires the determination of the cross-sectional properties of the structure by measuring strain values while a single known calibration load is applied. With these cross-sectional properties known at each domain, strain values induced by subsequent loads during operation can be used to determine the unknown loads acting on the structure. This paper considers loads only as bending moments; however, the method can be extended to include shear loads, as shown in Ref. 4. A flowchart of the LTF application process is shown in Fig. 2. Both the DTF and LTF equations are computationally efficient and are intended for use in a real-time environment.

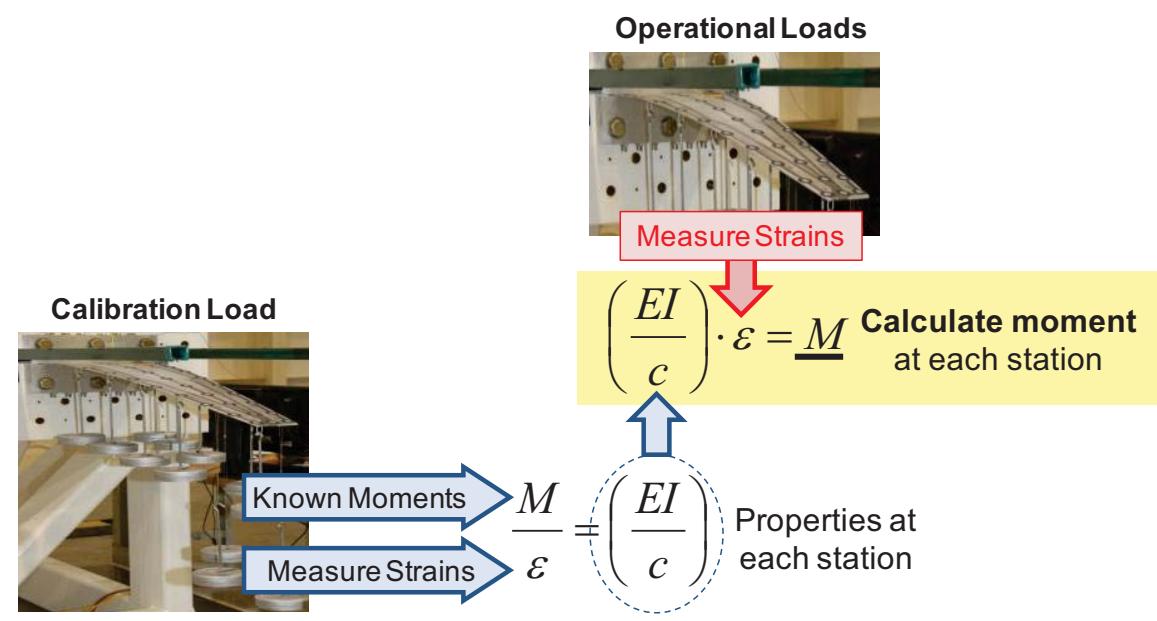

Figure 2. Load transfer function implementation process. 


\section{Fiber Optic Strain Sensing Technology}

Fiber Optic Strain Sensing offers the ability to make thousands of distributed surface strain measurements with a lightweight, flight-worthy system (Fig. 3). Many different fiber optic instrumentation systems exist; however, the NASA-developed system is ideally suited to make distributed measurements on aerospace structures. The FOSS system used for the tests described in this paper was capable of making strain measurements at one-half-inch intervals along up to eight fibers, each up to 40 feet in length at up to 100 samples per second. This allows nearly 8000 measurements covering 320 linear feet. The FOSS systems under development further expand this capability. Fiber Optic Strain Sensing technology makes the DTF and LTF methods practical for flight vehicles.

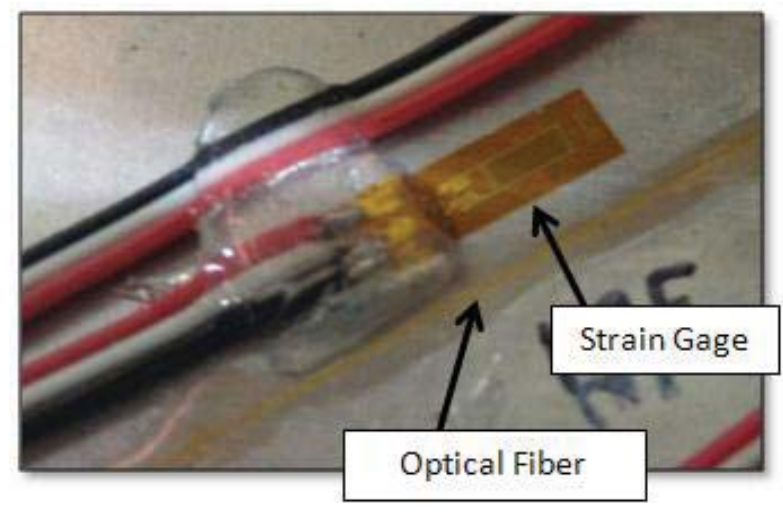

Figure 3. Fiber installation with strain gage shown for comparison.

\section{Test Description}

\section{A. Test Articles}

The objective of the small-scale demonstration tests was to validate the shape and load measurement methods against empirical data on a variety of test articles under various loading conditions. The tests were designed to be simple, in order to investigate the underlying principles and limitations of the method using empirical data. Four 6061-T6 aluminum plates of different planform shapes served as the test articles (Fig. 4). Each of these plates was 0.190 " thick with a span of 36 inches. The rectangular plate test article served as the baseline due to its simple geometry. The tapered plate and swept plate articles were each of shapes that are typical of aircraft wings. The open plate article was designed to have discontinuous cross-sectional properties, similar to a wing with internal ribs. One test article at a time was bolted into a cantilever fixture for testing, as shown in Fig. 4. 


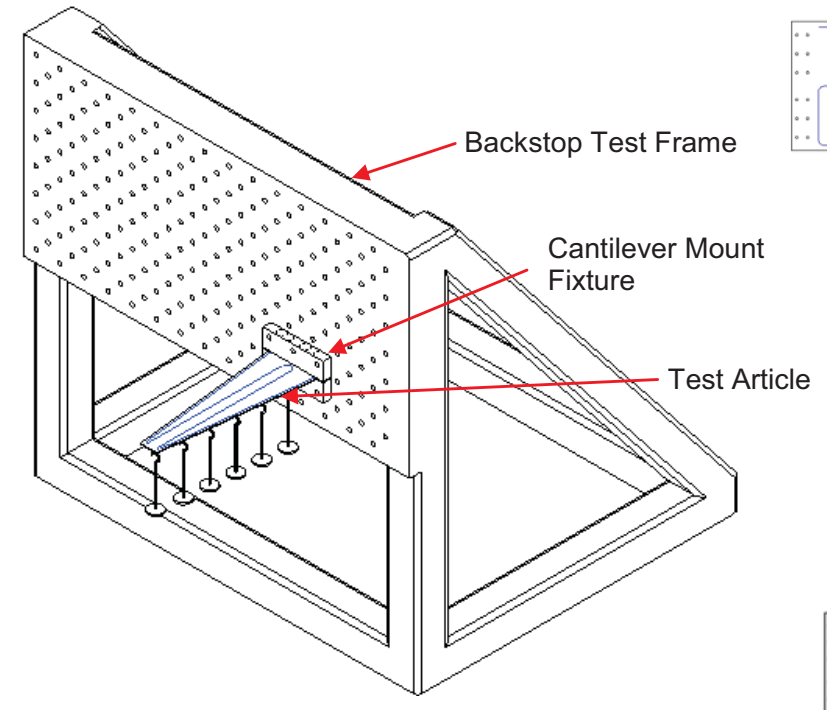

(a) Test Arrangement

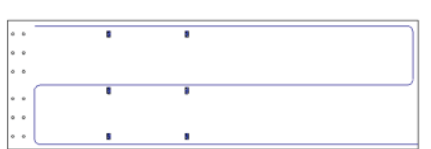

(b) Rectangular Plate

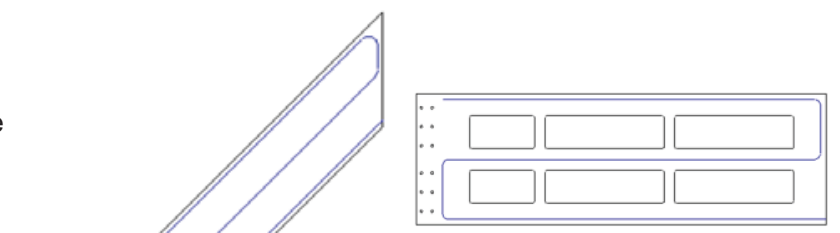

(e) Open Plate

Figure 4. Test arrangement and test articles.

\section{B. Instrumentation}

Each of the test articles was instrumented with a single optical fiber which made several passes on both the upper and lower surfaces of the test article (shown in blue in Fig. 4). Strain measurements were made every one-half-inch along these fibers.

The test articles were also instrumented with photogrammetry targets and a thermocouple, as can be seen in Fig. 5. The rectangular plate and swept plate also had metallic foil rosettes installed. The photogrammetry targets were placed along the fiber on the top surface of the test articles. An off-the-shelf two-camera photogrammetry system and its accompanying software were used during testing. The photogrammetric deflection measurements served as reference values to compare with the calculated deflections. The thermocouple provided a means to verify that the test article temperature did not change appreciably during testing. The strain rosettes provided a verification of the FOSS strain measurements. 


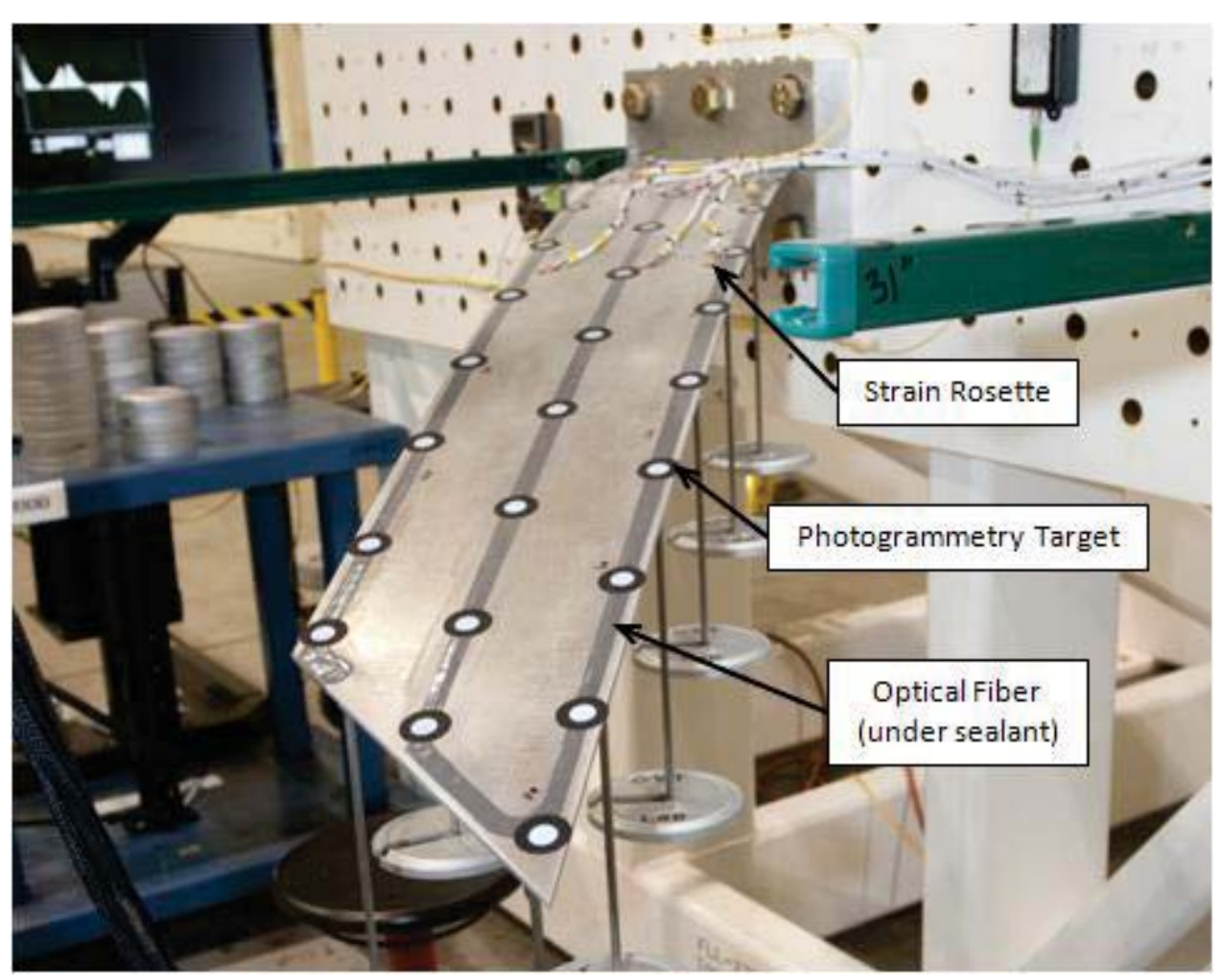

Figure 5. Swept plate during uniform load case.

\section{Load Cases}

At least five unique load cases were applied to each test article. Each load case consisted of calibrated dead weights hung from different load points on the underside of the test articles, as shown in Fig. 6. The "uniform" load case was applied multiple times to each test article (called "Uniform A," "Uniform B," and "Uniform C") to capture the repeatability of the test and calculations. The load cases applied to each test article are listed in Table 1.

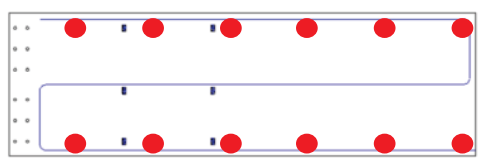

Uniform Load Case

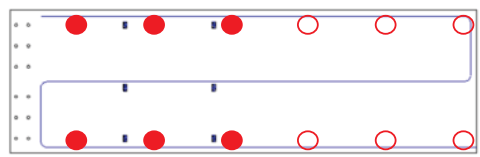

Root-Biased Load Case

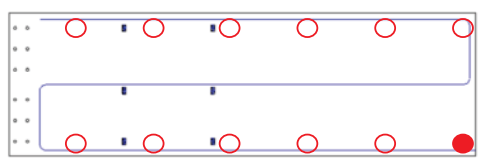

Single Point Load Case

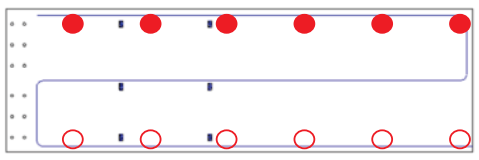

Leading Edge Load Case

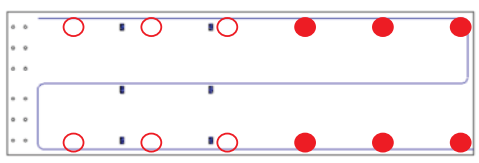

Tip-Biased Load Case

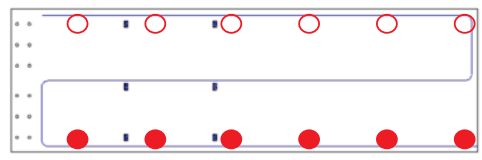

Trailing Edge Load Case

Figure 6. Load points used during each load case are shown in solid red. 
Table 1. Load cases performed on each test article.

\begin{tabular}{|lccccc|c|}
\hline Test article & $\begin{array}{c}\text { Uniform } \\
\text { load } \\
(\mathrm{A}, \mathrm{B}, \mathrm{C})\end{array}$ & $\begin{array}{c}\text { Tip- } \\
\text { biased } \\
\text { load }\end{array}$ & $\begin{array}{c}\text { Root- } \\
\text { biased } \\
\text { load }\end{array}$ & $\begin{array}{c}\text { Leading- } \\
\text { edge- } \\
\text { biased } \\
\text { load }\end{array}$ & $\begin{array}{c}\text { Trailing- } \\
\text { edge- } \\
\text { biased } \\
\text { load }\end{array}$ & $\begin{array}{c}\text { Single } \\
\text { point } \\
\text { load }\end{array}$ \\
\hline Rectangular plate & $\mathrm{X}$ & $\mathrm{X}$ & $\mathrm{X}$ & $\mathrm{X}$ & & $\mathrm{X}$ \\
\hline Tapered plate & $\mathrm{X}$ & $\mathrm{X}$ & $\mathrm{X}$ & $\mathrm{X}$ & & $\mathrm{X}$ \\
\hline Swept plate & $\mathrm{X}$ & $\mathrm{X}$ & $\mathrm{X}$ & $\mathrm{X}$ & $\mathrm{X}$ & $\mathrm{X}$ \\
\hline Open plate & $\mathrm{X}$ & $\mathrm{X}$ & $\mathrm{X}$ & $\mathrm{X}$ & $\mathrm{X}$ & $\mathrm{X}$ \\
\hline
\end{tabular}

Each load case was broken down into seven distinct load steps at which the test article motion was allowed to dampen out and photogrammetry images were captured. A description of the load steps is given in Fig. 7.

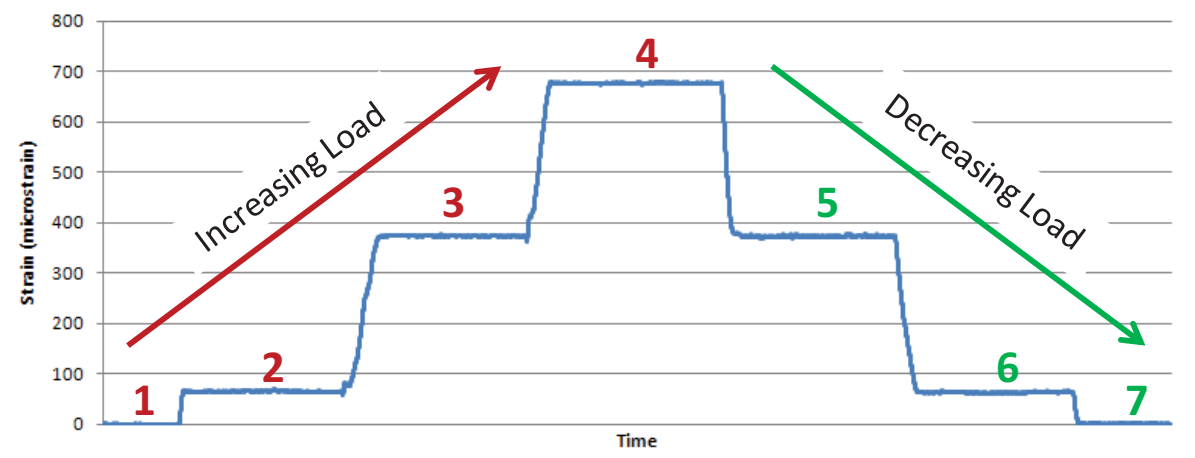

\begin{tabular}{|c|c|}
\hline Load Step & Description \\
\hline 1 & Unloaded \\
\hline 2 & Minimum Load \\
\hline 3 & Middle Load \\
\hline 4 & Maximum Load \\
\hline 5 & Middle Load \\
\hline 6 & Minimum Load \\
\hline 7 & Unloaded \\
\hline
\end{tabular}

Figure 7. Numbering of load steps (hold points during testing).

\section{Data Processing}

\section{A. Averaging at Load Steps}

Ten photogrammetry images were taken at each load step while the test article was in a static condition. The average of these ten images was used as the "true" vertical deflection for each target at each load step. The strain values were averaged over approximately 10 seconds at each load step. The effect of variation in the photogrammetric displacement values and strain values during these constant load conditions is discussed in the "Sensitivity Analysis" section.

\section{B. Interpolation and Extrapolation}

The spacing between the discrete domains used for deflection and load calculation was left to be variable, such that domains did not necessarily coincide with grating locations. Strain values at the domains were determined by linear interpolation using the two nearest measured strain values. Interpolation wasn't possible at the root of the test article because it was inboard of the first grating; therefore, the strain values for the last two inches of each test article were extrapolated (as shown in Fig. 8 ) using a fifth-order polynomial curve fit over the strain gratings along that fiber leg. For the purpose of this paper, the order of the polynomial curve fit was not formally optimized; a fifth-order curve fit was sufficient to characterize strains to the root. 


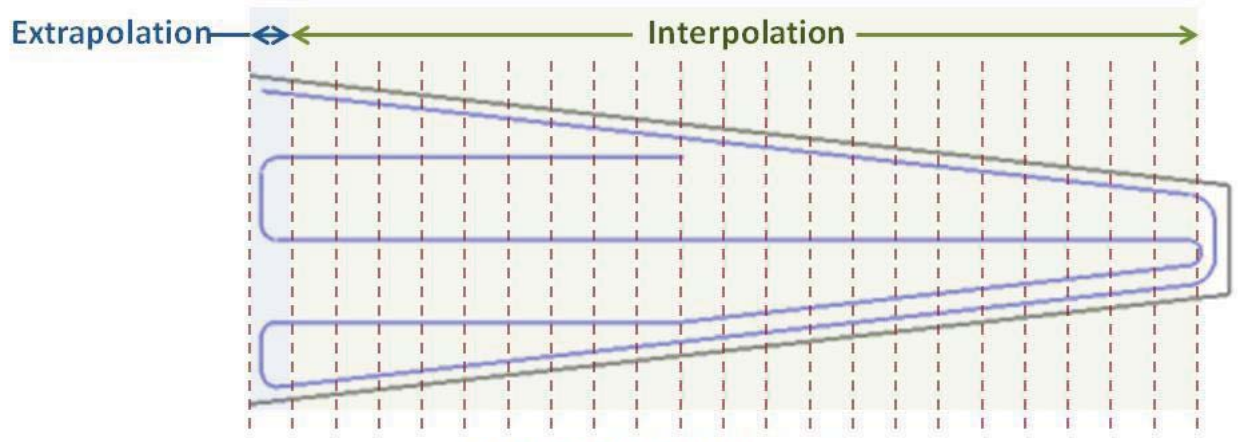

Analysis Domains

Figure 8. Strain values at analysis domains were interpolated when between two adjacent strain measurements, and extrapolated to the root.

\section{Neutral Axis Calculation}

The method for determining the location of the neutral axis discussed in Ref. 7 was not used in the final data analysis. The referenced method uses the top and bottom surface strains to determine the distance from a fiber to the neutral axis, c, as shown in Eq. 2. Due to the quantity in the denominator, this method is unstable when the top and bottom strains are equal.

$$
c_{\text {top }}=\left(\frac{\varepsilon_{\text {top }}}{\varepsilon_{\text {bottom }}-\varepsilon_{\text {top }}}\right) h
$$

A new method was developed which eliminates the need to calculate the location of the neutral axis by changing the inputs to the DTF. This new method, developed by Dr. William Ko of NASA Dryden, uses the distance separating the top and bottom fibers, $\mathrm{h}$, instead of the distance to the neutral axis, c, and uses the difference of the top and bottom strains, $\varepsilon_{\text {bottom }}-\varepsilon_{\text {top }}$, instead of strains from an individual surface, $\varepsilon_{\text {top }}$. The equivalency of this change is shown in Fig. 9. Thus, Eq. 1 becomes Eq. 3. This new method was found to eliminate errors associated with the instability in Eq. 2, and did not produce any adverse effects. 


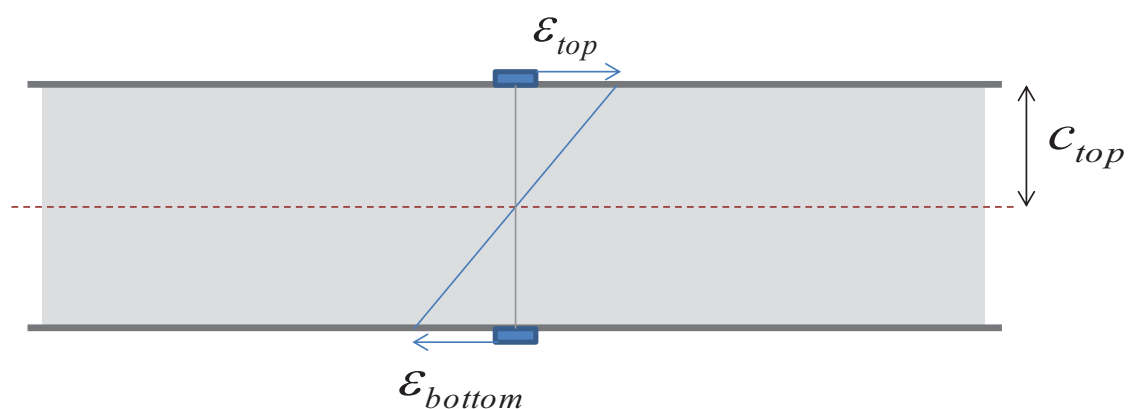

(a)

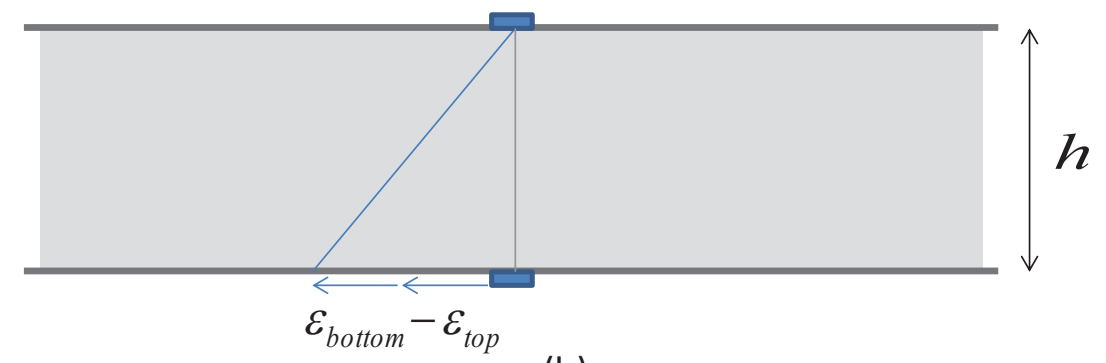

(b)

Figure 9. Change in strain location reference from neutral axis (a) to upper surface (b).

$$
y_{i}=\frac{(\Delta l)_{i}^{2}}{6 h_{i-1}}\left[\left(3-\frac{h_{i}}{h_{i-1}}\right)\left(\varepsilon_{\text {bottom }}-\varepsilon_{\text {top }}\right)_{i-1}+\left(\varepsilon_{\text {bottom }}-\varepsilon_{\text {top }}\right)_{i}\right]+y_{i-1}+(\Delta l)_{i} \tan \theta_{i-1}
$$

where,

$$
\tan \theta_{i}=\frac{(\Delta l)_{i}}{2 h_{i-1}}\left[\left(2-\frac{h_{i}}{h_{i-1}}\right)\left(\varepsilon_{\text {bottom }}-\varepsilon_{\text {top }}\right)_{i-1}+\left(\varepsilon_{\text {bottom }}-\varepsilon_{\text {top }}\right)_{i}\right]+\tan \theta_{i-1}
$$




\section{Results}

\section{A. Deflection}

The calculated deflection values generally compared very well with the photogrammetric measurements. Results for the middle fiber of the swept plate are shown in Figs. 10 and 11. Similar trends were observed in the other test articles and other load cases, which are shown in Appendix 1. Note that some load cases omit load steps 3 and 5 due to a lack of resolution in the available calibrated weights.

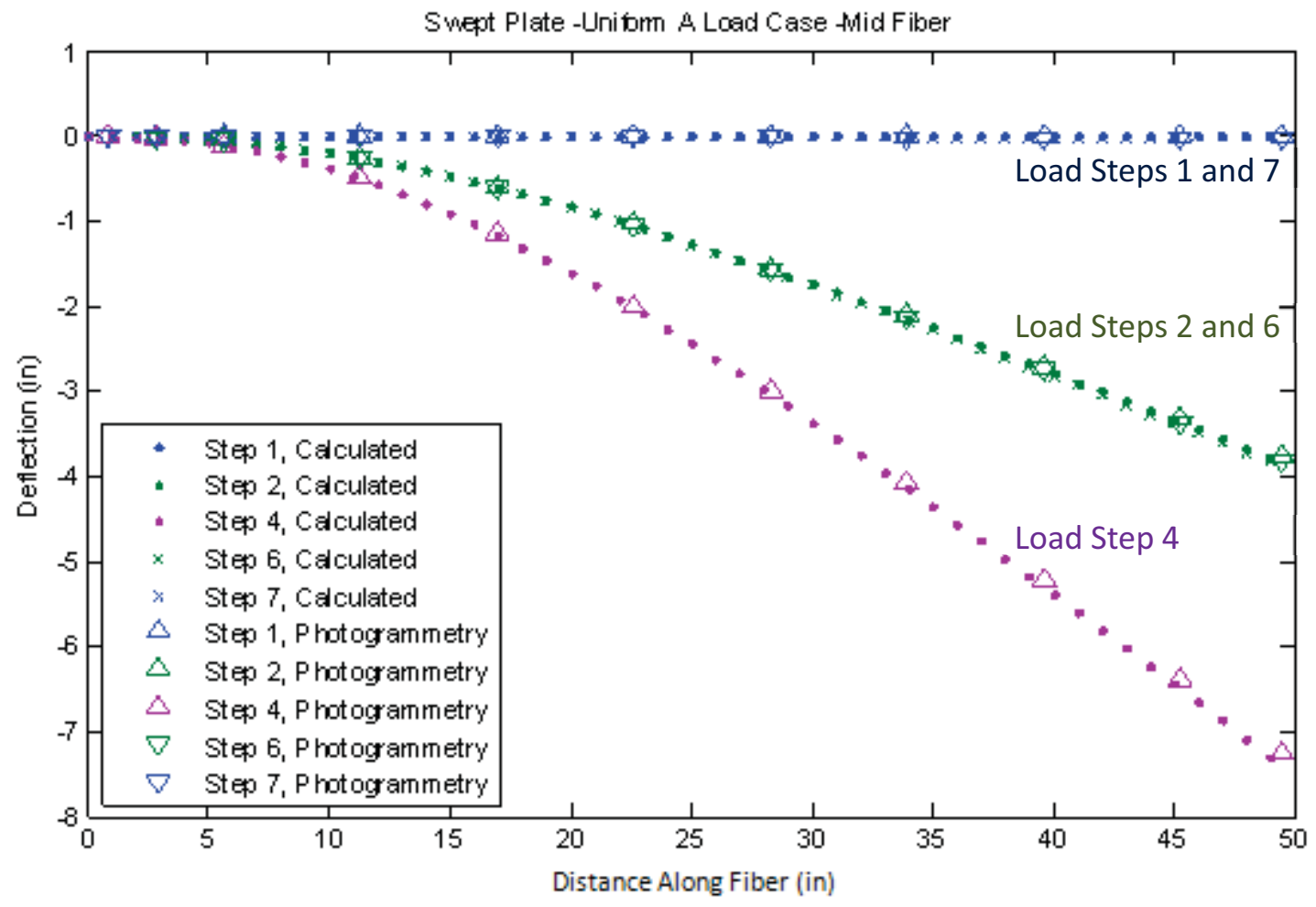

Figure 10. Swept plate deflection results for middle fiber during Uniform A load case. 


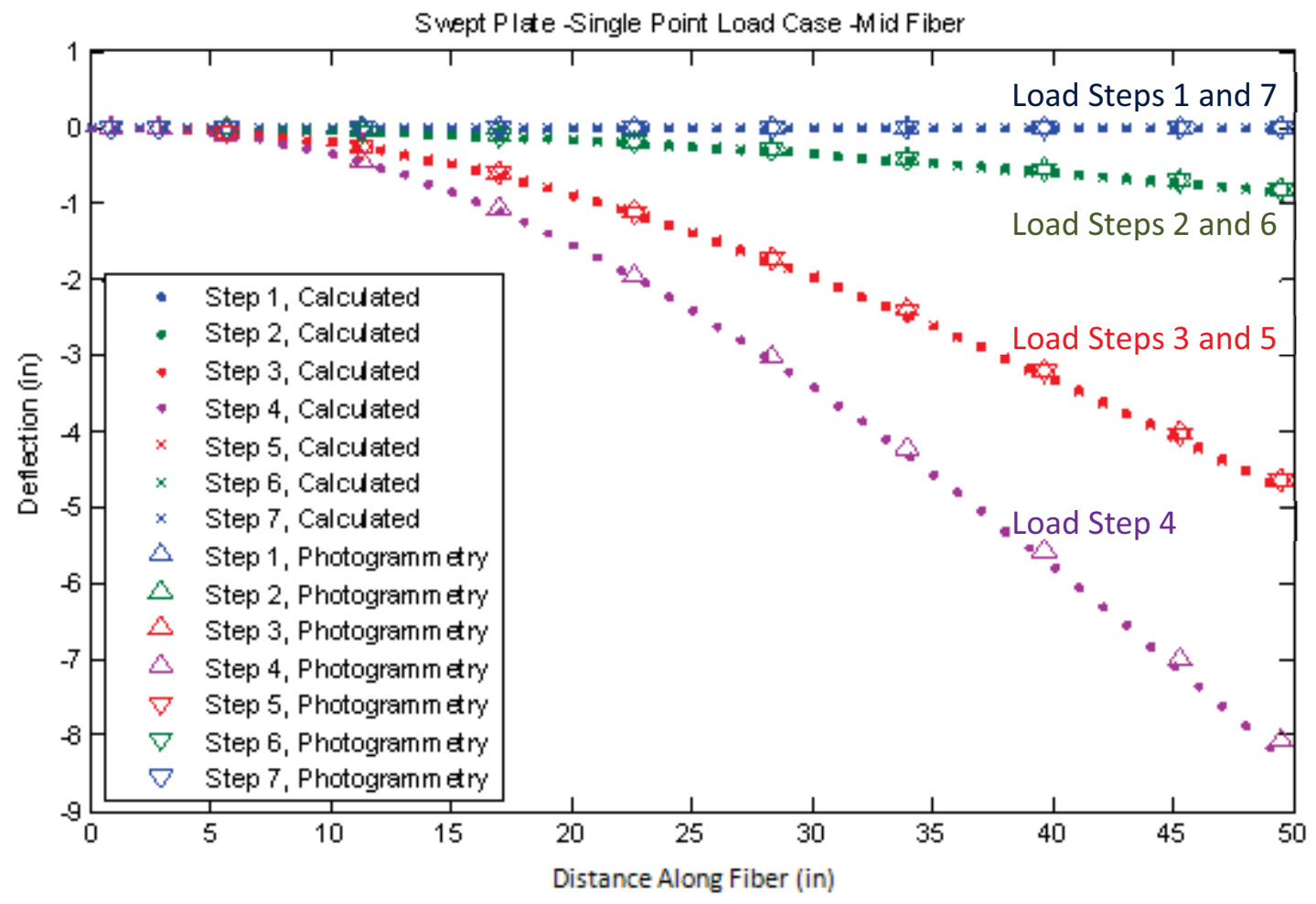

Figure 11. Swept plate deflection results for middle fiber during single point load case.

The deflection calculated along the trailing edge of the swept plate was consistently less accurate than in other areas. Toward the root of the swept plate test article, the principal strain direction quickly transitioned from the fiber direction to perpendicular to the root, as shown in Fig. 12. This is the area of greatest strain for the trailing edge fiber. The change in principal strain direction elsewhere is in areas with much less strain and did not cause the same inaccuracies. 


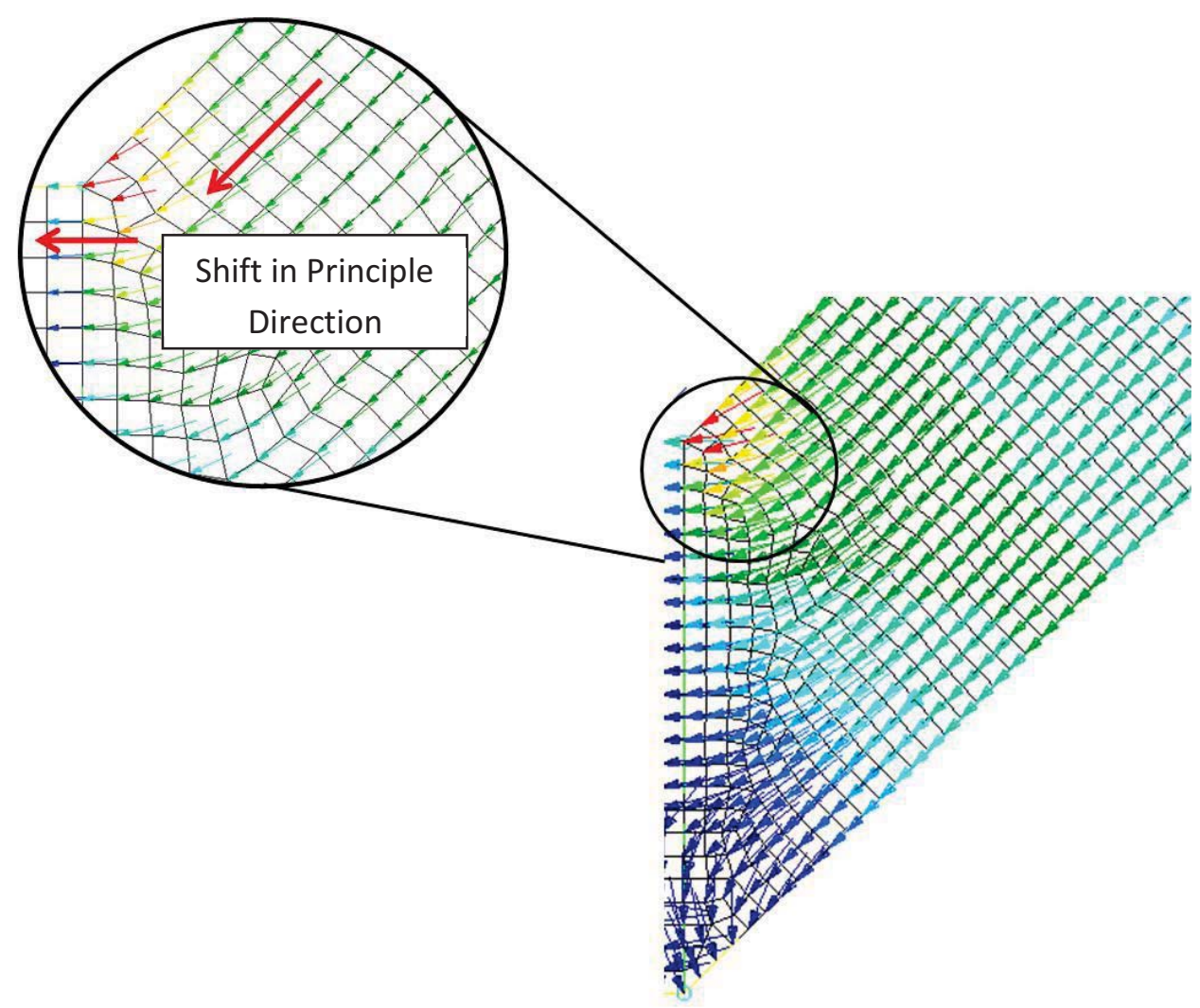

Figure 12. Change in principal direction close to the root of the swept plate test article shown in finite element model.

A summary of the tip deflection results is shown in Table 2. Comparing data at the maximum wingtip deflection (load step 4) from all test articles, all load cases, and all fiber legs, the root-mean-square error was 2.28 percent, or 0.106 inches. The greatest percent error was 10.9 , which occurred along the trailing edge leg of the swept plate during the root-biased load case. The greatest absolute error was 0.312 inches, which occurred along the trailing edge leg of the swept plate during the trailing-edge-biased load case. Both of these maximum error cases are on the trailing edge leg of the swept plate test article, which as mentioned previously, was prone to inaccuracy. If this area is ignored, the greatest percent error was 4.7 on the trailing edge leg of the open plate during the Uniform A load case, and the greatest absolute error was 0.229 inches on the trailing edge leg of the tapered plate during the leading edge biased load case. These accuracies (within 5 percent and .25 inches) were very encouraging for a strain-based method. 
Table 2. Tip deflection calculation results.

\begin{tabular}{|c|c|c|c|c|c|c|c|c|c|c|c|c|}
\hline \multirow[b]{3}{*}{ Load Case } & \multicolumn{12}{|c|}{ Rectangular Plate Deflection at Wingtip } \\
\hline & \multicolumn{4}{|c|}{ Trailing Edge } & \multicolumn{4}{|c|}{ Middle } & \multicolumn{4}{|c|}{ Leading Edge } \\
\hline & $\begin{array}{l}\text { Calc } \\
\text { (in) } \\
\end{array}$ & $\begin{array}{l}\text { Ref } \\
\text { (in) } \\
\end{array}$ & $\begin{array}{c}\text { Ref - Calc } \\
\text { (in) }\end{array}$ & $\begin{array}{c}\text { Error } \\
(\%) \\
\end{array}$ & $\begin{array}{l}\text { Calc } \\
\text { (in) } \\
\end{array}$ & $\begin{array}{l}\text { Ref } \\
\text { (in) }\end{array}$ & $\begin{array}{c}\text { Ref - Calc } \\
\text { (in) }\end{array}$ & $\begin{array}{c}\text { Error } \\
(\%) \\
\end{array}$ & $\begin{array}{l}\text { Calc } \\
\text { (in) }\end{array}$ & $\begin{array}{l}\text { Ref } \\
\text { (in) } \\
\end{array}$ & $\begin{array}{c}\text { Ref - Calc } \\
\text { (in) }\end{array}$ & $\begin{array}{c}\text { Error } \\
(\%) \\
\end{array}$ \\
\hline Uniform A & -5.488 & -5.398 & 0.090 & -1.7 & -5.334 & -5.408 & -0.074 & 1.4 & -5.360 & -5.408 & -0.048 & 0.9 \\
\hline Uniform B & -5.473 & -5.394 & 0.079 & -1.5 & -5.309 & -5.404 & -0.095 & 1.8 & -5.333 & -5.405 & -0.072 & 1.3 \\
\hline Uniform C & -5.461 & -5.394 & 0.067 & -1.2 & -5.212 & -5.403 & -0.191 & 3.5 & -5.301 & -5.405 & -0.104 & 1.9 \\
\hline Single Point & -2.202 & -2.172 & 0.030 & -1.4 & -2.163 & -2.267 & -0.105 & 4.6 & -2.282 & -2.358 & -0.076 & 3.2 \\
\hline Tip Biased & -5.851 & -5.769 & 0.081 & -1.4 & -5.727 & -5.774 & -0.047 & 0.8 & -5.763 & -5.777 & -0.014 & 0.2 \\
\hline Root Biased & -2.088 & -2.119 & -0.031 & 1.5 & -1.962 & - & - & - & -2.031 & -2.117 & -0.086 & 4.1 \\
\hline \multirow[t]{4}{*}{ Leading Edge } & -4.014 & -4.035 & -0.021 & 0.5 & -3.736 & -3.857 & -0.122 & 3.2 & -3.730 & -3.676 & 0.054 & -1.5 \\
\hline & \multicolumn{12}{|c|}{ Tapered Plate Deflection at Wingtip } \\
\hline & \multicolumn{4}{|c|}{ Trailing Edge } & \multicolumn{4}{|c|}{ Middle } & \multicolumn{4}{|c|}{ Leading Edge } \\
\hline & $\begin{array}{l}\text { Calc } \\
\text { (in) }\end{array}$ & $\begin{array}{l}\text { Ref } \\
\text { (in) }\end{array}$ & $\begin{array}{l}\text { Ref - Calc } \\
\text { (in) }\end{array}$ & $\begin{array}{c}\text { Error } \\
(\%)\end{array}$ & $\begin{array}{l}\text { Calc } \\
\text { (in) }\end{array}$ & $\begin{array}{l}\text { Ref } \\
\text { (in) }\end{array}$ & \begin{tabular}{|c|} 
Ref - Calc \\
(in)
\end{tabular} & $\begin{array}{c}\text { Error } \\
(\%)\end{array}$ & $\begin{array}{l}\text { Calc } \\
\text { (in) }\end{array}$ & $\begin{array}{l}\text { Ref } \\
\text { (in) } \\
\end{array}$ & $\begin{array}{c}\text { Ref - Calc } \\
\text { (in) }\end{array}$ & $\begin{array}{c}\text { Error } \\
(\%)\end{array}$ \\
\hline Uniform A & - & - & - & - & - & - & - & - & - & - & - & - \\
\hline Uniform B & -6.493 & -6.507 & -0.014 & 0.2 & -6.467 & -6.507 & -0.040 & 0.6 & -6.379 & -6.519 & -0.141 & 2.2 \\
\hline Uniform C & -6.448 & -6.512 & -0.064 & 1.0 & -6.468 & -6.512 & -0.045 & 0.7 & -6.376 & -6.524 & -0.148 & 2.3 \\
\hline Single Point & -2.851 & -2.869 & -0.018 & 0.6 & -2.863 & -2.881 & -0.018 & 0.6 & -2.847 & -2.893 & -0.046 & 1.6 \\
\hline Tip Biased & -7.110 & -7.141 & -0.031 & 0.4 & -7.179 & -7.147 & 0.032 & -0.4 & -7.121 & -7.161 & -0.040 & 0.6 \\
\hline Root Biased & -2.355 & -2.396 & -0.041 & 1.7 & -2.379 & -2.398 & -0.020 & 0.8 & -2.351 & -2.403 & -0.052 & 2.1 \\
\hline \multirow[t]{4}{*}{ Leading Edge } & -5.576 & -5.805 & -0.229 & 4.0 & -5.777 & -5.763 & 0.014 & -0.2 & -5.767 & -5.730 & 0.037 & -0.6 \\
\hline & \multicolumn{12}{|c|}{ Swept Plate Deflection at Wingtip } \\
\hline & \multicolumn{4}{|c|}{ Trailing Edge } & \multicolumn{4}{|c|}{ Middle } & \multicolumn{4}{|c|}{ Leading Edge } \\
\hline & $\begin{array}{l}\text { Calc } \\
\text { (in) } \\
\end{array}$ & $\begin{array}{l}\text { Ref } \\
\text { (in) } \\
\end{array}$ & $\begin{array}{c}\text { Ref - Calc } \\
\text { (in) }\end{array}$ & $\begin{array}{c}\text { Error } \\
(\%) \\
\end{array}$ & $\begin{array}{l}\text { Calc } \\
\text { (in) } \\
\end{array}$ & $\begin{array}{l}\text { Ref } \\
\text { (in) } \\
\end{array}$ & \begin{tabular}{|c|} 
Ref - Calc \\
(in)
\end{tabular} & $\begin{array}{c}\text { Error } \\
(\%) \\
\end{array}$ & $\begin{array}{l}\text { Calc } \\
\text { (in) } \\
\end{array}$ & $\begin{array}{l}\text { Ref } \\
\text { (in) } \\
\end{array}$ & $\begin{array}{c}\text { Ref - Calc } \\
\text { (in) }\end{array}$ & $\begin{array}{c}\text { Error } \\
\text { (\%) } \\
\end{array}$ \\
\hline Uniform A & -7.361 & -7.661 & -0.300 & 3.9 & -7.088 & -6.953 & 0.134 & -1.9 & -6.229 & -6.233 & -0.005 & 0.1 \\
\hline Uniform B & -7.361 & -7.655 & -0.294 & 3.8 & -6.981 & -6.944 & 0.037 & -0.5 & -6.172 & -6.219 & -0.046 & 0.7 \\
\hline Uniform C & -7.358 & -7.658 & -0.300 & 3.9 & -7.082 & -6.949 & 0.132 & -1.9 & -6.244 & -6.225 & 0.019 & -0.3 \\
\hline Single Point & -8.601 & -8.669 & -0.068 & 0.8 & -7.876 & -7.695 & 0.180 & -2.3 & -6.747 & -6.711 & 0.036 & -0.5 \\
\hline Tip Biased & -6.409 & -6.576 & -0.167 & 2.5 & -6.034 & -5.925 & 0.110 & -1.9 & -5.259 & -5.255 & 0.004 & -0.1 \\
\hline Root Biased & -2.059 & -2.310 & -0.251 & 10.9 & -2.167 & -2.145 & 0.022 & -1.0 & -1.919 & -1.976 & -0.057 & 2.9 \\
\hline Leading Edge & -4.868 & -5.096 & -0.228 & 4.5 & -4.745 & -4.714 & 0.031 & -0.7 & -4.294 & -4.320 & -0.026 & 0.6 \\
\hline Trailing Edge & -6.877 & -7.189 & -0.312 & 4.3 & -6.481 & -6.447 & 0.034 & -0.5 & -5.635 & -5.688 & -0.052 & 0.9 \\
\hline
\end{tabular}

\begin{tabular}{|c|c|c|c|c|c|c|c|c|c|c|c|c|}
\hline \multirow[b]{3}{*}{ Load Case } & \multicolumn{12}{|c|}{ Open Plate Deflection at Wingtip } \\
\hline & \multicolumn{4}{|c|}{ Trailing Edge } & \multicolumn{4}{|c|}{ Middle } & \multicolumn{4}{|c|}{ Leading Edge } \\
\hline & $\begin{array}{l}\text { Calc } \\
\text { (in) }\end{array}$ & $\begin{array}{l}\text { Ref } \\
\text { (in) }\end{array}$ & $\begin{array}{c}\text { Ref - Calc } \\
\text { (in) }\end{array}$ & $\begin{array}{c}\text { Error } \\
(\%)\end{array}$ & $\begin{array}{l}\text { Calc } \\
\text { (in) }\end{array}$ & $\begin{array}{l}\text { Ref } \\
\text { (in) }\end{array}$ & \begin{tabular}{|c} 
Ref - Calc \\
(in)
\end{tabular} & $\begin{array}{c}\text { Error } \\
(\%)\end{array}$ & $\begin{array}{l}\text { Calc } \\
\text { (in) }\end{array}$ & $\begin{array}{l}\text { Ref } \\
\text { (in) }\end{array}$ & $\begin{array}{c}\text { Ref - Calc } \\
\text { (in) }\end{array}$ & $\begin{array}{c}\text { Error } \\
(\%)\end{array}$ \\
\hline Uniform A & -3.677 & -3.511 & 0.166 & -4.7 & -3.499 & -3.513 & -0.015 & 0.4 & -3.486 & -3.510 & -0.024 & 0.7 \\
\hline Uniform B & -3.503 & -3.509 & -0.006 & 0.2 & -3.497 & -3.513 & -0.015 & 0.4 & -3.554 & -3.508 & 0.047 & -1.3 \\
\hline Uniform C & -3.430 & -3.511 & -0.081 & 2.3 & -3.483 & -3.514 & -0.031 & 0.9 & -3.493 & -3.510 & -0.016 & 0.5 \\
\hline Single Point & -3.430 & -3.401 & 0.029 & -0.9 & -3.555 & - & - & - & -3.738 & -3.722 & 0.016 & -0.4 \\
\hline Tip Biased & -4.728 & -4.653 & 0.075 & -1.6 & -4.719 & -4.649 & 0.070 & -1.5 & -4.687 & -4.647 & 0.040 & -0.9 \\
\hline Root Biased & -1.973 & -2.020 & -0.047 & 2.3 & -2.002 & -2.020 & -0.017 & 0.9 & -1.996 & -2.017 & -0.021 & 1.0 \\
\hline Leading Edge & -4.430 & -4.595 & -0.165 & 3.6 & -4.300 & -4.345 & -0.045 & 1.0 & -4.062 & -4.092 & -0.029 & 0.7 \\
\hline Trailing Edge & -4.171 & -4.096 & 0.075 & -1.8 & -4.290 & -4.342 & -0.053 & 1.2 & -4.574 & -4.592 & -0.018 & 0.4 \\
\hline
\end{tabular}

Calc: Calculated value, using DTF and FOSS Strain

Ref: Reference value, using photogrammetry data

Ref-Calc: Difference between reference and calculated

Error: (Ref-Calc)/Ref

" - " : Value not available due to data corruption

13

American Institute of Aeronautics and Astronautics 


\section{B. Twist}

The angle of twist is calculated by comparing the deflection values at two chord-wise locations. Despite the accuracy of the individual deflection measurements, the calculated twist values were less accurate. The simple trigonometric relationship used to determine the angle of twist is very sensitive to errors in the calculated deflections. This caused errors of greater than 0.5 degrees at the tip of the test article in a majority of the load cases; results are shown in Table 3 . The sensitivity of the twist equation is further examined in the "sensitivity analysis" section. 
Table 3. Twist calculation results.

\begin{tabular}{|l|c|c|c|}
\hline \multicolumn{4}{|c|}{ Rectangular Plate Twist at Wingtip (degrees) } \\
\hline Load Case & Calc & Ref & Ref-Calc \\
\hline \hline Uniform A & -0.67 & 0.05 & 0.72 \\
\hline Uniform B & -0.73 & 0.06 & 0.79 \\
\hline Uniform C & -0.83 & 0.06 & 0.89 \\
\hline Single Point & 0.42 & 0.97 & 0.55 \\
\hline Tip Biased & -0.45 & 0.04 & 0.50 \\
\hline Root Biased & -0.30 & -0.01 & 0.29 \\
\hline Leading Edge & -1.48 & -1.87 & -0.39 \\
\hline
\end{tabular}

\begin{tabular}{|l|c|c|c|}
\hline \multicolumn{4}{|c|}{ Tapered Plate Twist at Wingtip (degrees) } \\
\hline Load Case & Calc & Ref & Ref-Calc \\
\hline \hline Uniform A & - & - & - \\
\hline Uniform B & -2.17 & 0.07 & 2.24 \\
\hline Uniform C & -1.37 & 0.06 & 1.43 \\
\hline Single Point & -0.08 & 0.13 & 0.20 \\
\hline Tip Biased & 0.21 & 0.11 & -0.10 \\
\hline Root Biased & -0.07 & 0.04 & 0.11 \\
\hline Leading Edge & 3.66 & -0.40 & -4.06 \\
\hline
\end{tabular}

Swept Plate Twist at Wingtip (degrees)

\begin{tabular}{|l|c|c|c|}
\hline Load Case & Calc & Ref & Ref-Calc \\
\hline \hline Uniform A & -5.91 & -7.47 & -1.56 \\
\hline Uniform B & -6.20 & -7.51 & -1.31 \\
\hline Uniform C & -5.82 & -7.50 & -1.69 \\
\hline Single Point & -9.71 & -10.32 & -0.62 \\
\hline Tip Biased & -6.00 & -6.91 & -0.91 \\
\hline Root Biased & -0.73 & -1.74 & -1.01 \\
\hline Leading Edge & -2.99 & -4.04 & -1.04 \\
\hline Trailing Edge & -6.48 & -7.85 & -1.37 \\
\hline
\end{tabular}

Open Plate Twist at Wingtip (degrees)

\begin{tabular}{|l|c|c|c|}
\hline Load Case & Calc & Ref & Ref-Calc \\
\hline \hline Uniform A & -0.99 & 0.00 & 0.99 \\
\hline Uniform B & 0.27 & -0.01 & -0.28 \\
\hline Uniform C & 0.33 & -0.01 & -0.34 \\
\hline Single Point & 1.61 & 1.68 & 0.07 \\
\hline Tip Biased & -0.21 & -0.03 & 0.18 \\
\hline Root Biased & 0.12 & -0.02 & -0.14 \\
\hline Leading Edge & -1.91 & -2.62 & -0.71 \\
\hline Trailing Edge & 2.10 & 2.58 & 0.49 \\
\hline
\end{tabular}

Calc: Calculated value, using DTF and FOSS Strain

Ref: Reference value, using photogrammetry data Ref-Calc: Difference between reference and calculated

" - " : Value not available due to data corruption

15

American Institute of Aeronautics and Astronautics 


\section{Load}

The load calculations produced promising results. The accuracy of the calculated loads, however, was found to be sensitive to the load distribution chosen for the calibration load, recalling that the calibration load is used to determine the cross-sectional properties required for subsequent load calculations. During this study, one of the uniform load case applications served as the calibration load. Results from the load calculations closely followed the actual for subsequent uniform load applications. Calculations for different load cases follow the same trend as the actual values but were less accurate. Figures 13 and 14 show the load calculation results for the tapered plate test article. Table 4 shows a summary of the load calculation results at the root of the test article during the maximum load step (load step 4) for each load case. The root-mean-squared bending moment error at the root is 10.7 percent; however, this number is greatly influenced by the large errors during the root-biased load cases. The error is much less for load cases that are similar to the calibration load, which indicates that using a realistic load distribution during the check loading will produce the best results during operation.

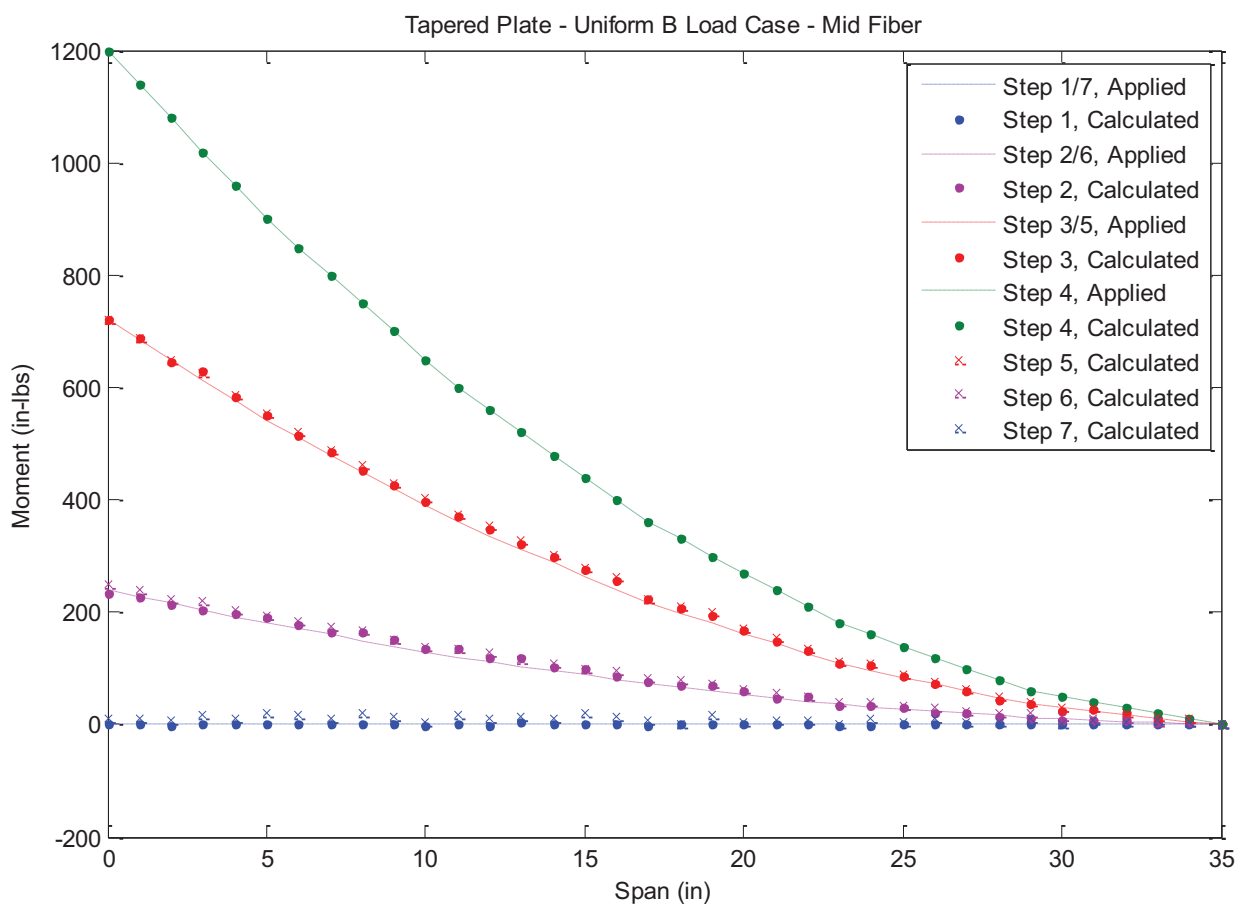

Figure 13. Tapered plate load calculation results for the middle fiber during the Uniform B load case. 


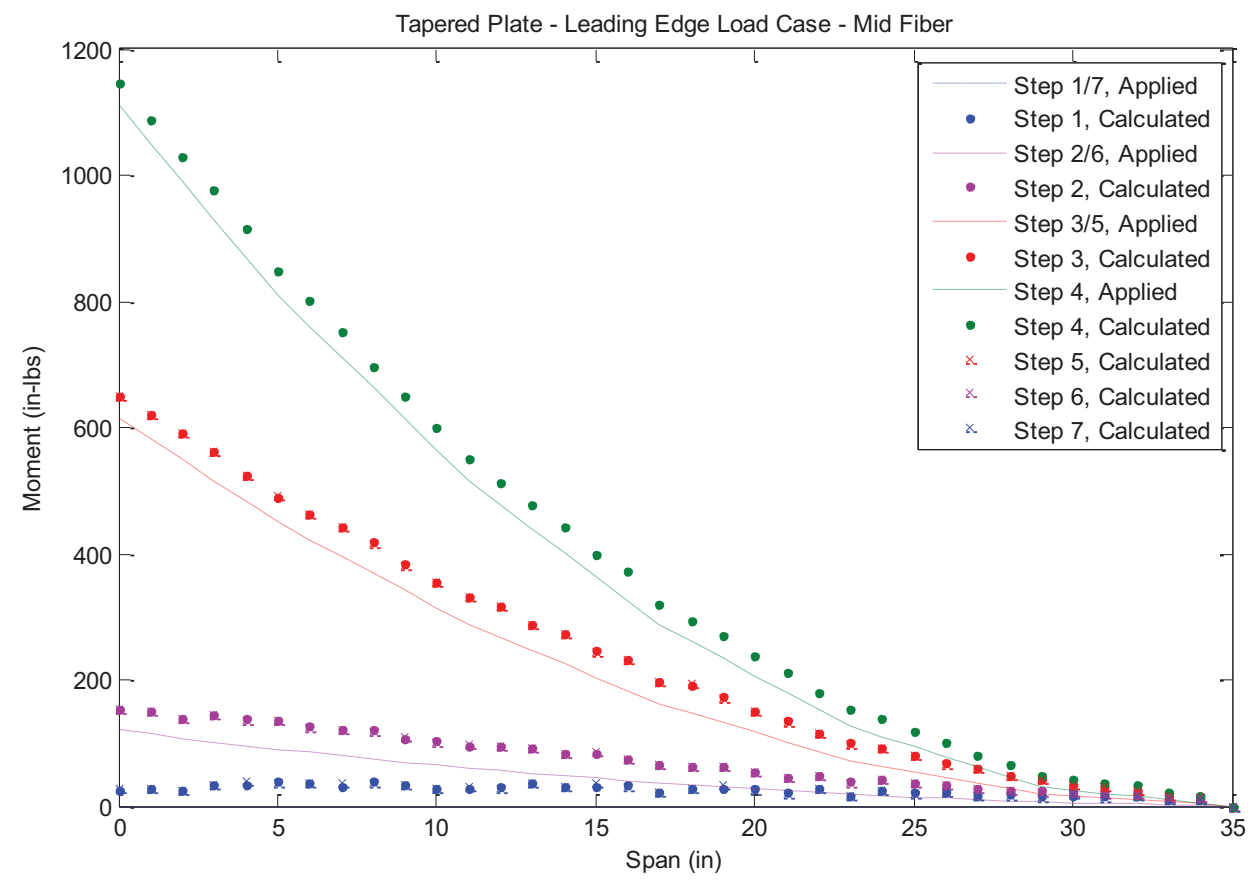

Figure 14. Tapered plate load calculation results for the middle fiber during the leading edge load case. 
Table 4. Summary of Load Transfer Function error; the first load case for each test article was used as the "calibration load."

\begin{tabular}{|l|c|c|c|c|}
\hline \multicolumn{5}{|c|}{ Rectangular Plate Bending Moment at Root (in-lbs) } \\
\hline Load Case & Calc & Ref & Ref - Calc & Error (\%) \\
\hline \hline Uniform A & 1200.0 & 1200.0 & 0.0 & 0.0 \\
\hline Uniform B & 1191.6 & 1200.0 & 8.4 & 0.7 \\
\hline Uniform C & 1156.1 & 1200.0 & 43.9 & 3.7 \\
\hline Single Point & 376.4 & 385.0 & 8.6 & 2.2 \\
\hline Tip Biased & 1034.2 & 1176.0 & 141.8 & 12.1 \\
\hline Root Biased & 720.5 & 726.0 & 5.5 & 0.8 \\
\hline Leading Edge & 835.6 & 840.0 & 4.4 & 0.5 \\
\hline
\end{tabular}

Tapered Plate Bending Moment at Root (in-lbs)

\begin{tabular}{|l|c|c|c|c|}
\hline Load Case & Calc & Ref & Ref - Calc & Error (\%) \\
\hline \hline Uniform A & - & - & - & - \\
\hline Uniform B & 1200.0 & 1200.0 & 0.0 & 0.0 \\
\hline Uniform C & 1196.2 & 1200.0 & 3.8 & 0.3 \\
\hline Single Point & 403.1 & 385.0 & -18.1 & -4.7 \\
\hline Tip Biased & 1061.8 & 1060.0 & -1.8 & -0.2 \\
\hline Root Biased & 813.5 & 726.0 & -87.5 & -12.1 \\
\hline Leading Edge & 1145.8 & 1110.0 & -35.8 & -3.2 \\
\hline
\end{tabular}

\begin{tabular}{|l|c|c|c|c|}
\hline \multicolumn{5}{|c|}{ Swept Plate Bending Moment at Root (in-lbs) } \\
\hline Load Case & Calc & Ref & Ref - Calc & Error (\%) \\
\hline \hline Uniform A & 480.0 & 480.0 & 0.0 & 0.0 \\
\hline Uniform B & 474.0 & 480.0 & 6.0 & 1.2 \\
\hline Uniform C & 474.9 & 480.0 & 5.1 & 1.1 \\
\hline Single Point & 374.5 & 385.0 & 10.5 & 2.7 \\
\hline Tip Biased & 327.4 & 326.0 & -1.4 & -0.4 \\
\hline Root Biased & 465.1 & 352.0 & -113.1 & -32.1 \\
\hline Leading Edge & 451.0 & 408.0 & -43.0 & -10.5 \\
\hline Trailing Edge & 393.0 & 408.0 & 15.0 & 3.7 \\
\hline
\end{tabular}

\begin{tabular}{|l|c|c|c|c|}
\hline \multicolumn{5}{|c|}{ Open Plate Bending Moment at Root (in-lbs) } \\
\hline Load Case & Calc & Ref & Ref - Calc & Error (\%) \\
\hline \hline Uniform A & 480.0 & 480.0 & 0.0 & 0.0 \\
\hline Uniform B & 511.3 & 480.0 & -31.3 & -6.5 \\
\hline Uniform C & 450.8 & 480.0 & 29.2 & 6.1 \\
\hline Single Point & 361.0 & 385.0 & 24.0 & 6.2 \\
\hline Tip Biased & 498.0 & 524.0 & 26.0 & 5.0 \\
\hline Root Biased & 687.2 & 522.0 & -165.2 & -31.6 \\
\hline Leading Edge & 515.5 & 600.0 & 84.5 & 14.1 \\
\hline Trailing Edge & 597.8 & 600.0 & 2.2 & 0.4 \\
\hline
\end{tabular}

Calc: Calculated value, using LTF and FOSS Strain

Ref: Actual value

Ref-Calc: Difference between reference and calculated

Error: (Ref-Calc)/Ref

" - " : Value not available due to data corruption

18

American Institute of Aeronautics and Astronautics 


\section{Sensitivity Analyses}

\section{A. Deflection Sensitivity}

Following the initial deflection and load calculations, a sensitivity analysis was performed to determine the primary sources of error. The sources of error examined were strain values, plate thickness values, and photogrammetry deflection values. The middle fiber of the swept plate test article during the Uniform C load case, load step 4, was used as the basis for the sensitivity study.

The maximum observed standard deviation of a strain value at the investigated load step was 5.9 microstrain. The deviation in strain values at several load steps was analyzed and determined to fit a normal distribution. For a normal distribution, the probability of the data falling within two standard deviations of the mean is approximately 95 percent. Twice the maximum standard deviation was applied to both the upper and lower surface strains (a total offset of 23.6 microstrain to the difference in strain values) as a conservative method for studying errors in the measured strain values. Errors in strain values may be attributed to several different causes. The most obvious cause for errors in strain values is measurement error in the Fiber Bragg Grating and FOSS interrogation system. Another cause for error in strain is incorrect location of the strain measurement. If the location of the strain measurement is incorrect, then the strain value is effectively incorrect. A final possible source for error is in poor fiber alignment during installation. Table 5 shows that errors in strain values can cause an error of just over 2 percent for the swept plate.

Table 5. Change in deflection calculation due to error in strain values.

\begin{tabular}{|lccc|}
\hline Measured & $\begin{array}{c}\text { Offset } \\
\text { (microstrain) }\end{array}$ & $\begin{array}{c}\text { Deflection } \\
\text { (in) }\end{array}$ & $\begin{array}{c}\text { Deflection } \\
\text { change (\%) }\end{array}$ \\
\hline Measured + Offset & n/a & 7.296 & n/a \\
\hline Measured - Offset & 23.6 & 7.147 & -2.04 \\
\hline
\end{tabular}

Measured $=$ lower surface strain - upper surface strain

The thickness of the test articles was an input to the DTF and another potential source of error. For these tests, the nominal thickness (.190 inches) of the aluminum plate was assumed to be constant. An offset of .015 inches was used for this analysis, which accounts for both the manufacturer's thickness tolerance of the plate ( \pm .009 inches) and the diameter of the fiber (.006 inches), which makes a significant difference in thickness for this test article. The deflection changes are nearly proportionally with thickness, so thickness errors are directly propagated into deflection errors, Table 6.

Table 6. Change in calculated tip deflection due to change in thickness (performed using the swept plate test article, Uniform $C$ load case, middle fiber).

\begin{tabular}{|c|c|c|c|c|}
\hline & $\begin{array}{l}\text { Thickness } \\
\text { (in) }\end{array}$ & $\begin{array}{l}\text { Thickness } \\
\text { error }(\%)\end{array}$ & $\begin{array}{l}\text { Deflection } \\
\text { (in) }\end{array}$ & $\begin{array}{l}\text { Deflection } \\
\text { change (\%) }\end{array}$ \\
\hline Nominal & .190 & $\mathrm{n} / \mathrm{a}$ & 7.296 & $\mathrm{n} / \mathrm{a}$ \\
\hline Nominal + Offset & .205 & 7.89 & 6.762 & -7.32 \\
\hline Nominal - Offset & .175 & -7.89 & 7.921 & 8.57 \\
\hline
\end{tabular}

The maximum standard deviation of a photogrammetry target displacement at the investigated load step was .0064 inches. An offset of twice this maximum standard deviation was applied to all the photogrammetry targets as a conservative method for studying the effect of errors in the photogrammetry values. This creates a range of \pm .0128 inches around the measured value within which the true displacement can be expected to fall. Table 7 shows that photogrammetry uncertainty is insignificant (less 
than one percent) when measuring tip deflections. This uncertainty is assumed to be equal among all targets, which means that the photogrammetric error has the greatest influence at locations with small displacements.

Table 7. Change in tip deflection due to error in photogrammetry values.

\begin{tabular}{|lccc|}
\hline Offset (in) & $\begin{array}{c}\text { Tip deflection } \\
\text { (in) }\end{array}$ & $\begin{array}{c}\text { Tip deflection } \\
\text { change (\%) }\end{array}$ \\
\hline Measured & $\mathrm{n} / \mathrm{a}$ & 7.2511 & $\mathrm{n} / \mathrm{a}$ \\
\hline Measured + Offset & .0128 & 7.2639 & 0.18 \\
\hline Measured - Offset & .0128 & 7.2383 & -0.18 \\
\hline
\end{tabular}

\section{B. Twist Sensitivity}

The twist angle is calculated using the trigonometric relationship between the leading edge and trailing edge deflections, as shown in Eq. 4. This approach is very sensitive to errors in vertical deflection measurements $\left(\mathrm{y}_{\text {Leading Edge }}\right.$ and $\left.\mathrm{y}_{\text {Trailing Edge }}\right)$. Errors that would be considered low and acceptable for deflection can cause extremely large errors in the twist calculation.

$$
\phi=\sin ^{-1}\left(\frac{y_{\text {LeadingEdgg }}-y_{\text {TrailingEdge }}}{\Delta_{\text {Chord }}}\right)
$$

Table 8 shows that 2.04 percent error in each of the deflection values (as calculated in the previous section) for the rectangular test article can cause an unacceptably large error (49 percent) in the calculated angle of twist. This extreme sensitivity to deflection errors makes the presented method for determining twist angle impractical.

Table 8. Change in twist calculation due to change in deflection.

\begin{tabular}{|c|c|c|c|c|c|}
\hline & & & Reference & Calculated & Error \\
\hline Leading edge deflection & $\mathrm{y}_{1}$ & in & 6.25 & 6.38 & $2.04 \%$ \\
\hline Trailing edge deflection & $y_{2}$ & in & 5.75 & 5.63 & $-2.04 \%$ \\
\hline Distance between fibers & d & in & 11.0 & 11.0 & $0 \%$ \\
\hline Calculated twist angle & $\phi$ & deg & 2.61 & 3.88 & $49 \%$ \\
\hline
\end{tabular}

\section{Load Sensitivity}

The inputs to the LTF are strain values and loads measured during the calibration loading, and strain values measured during operation. The same variations in strain values described above were used in the analysis of the load equations (twice the maximum standard deviation). A potential variation in weight of .01 pounds was used. This corresponded to the resolution of the scale that was used to verify the calibration weights. Table 9 shows that these two sources of error could result in a measurement error of over six percent. 
Table 9. Change in load measurement due to error in strain values and calibrated weights.

\begin{tabular}{|l|cccc|}
\hline Measured & $\begin{array}{c}\text { Strain offset } \\
\text { (microstrain) }\end{array}$ & $\begin{array}{c}\text { Load offset } \\
\text { (lbs) }\end{array}$ & $\begin{array}{c}\text { Calculated } \\
\text { moment (in-lbs) }\end{array}$ & Change (\%) \\
\hline Measured + Offset & $\mathrm{n} / \mathrm{a}$ & $\mathrm{n} / \mathrm{a}$ & 474.0 & $\mathrm{n} / \mathrm{a}$ \\
\hline Measured - Offset & 11.6 & .01 & 505.8 & 6.7 \\
\hline
\end{tabular}

\section{Discussion}

\section{A. Applicability of Results}

The test articles used for this testing were simple, thin, monolithic and isotropic structures. Typical aerospace structures are much more complex. These tests, however, served as a valuable application of the measurement methods and provided an opportunity to collect and utilize empirical strain data within the DTF and LTF. The experiment uncovered limitations of the twist and load calculation methods, however the deflection calculation method was shown to be robust among the test articles and load cases.

The DTF results from the described tests compare well with results from a test performed on a full-scale wing, ${ }^{8}$ indicating that the method is not compromised by increasing test article size or complexity.

\section{Conclusions}

The Deflection Transfer Functions were able to accurately measure wing deflection, with a root-mean-squared error of 2.28 percent of the actual deflection. These results were seen as a success for the technology. The DTF equations are not particularly sensitive to moderate errors in strain values. The relatively thin geometry of the plate test articles used for this testing made the equations more sensitive to errors in thickness measurement. The 7.89-percent thickness error used in the sensitivity analysis would correspond to nearly one-half inch on a 6-inch-thick wing; in reality, wing thickness can be measured much more accurately.

The twist measurement method proved to be poorly suited to use with empirical data due to a great sensitivity to error in the deflection measurements. This sensitivity makes the twist measurement method impractical unless if the error in the deflection measurement is greatly reduced.

Though not yet as accurate as photography-based deflection measurements, these strain-based methods offer unique capabilities. For many applications, the benefits of the weight reduction and realtime capability will outweigh the reduced accuracy.

The LTF results are also very encouraging. The root-mean-squared error value listed above (10.7 percent) is greater than a conventional strain bridge system may exhibit (in certain circumstances lower than 3 percent error); however, many of the load cases exhibited less error than a conventional system. The load measurement method would be particularly valuable when the load distribution that will be experienced in operation is understood; a calibration load should be chosen which simulates the load distribution that the structure will encounter during operation. 


\section{Acknowledgements}

The work presented in this paper builds upon the work of many engineers at NASA Dryden. The author thanks Dr. Patrick Chan, Dr. William Ko, Allen Parker, Anthony Piazza, and Dr. Lance Richards for their support of this test effort and their determination in pursuing new capabilities.

\section{References}

${ }^{1}$ Lokos, W.A., Bahm, C.M., and Heinle, R.A., Determination of Stores Pointing Error Due to Wing Flexibility Under Flight Load, NASA TM-4646, 1994.

${ }^{2}$ Lizotte, A.M., and Lokos, W.A., Deflection-Based Structural Loads Estimation From the Active Aeroelastic Wing F/A-18 Aircraft, NASA TM-2005-212871, 2005.

${ }^{3}$ Ko, W.L., Richards, W.L., and Tran, V.T., Displacement Theories for In-Flight Deformed Shape Predictions of Aerospace Structures, NASA TP-2007-214612, 2007.

${ }^{4}$ Richards, W.L., and Ko,W.L., Process for Using Surface Strain Measurements to Obtain Operational Loads for Complex Structures, United States Patent No. 7,715,994, issued May 11, 2010.

${ }^{5}$ Jenkins, J.M., and DeAngelis, V.M., A Summary of Numerous Strain-Gage Load Calibrations on Aircraft Wings and Tails in a Technological Format. NASA TM-4804, 1997.

${ }^{6}$ Skopinski, T.H; Aiken, W.S., Jr, and Huston, W.B., Calibration of Strain-Gage Installations in Aircraft Structures for the Measurement of Flight Loads, NACA TN-2993, 1953.

${ }^{7}$ Ko, W.L., and Tran, V.T., Further Development of Ko Displacement Theory for Deformed Shape Predictions of Nonuniform Aerospace Structures, NASA/TP-2009-214643, 2009.

${ }^{8}$ Jutte, C.V., Ko, W.L., Stephens, C.A., Bakalyar, J.A., Richards, W.L., and Parker, A.R., Deformed Shape Calculation of a Full-Scale Wing Using Fiber Optic Strain Data from a Ground Loads Test. NASA/TP-2011-215975, 2011. 


\section{APPENDIX 1: Deflection Plots}

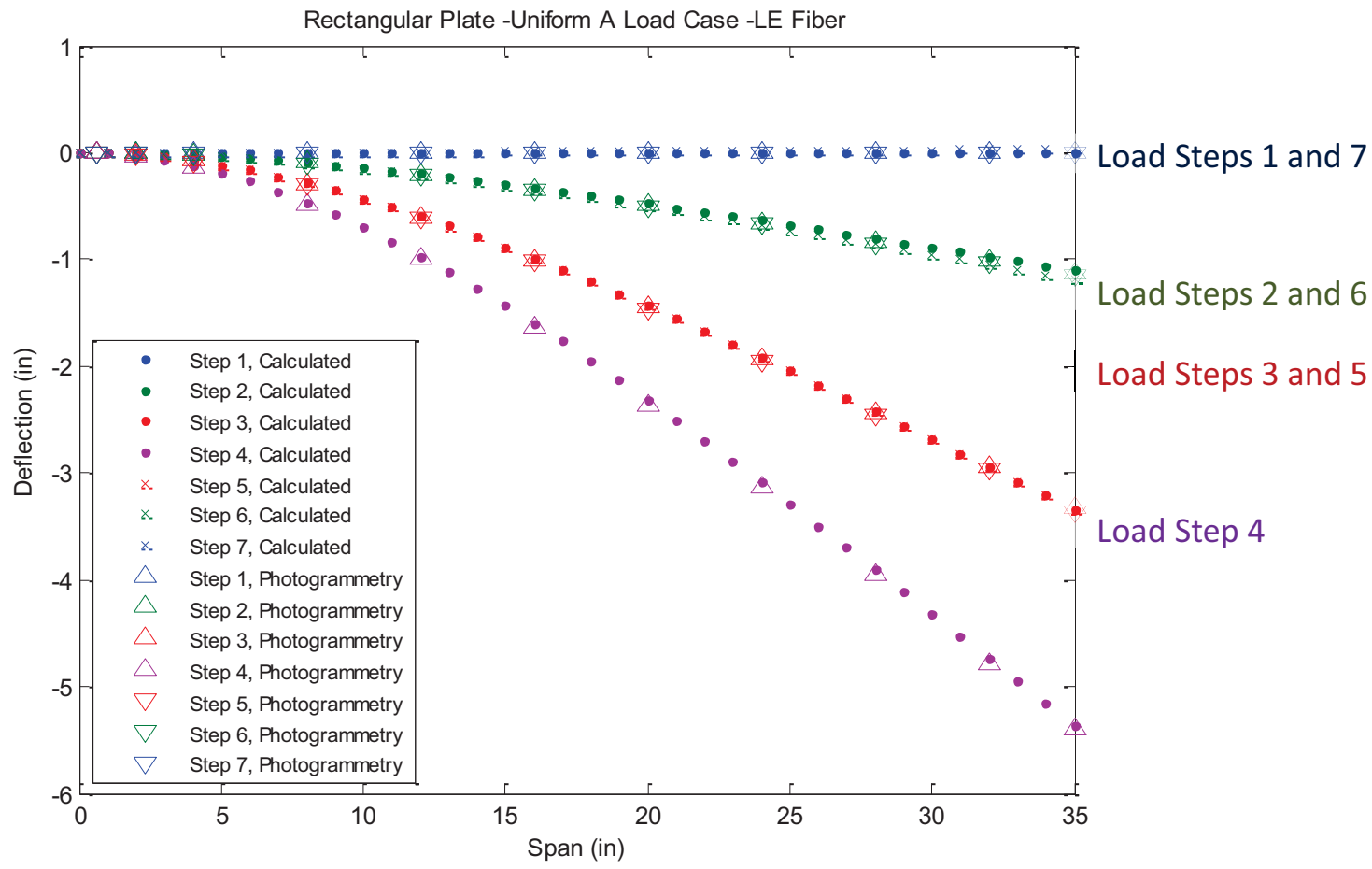

Figure A1_1. Rectangular plate deflection results for leading edge fiber during Uniform A load case.

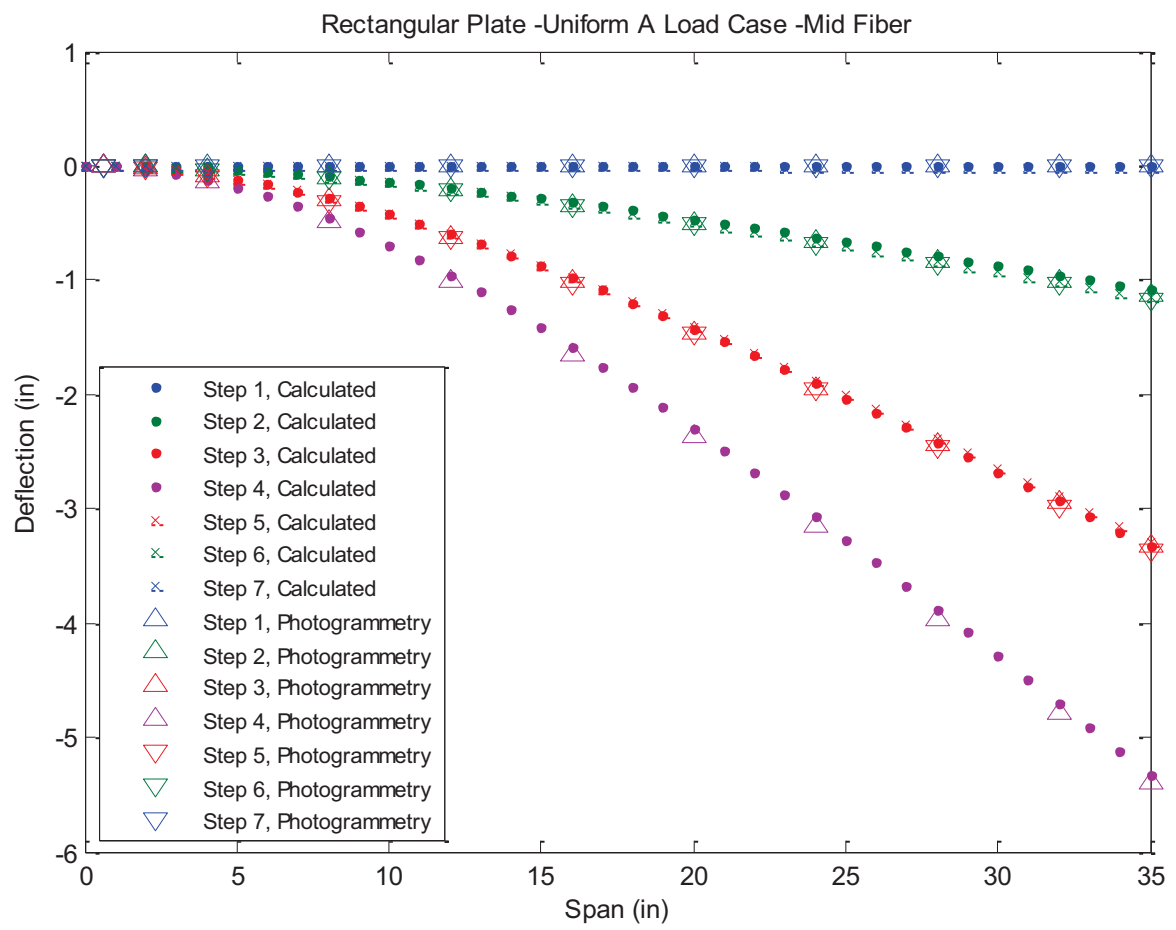

Figure A1_2. Rectangular plate deflection results for middle fiber during Uniform A load case.

American Institute of Aeronautics and Astronautics 


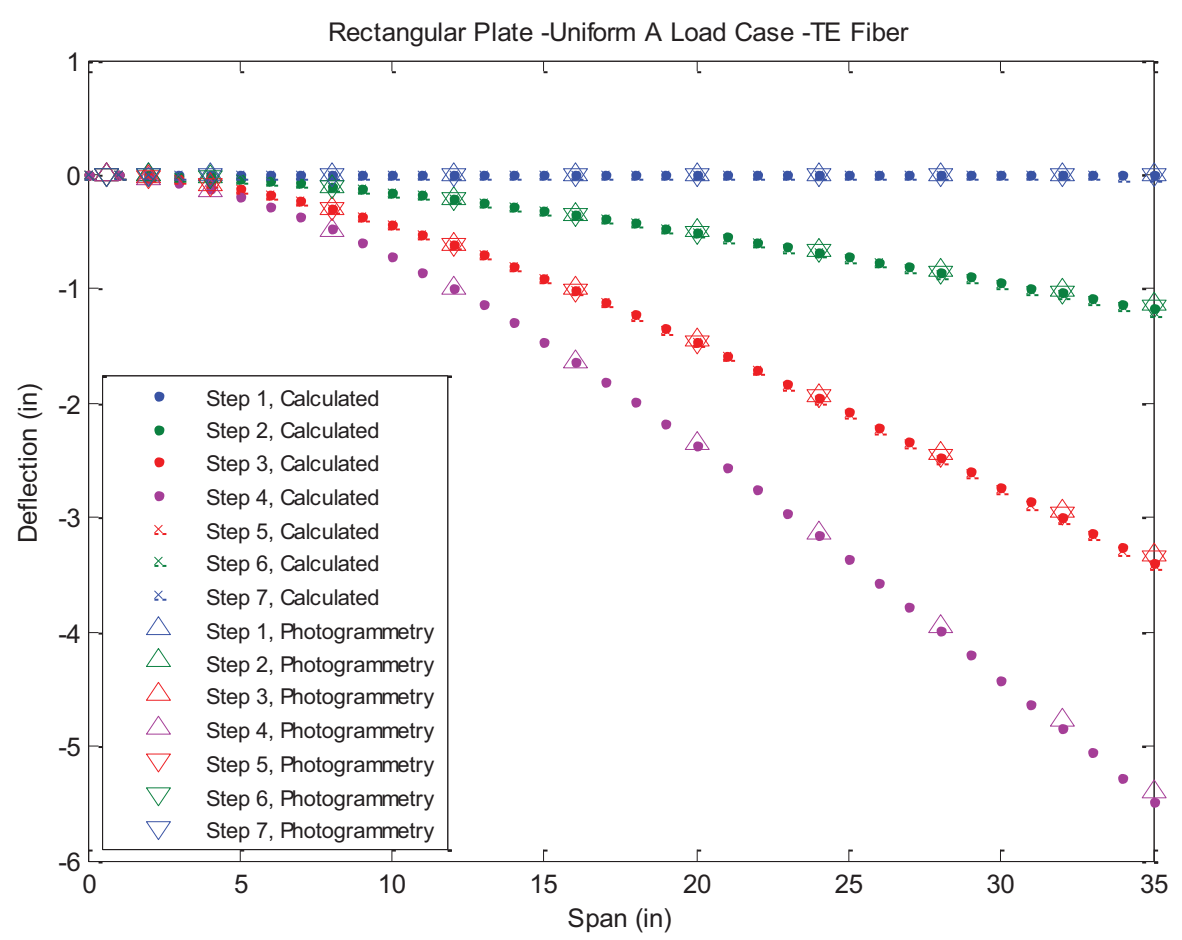

Figure A1_3. Rectangular plate deflection results for trailing edge fiber during Uniform A load case.

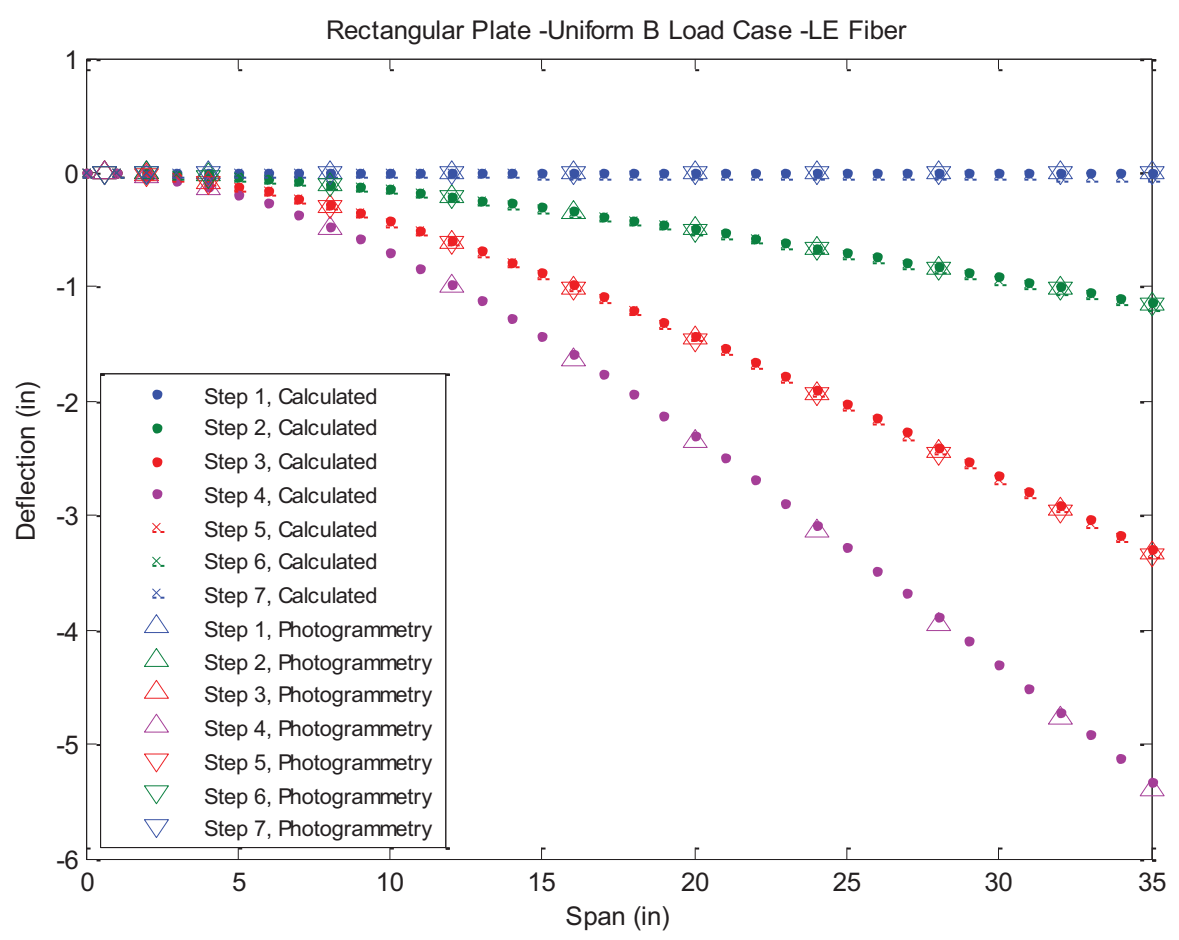

Figure A1_4. Rectangular plate deflection results for leading edge fiber during Uniform B load case.

American Institute of Aeronautics and Astronautics 


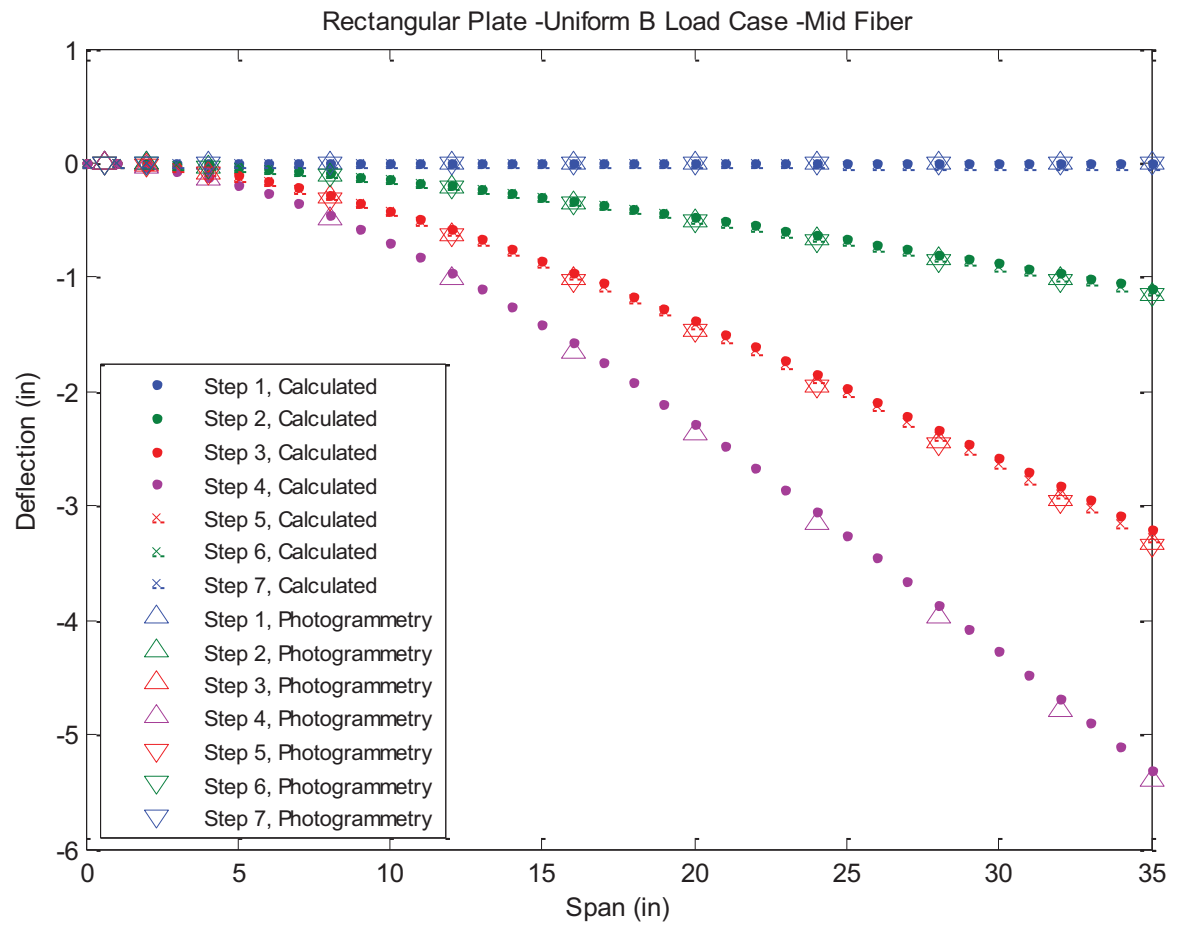

Figure A1_5. Rectangular plate deflection results for middle fiber during Uniform B load case.

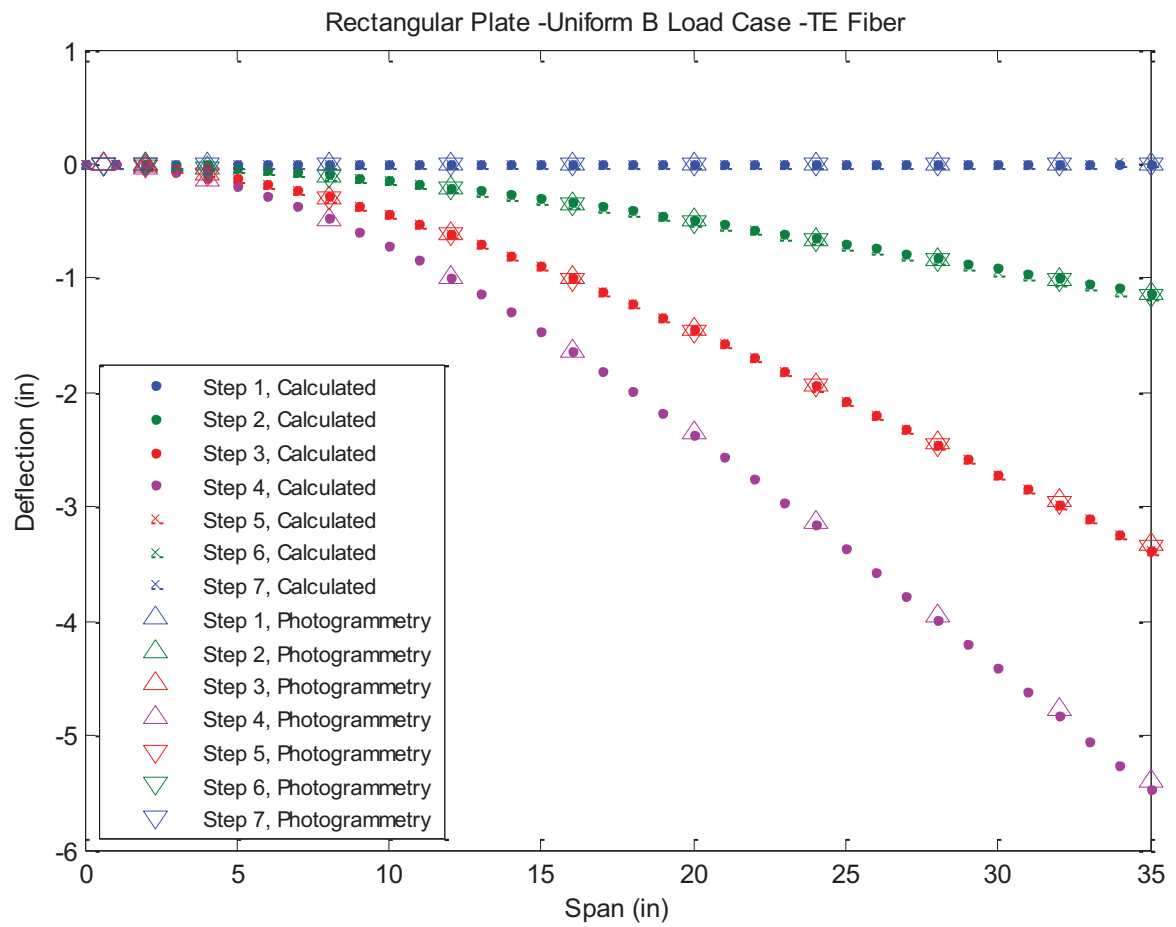

Figure A1_6. Rectangular plate deflection results for trailing edge fiber during Uniform B load case.

American Institute of Aeronautics and Astronautics 


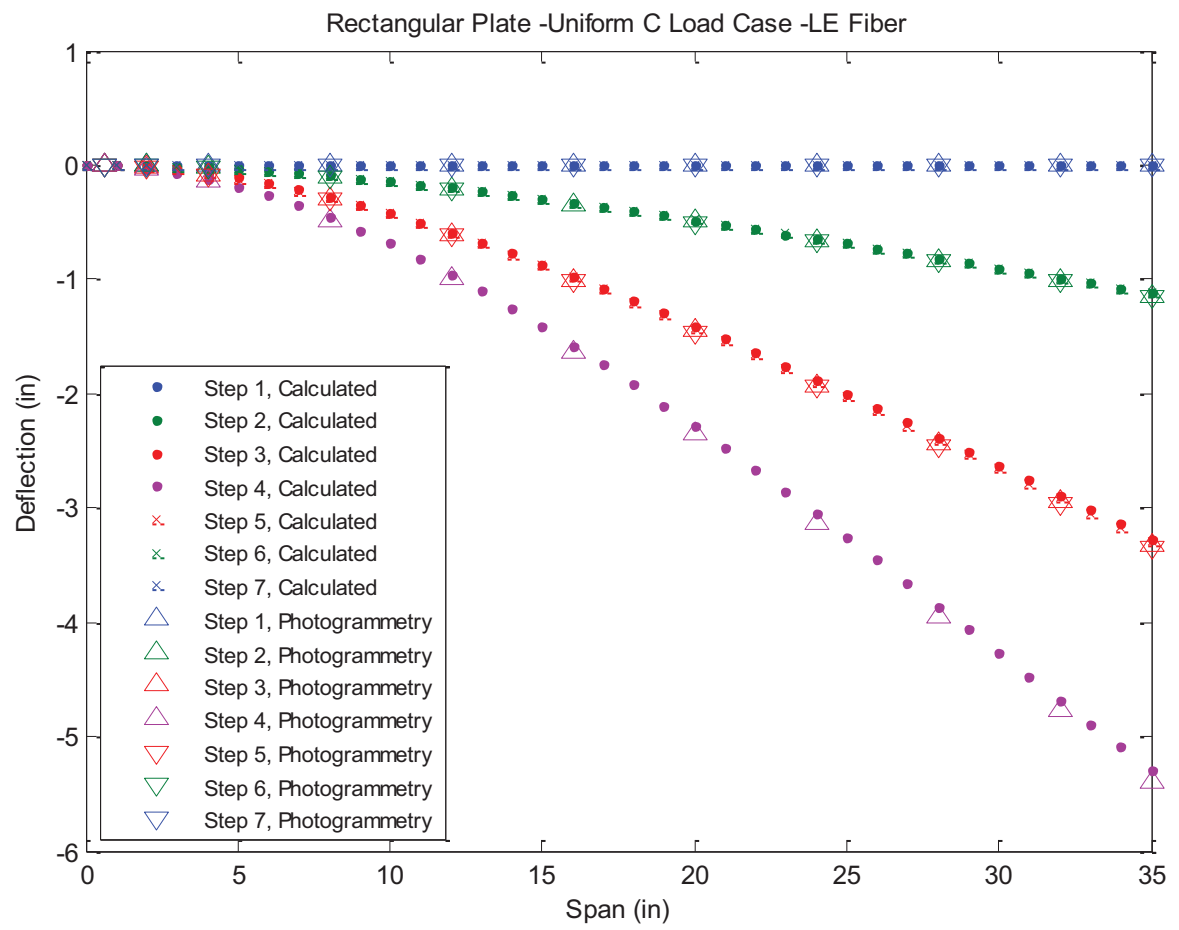

Figure A1_7. Rectangular plate deflection results for leading edge fiber during Uniform C load case.

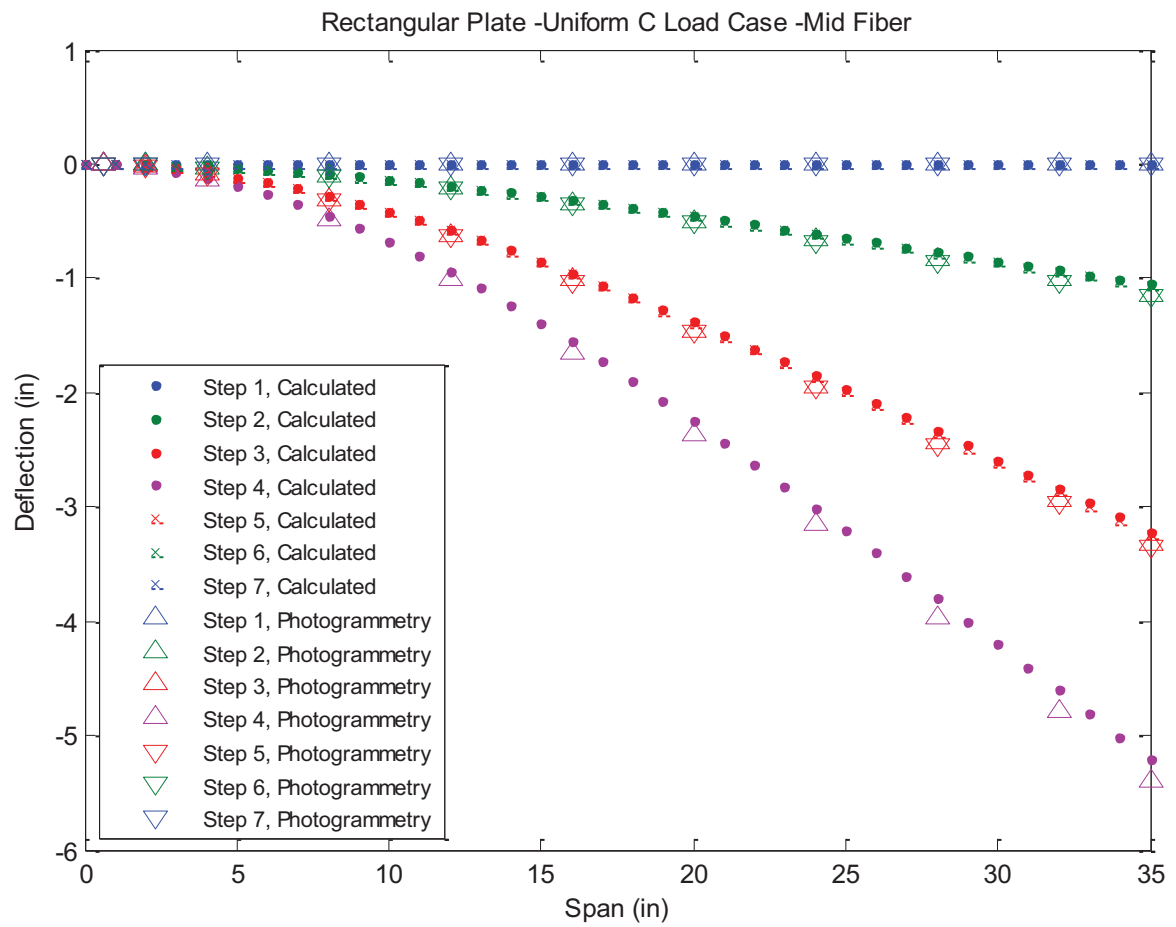

Figure A1_8. Rectangular plate deflection results for middle fiber during Uniform C load case.

American Institute of Aeronautics and Astronautics 


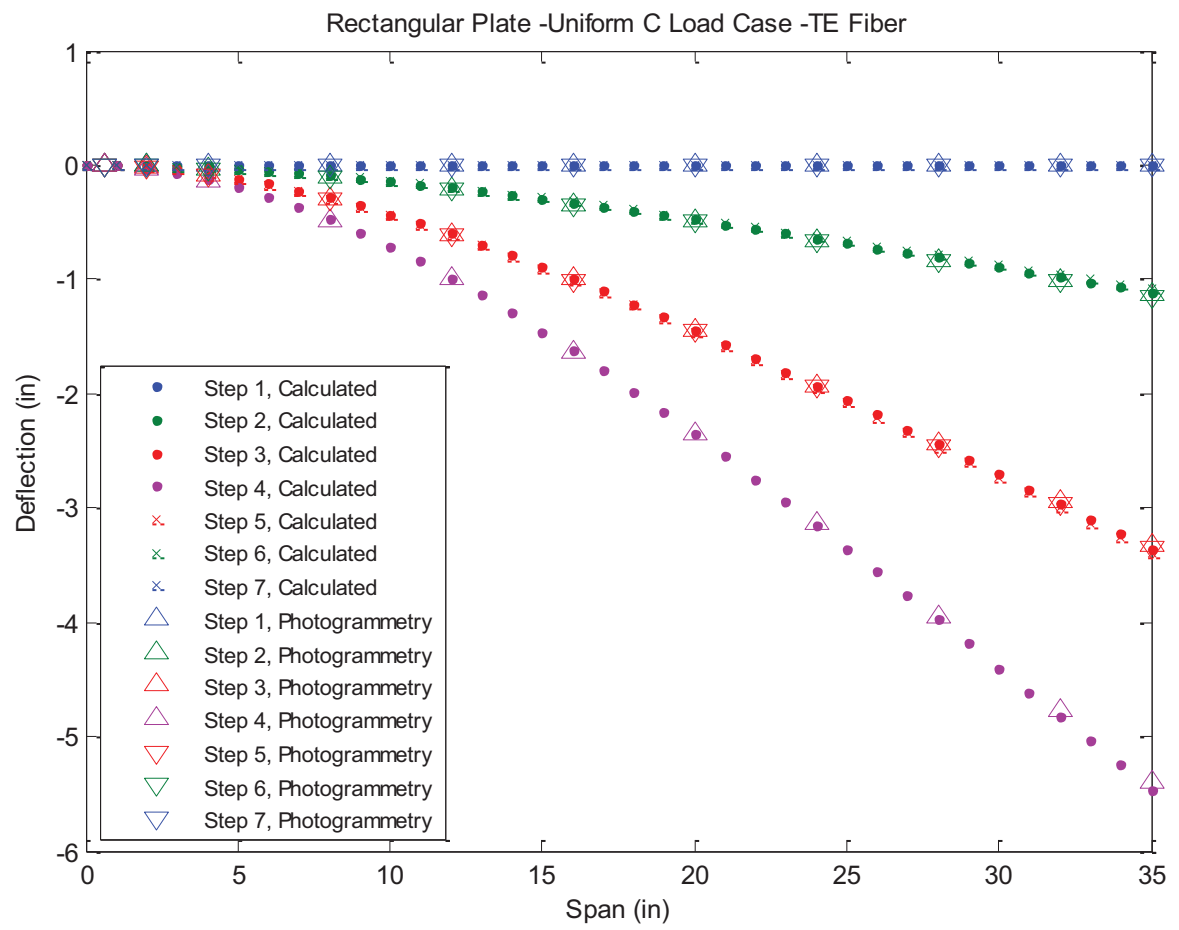

Figure A1_9. Rectangular plate deflection results for trailing edge fiber during Uniform C load case.

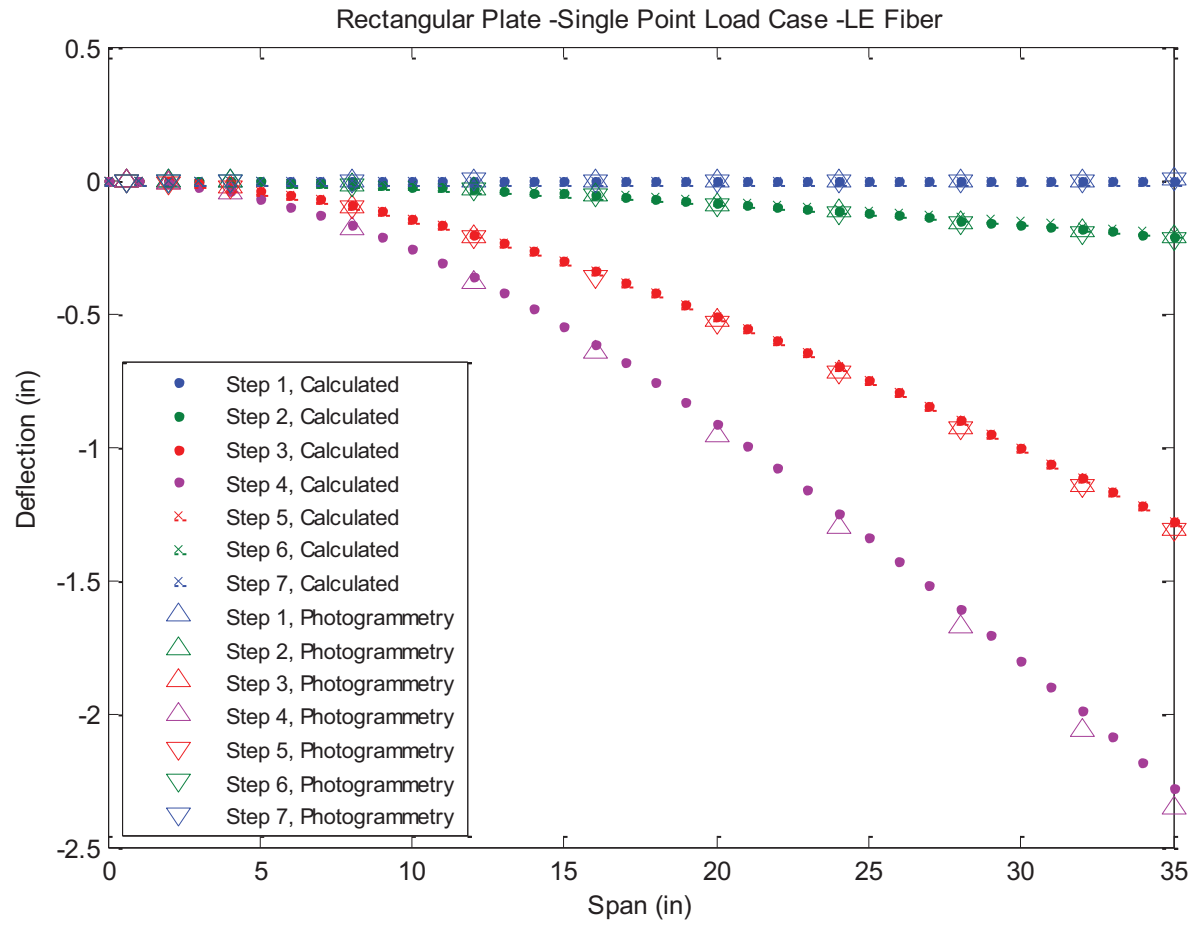

Figure A1_10. Rectangular plate deflection results for leading edge fiber during single point load case.

American Institute of Aeronautics and Astronautics 


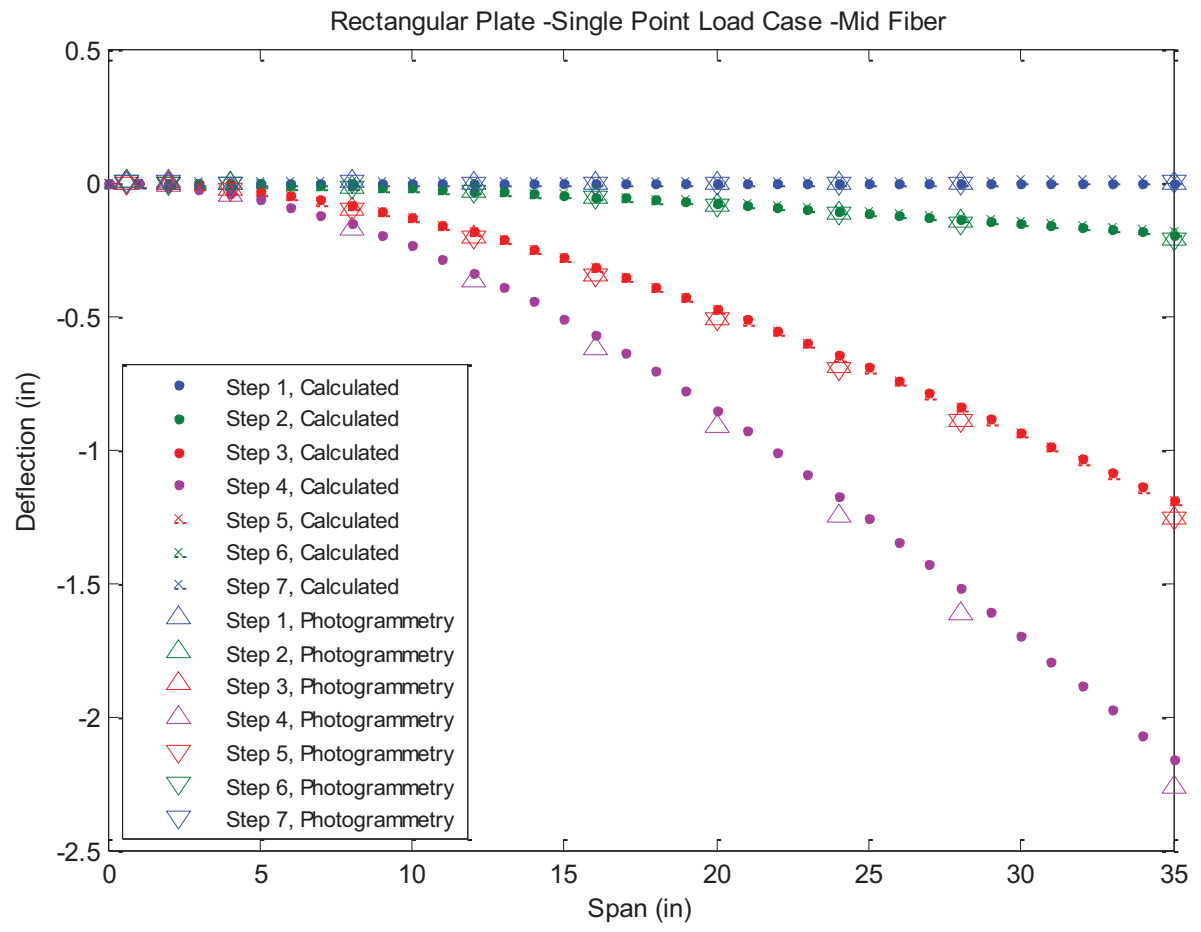

Figure A1_11. Rectangular plate deflection results for middle fiber during single point load case.

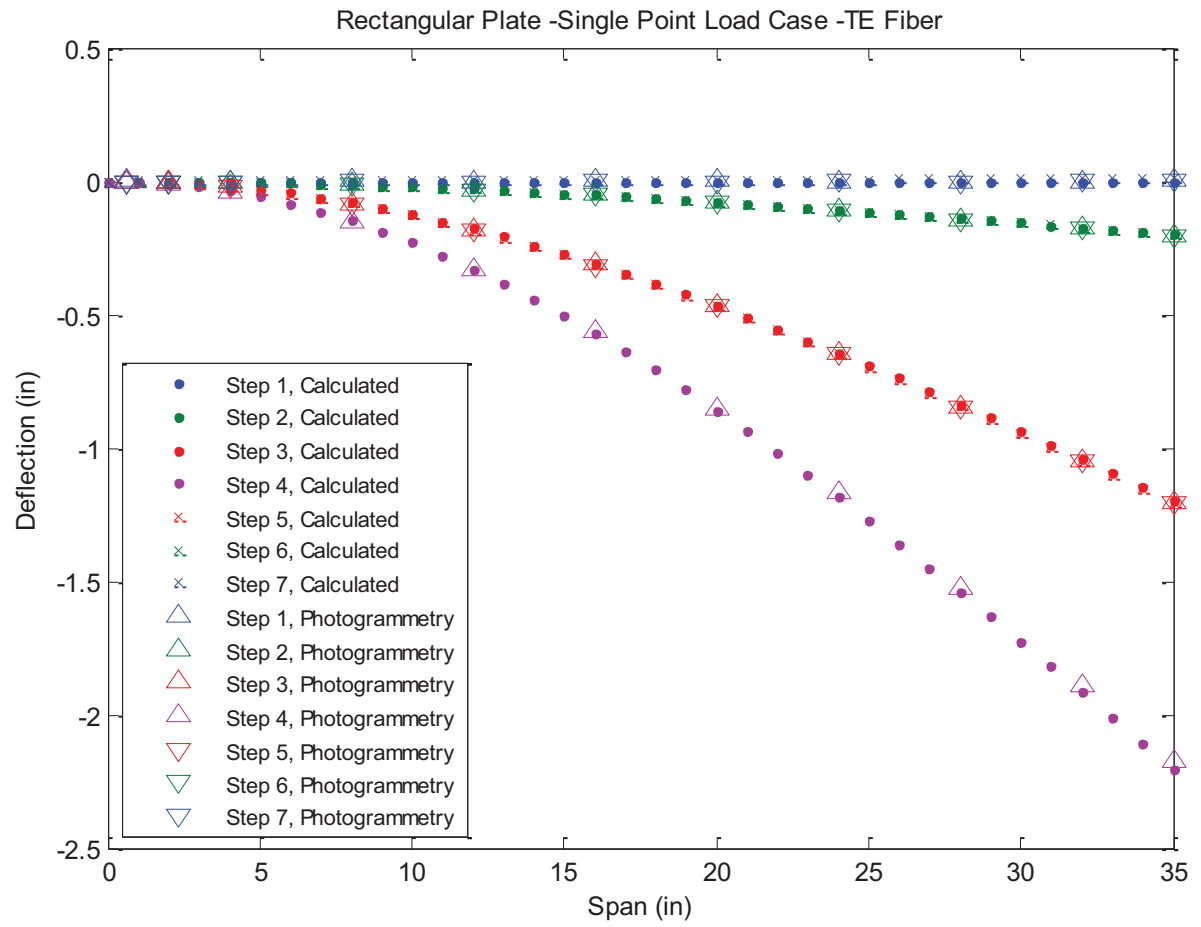

Figure A1_12. Rectangular plate deflection results for trailing edge fiber during single point load case.

American Institute of Aeronautics and Astronautics 


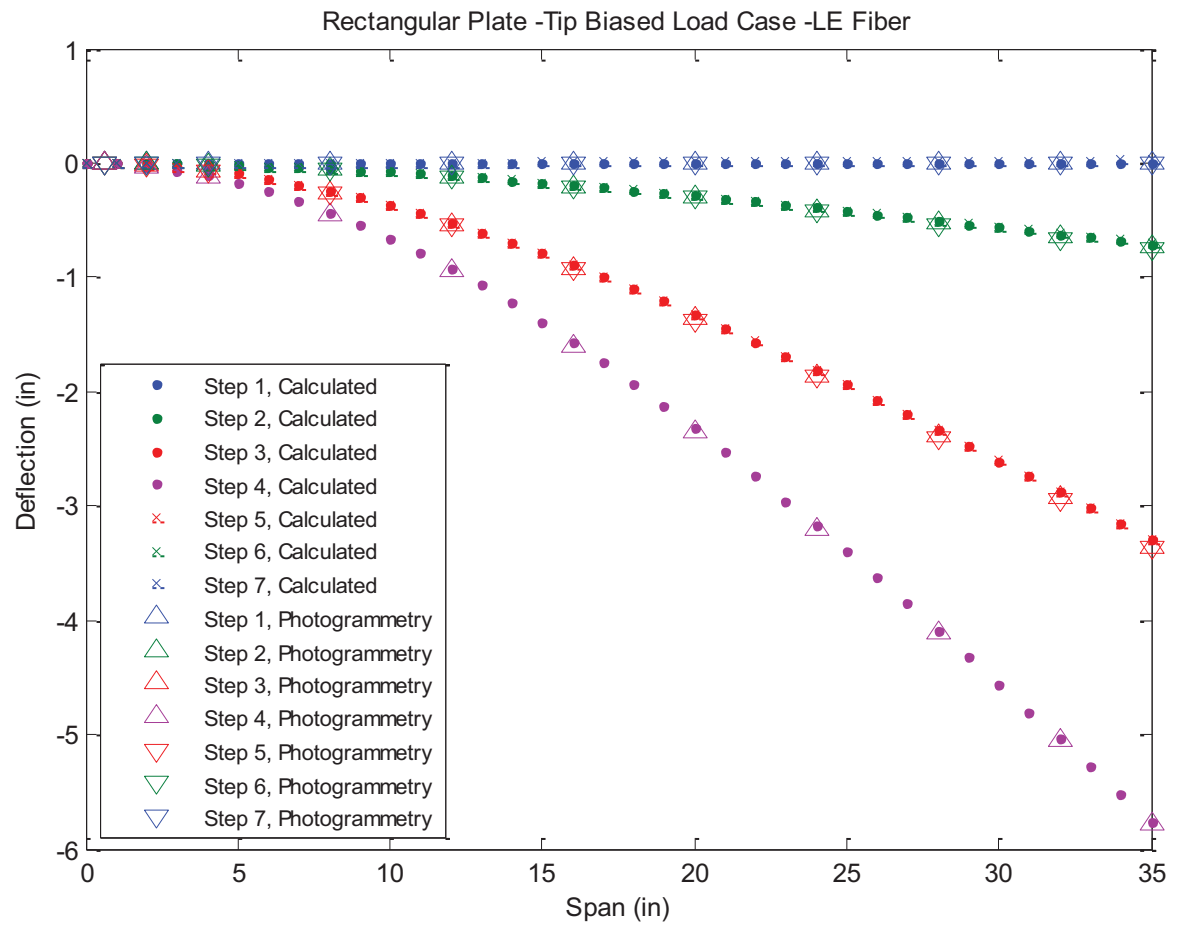

Figure A1_13. Rectangular plate deflection results for leading edge fiber during tip-biased load case.

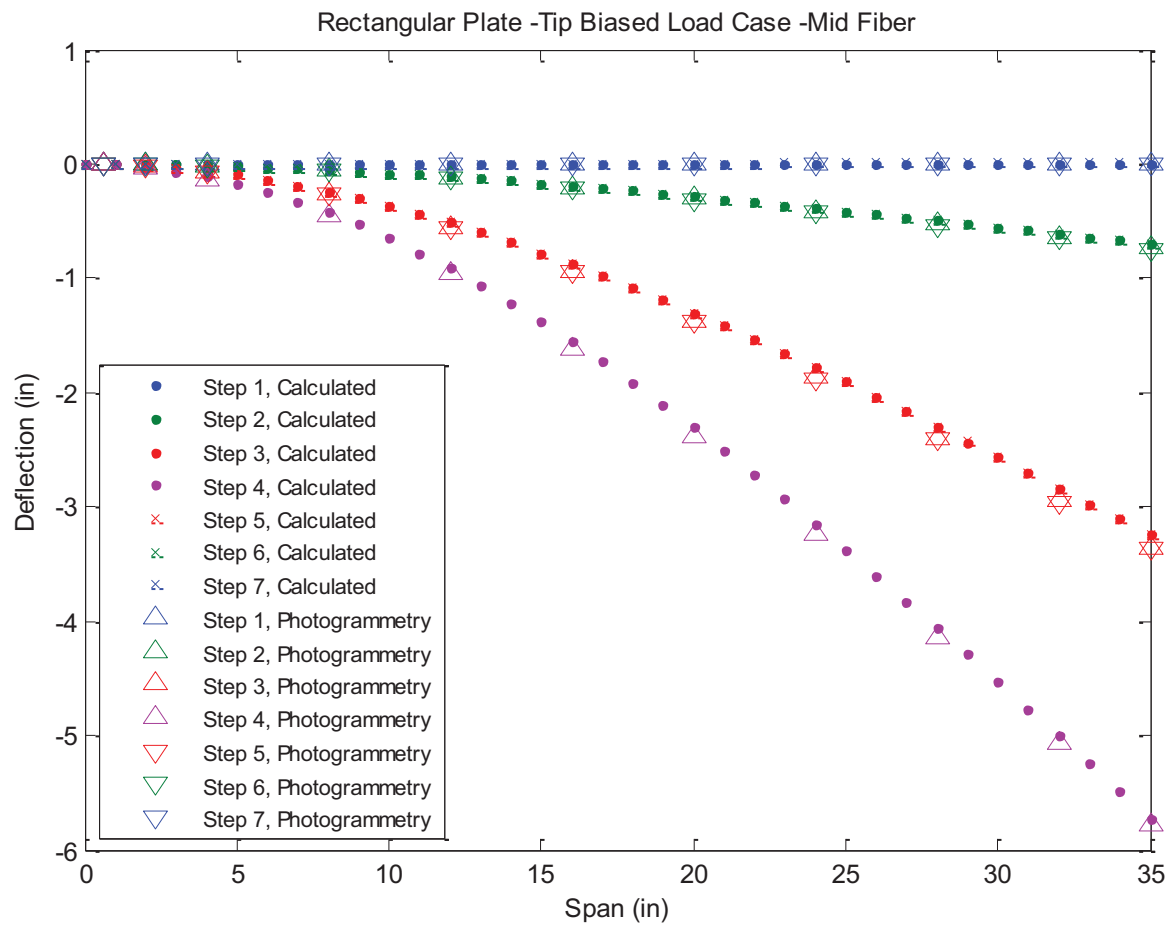

Figure A1_14. Rectangular plate deflection results for middle fiber during tip-biased load case.

American Institute of Aeronautics and Astronautics 


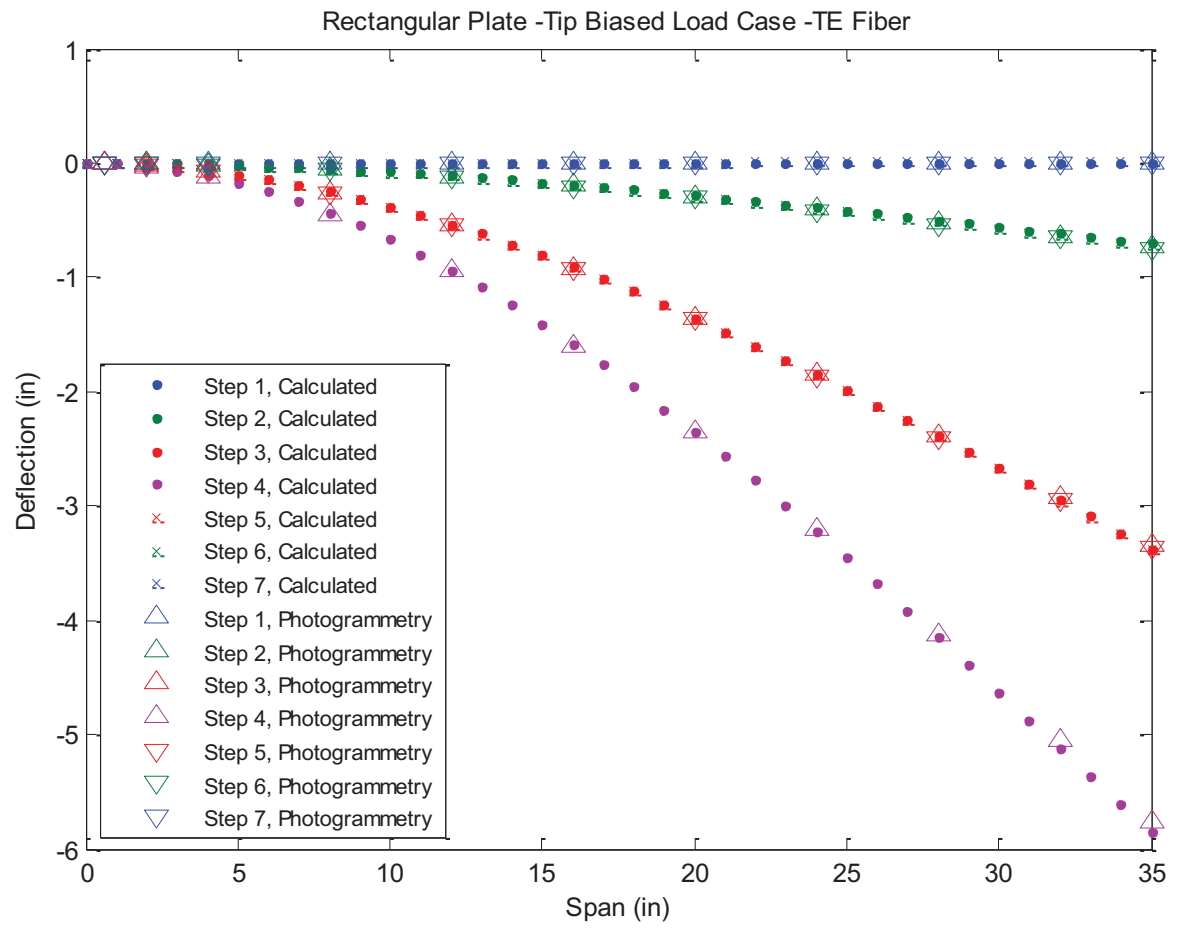

Figure A1_15. Rectangular plate deflection results for trailing edge fiber during tip-biased load case.

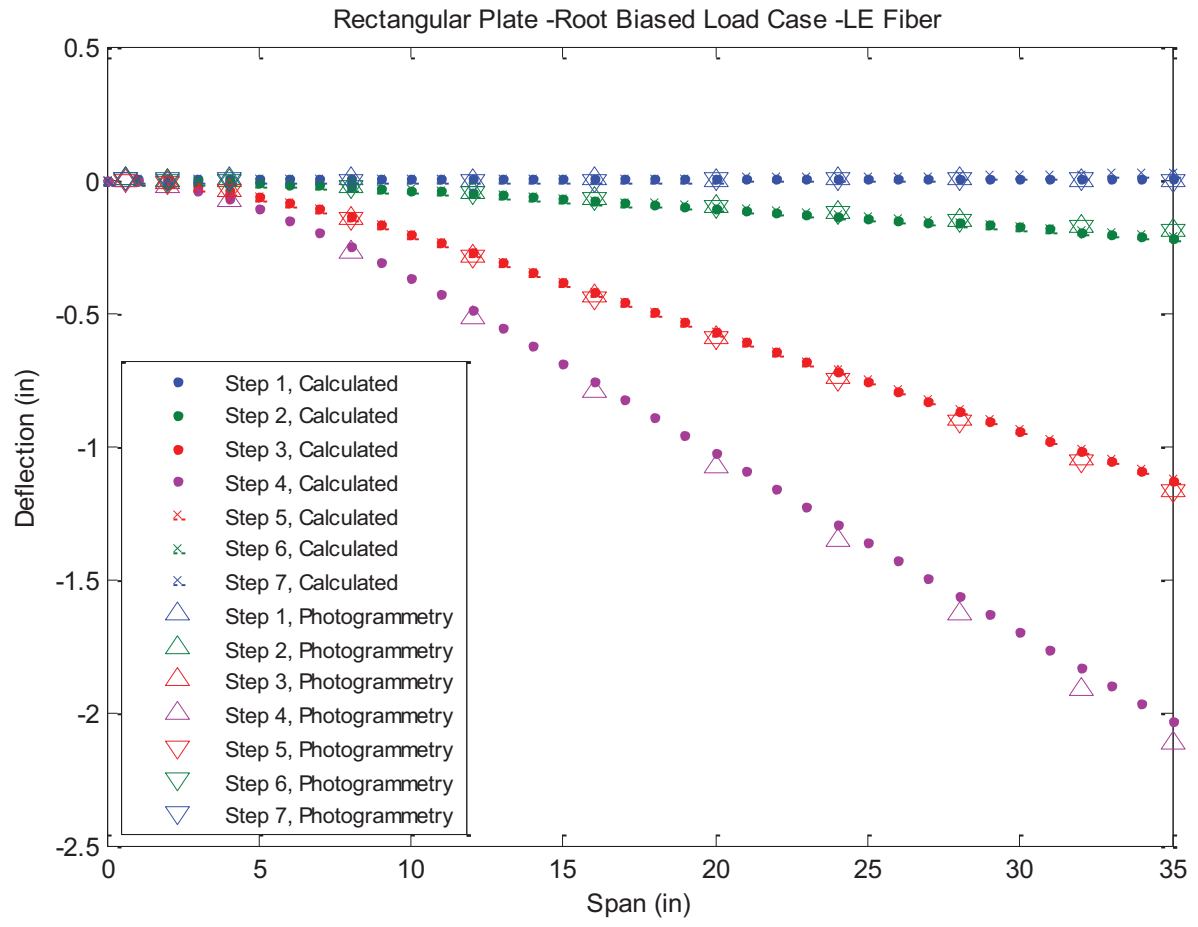

Figure A1_16. Rectangular plate deflection results for leading edge fiber during root-biased load case.

American Institute of Aeronautics and Astronautics 


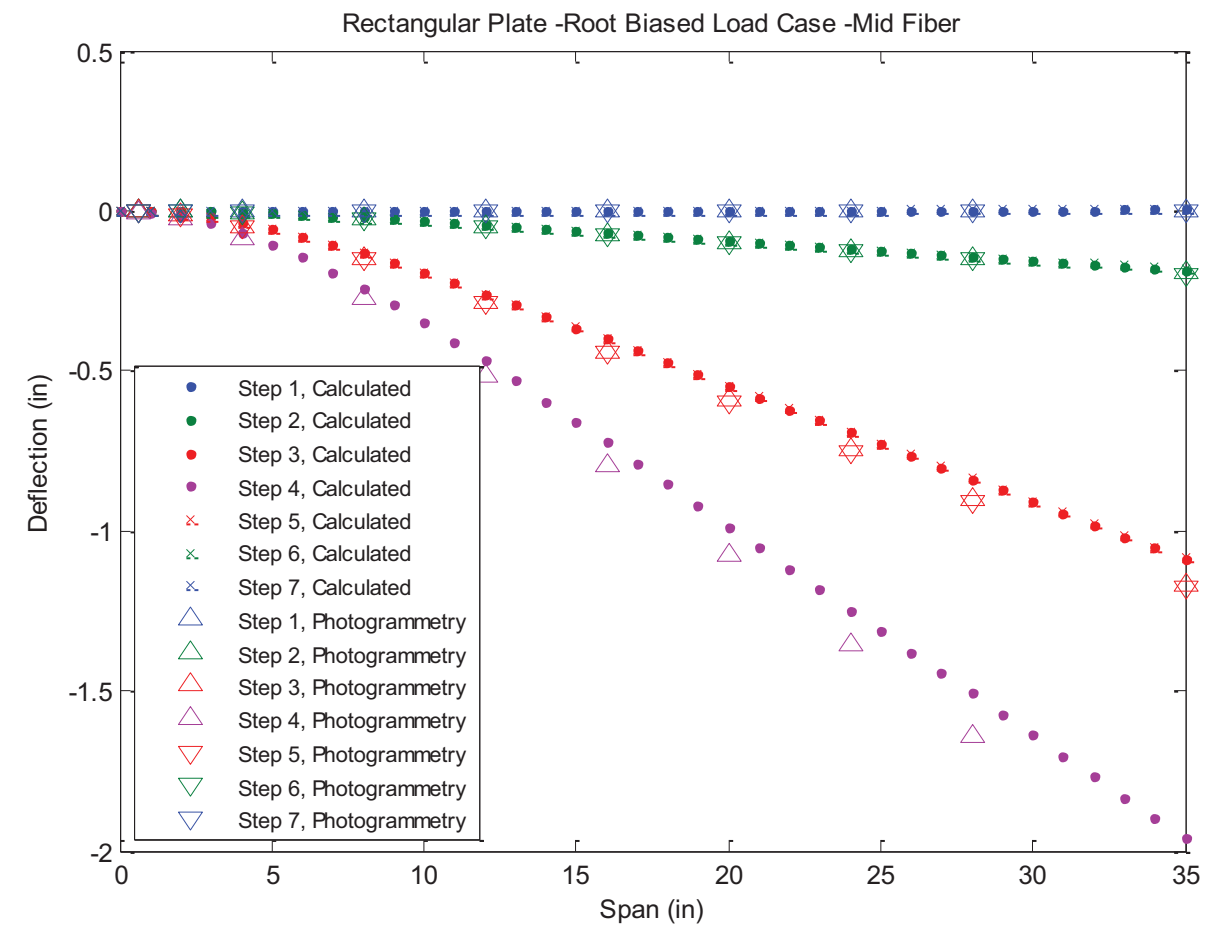

Figure A1_17. Rectangular plate deflection results for middle fiber during root-biased load case.

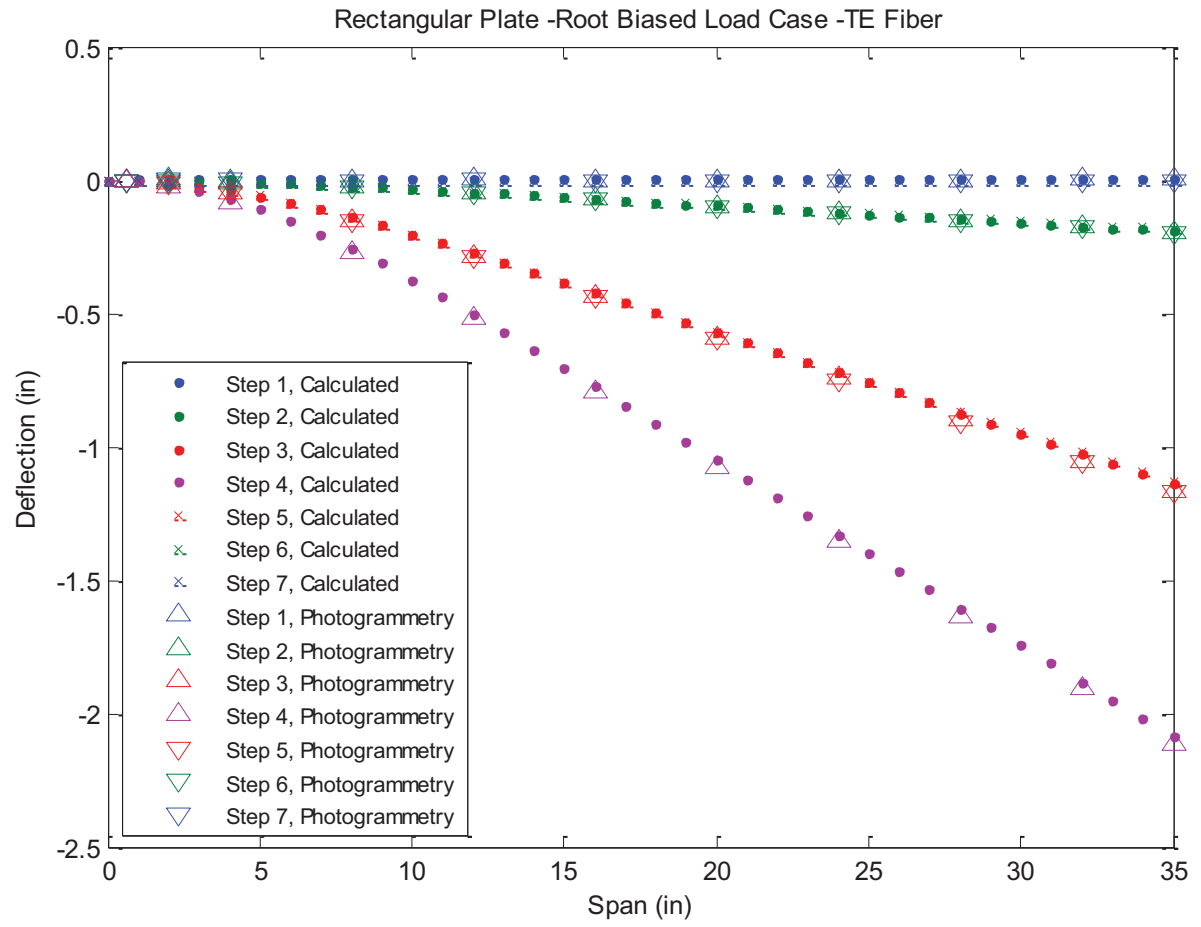

Figure A1_18. Rectangular plate deflection results for trailing edge fiber during root-biased load case.

American Institute of Aeronautics and Astronautics 


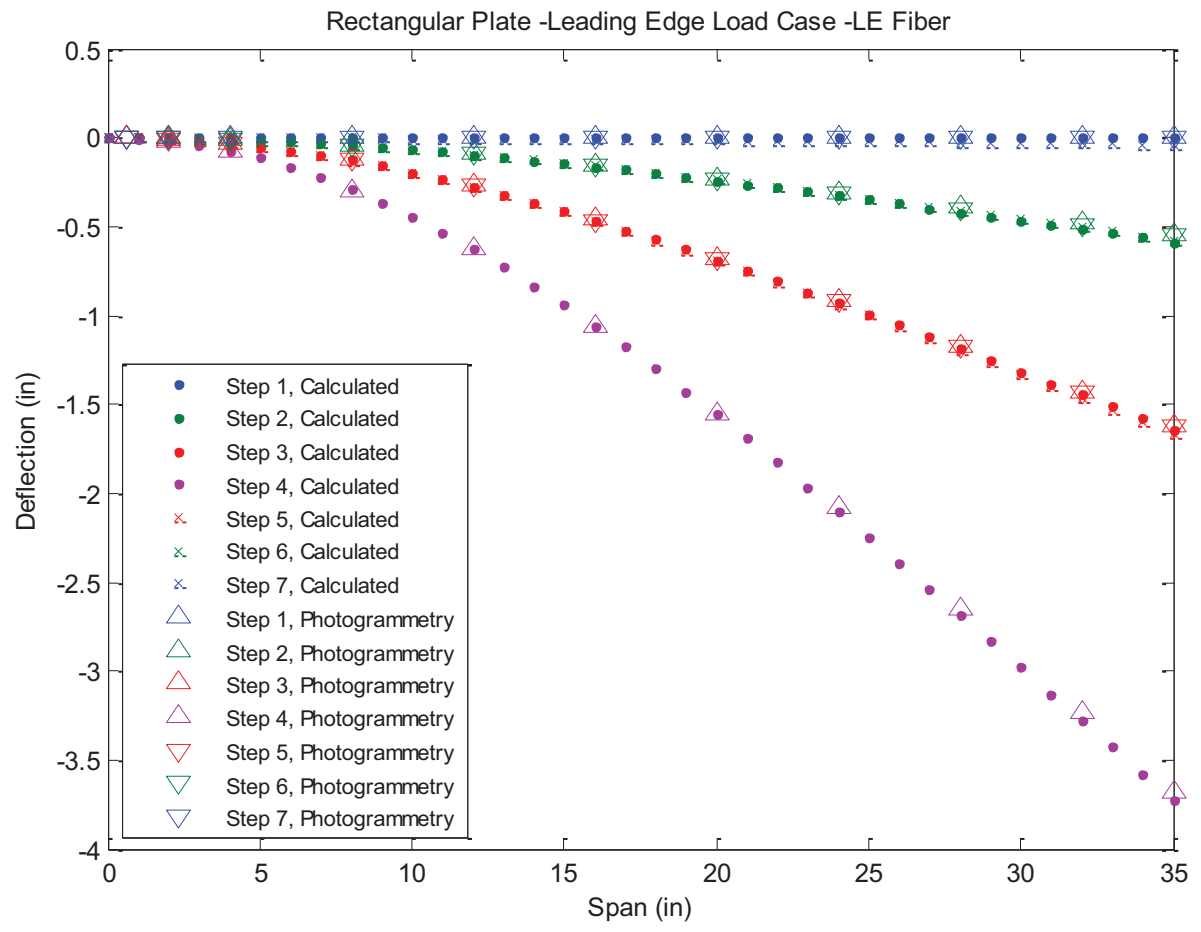

Figure A1_19. Rectangular plate deflection results for leading edge fiber during leading edge load case.

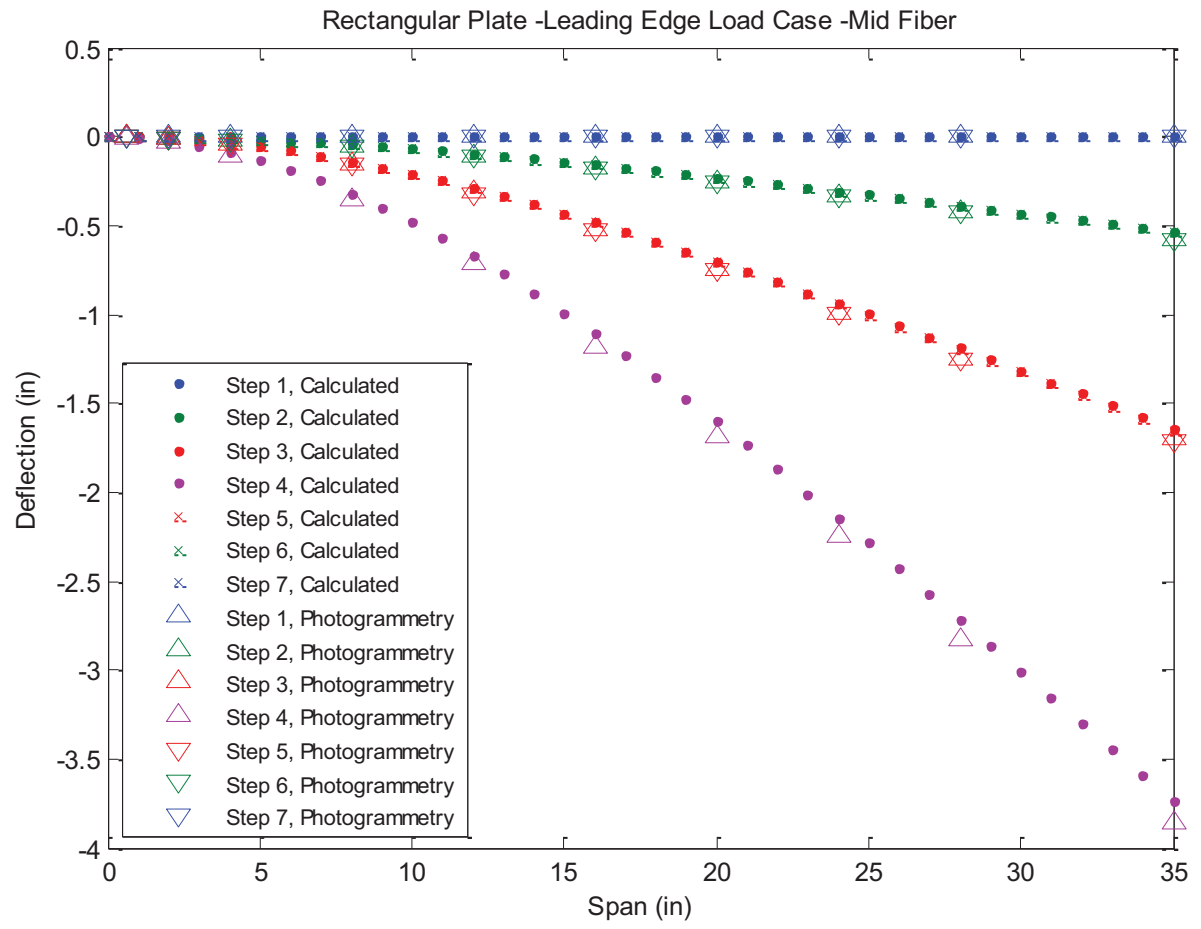

Figure A1_20. Rectangular plate deflection results for middle fiber during leading edge load case.

American Institute of Aeronautics and Astronautics 


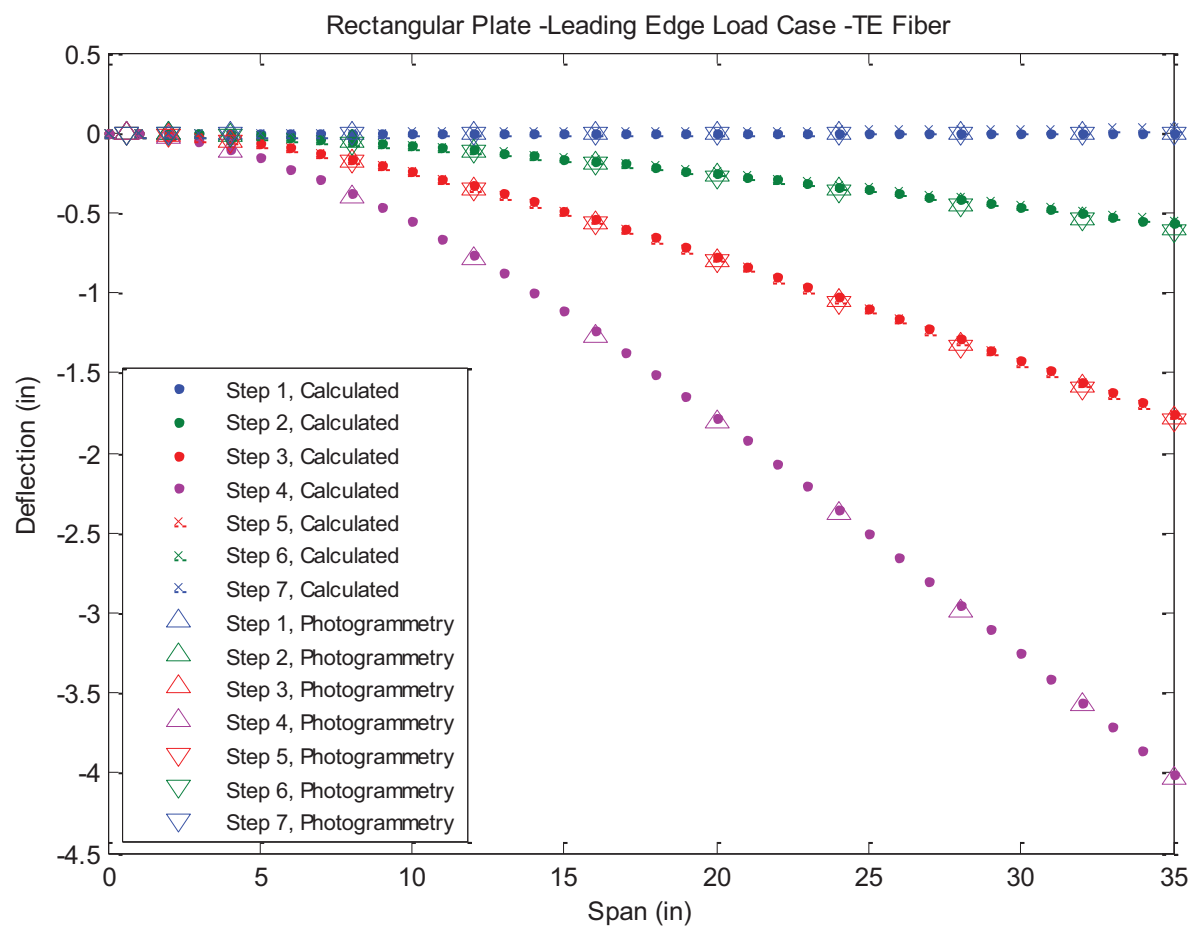

Figure A1_21. Rectangular plate deflection results for trailing edge fiber during leading edge load case.

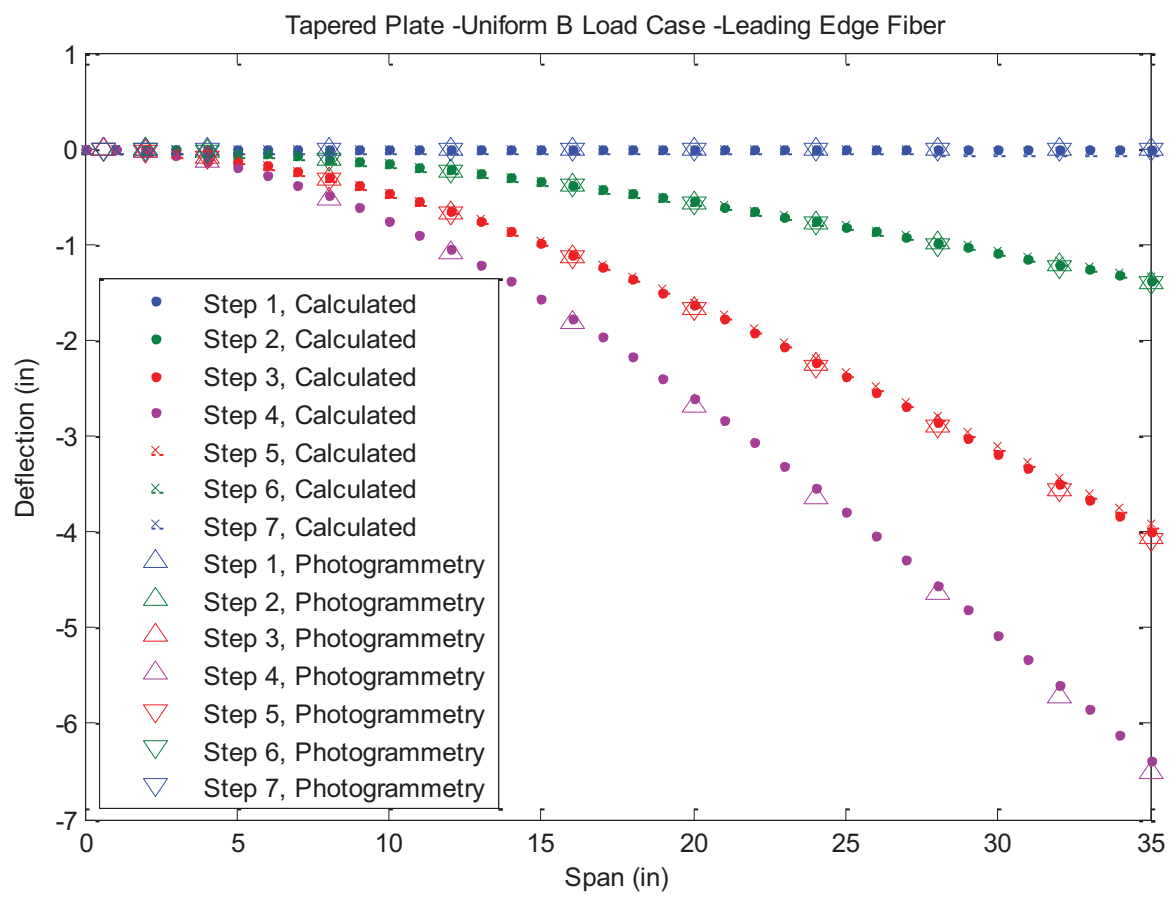

Figure A1_22. Tapered plate deflection results for leading edge fiber during Uniform B load case.

American Institute of Aeronautics and Astronautics 


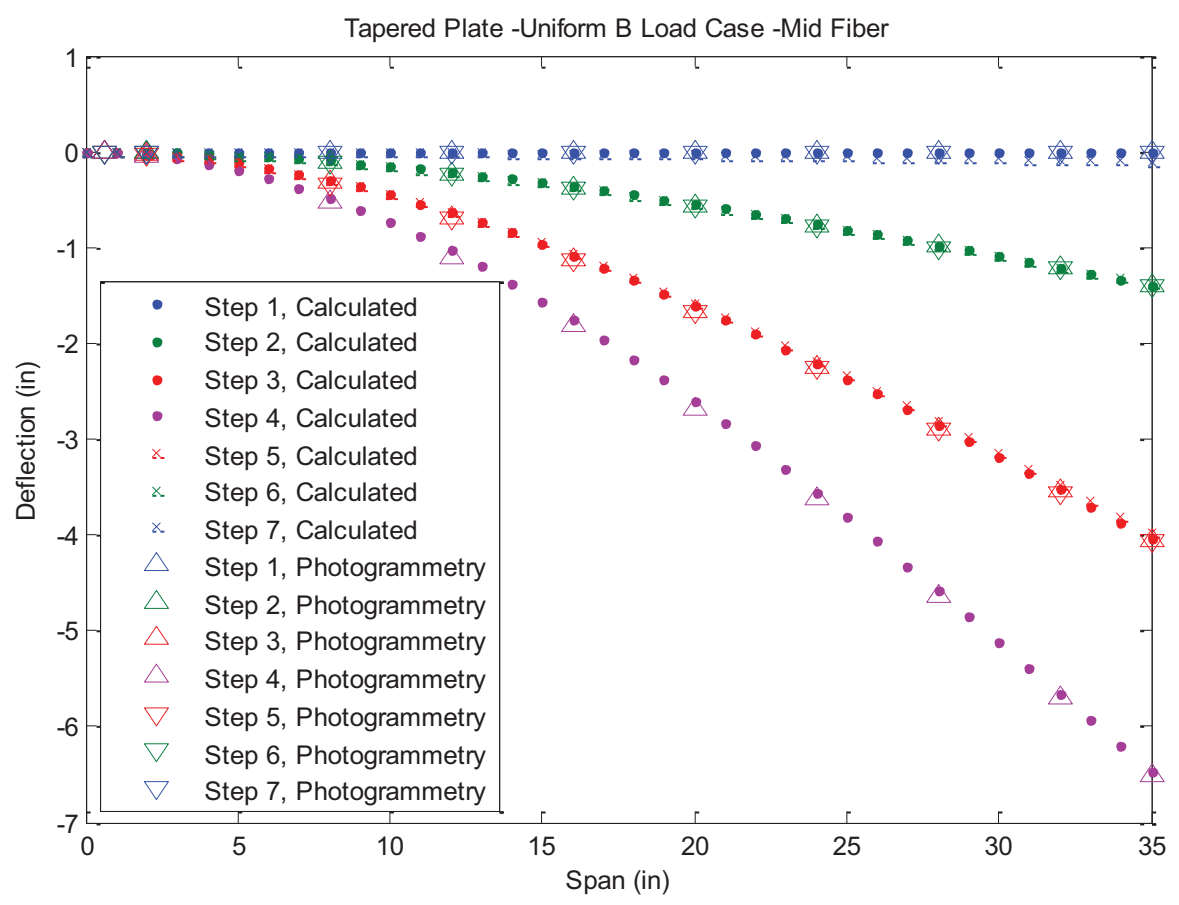

Figure A1_23. Tapered plate deflection results for middle fiber during Uniform B load case.

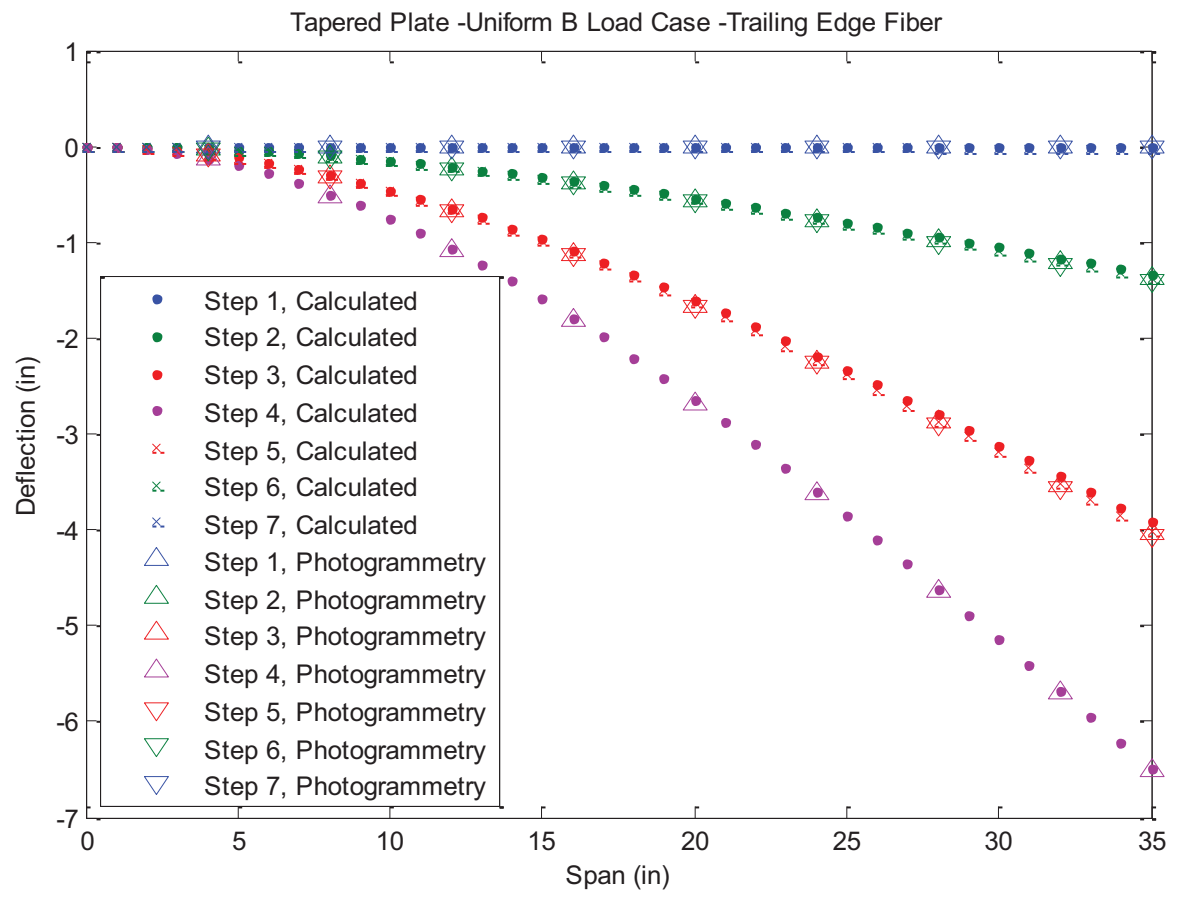

Figure A1_24. Tapered plate deflection results for trailing edge fiber during Uniform B load case.

American Institute of Aeronautics and Astronautics 


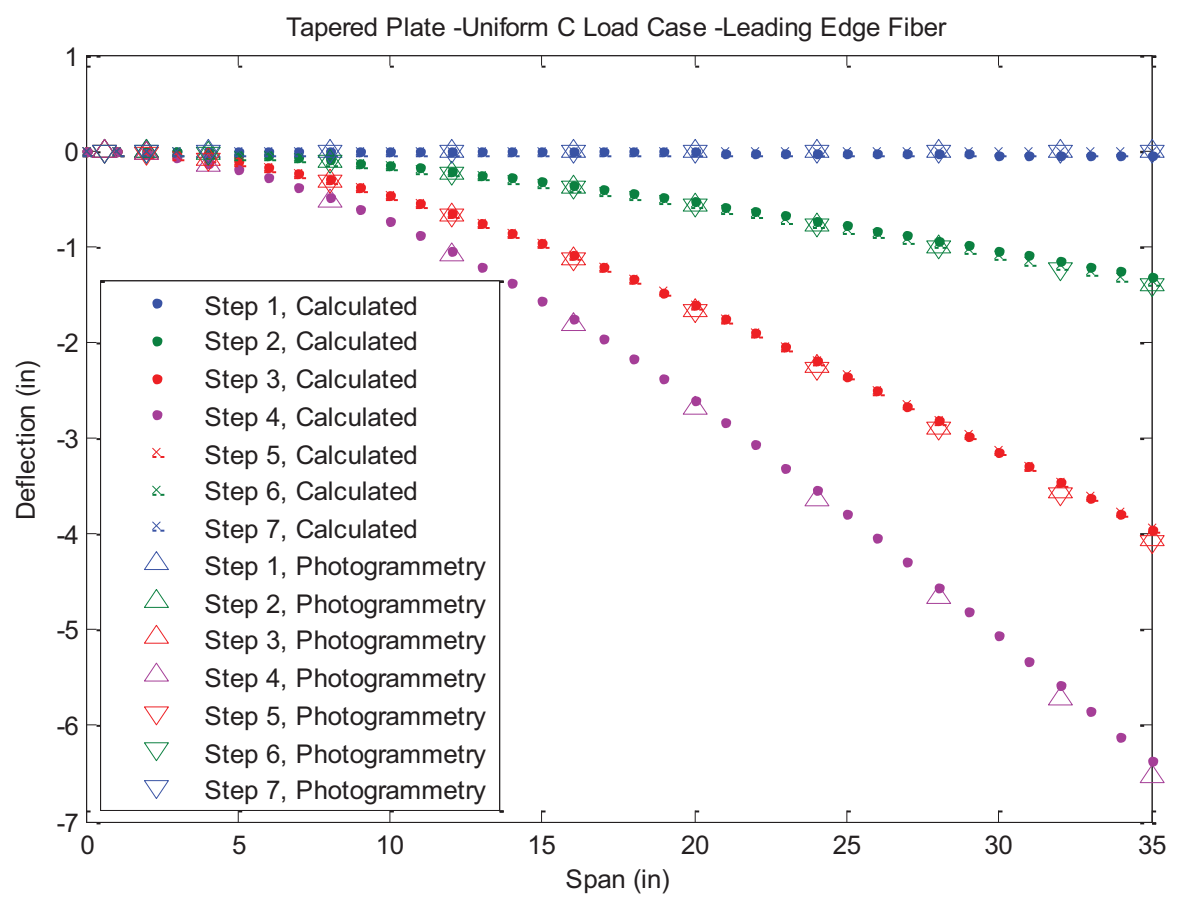

Figure A1_25. Tapered plate deflection results for leading edge fiber during Uniform C load case.

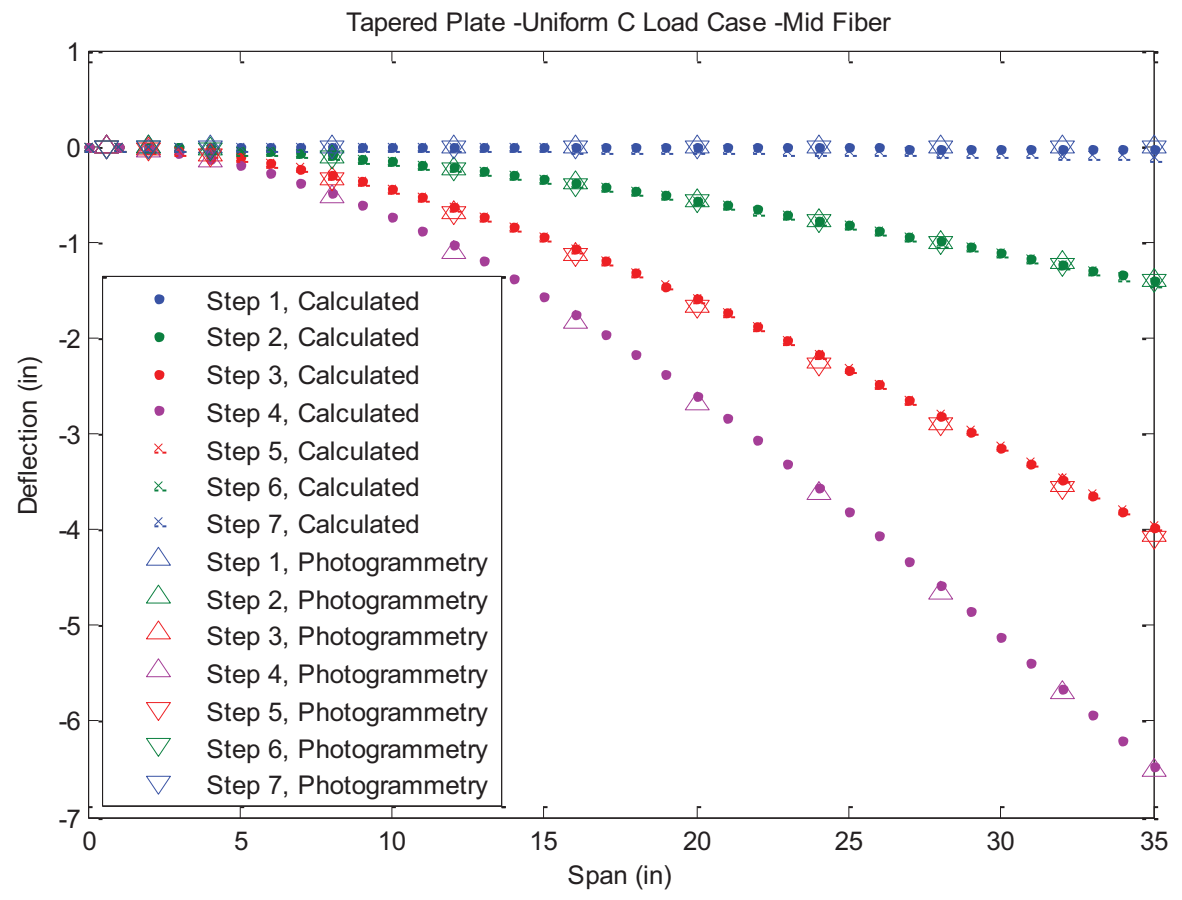

Figure A1_26. Tapered plate deflection results for middle fiber during Uniform C load case. 


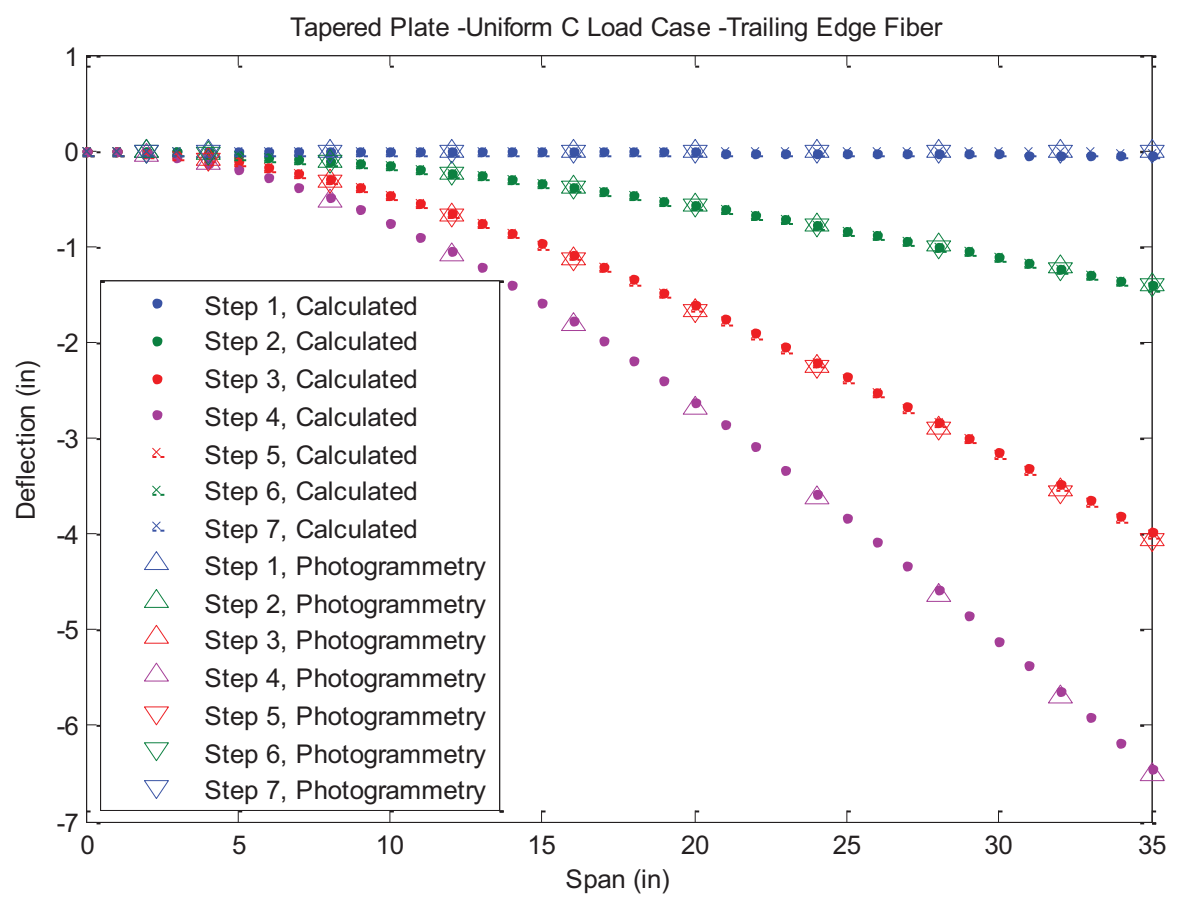

Figure A1_27. Tapered plate deflection results for trailing edge fiber during Uniform C load case.

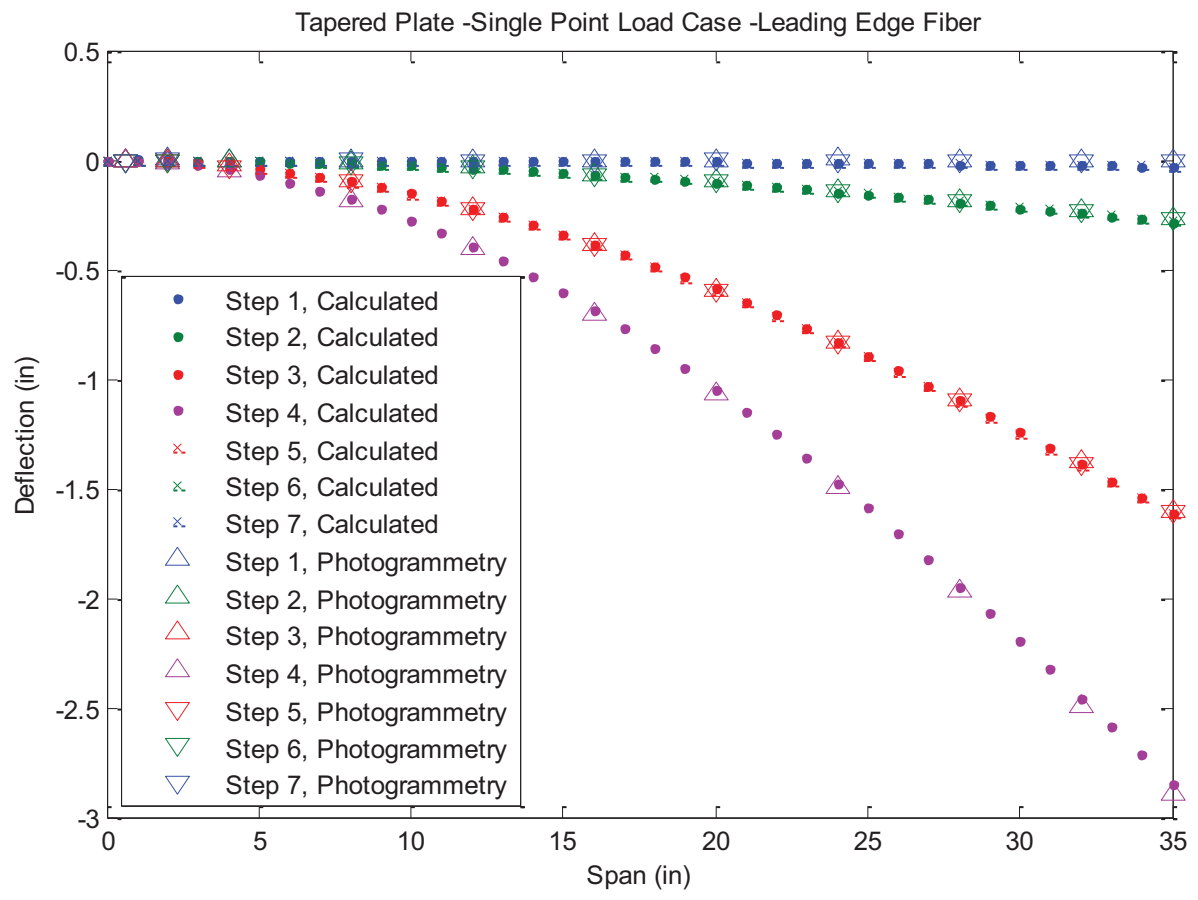

Figure A1_28. Tapered plate deflection results for leading edge fiber during single point load case.

American Institute of Aeronautics and Astronautics 


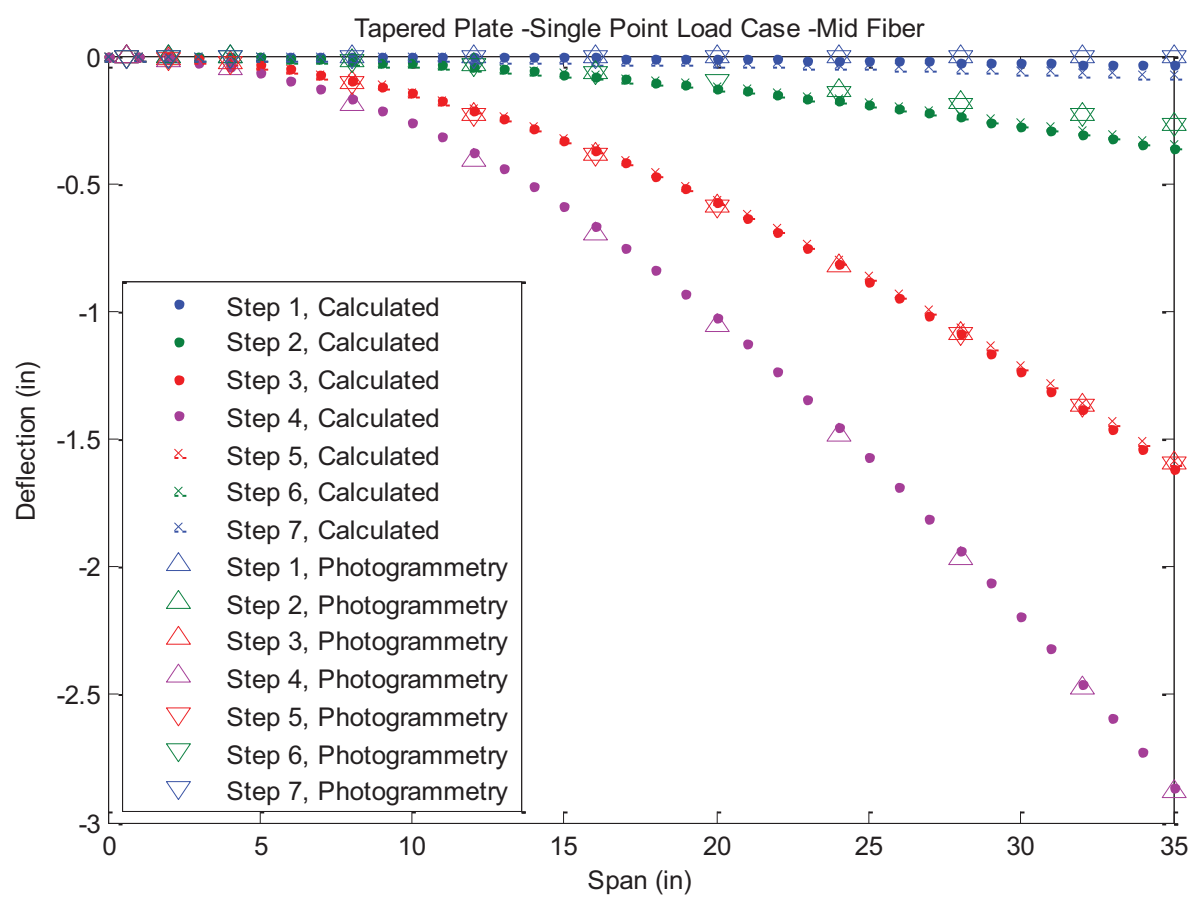

Figure A1_29. Tapered plate deflection results for middle fiber during single point load case.

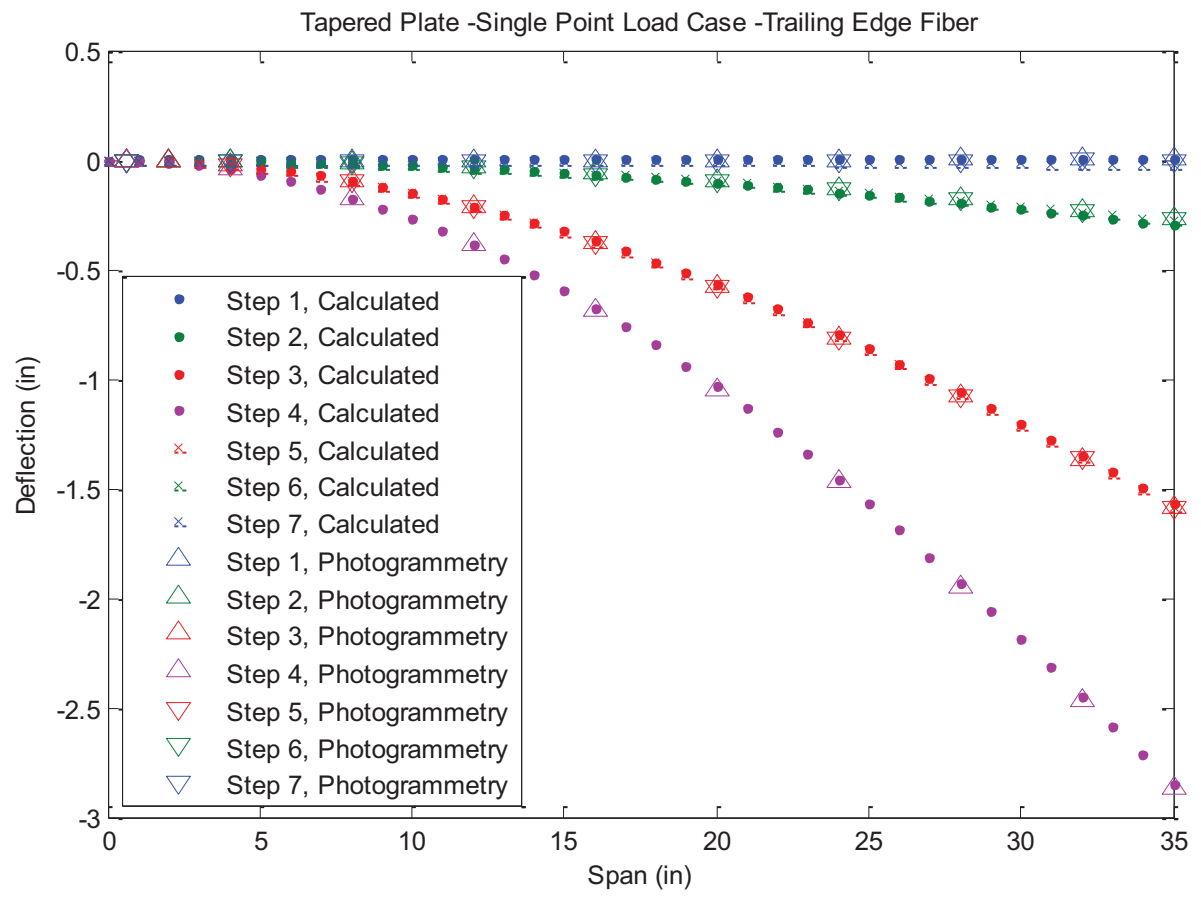

Figure A1_30. Tapered plate deflection results for trailing edge fiber during single point load case.

American Institute of Aeronautics and Astronautics 


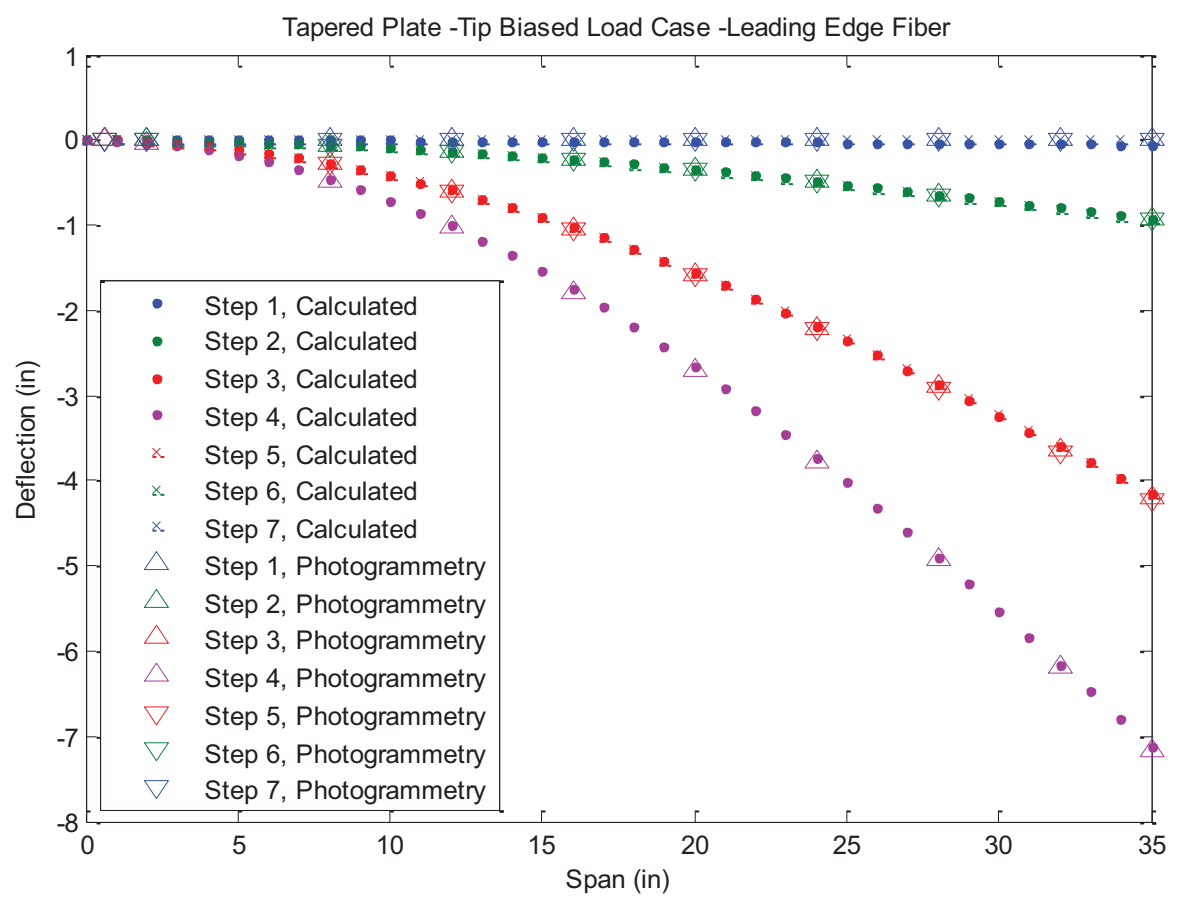

Figure A1_31. Tapered plate deflection results for leading edge fiber during tip-biased load case.

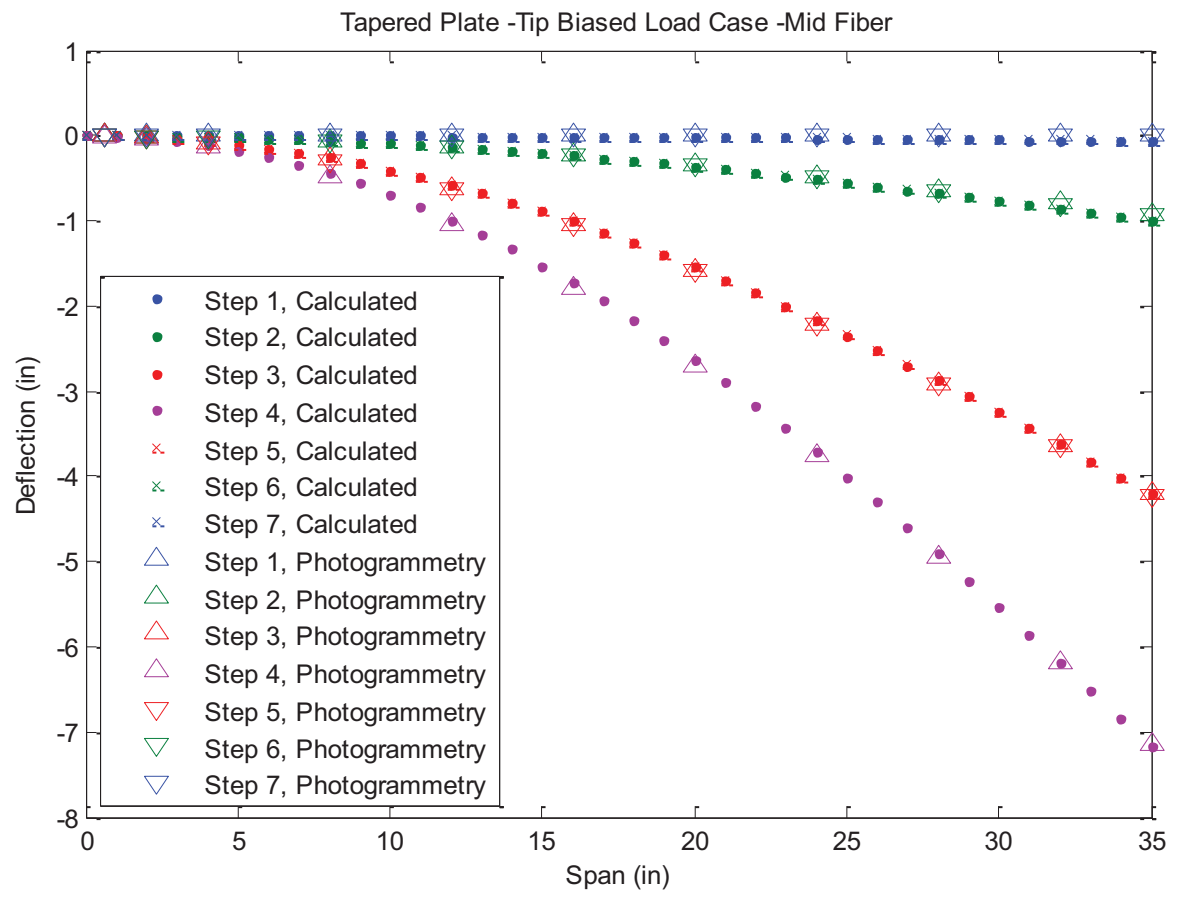

Figure A1_32. Tapered plate deflection results for middle fiber during tip-biased load case. 


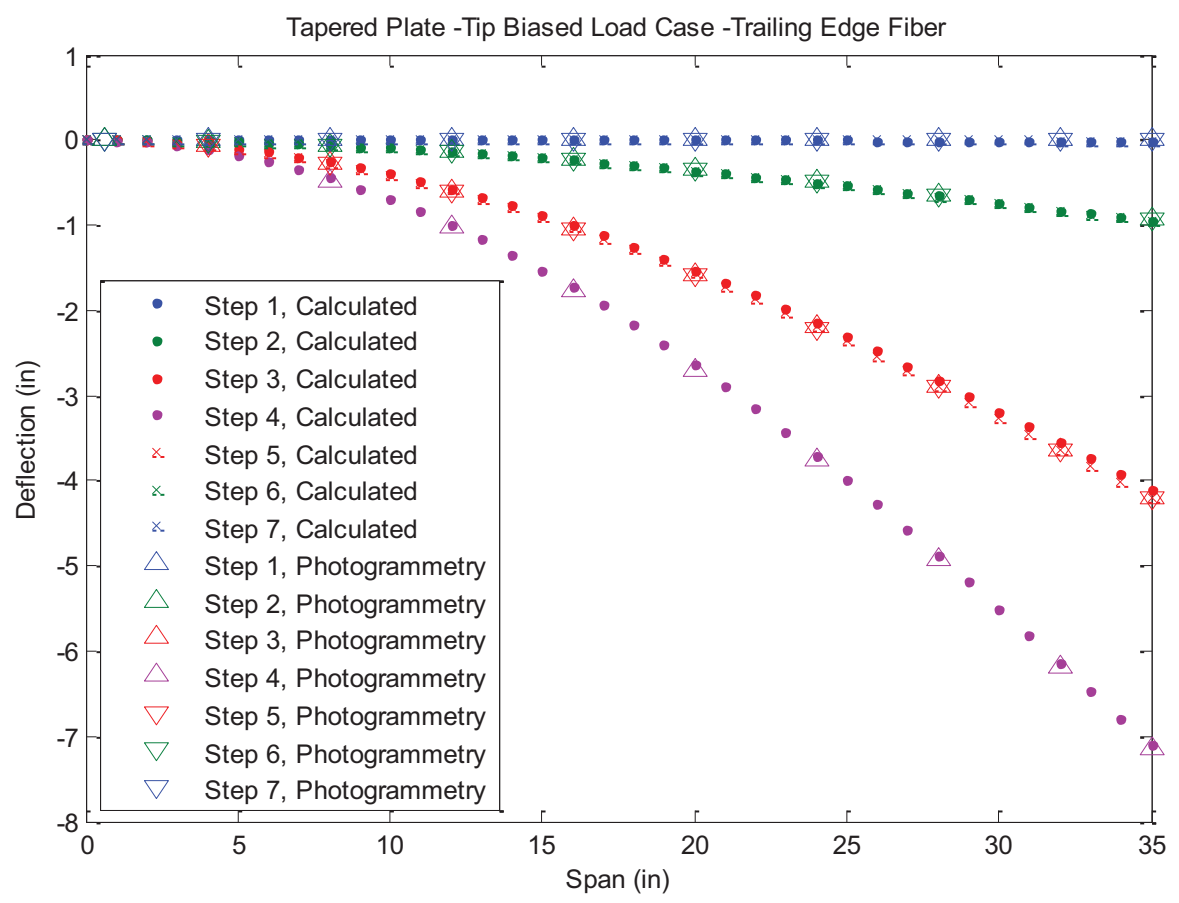

Figure A1_33. Tapered plate deflection results for trailing edge fiber during tip-biased load case.

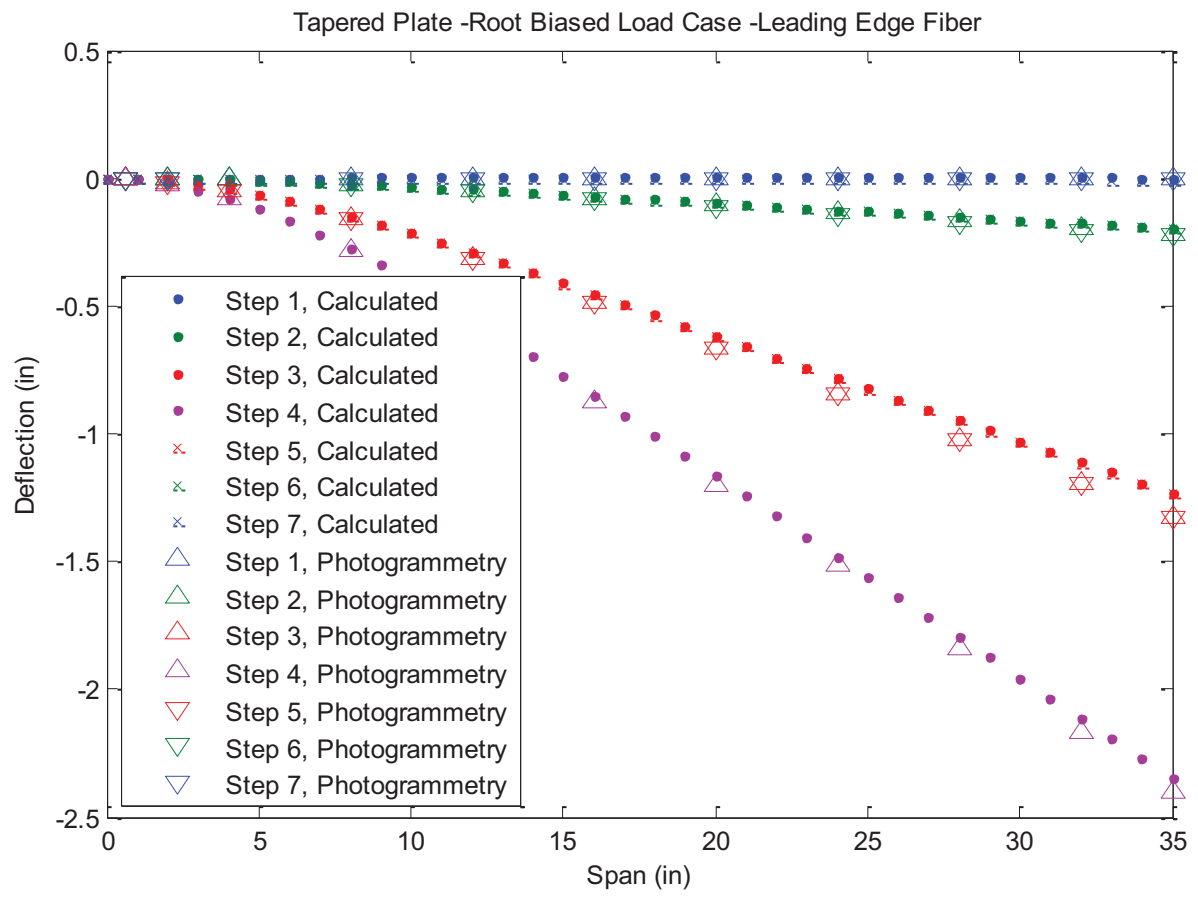

Figure A1_34. Tapered plate deflection results for leading edge fiber during root-biased load case.

American Institute of Aeronautics and Astronautics 


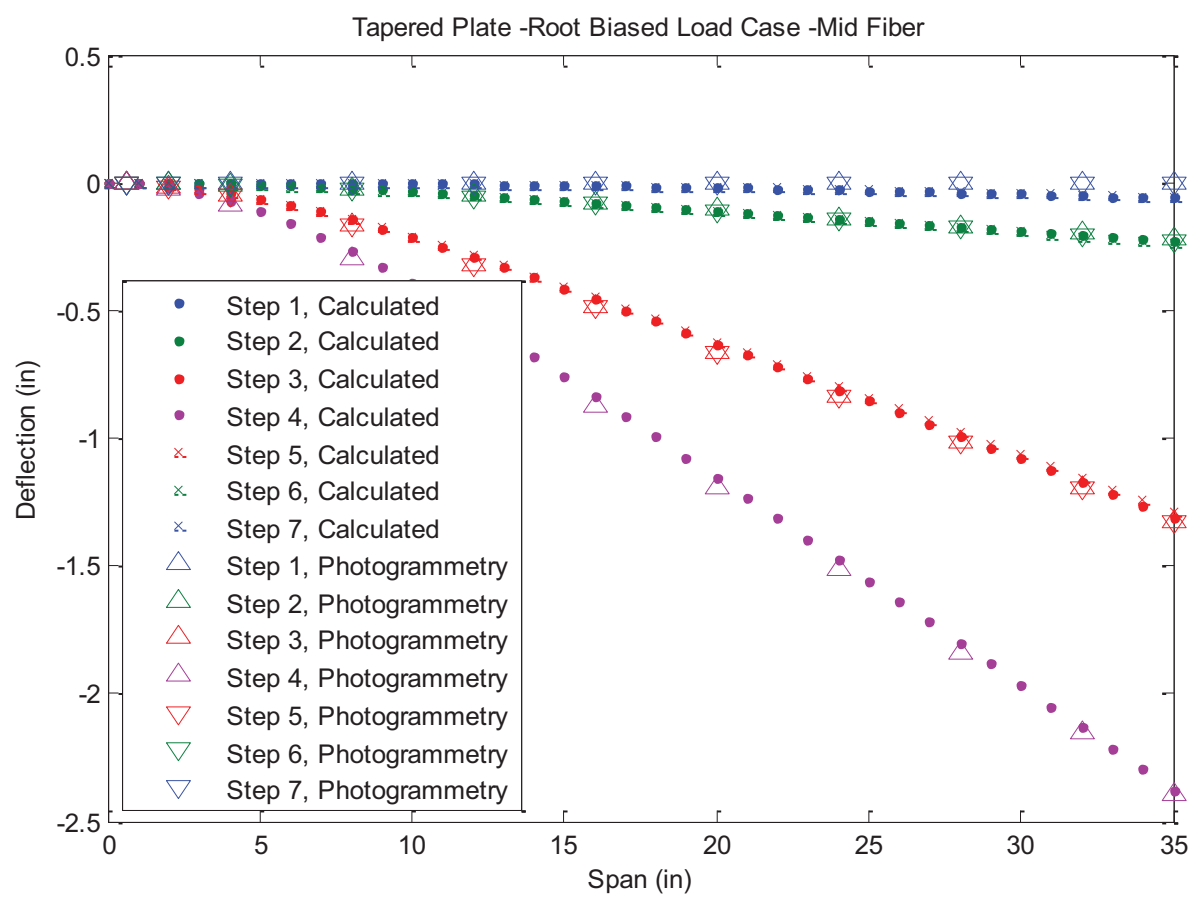

Figure A1_35. Tapered plate deflection results for middle fiber during root-biased load case.

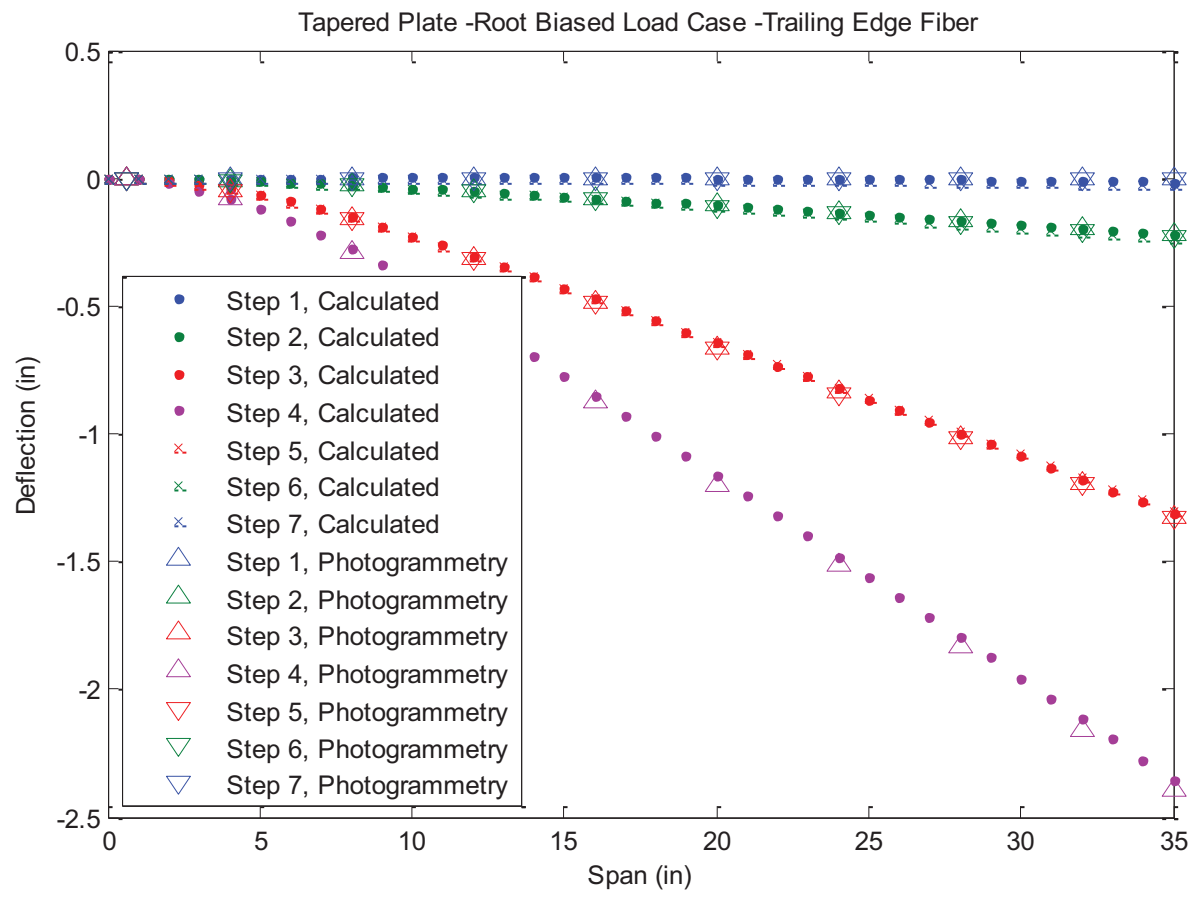

Figure A1_36. Tapered plate deflection results for trailing edge fiber during root-biased load case.

American Institute of Aeronautics and Astronautics 


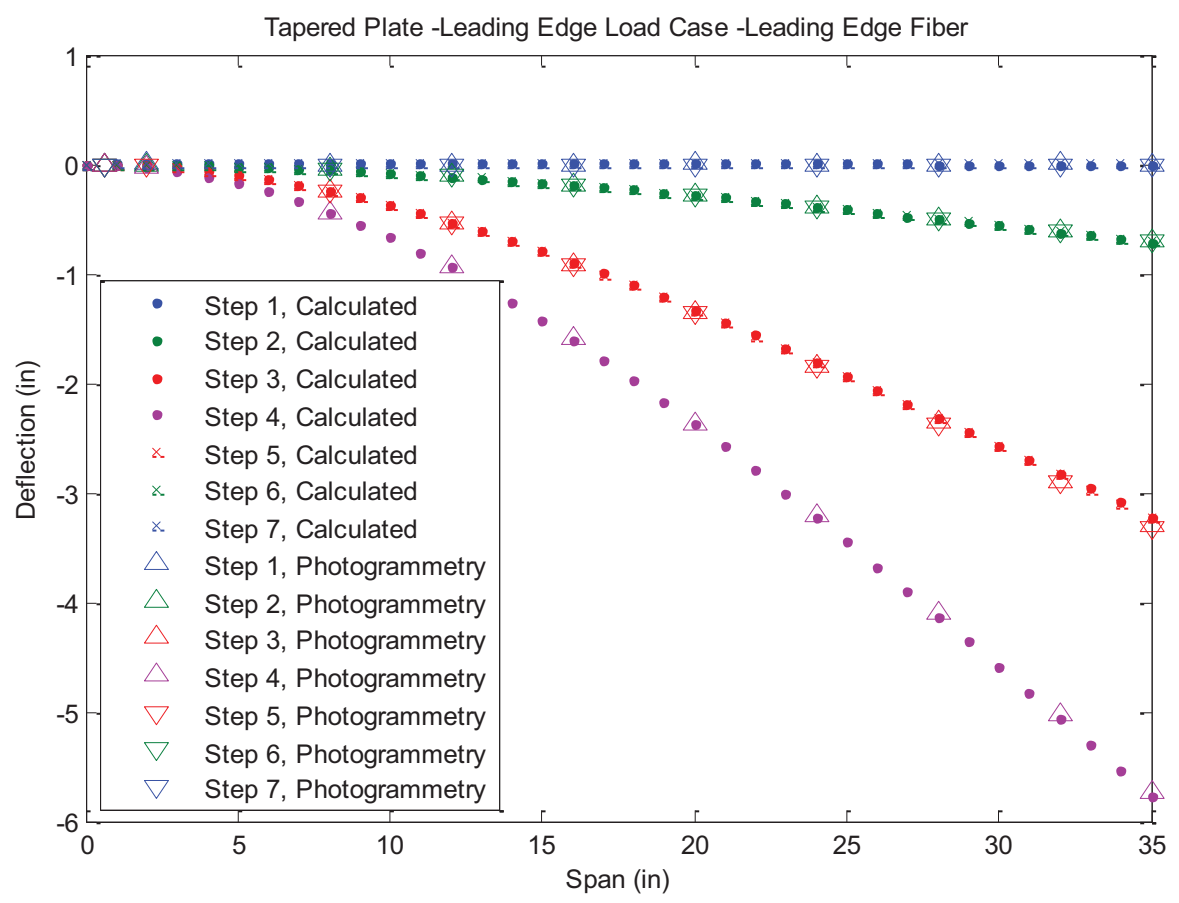

Figure A1_37. Tapered plate deflection results for leading edge fiber during leading edge load case.

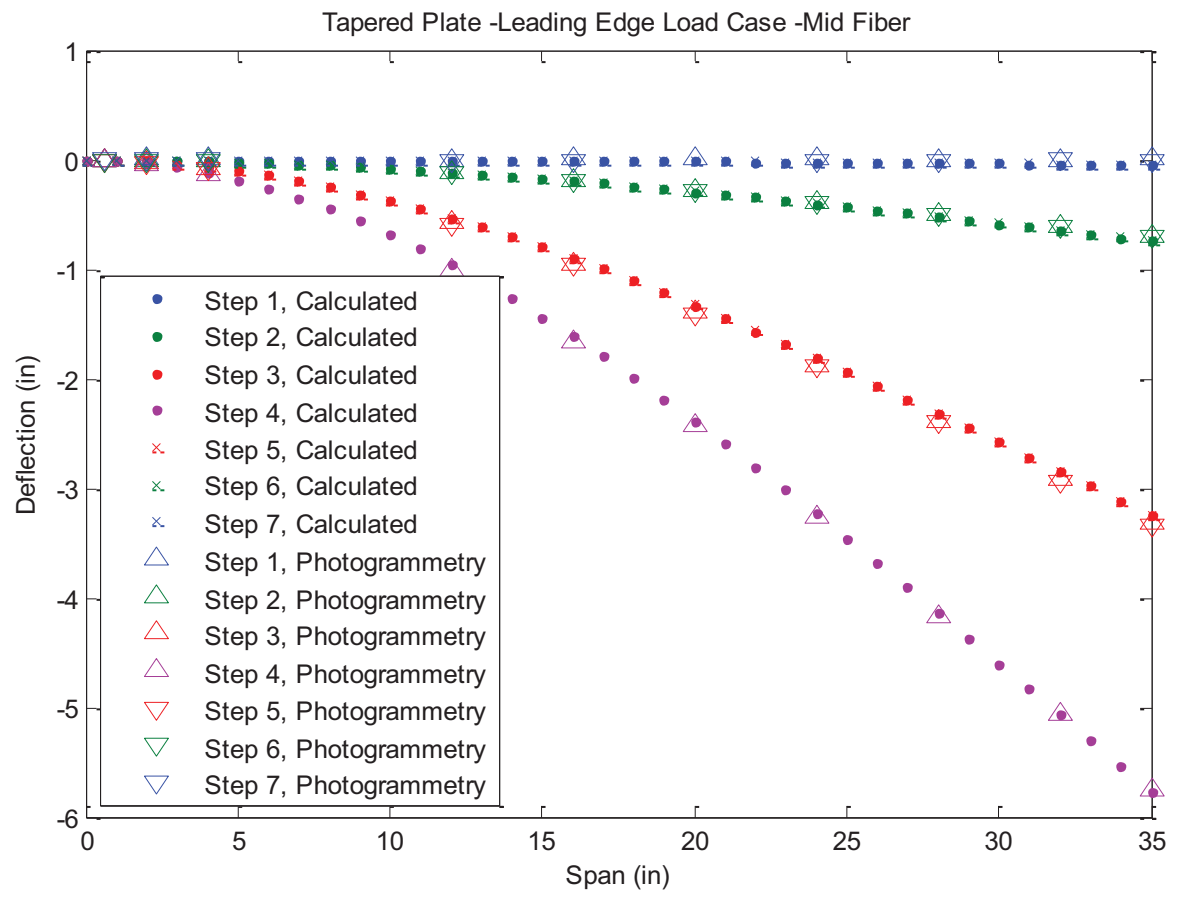

Figure A1_38. Tapered plate deflection results for middle fiber during leading edge load case. 


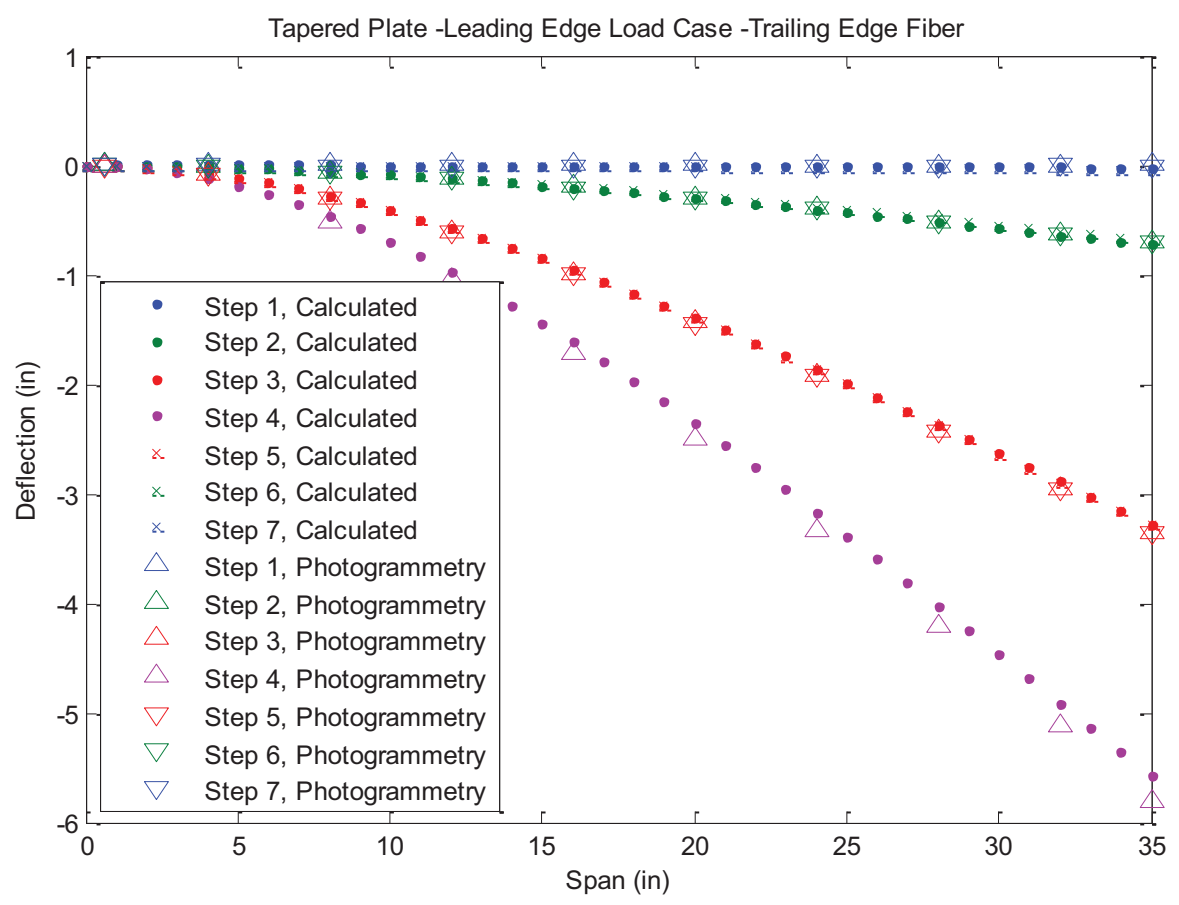

Figure A1_39. Tapered plate deflection results for trailing edge fiber during leading edge load case.

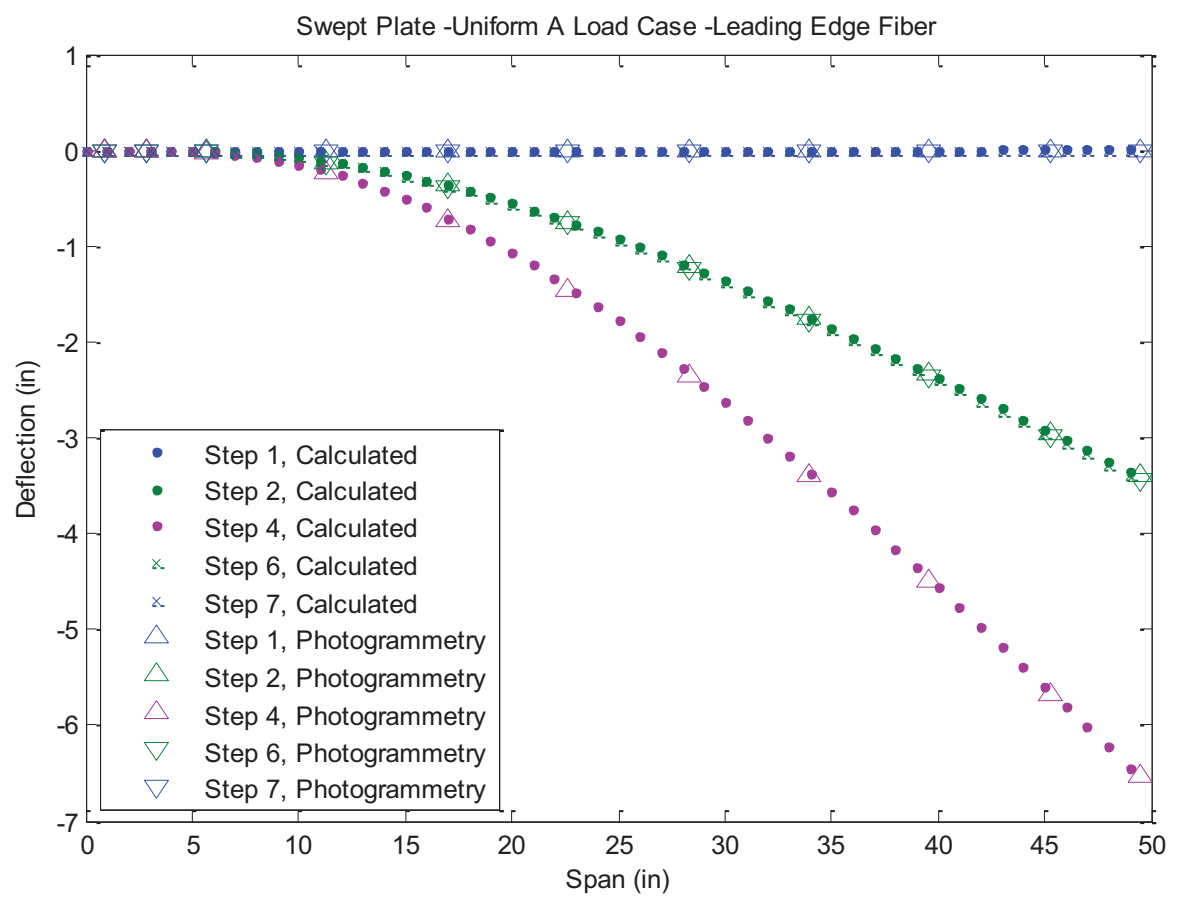

Figure A1_40. Swept plate deflection results for leading edge fiber during Uniform A load case.

American Institute of Aeronautics and Astronautics 


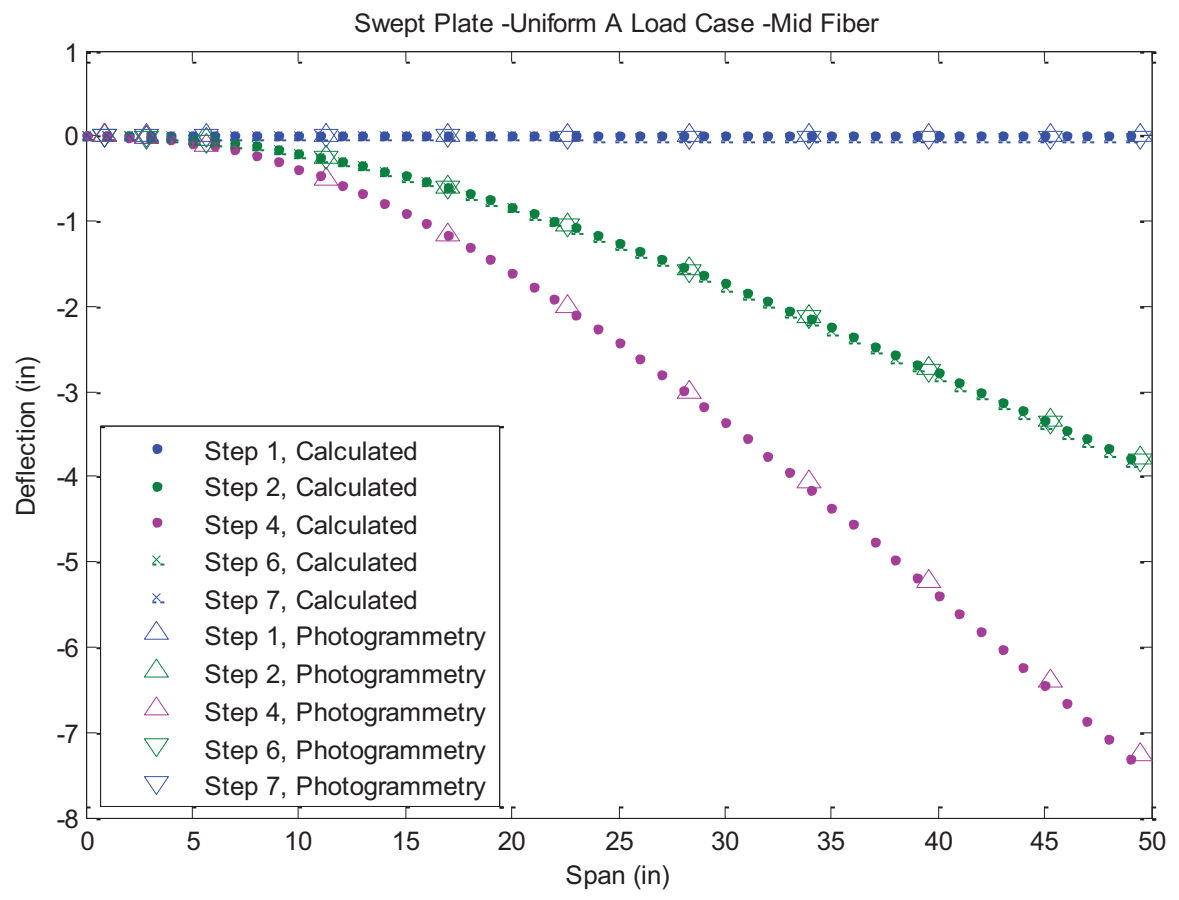

Figure A1_41. Swept plate deflection results for middle fiber during Uniform A load case.

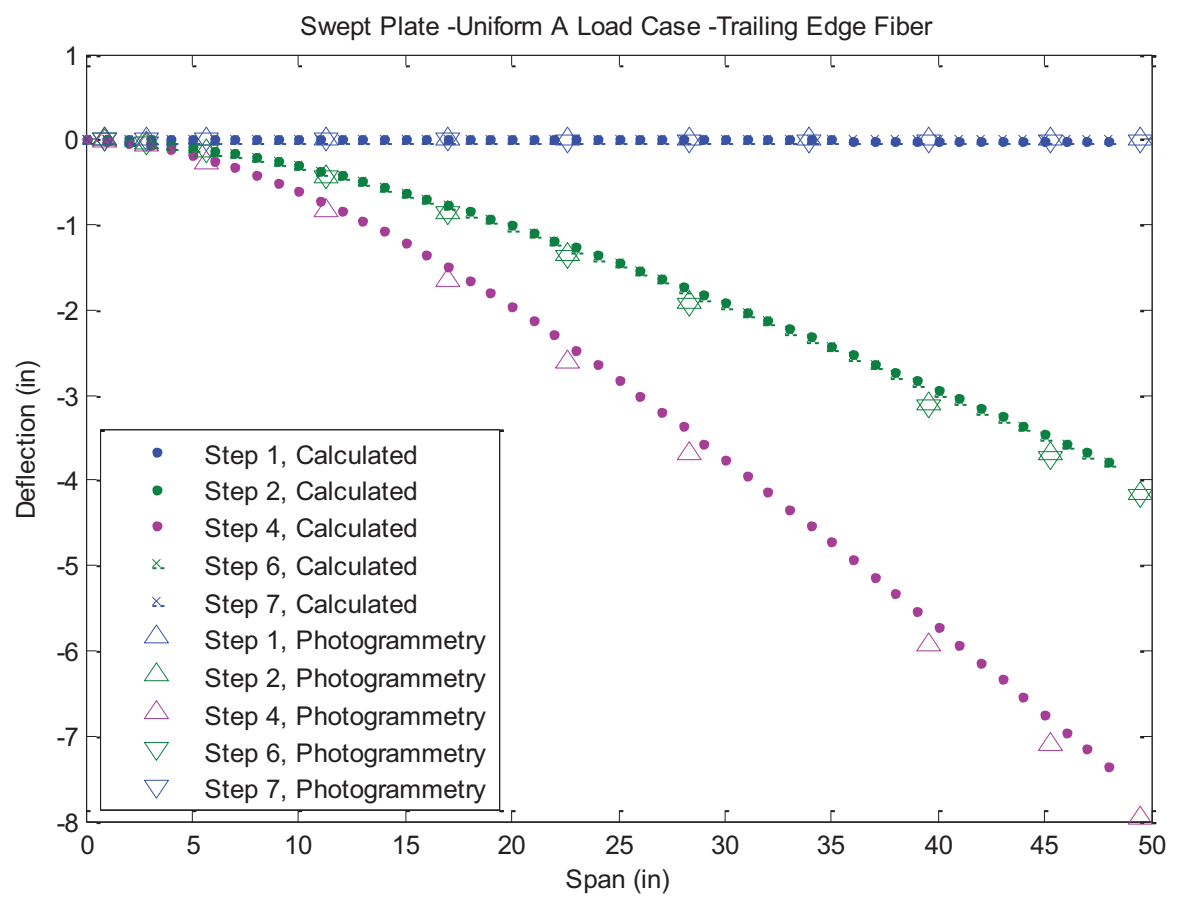

Figure A1_42. Swept plate deflection results for trailing edge fiber during Uniform A load case.

American Institute of Aeronautics and Astronautics 


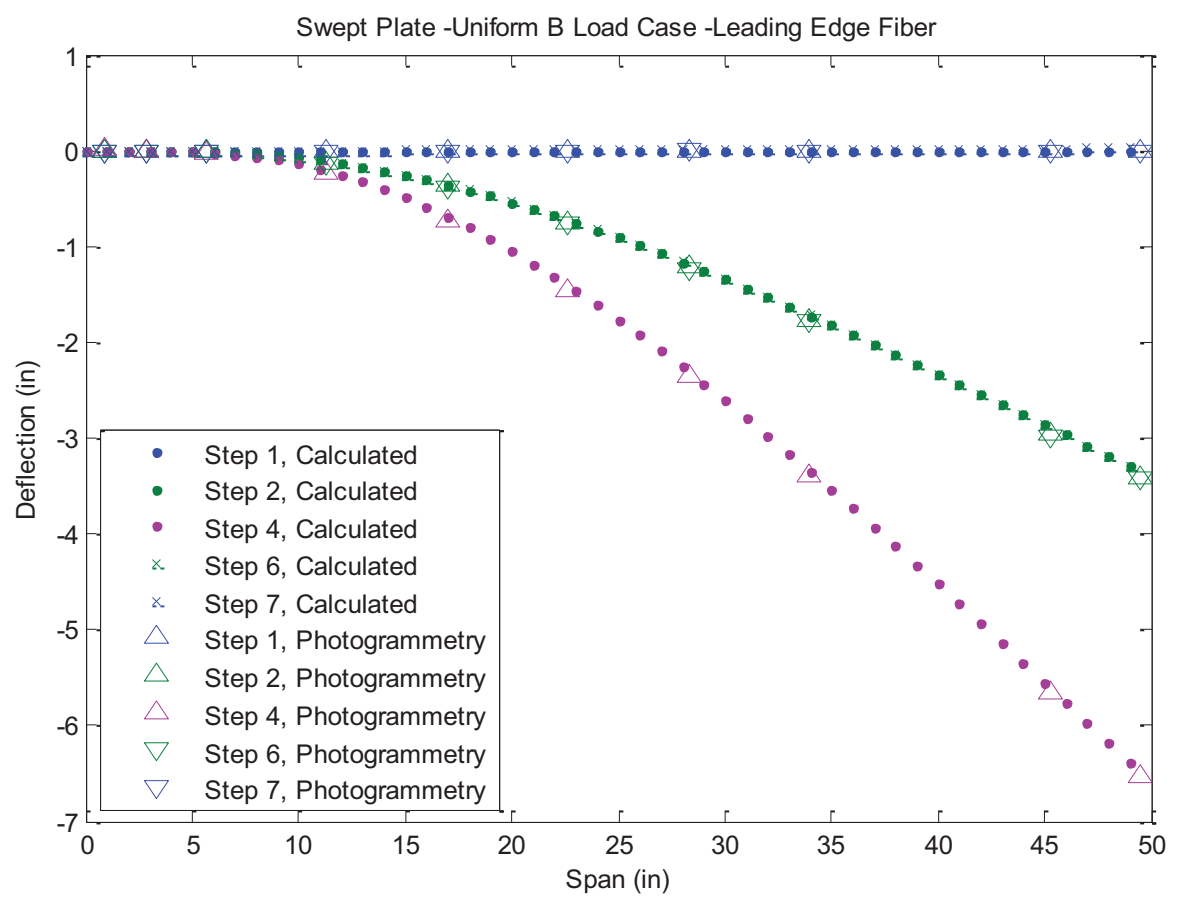

Figure A1_43. Swept plate deflection results for leading edge fiber during Uniform B load case.

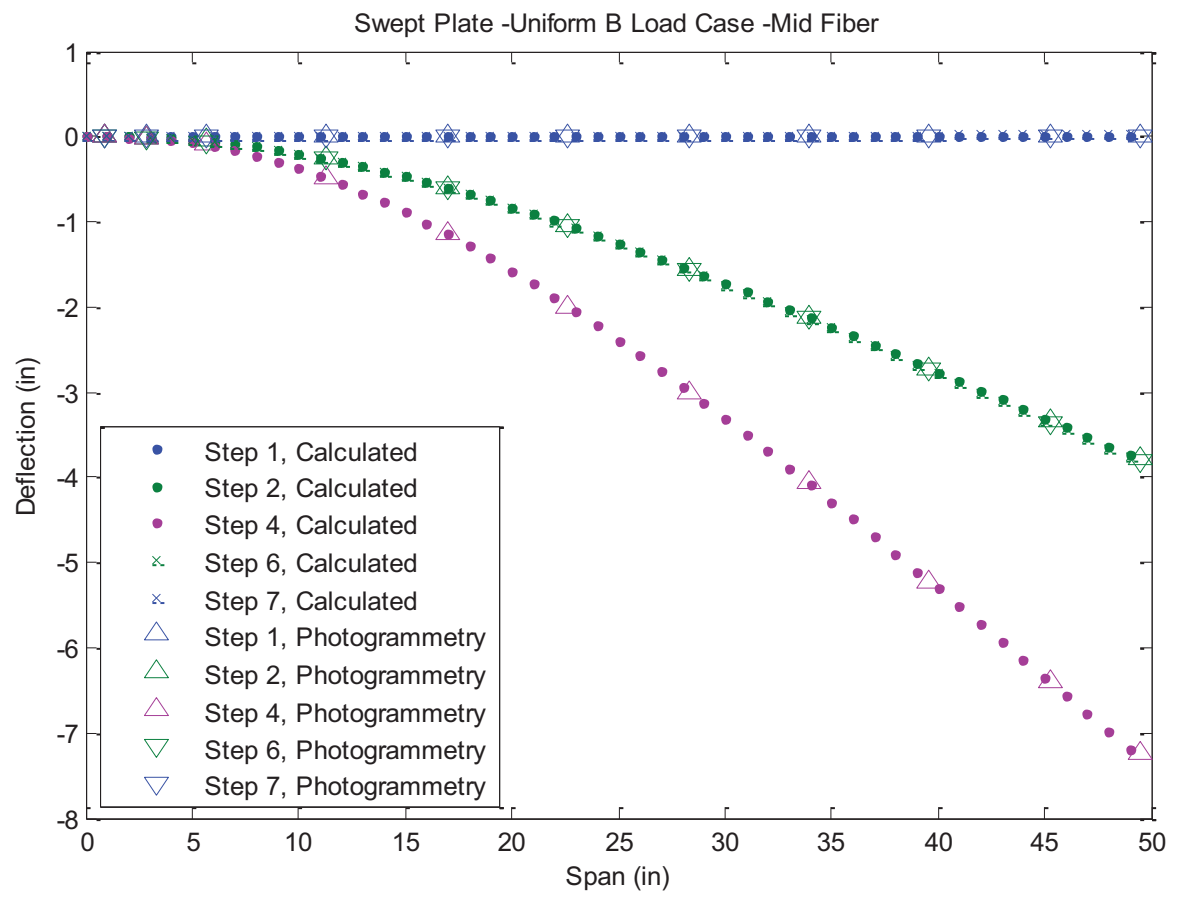

Figure A1_44. Swept plate deflection results for middle fiber during Uniform B load case.

American Institute of Aeronautics and Astronautics 


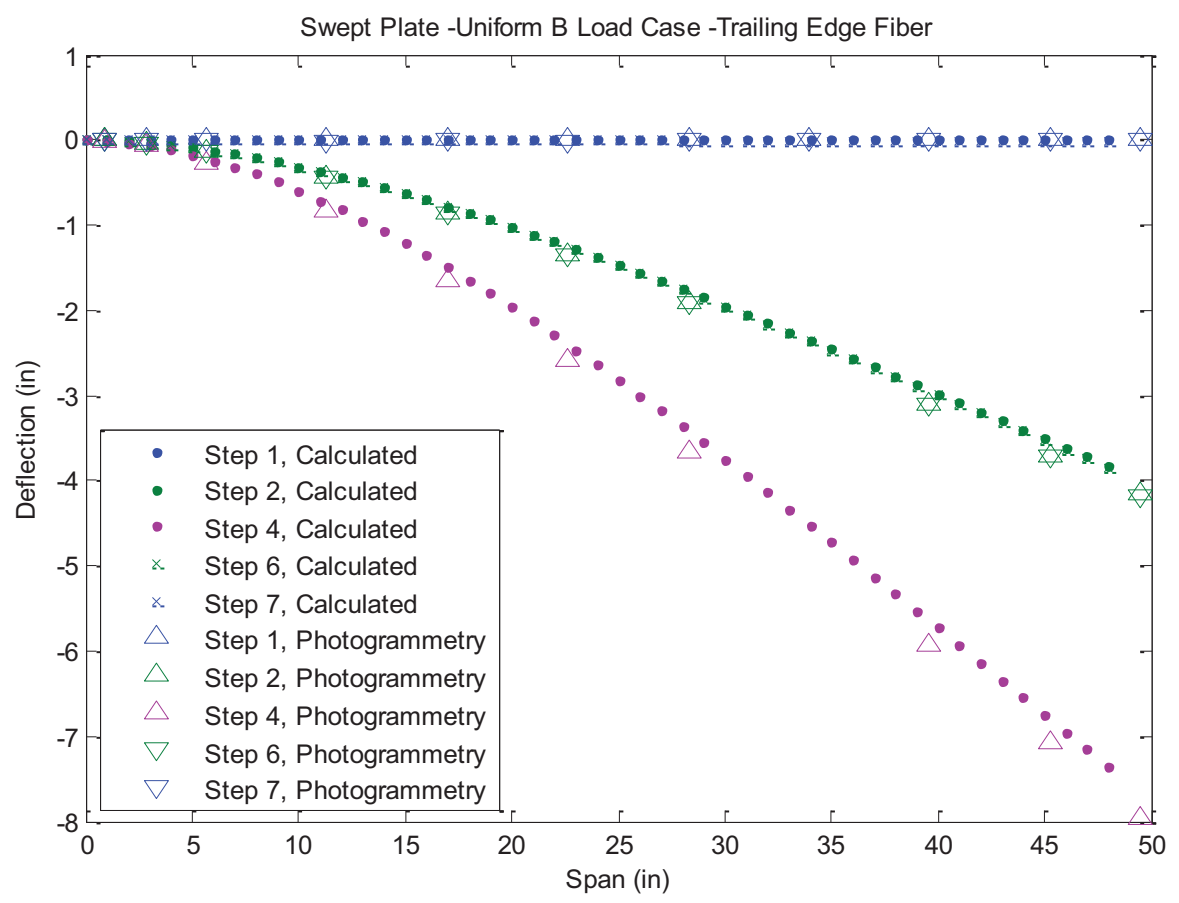

Figure A1_45. Swept plate deflection results for trailing edge fiber during Uniform B load case.

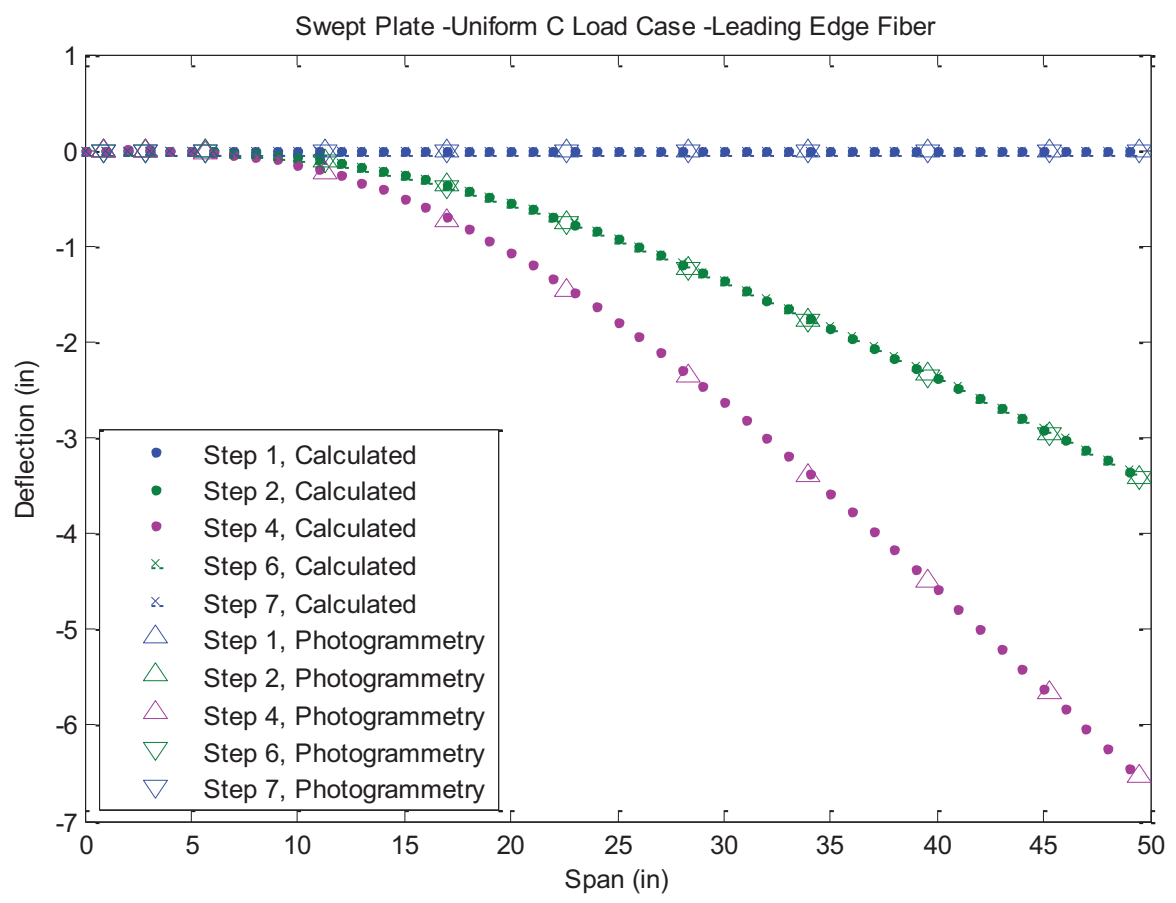

Figure A1_46. Swept plate deflection results for leading edge fiber during Uniform C load case. 


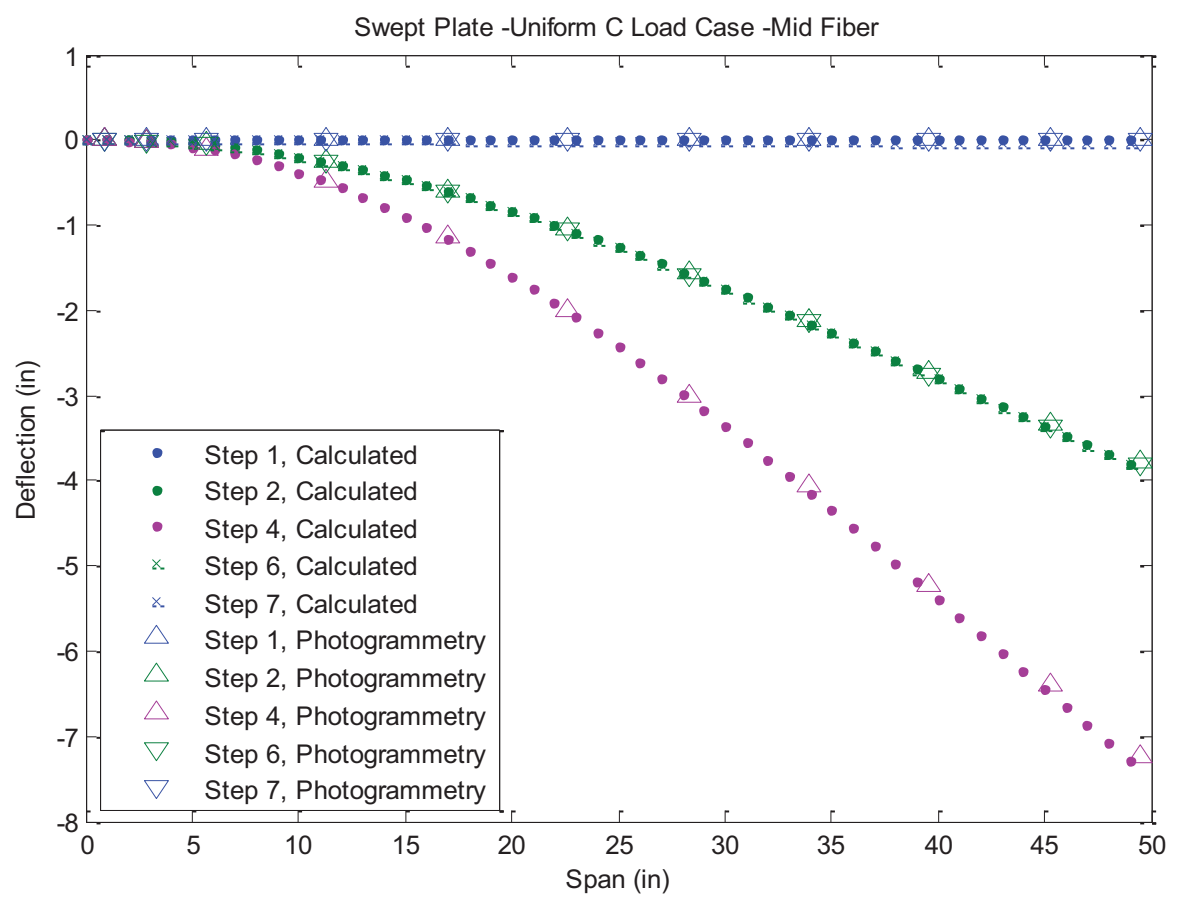

Figure A1_47. Swept plate deflection results for middle fiber during Uniform C load case.

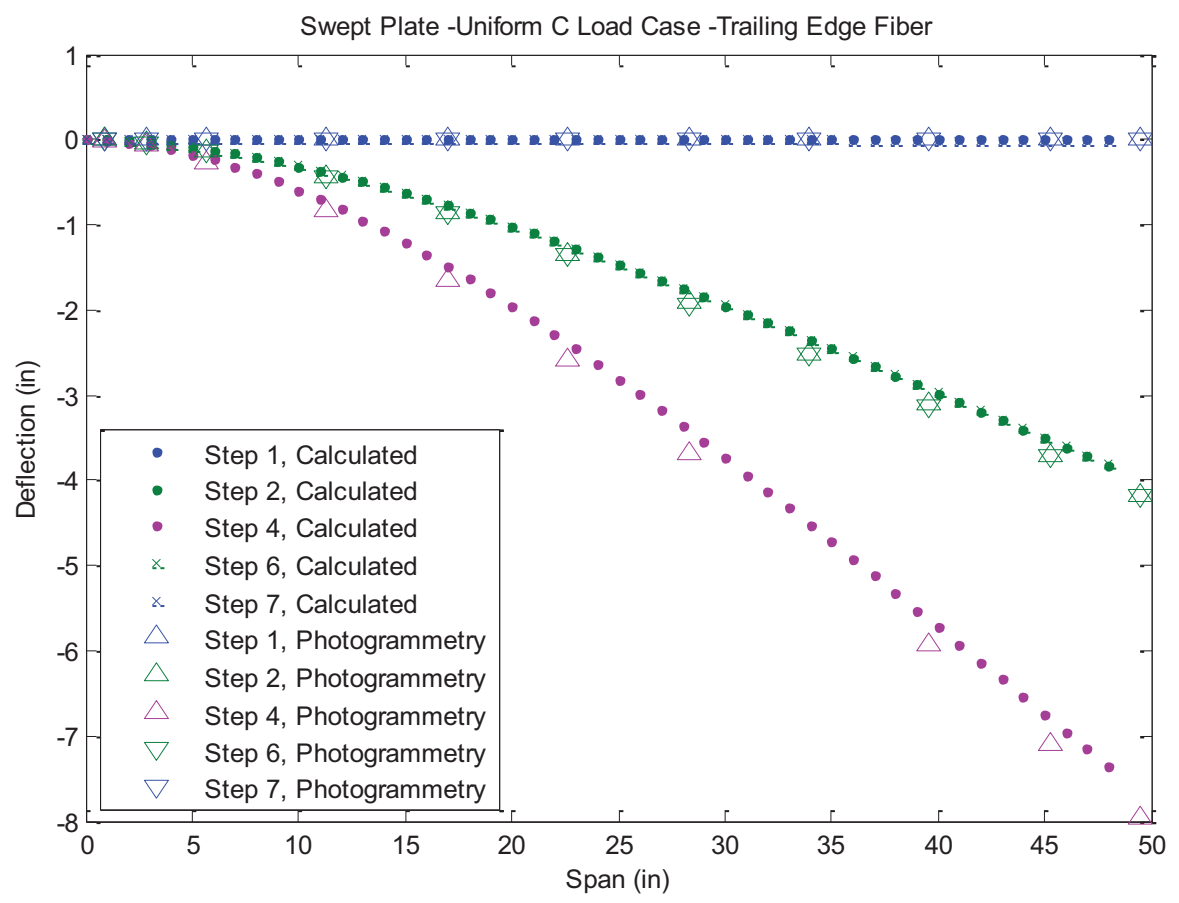

Figure A1_48. Swept plate deflection results for trailing edge fiber during Uniform C load case.

American Institute of Aeronautics and Astronautics 


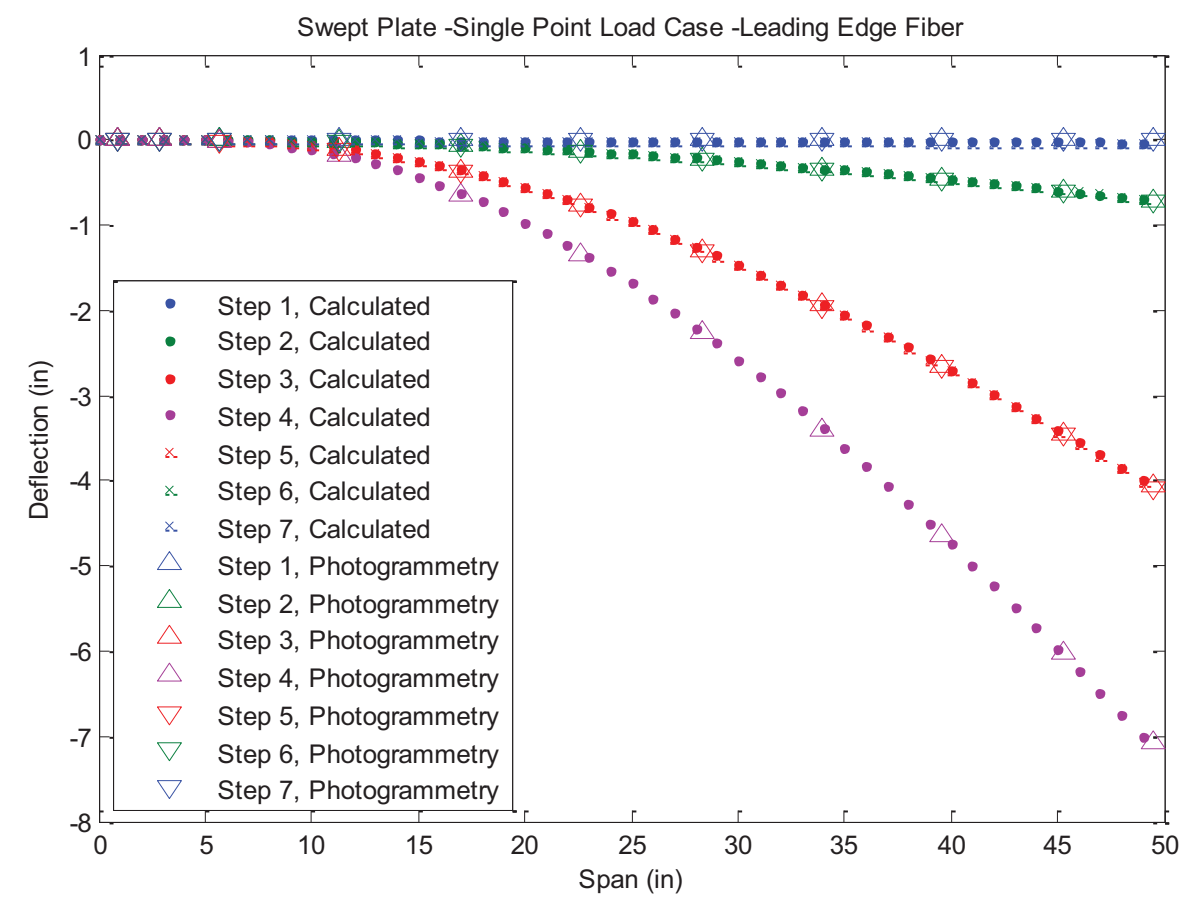

Figure A1_49. Swept plate deflection results for leading edge fiber during single point load case.

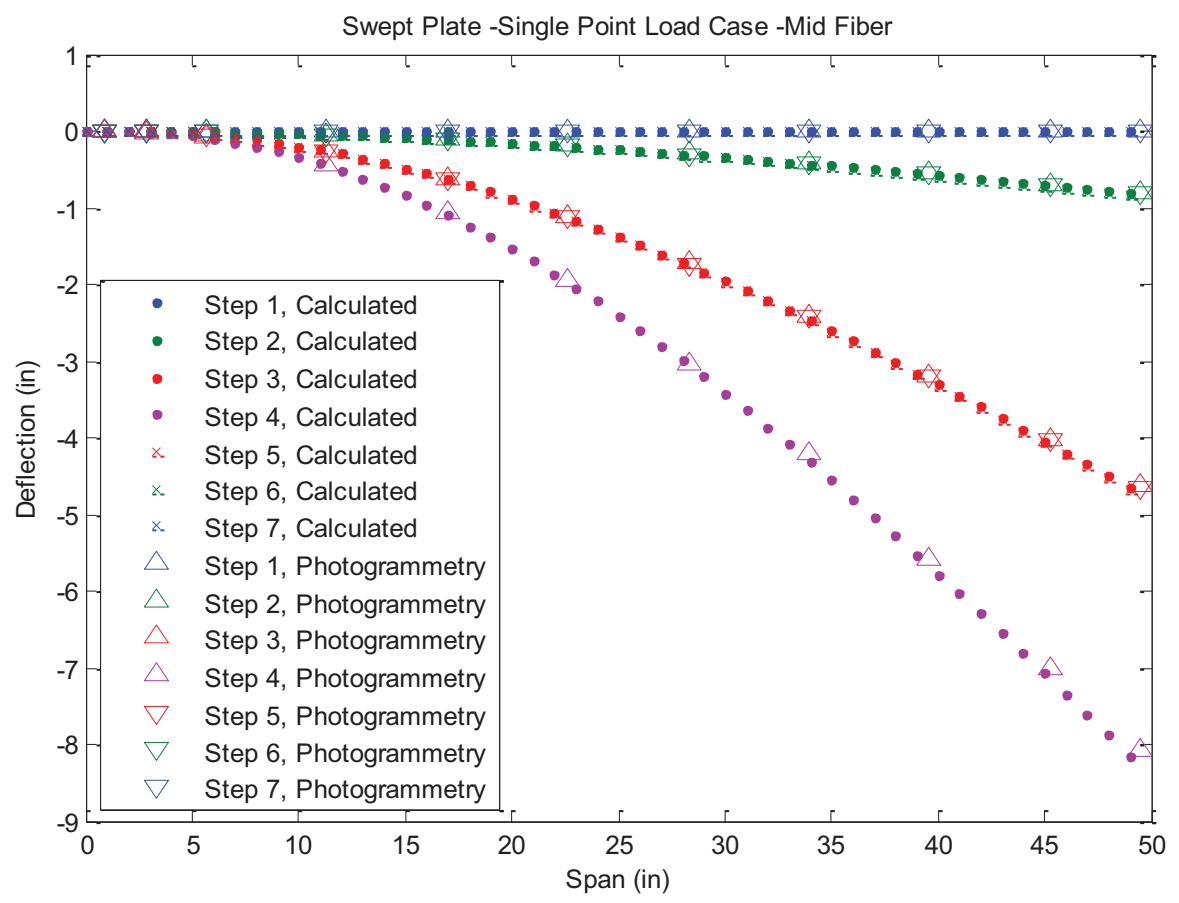

Figure A1_50. Swept plate deflection results for middle fiber during single point load case. 


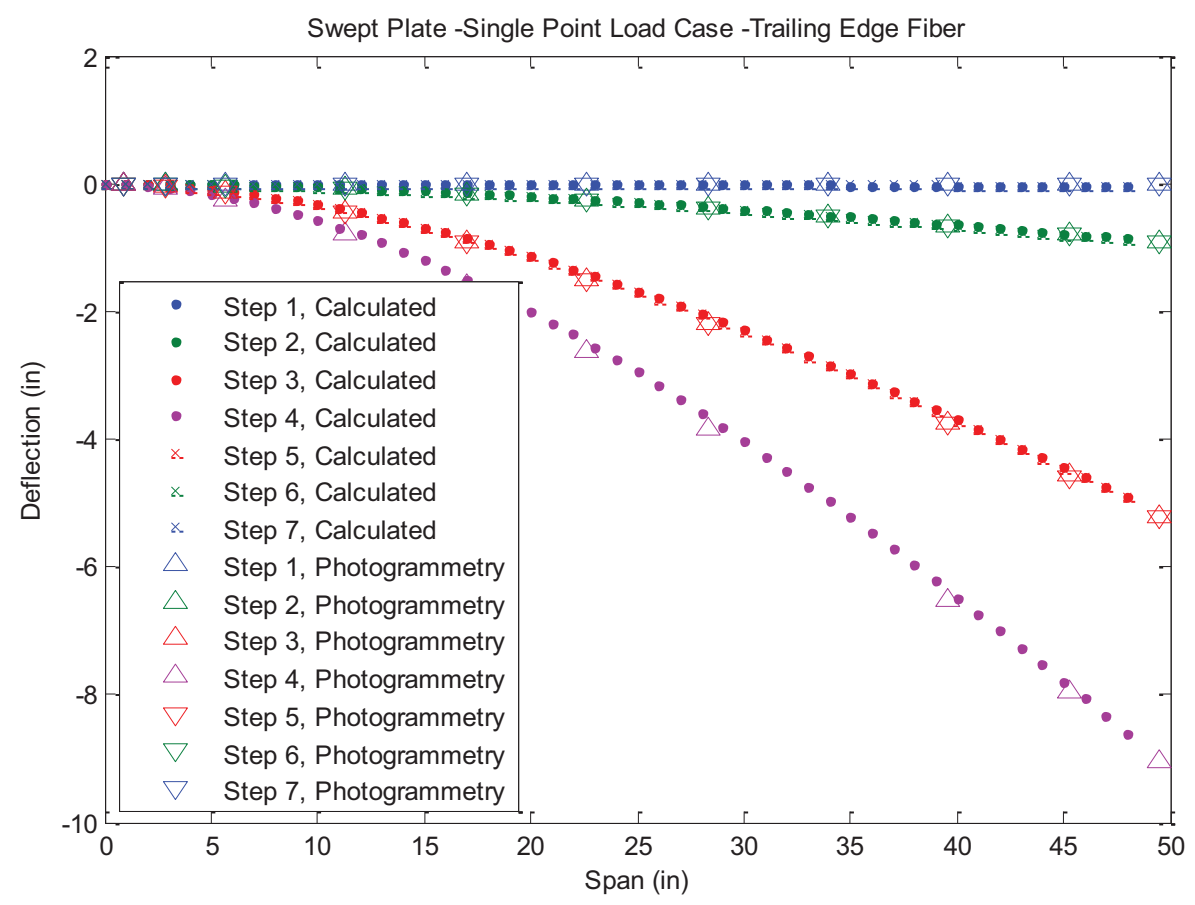

Figure A1_51. Swept plate deflection results for trailing edge fiber during single point load case.

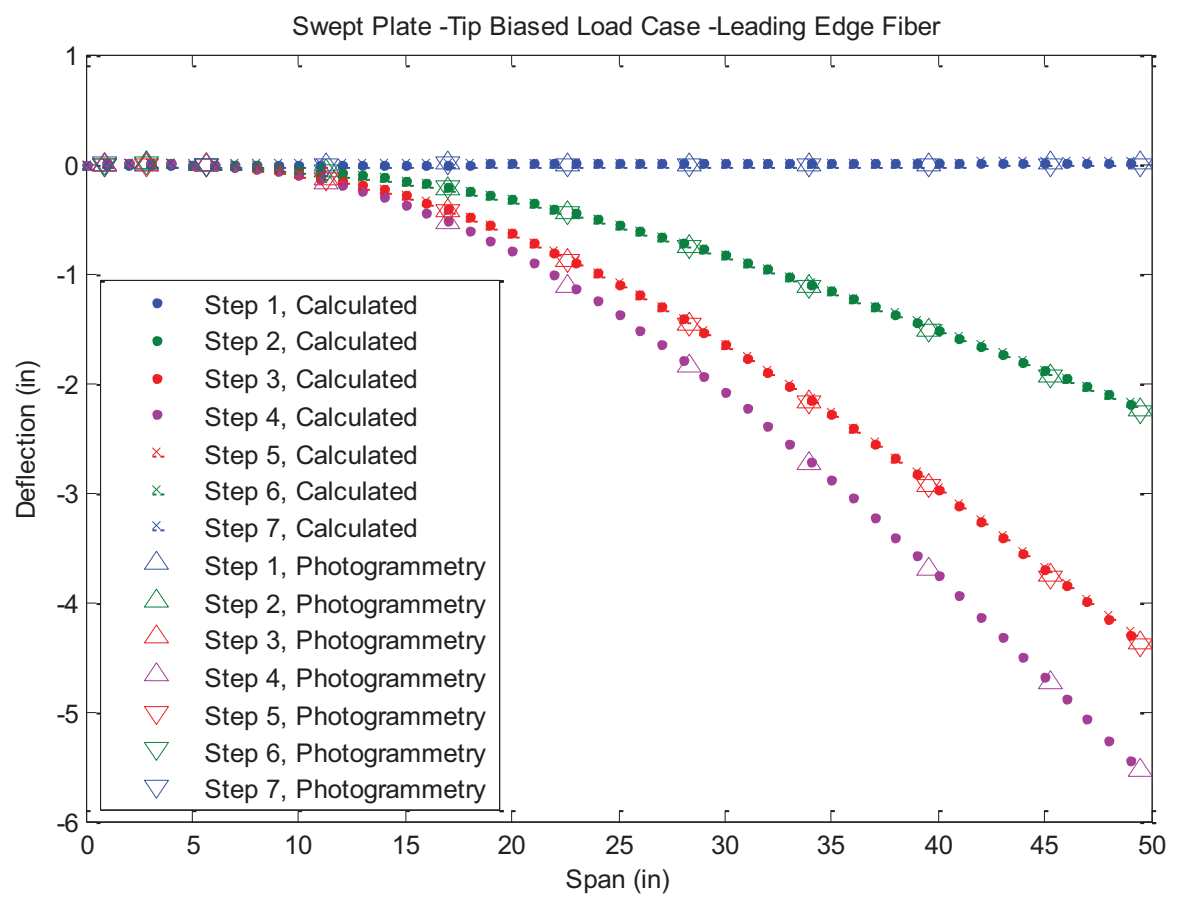

Figure A1_52. Swept plate deflection results for leading edge fiber during tip-biased load case.

American Institute of Aeronautics and Astronautics 
Swept Plate -Tip Biased Load Case -Mid Fiber

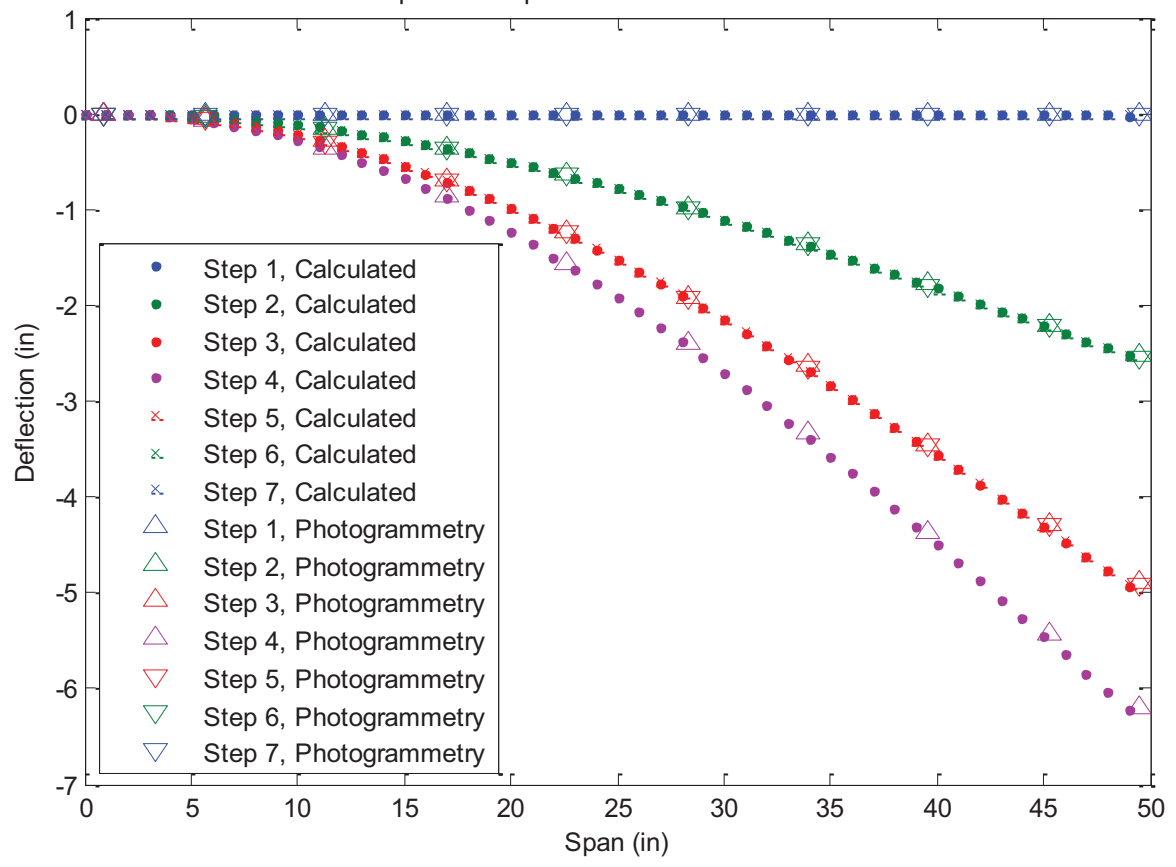

Figure A1_53. Swept plate deflection results for middle fiber during tip-biased load case.

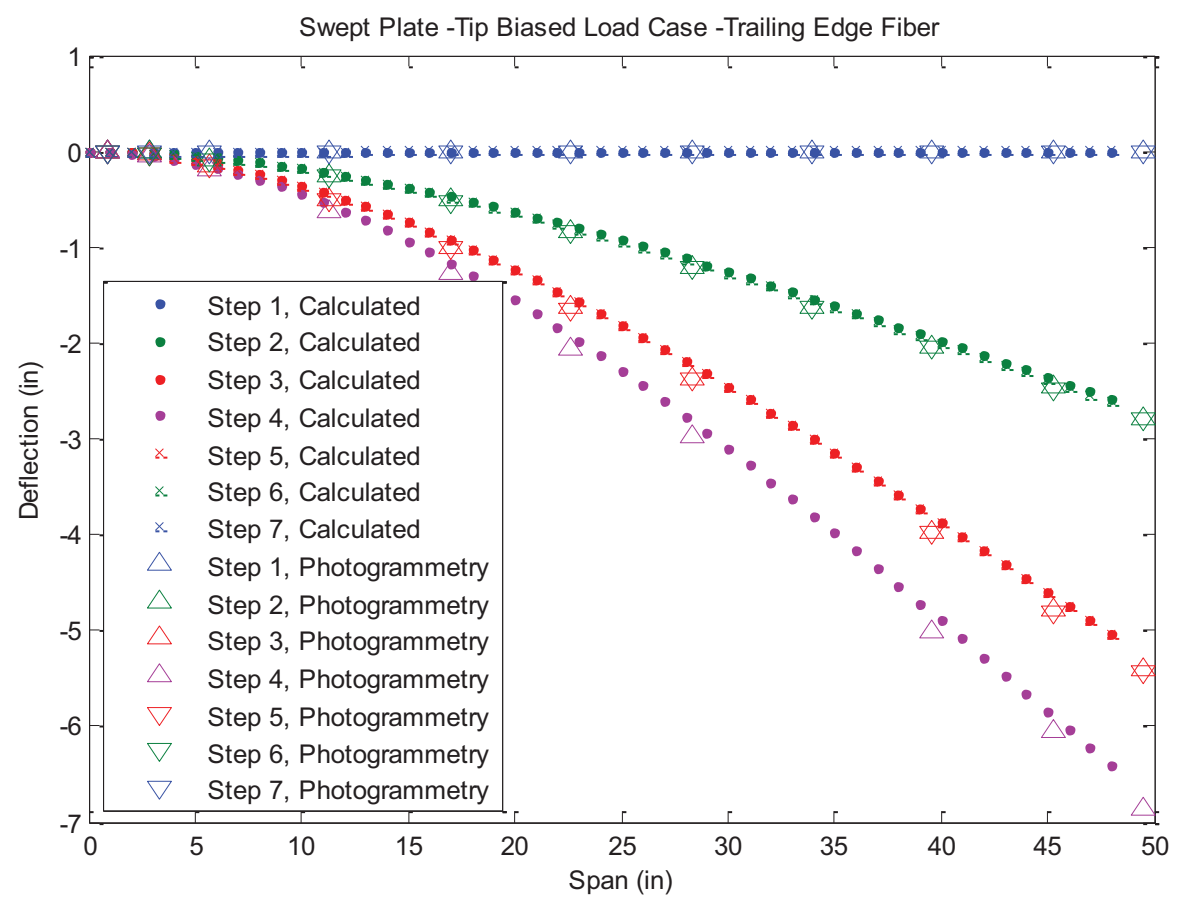

Figure A1_54. Swept plate deflection results for trailing edge fiber during tip-biased load case.

American Institute of Aeronautics and Astronautics 


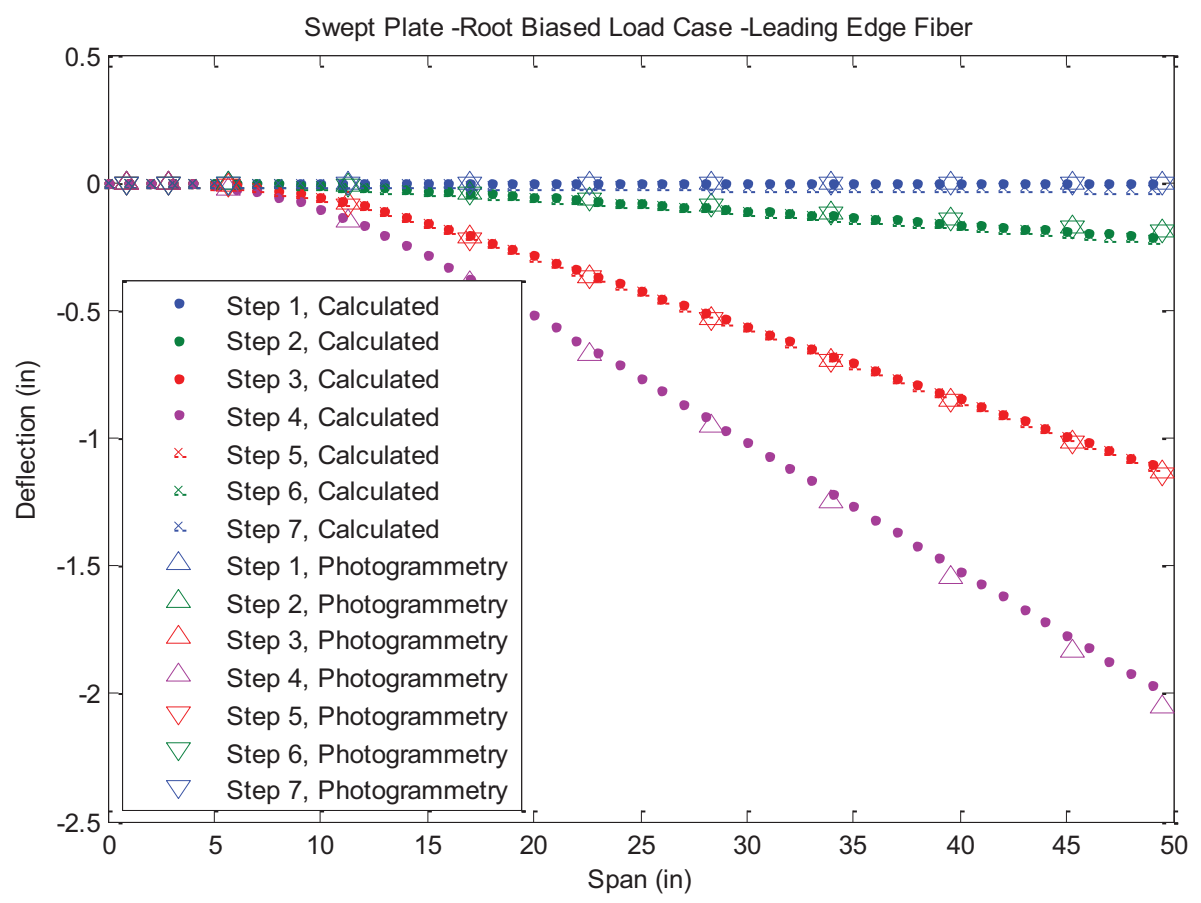

Figure A1_55. Swept plate deflection results for leading edge fiber during root-biased load case.

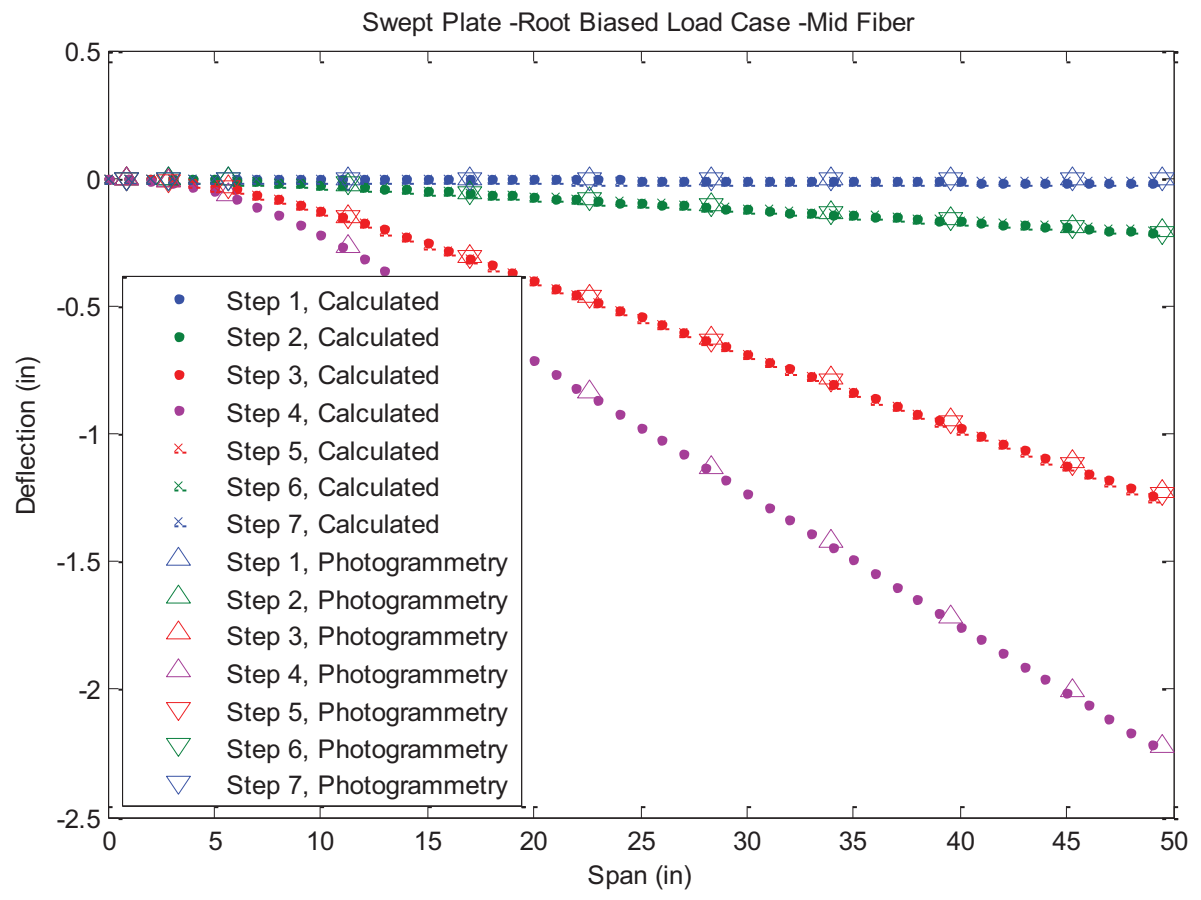

Figure A1_56. Swept plate deflection results for middle fiber during root-biased load case.

American Institute of Aeronautics and Astronautics 


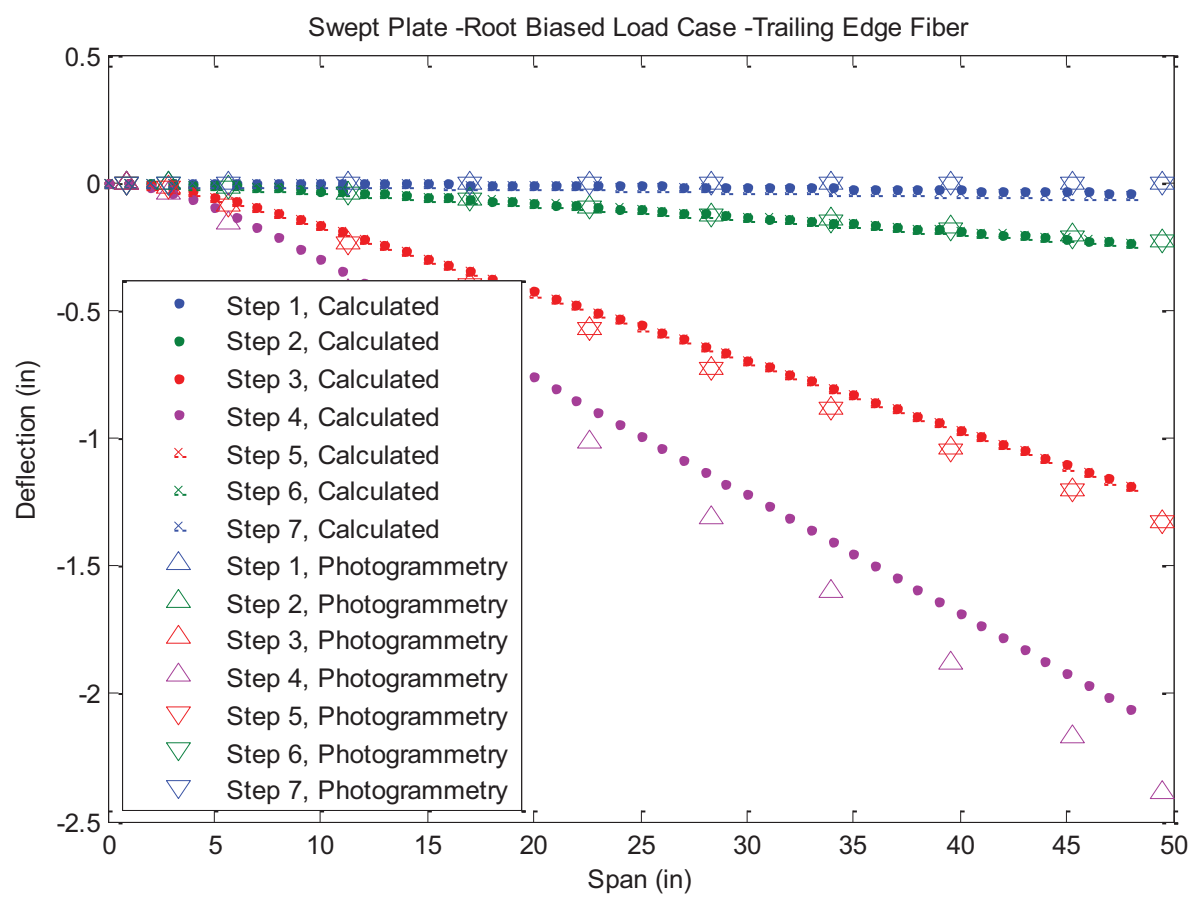

Figure A1_57. Swept plate deflection results for trailing edge fiber during root-biased load case.

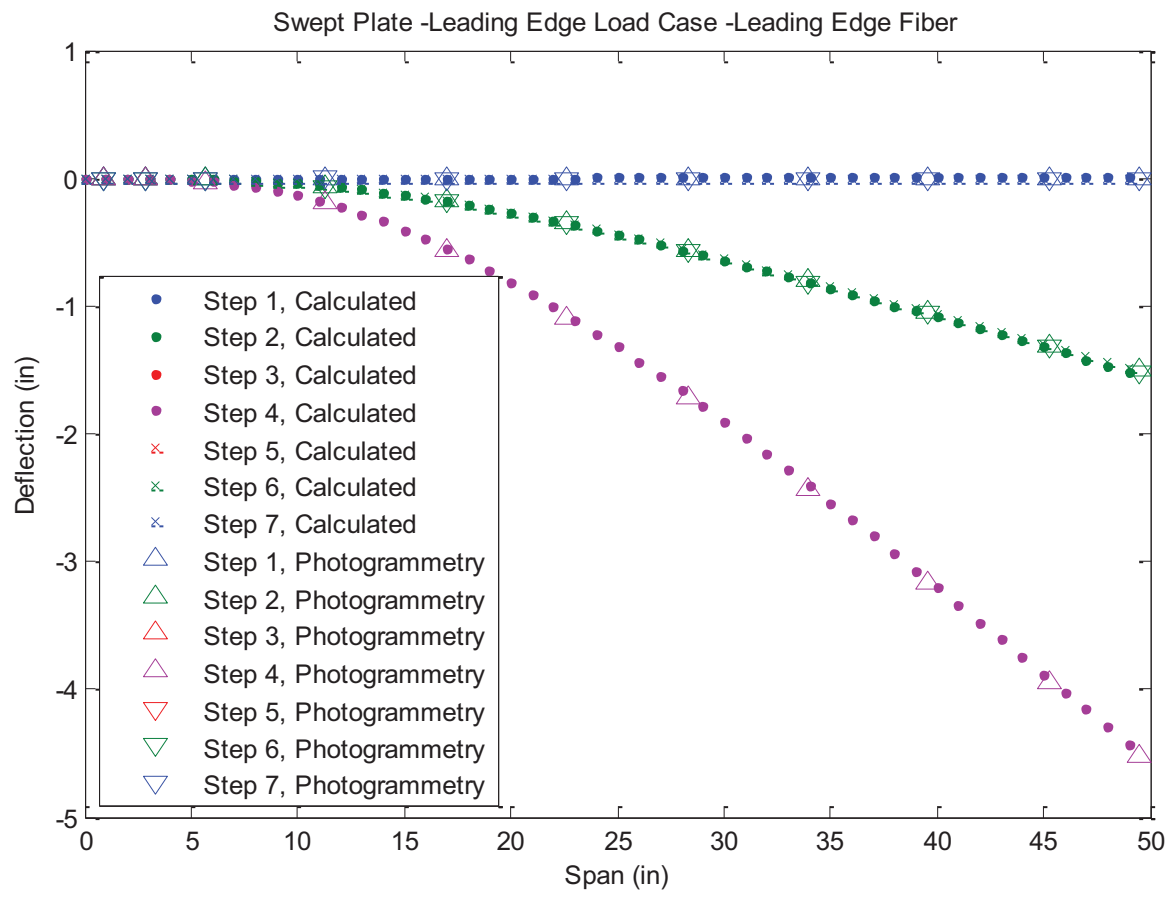

Figure A1_58. Swept plate deflection results for leading edge fiber during leading edge load case. 


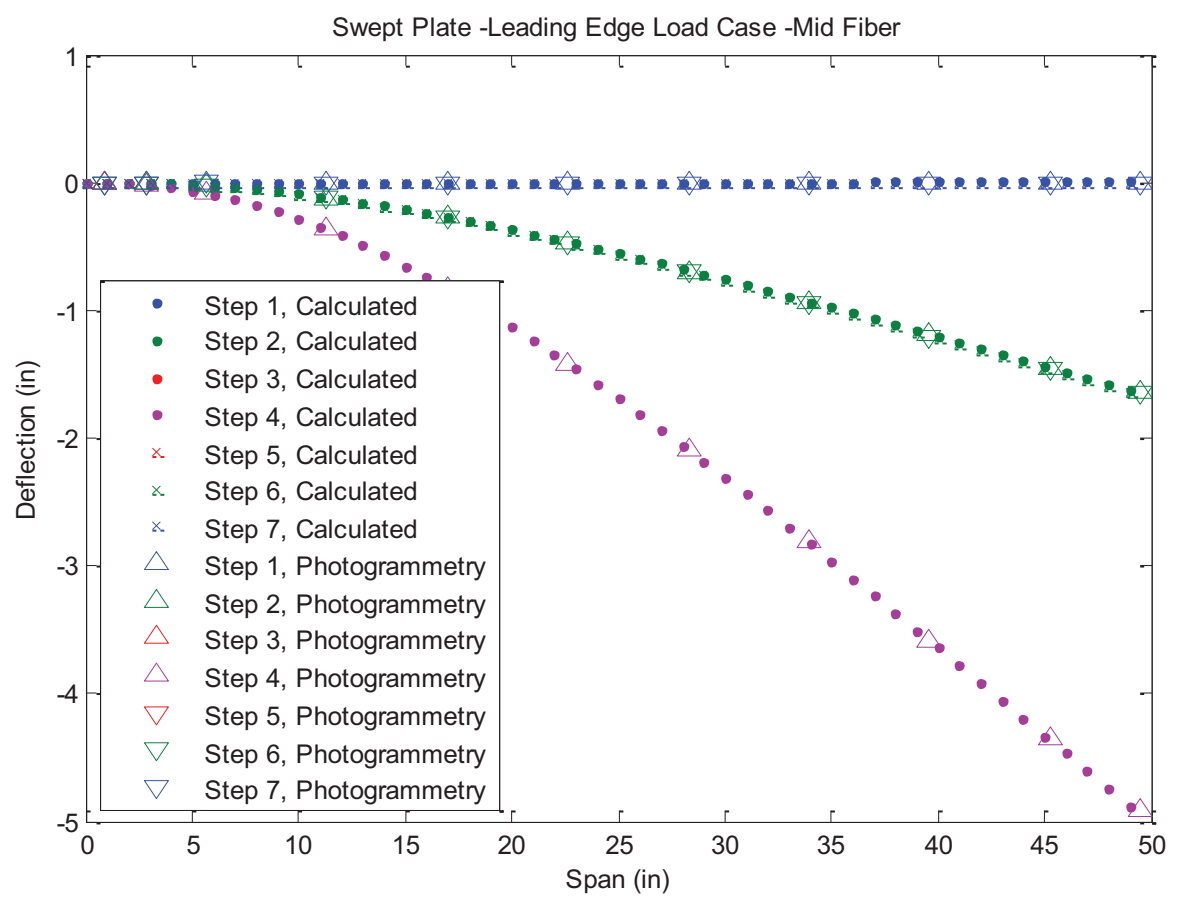

Figure A1_59. Swept plate deflection results for middle fiber during leading edge load case.

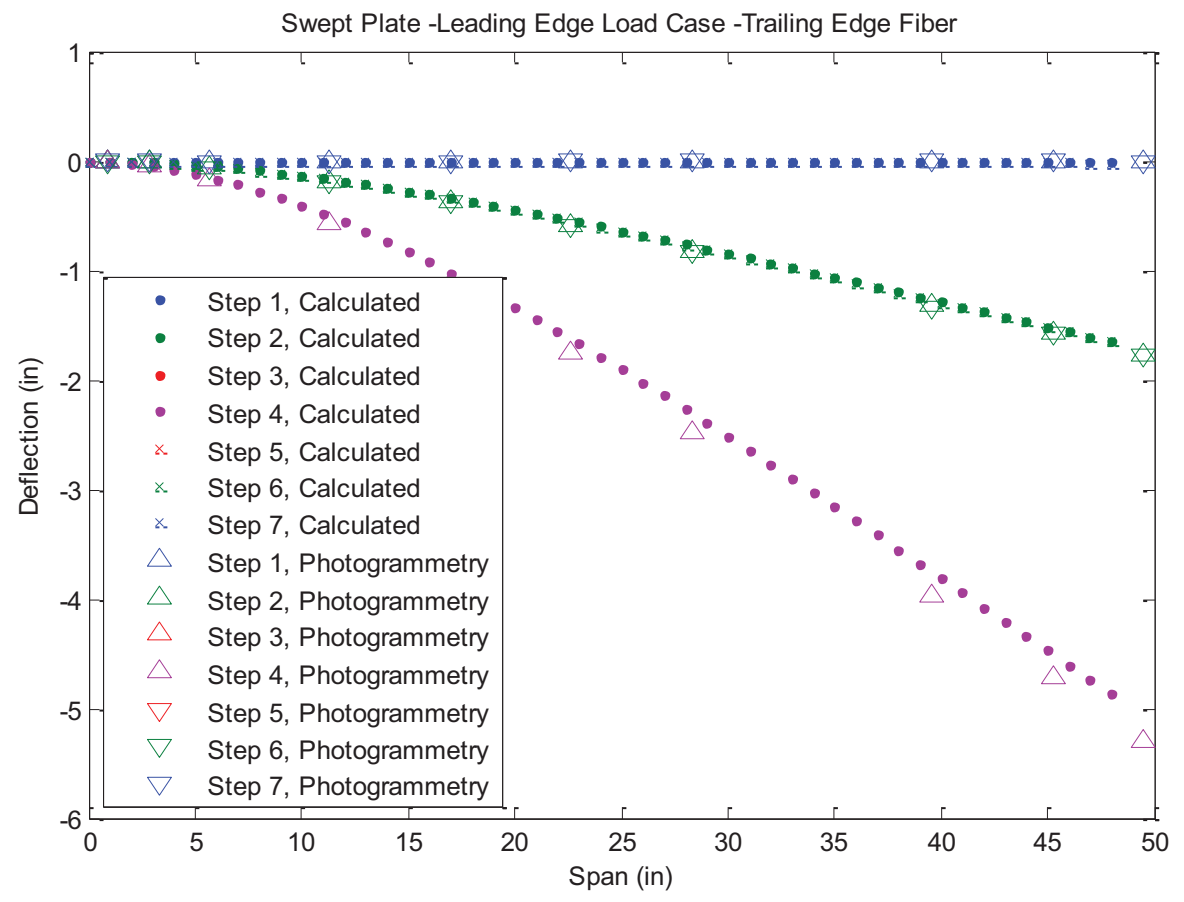

Figure A1_60. Swept plate deflection results for trailing edge fiber during leading edge load case.

American Institute of Aeronautics and Astronautics 


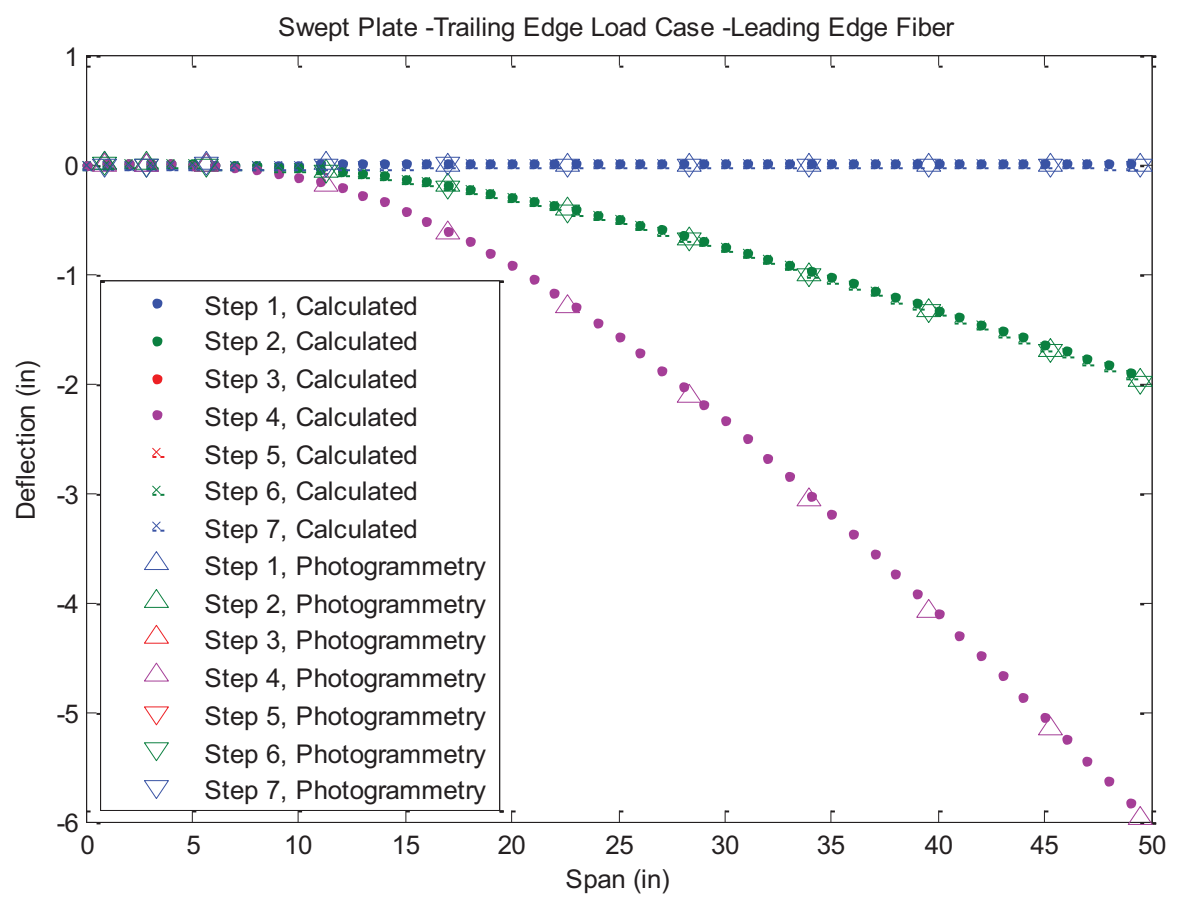

Figure A1_61. Swept plate deflection results for leading edge fiber during trailing edge load case.

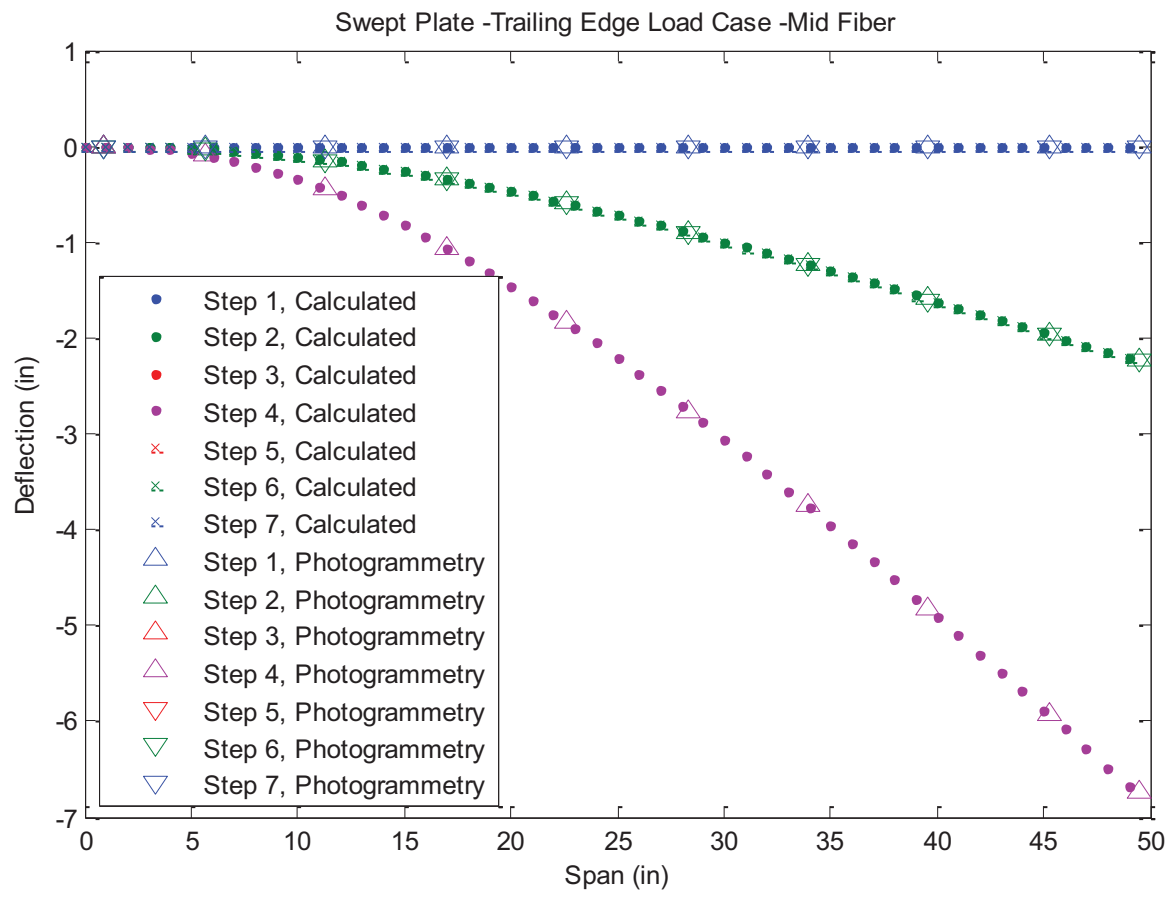

Figure A1_62. Swept plate deflection results for middle fiber during trailing edge load case.

American Institute of Aeronautics and Astronautics 


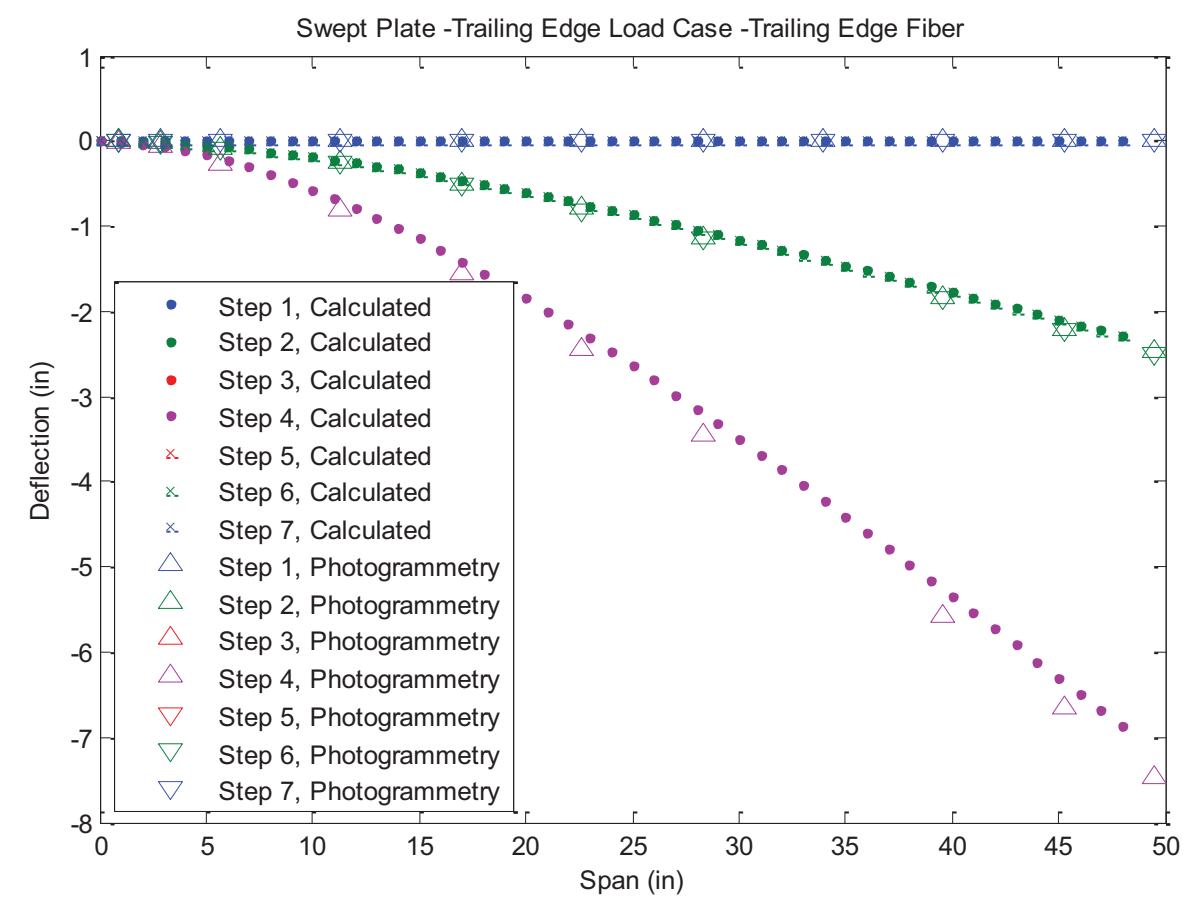

Figure A1_63. Swept plate deflection results for trailing edge fiber during trailing edge load case.

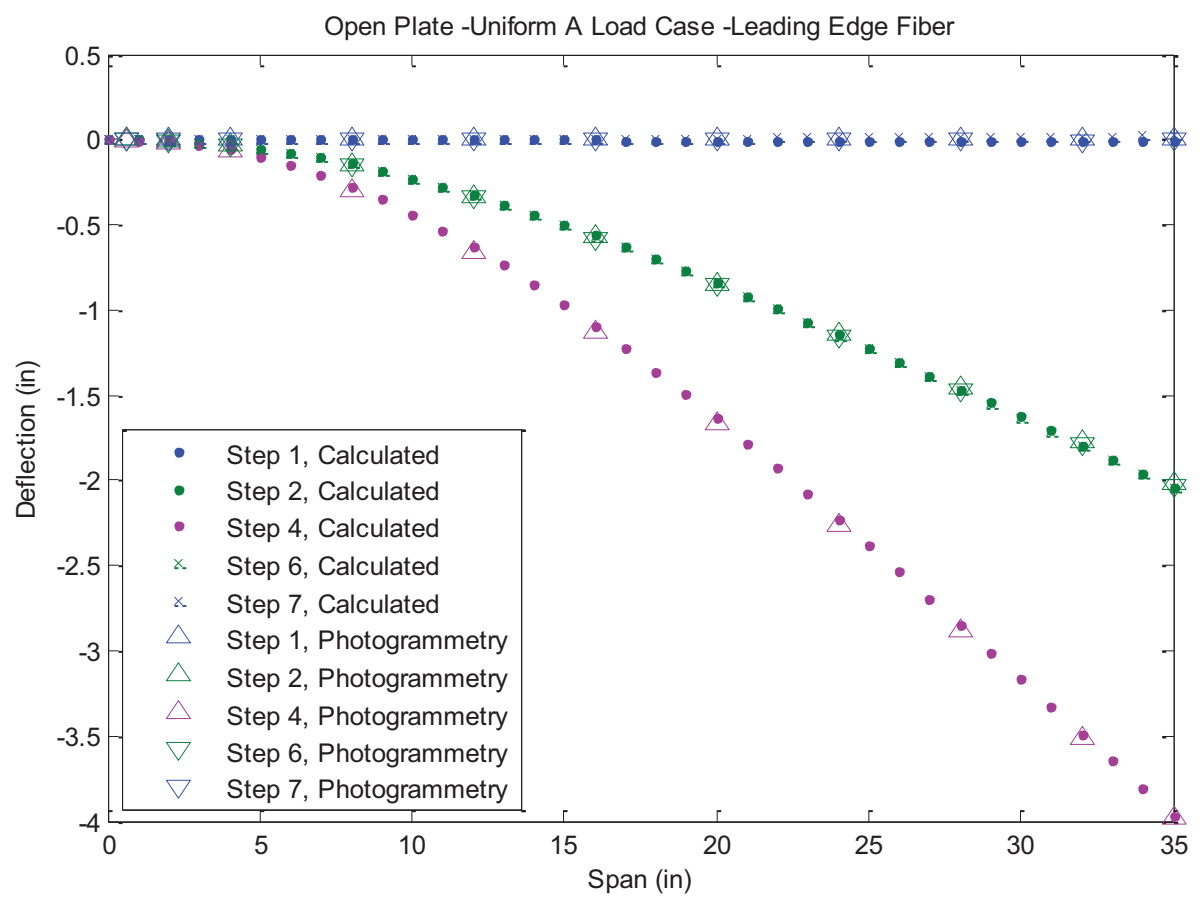

Figure A1_64. Open plate deflection results for leading edge fiber during Uniform A load case.

American Institute of Aeronautics and Astronautics 


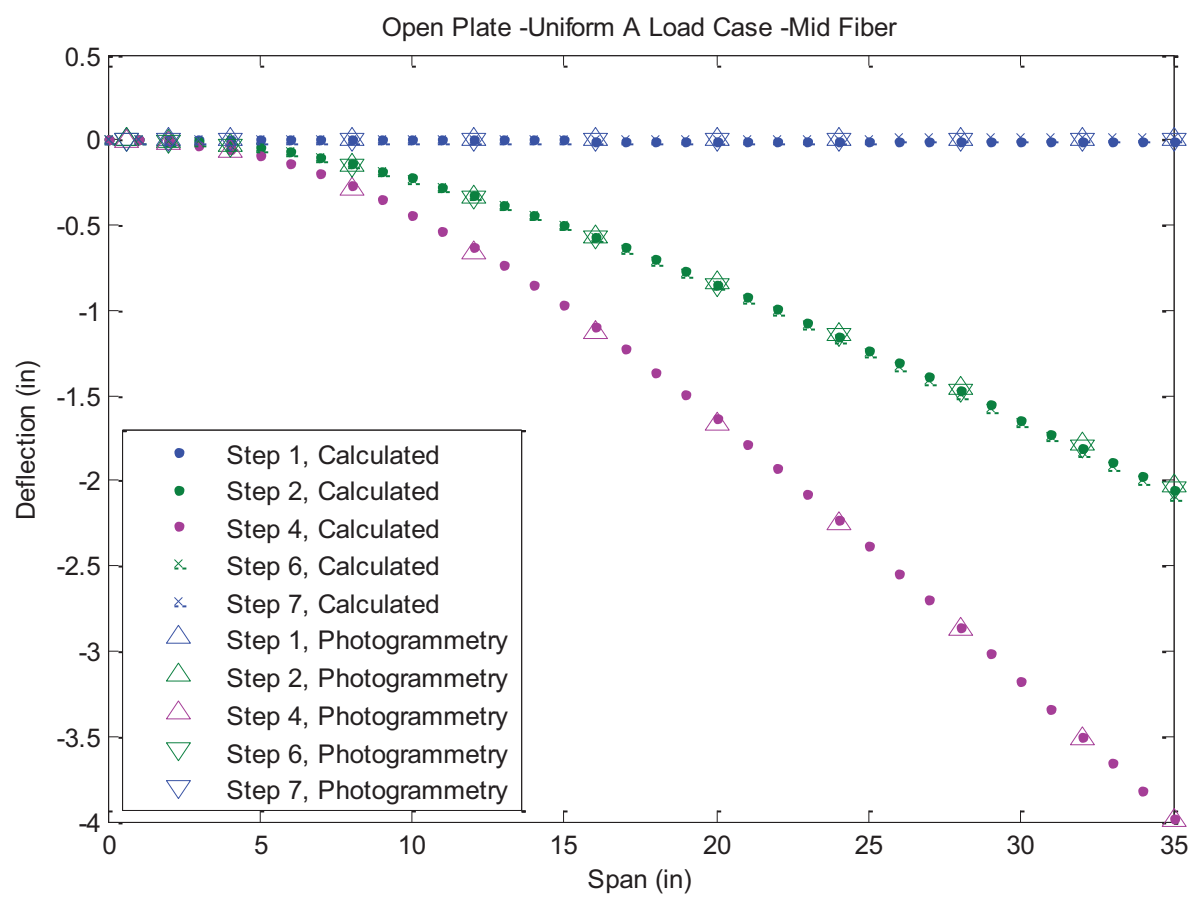

Figure A1_65. Open plate deflection results for middle fiber during Uniform A load case.

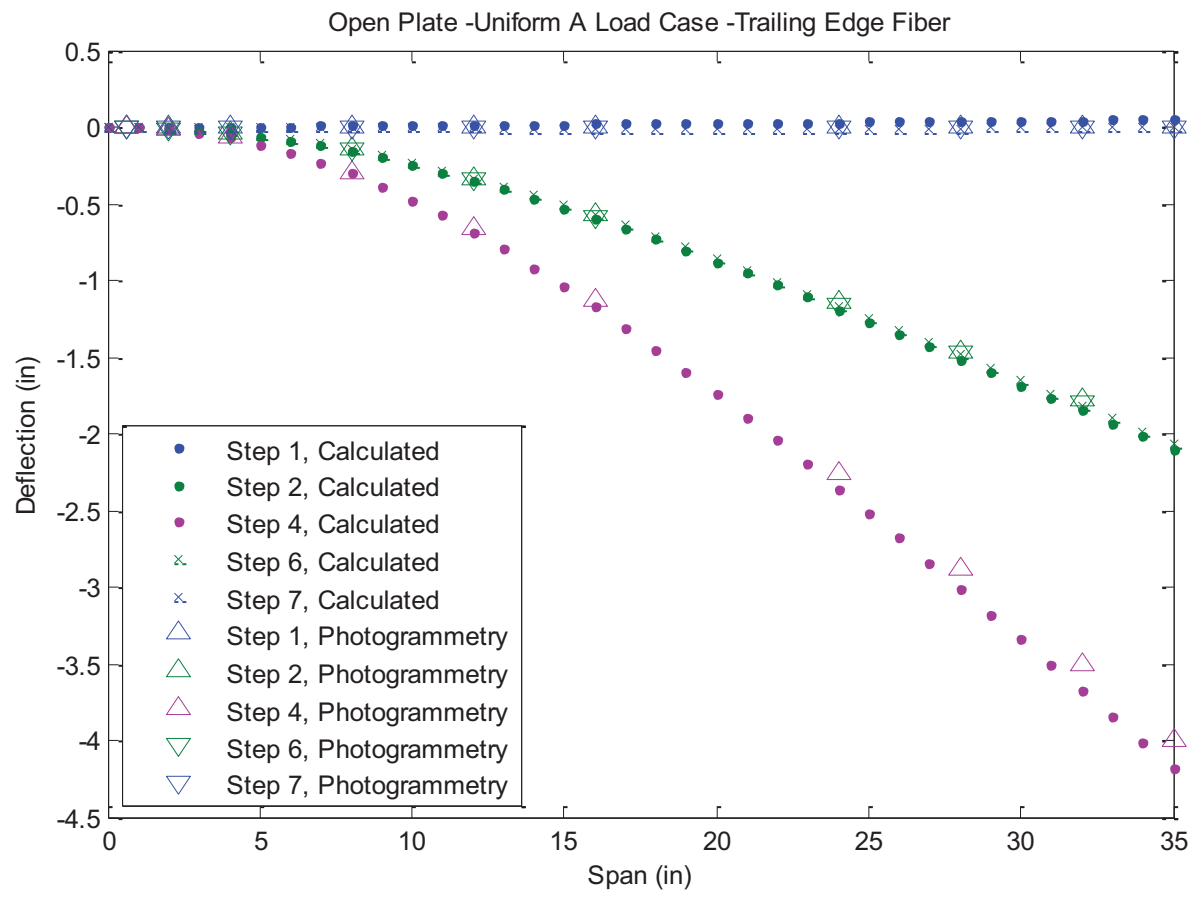

Figure A1_66. Open plate deflection results for trailing edge fiber during Uniform A load case. 


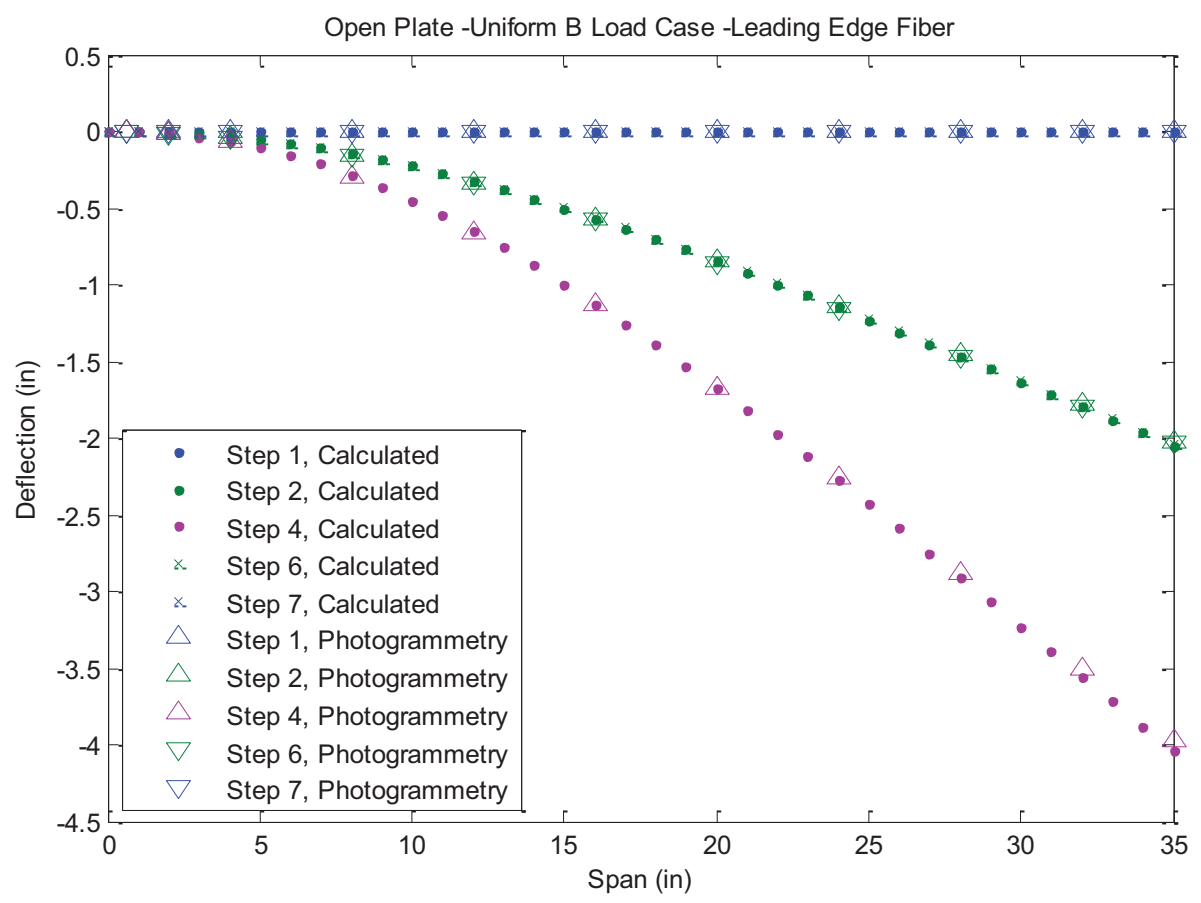

Figure A1_67. Open plate deflection results for leading edge fiber during Uniform B load case.

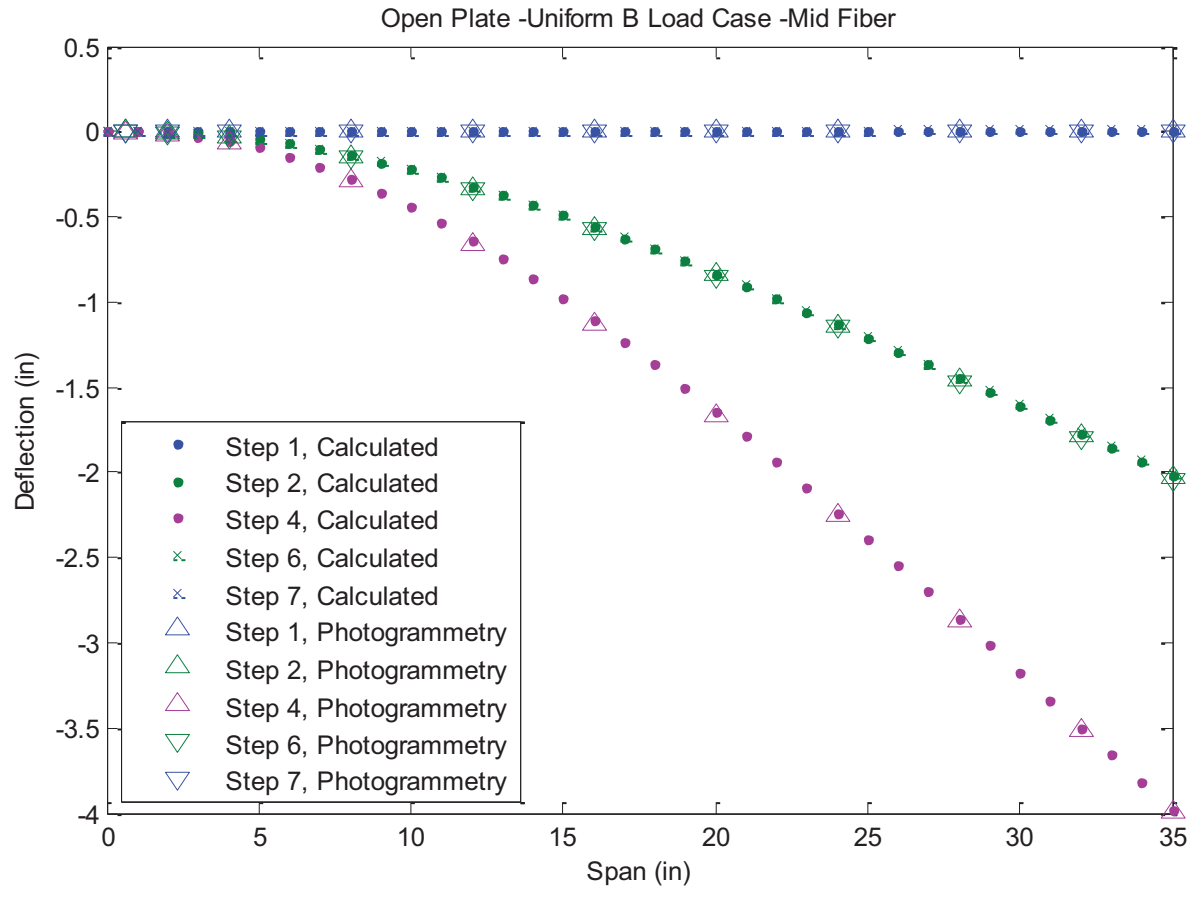

Figure A1_68. Open plate deflection results for middle fiber during Uniform B load case.

American Institute of Aeronautics and Astronautics 


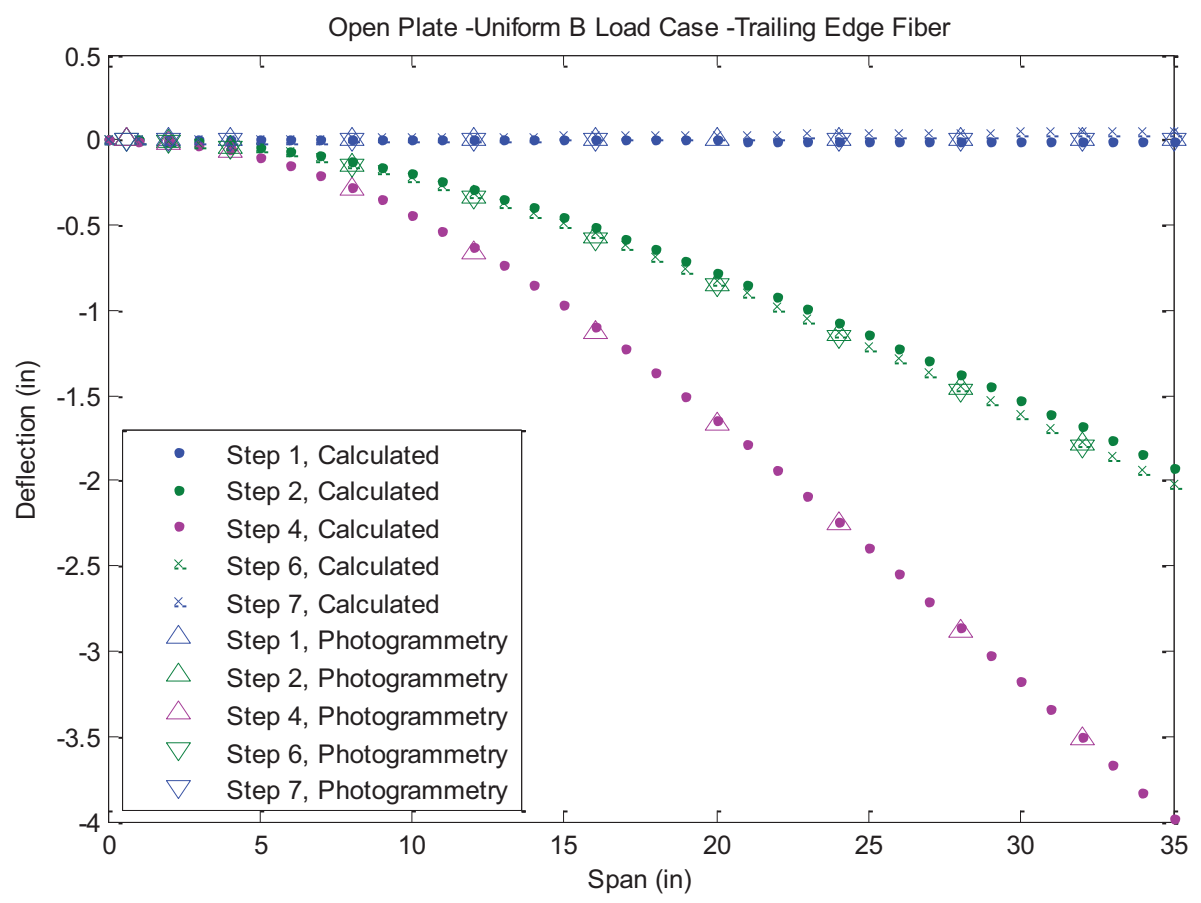

Figure A1_69. Open plate deflection results for trailing edge fiber during Uniform B load case.

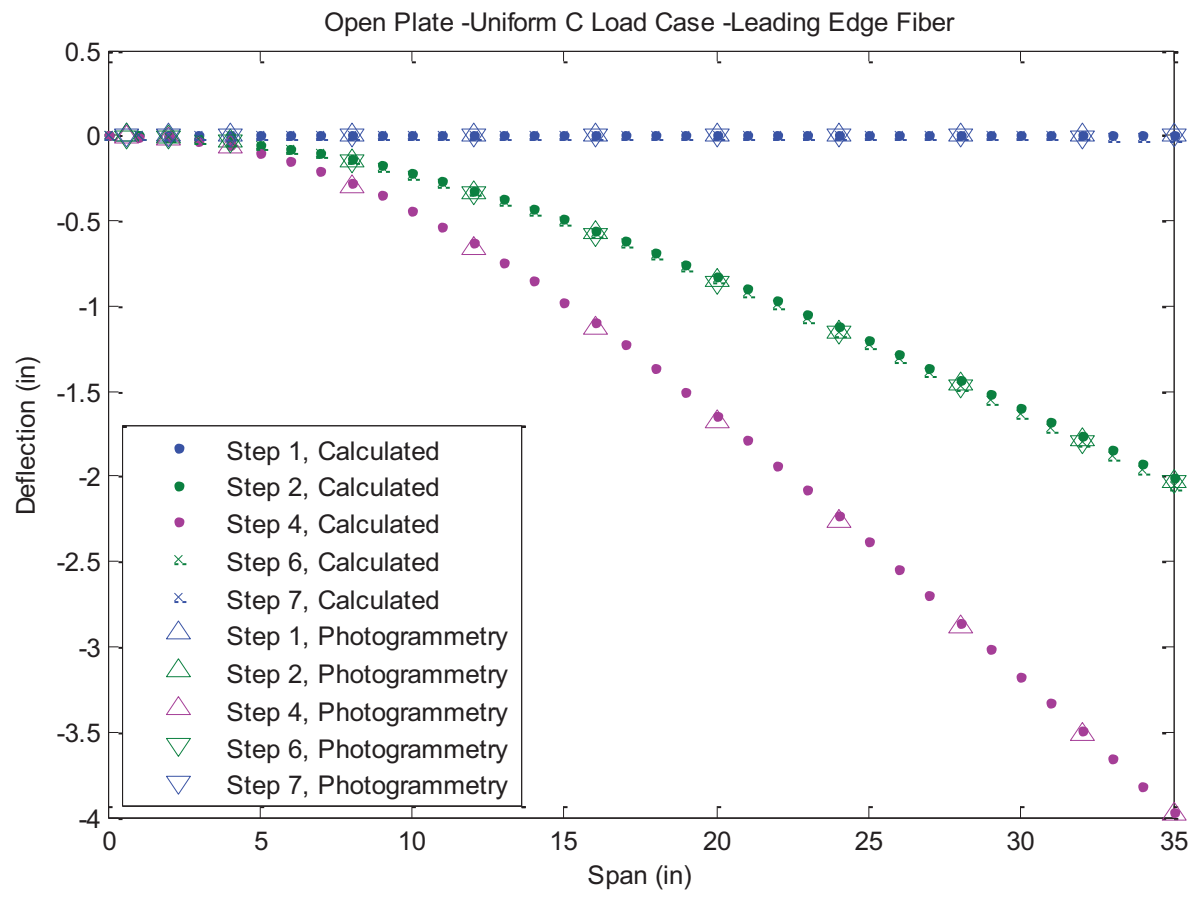

Figure A1_70. Open plate deflection results for leading edge fiber during Uniform C load case.

American Institute of Aeronautics and Astronautics 


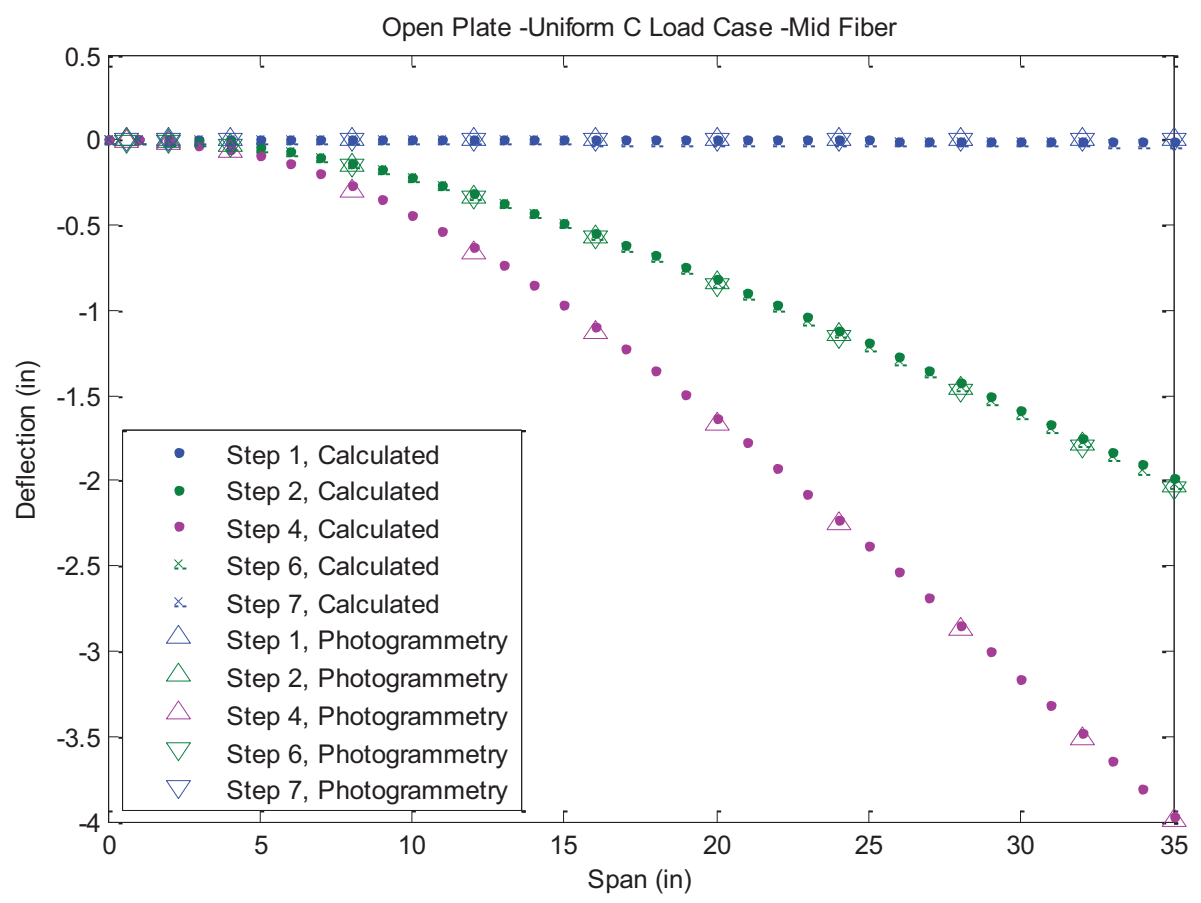

Figure A1_71. Open plate deflection results for middle fiber during Uniform C load case.

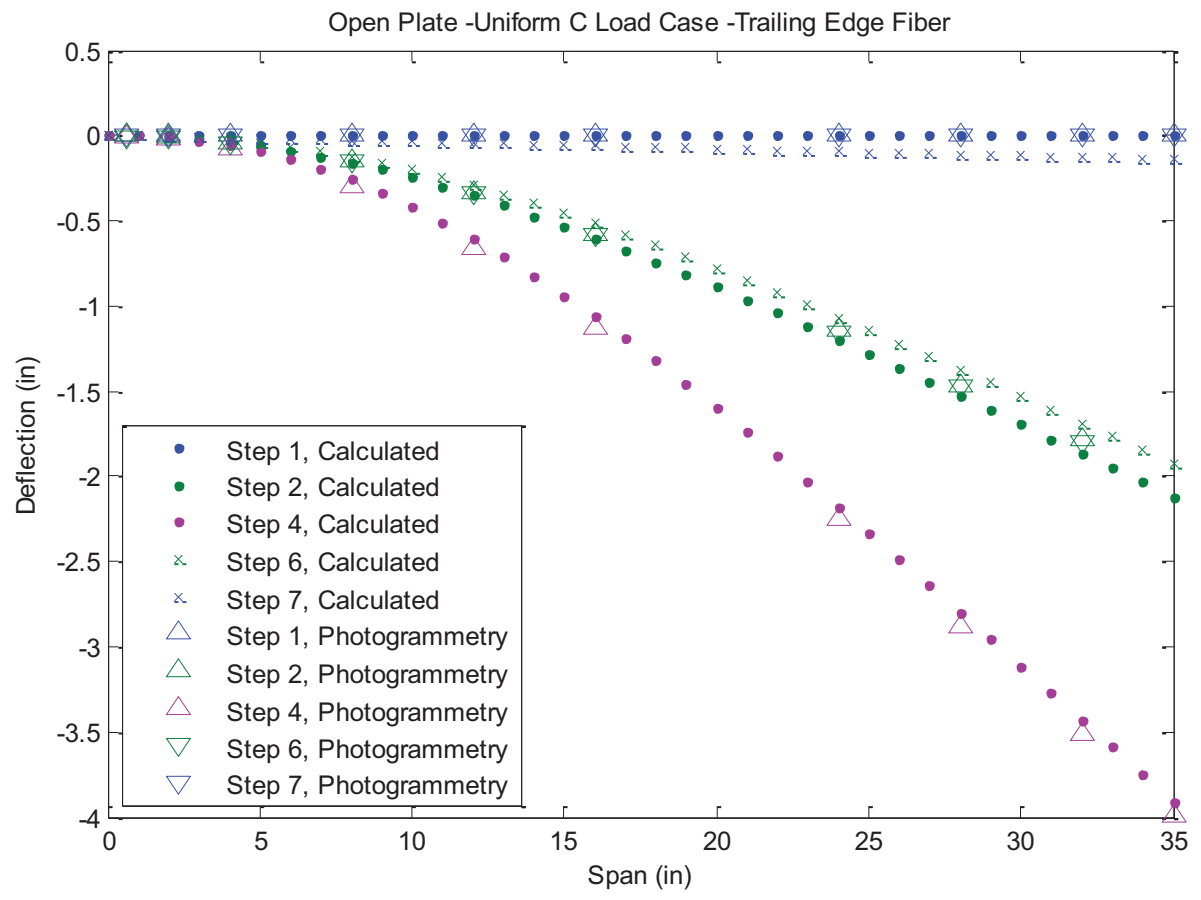

Figure A1_72. Open plate deflection results for trailing edge fiber during Uniform C load case. 


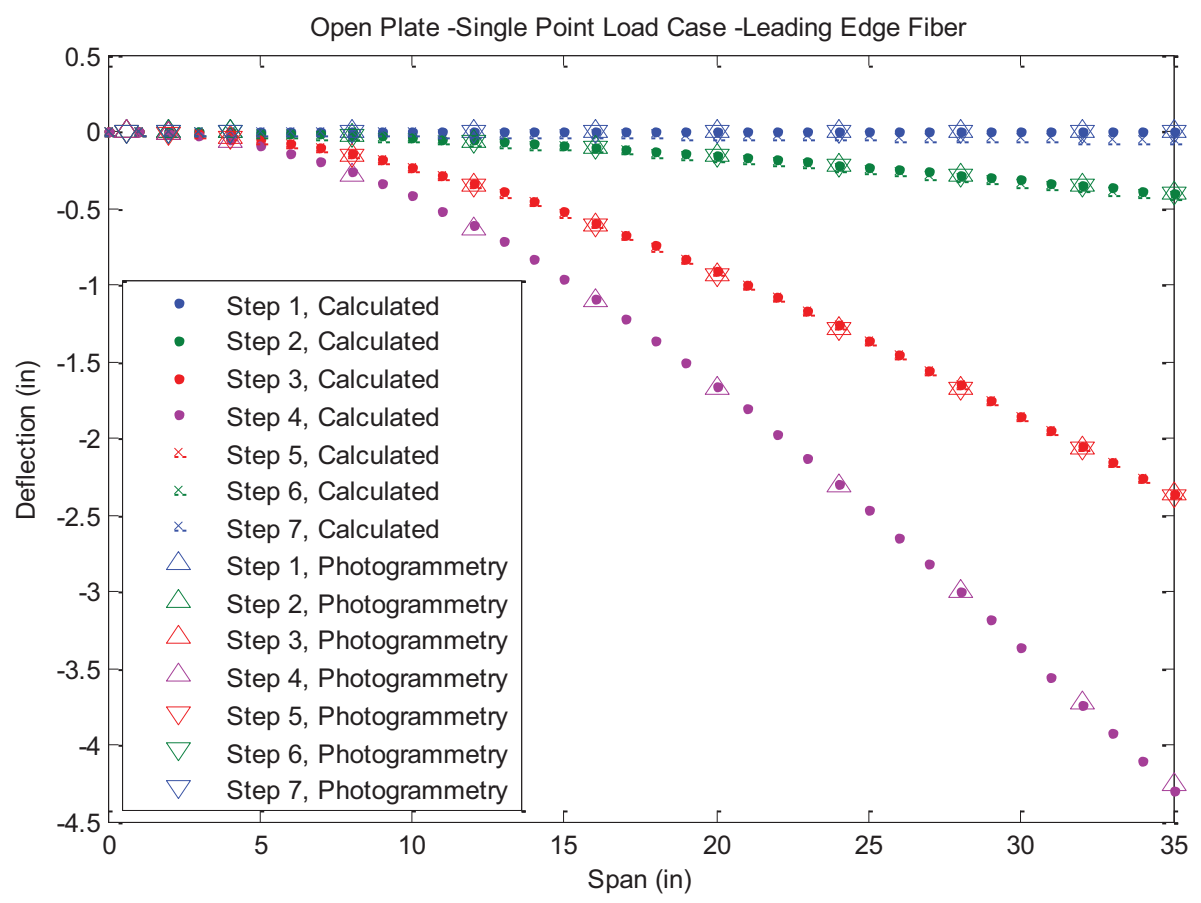

Figure A1_73. Open plate deflection results for leading edge fiber during single point load case.

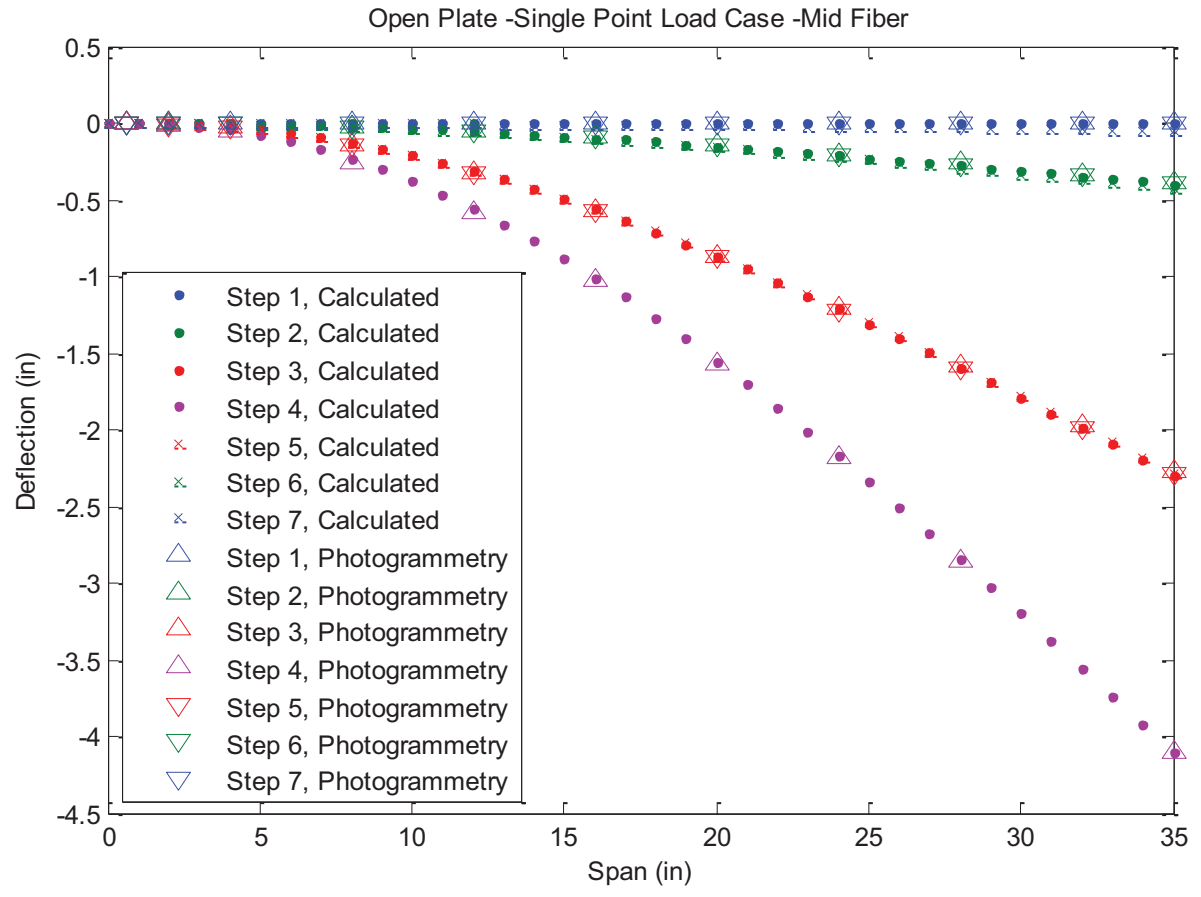

Figure A1_74. Open plate deflection results for middle fiber during single point load case.

American Institute of Aeronautics and Astronautics 


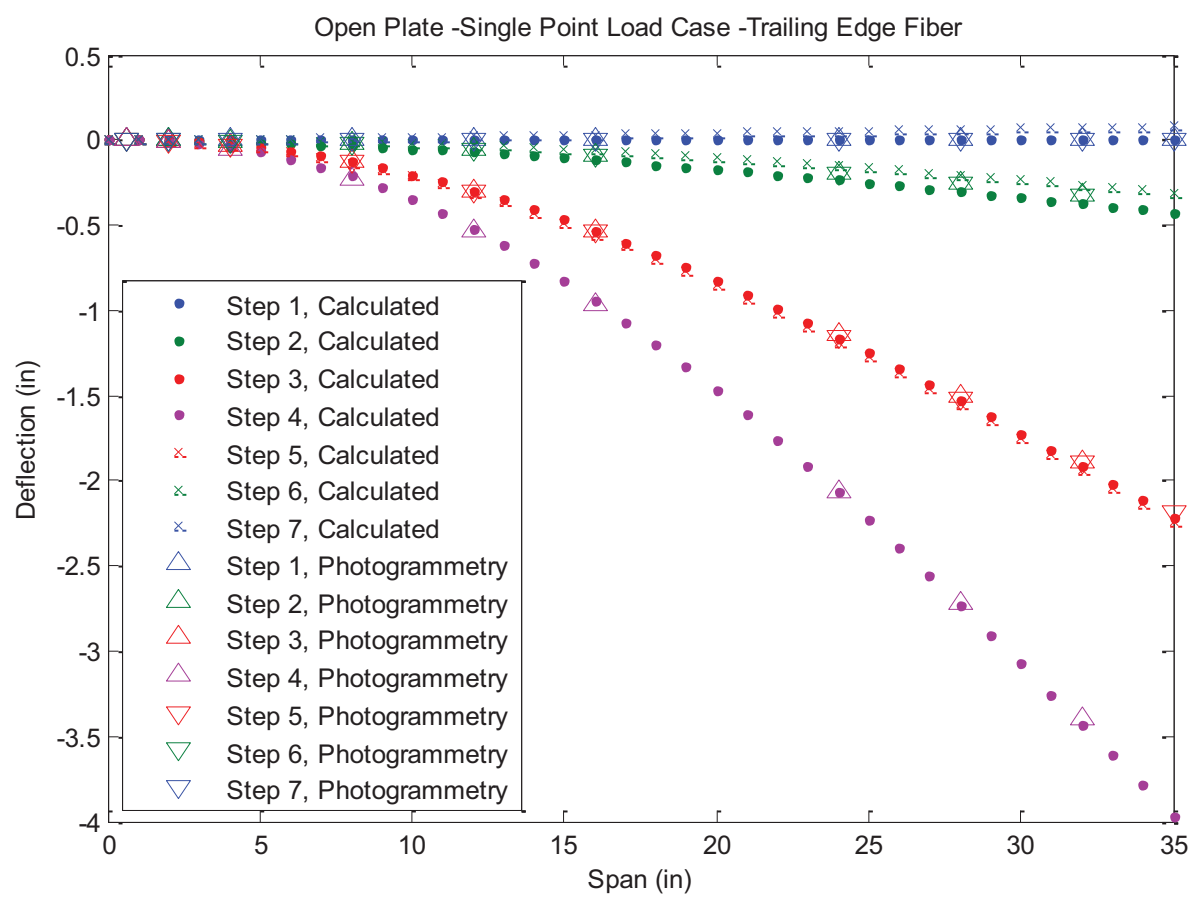

Figure A1_75. Open plate deflection results for trailing edge fiber during single point load case.

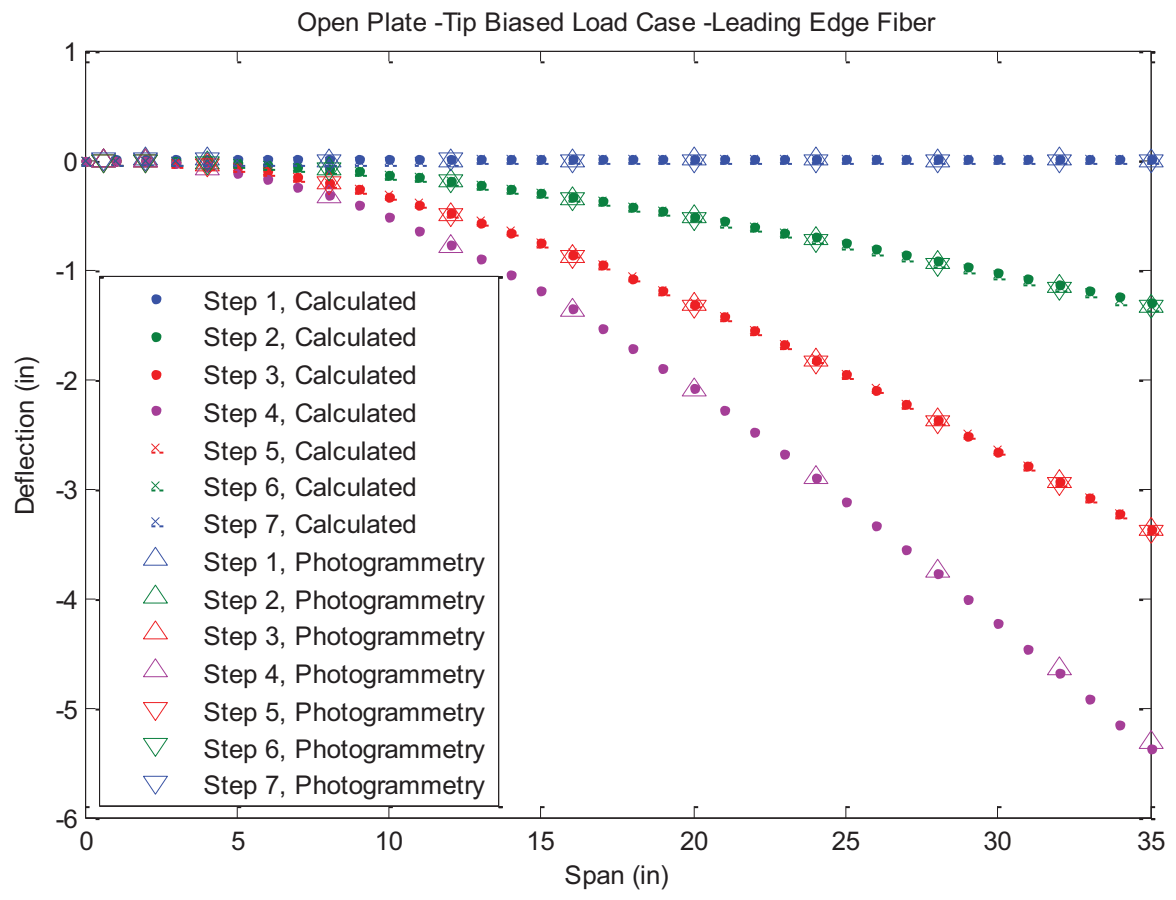

Figure A1_76. Open plate deflection results for leading edge fiber during tip-biased load case. 


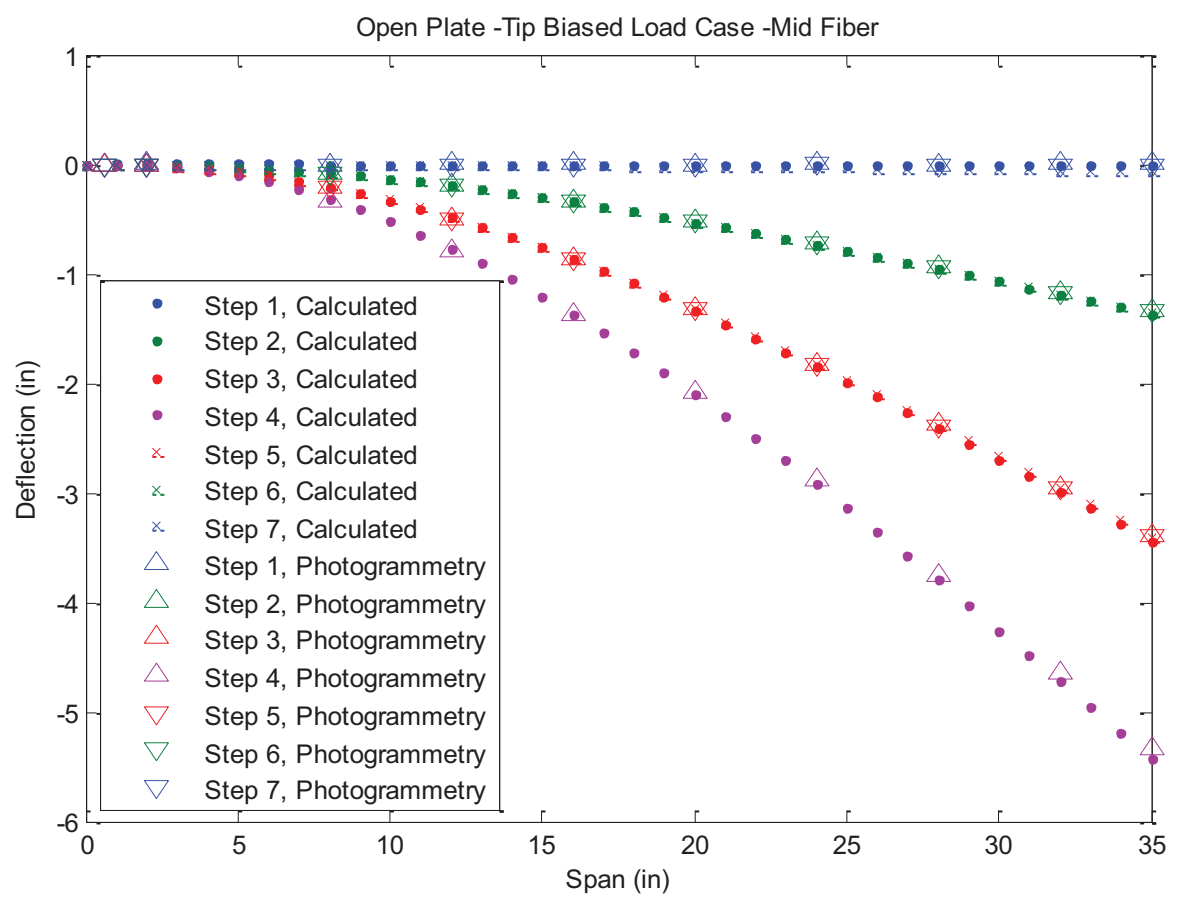

Figure A1_77. Open plate deflection results for middle fiber during tip-biased load case.

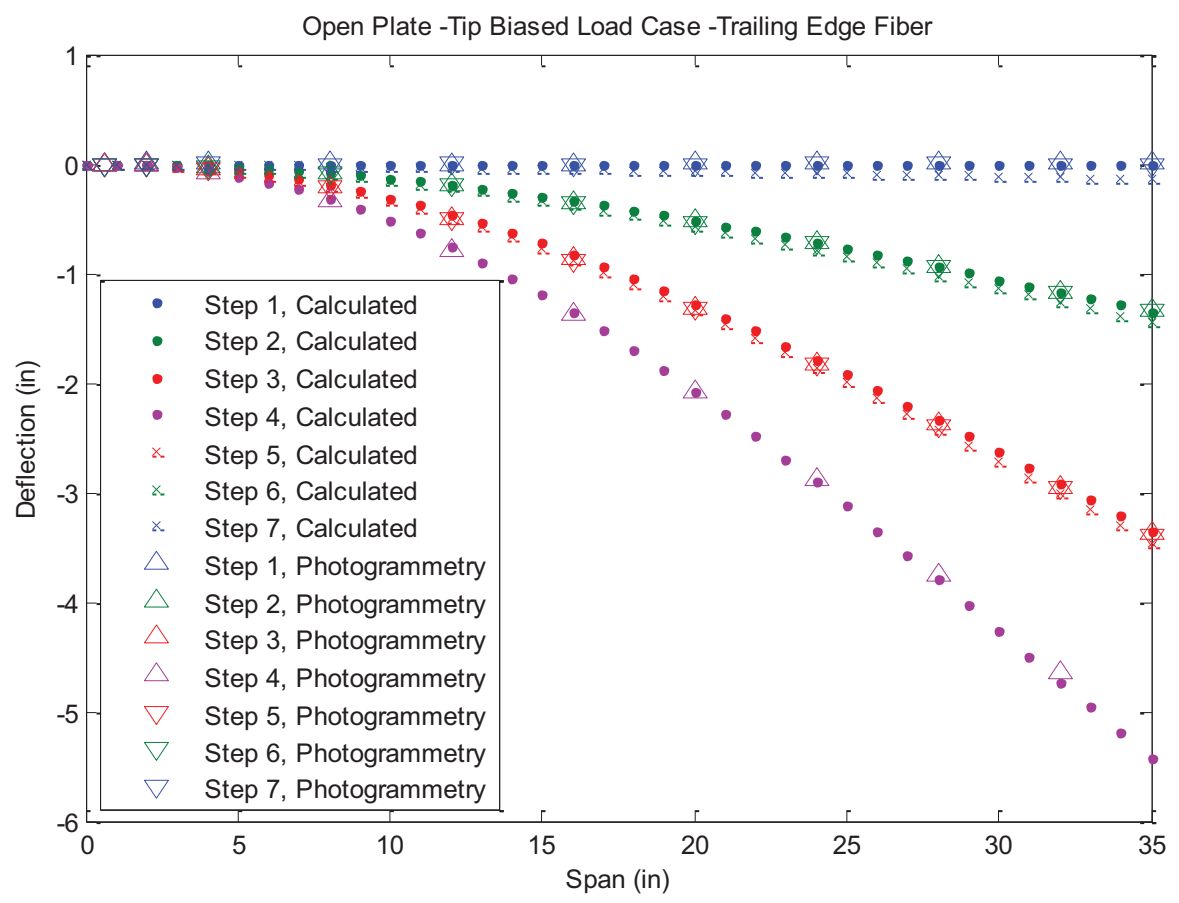

Figure A1_78. Open plate deflection results for trailing edge fiber during tip-biased load case. 


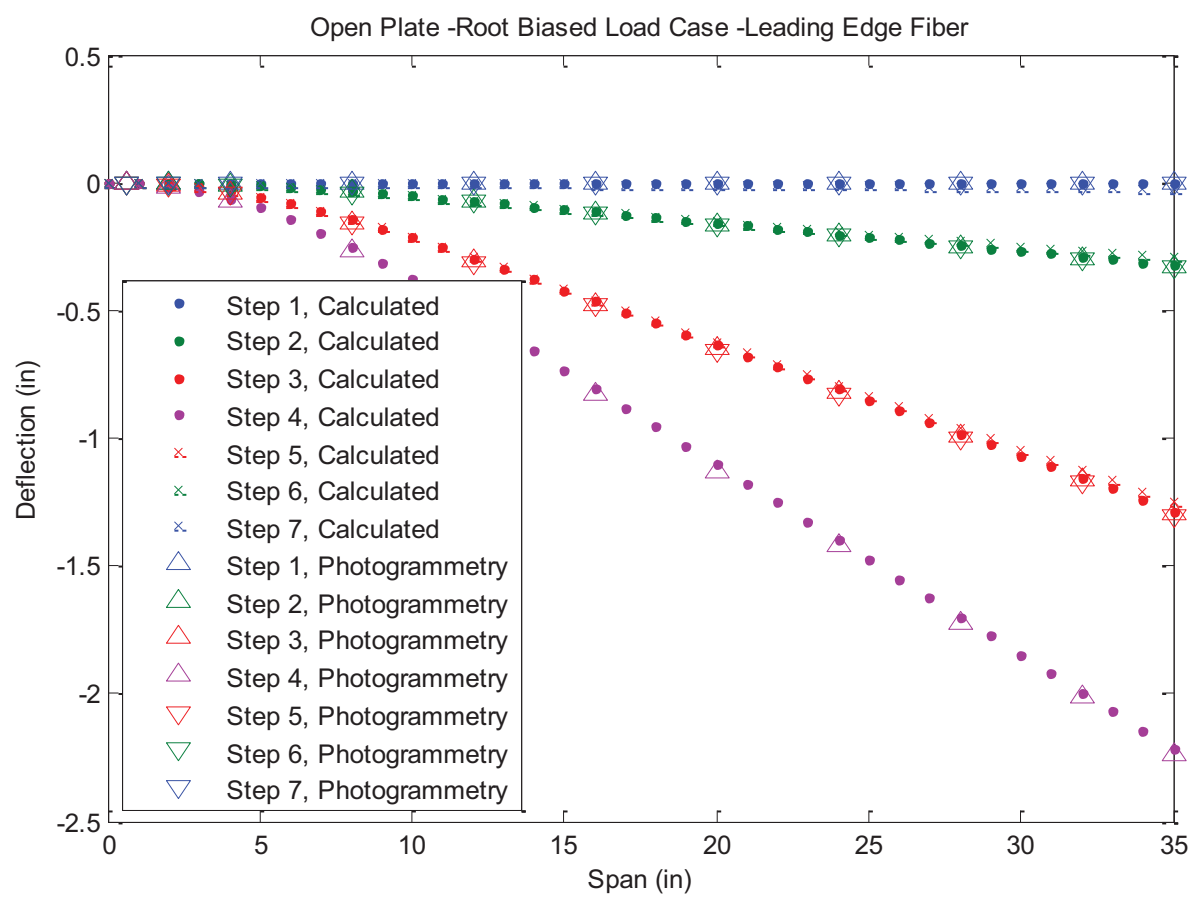

Figure A1_79. Open plate deflection results for leading edge fiber during root-biased load case.

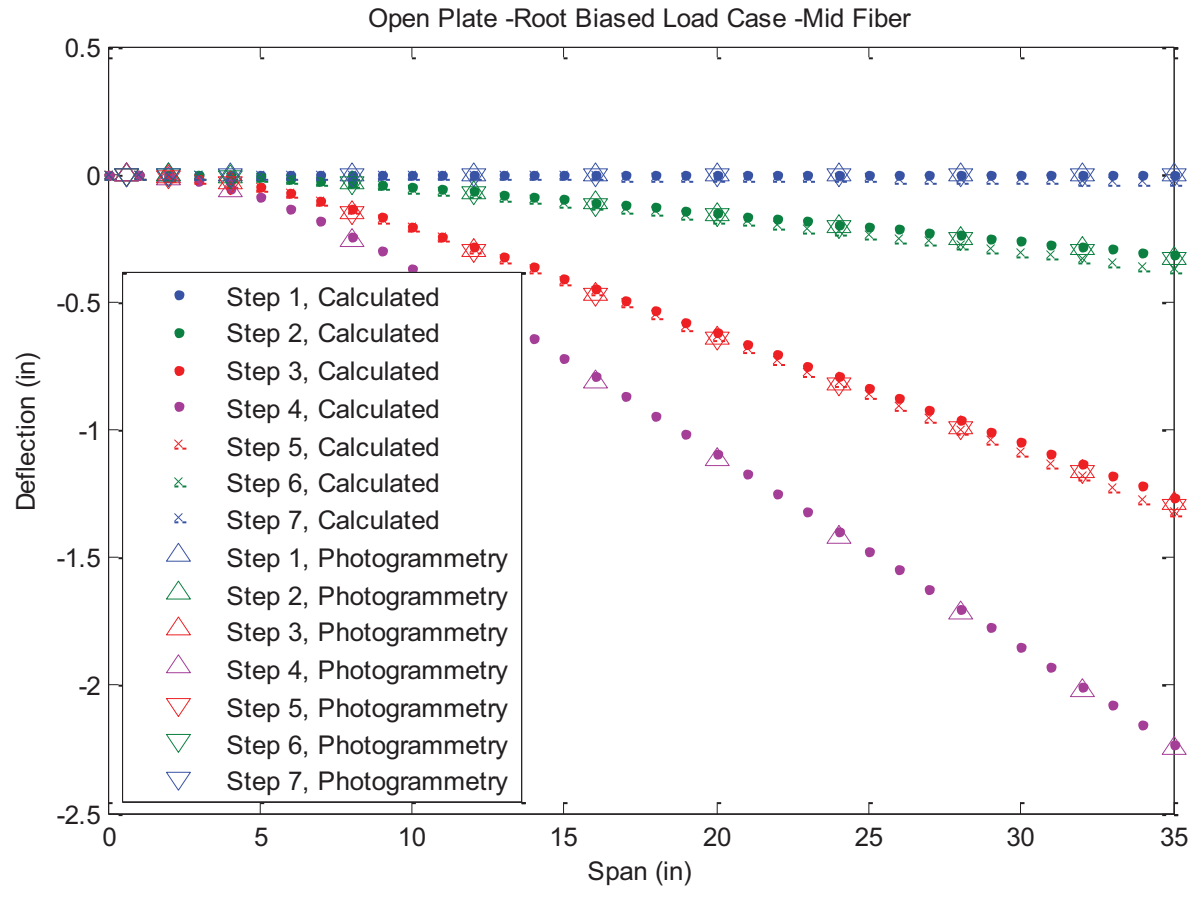

Figure A1_80. Open plate deflection results for middle fiber during root-biased load case.

American Institute of Aeronautics and Astronautics 


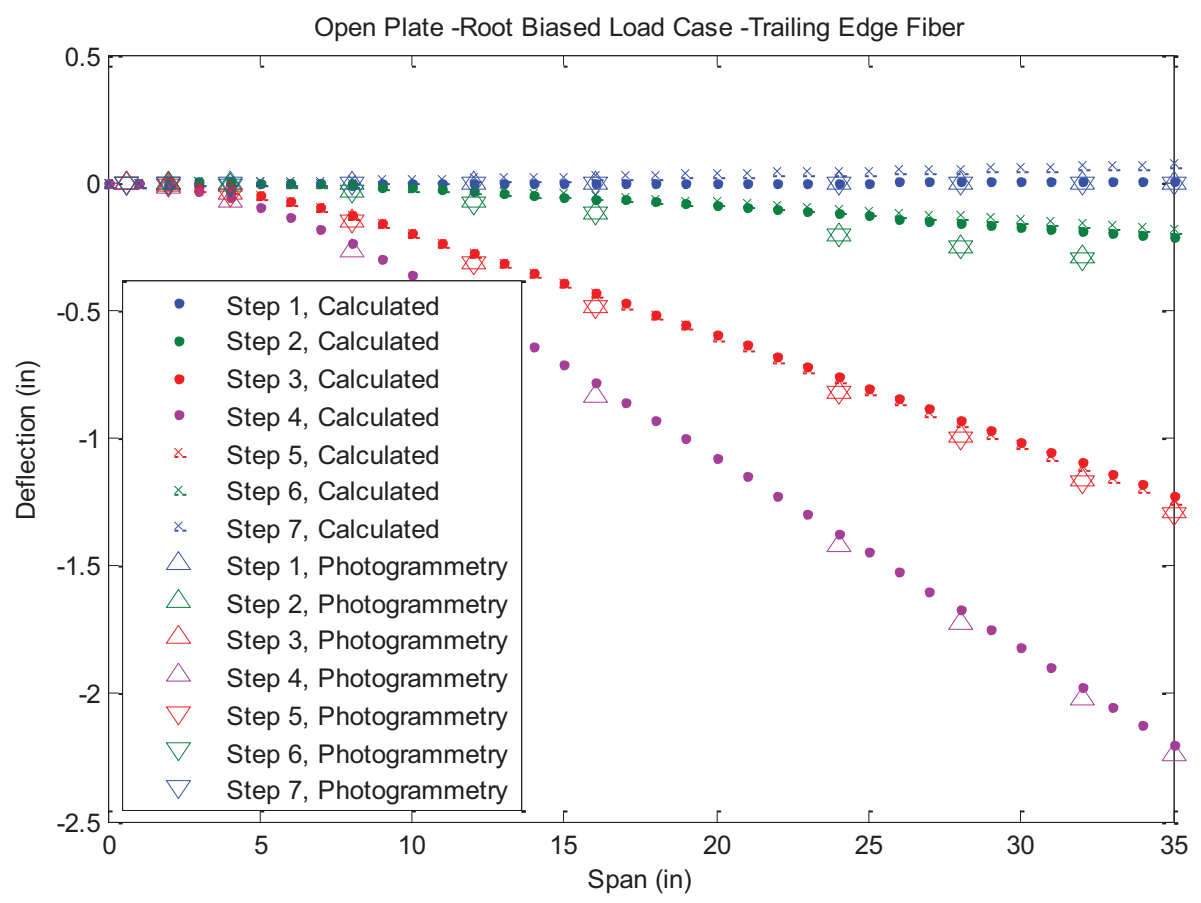

Figure A1_81. Open plate deflection results for trailing edge fiber during root-biased load case.

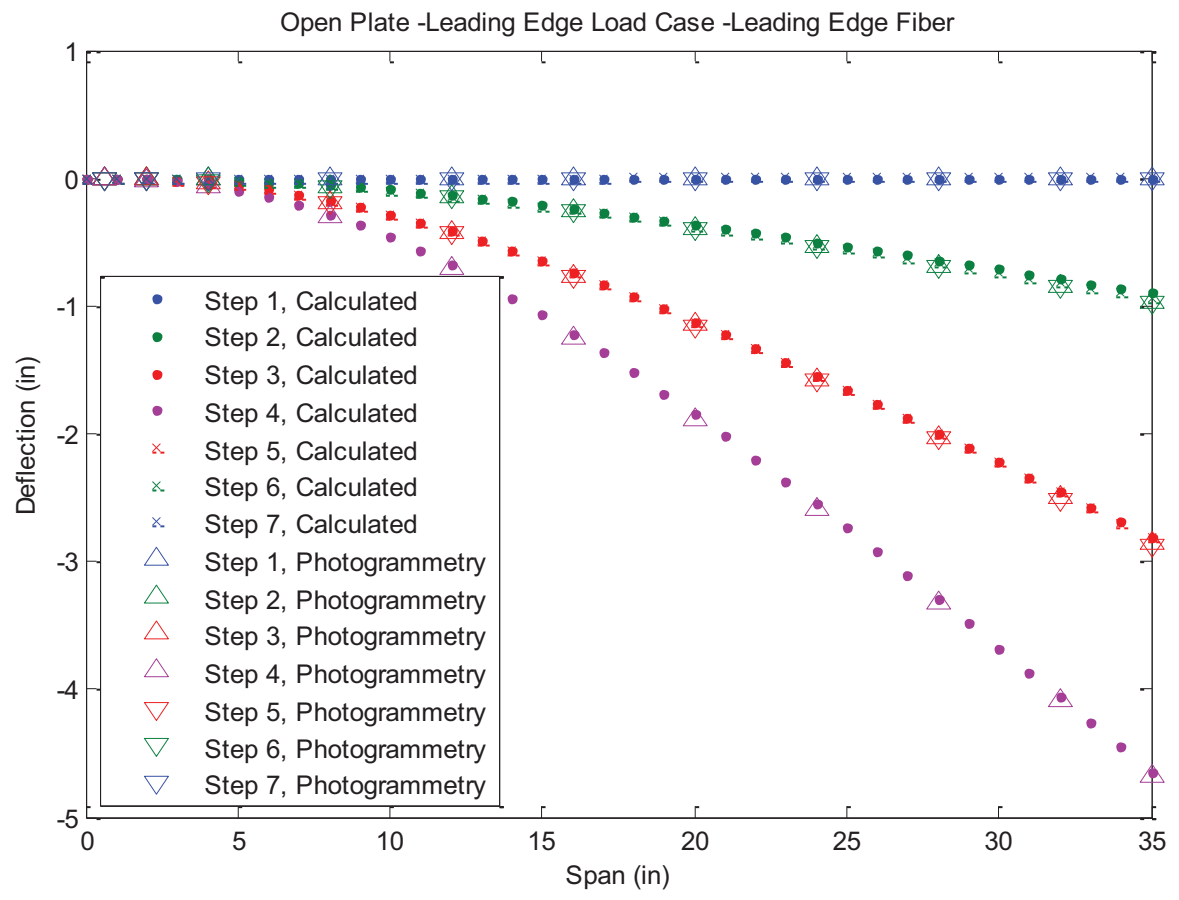

Figure A1_82. Open plate deflection results for leading edge fiber during leading edge load case.

American Institute of Aeronautics and Astronautics 


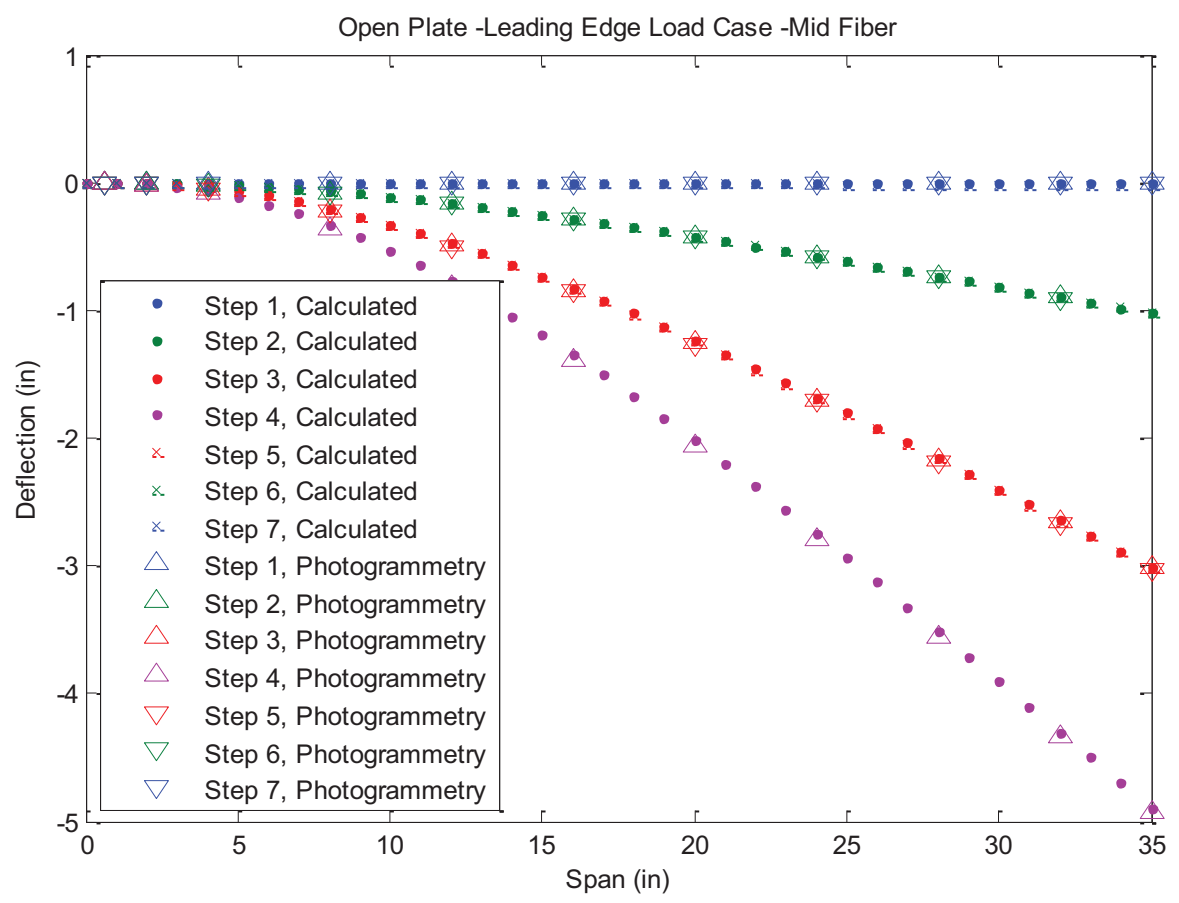

Figure A1_83. Open plate deflection results for middle fiber during leading edge load case.

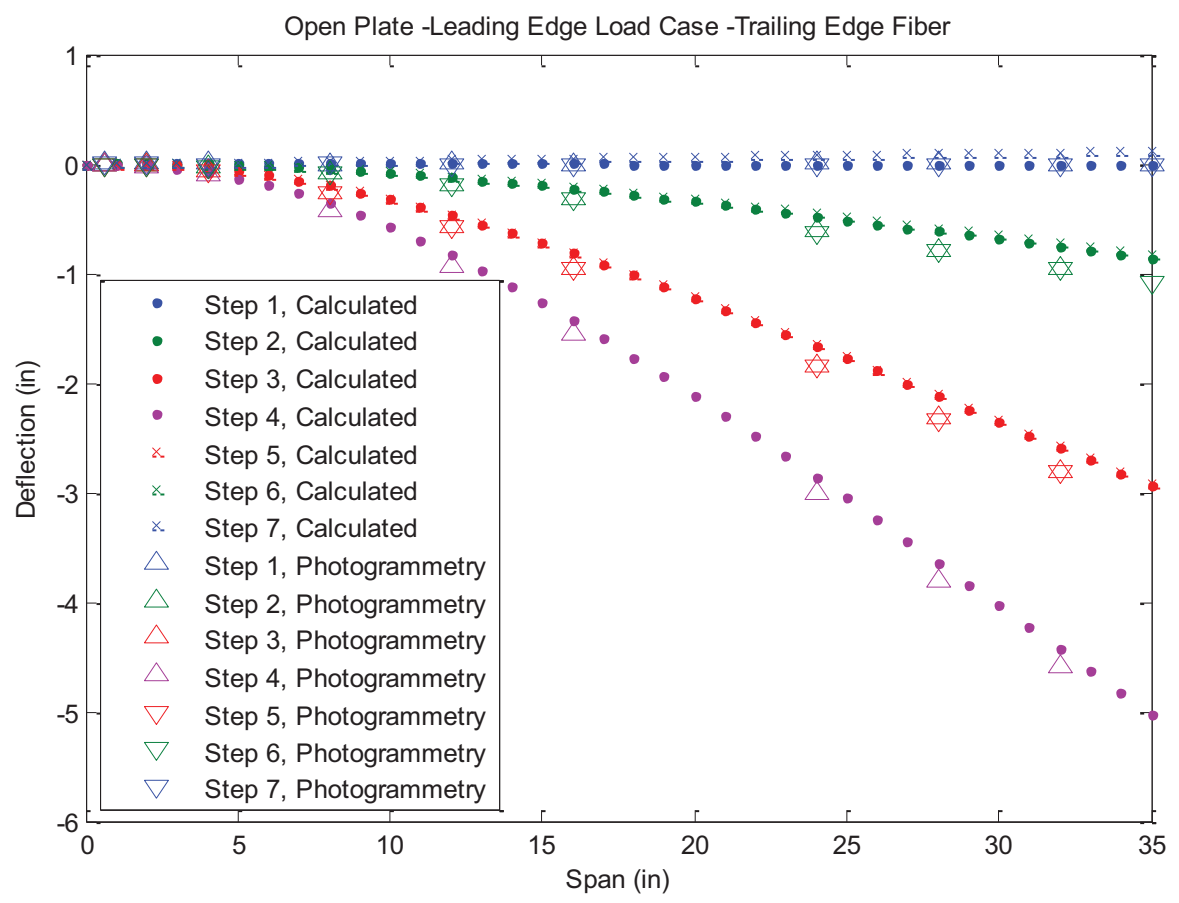

Figure A1_84. Open plate deflection results for trailing edge fiber during leading edge load case.

American Institute of Aeronautics and Astronautics 


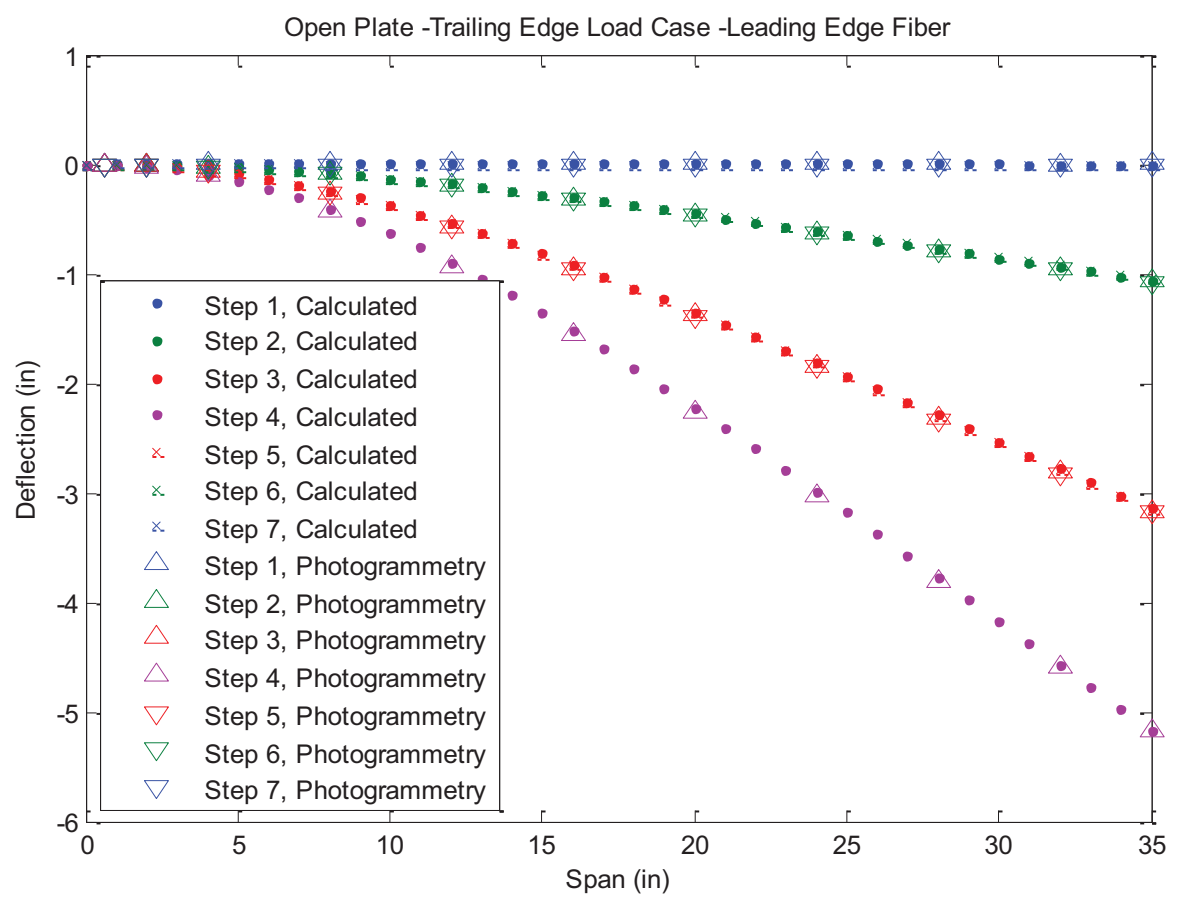

Figure A1_85. Open plate deflection results for leading edge fiber during trailing edge load case.

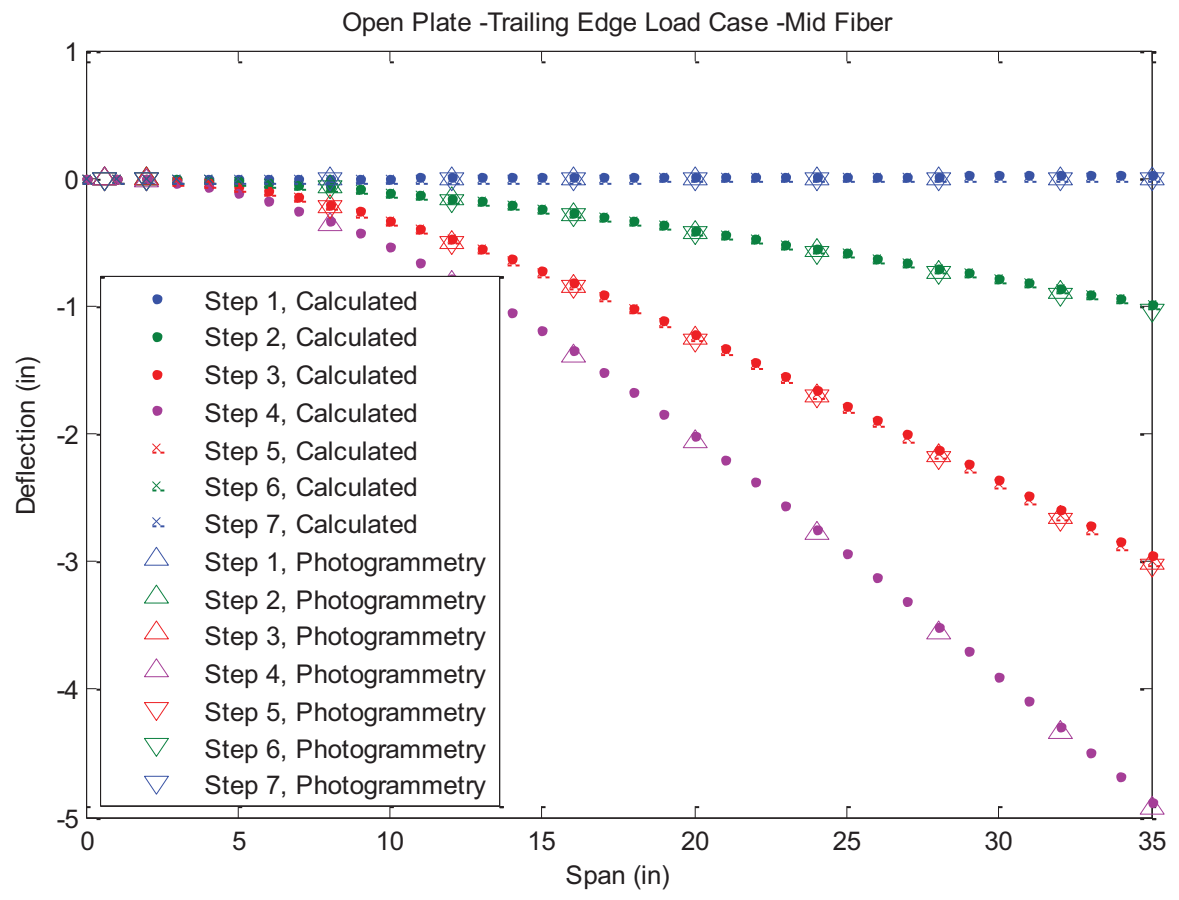

Figure A1_86. Open plate deflection results for middle fiber during trailing edge load case. 


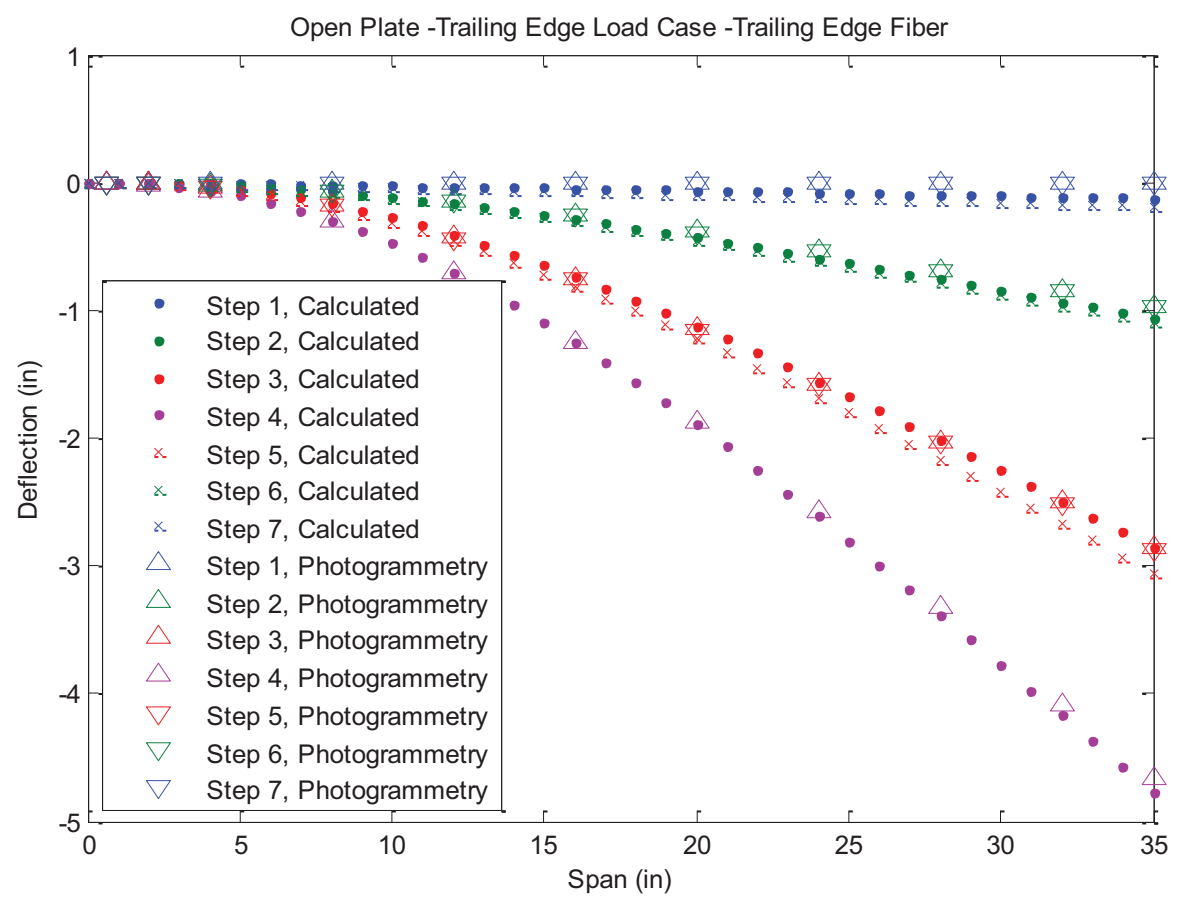

Figure A1_87. Open plate deflection results for trailing edge fiber during trailing edge load case. 


\section{APPENDIX 2: Load Plots}

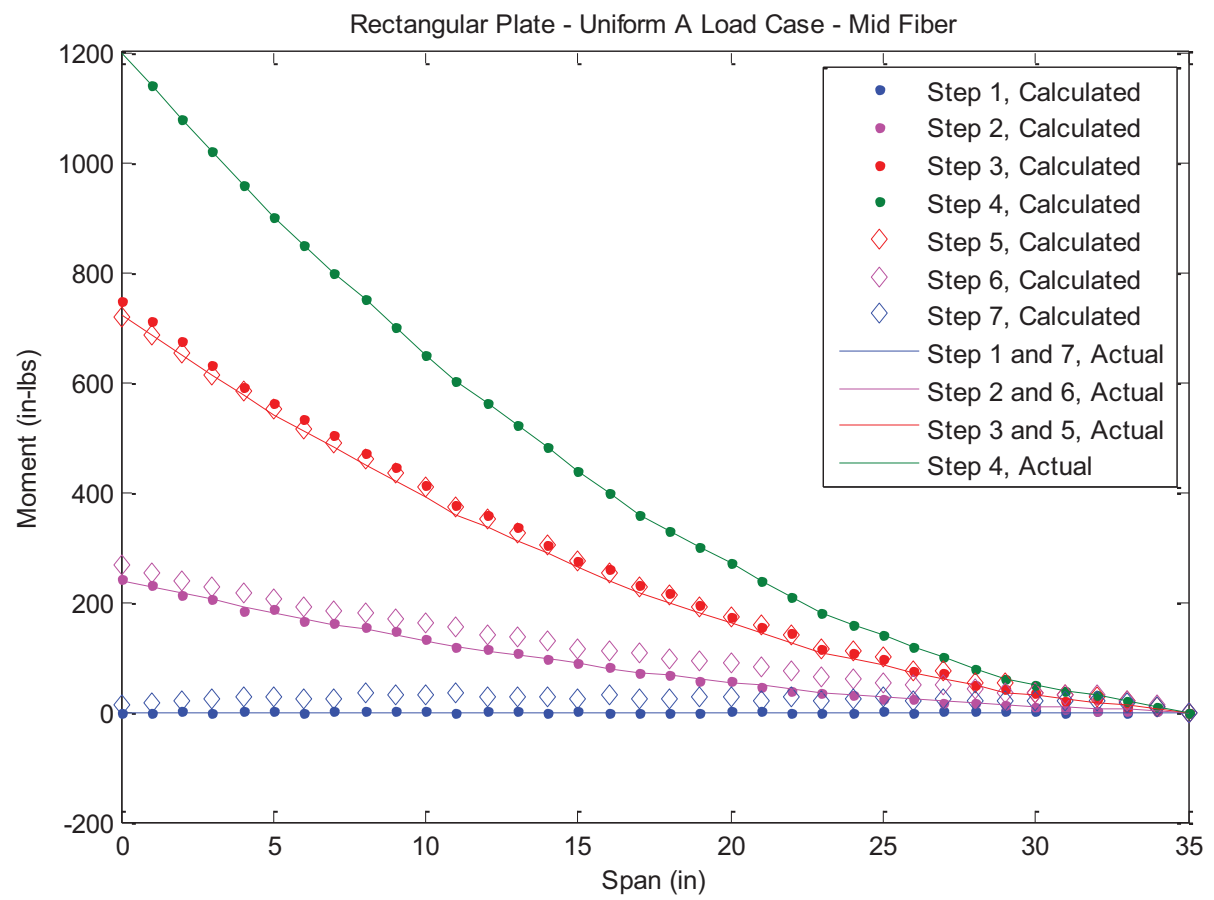

Figure A2_1. Rectangular plate load results for middle fiber during Uniform A load case.

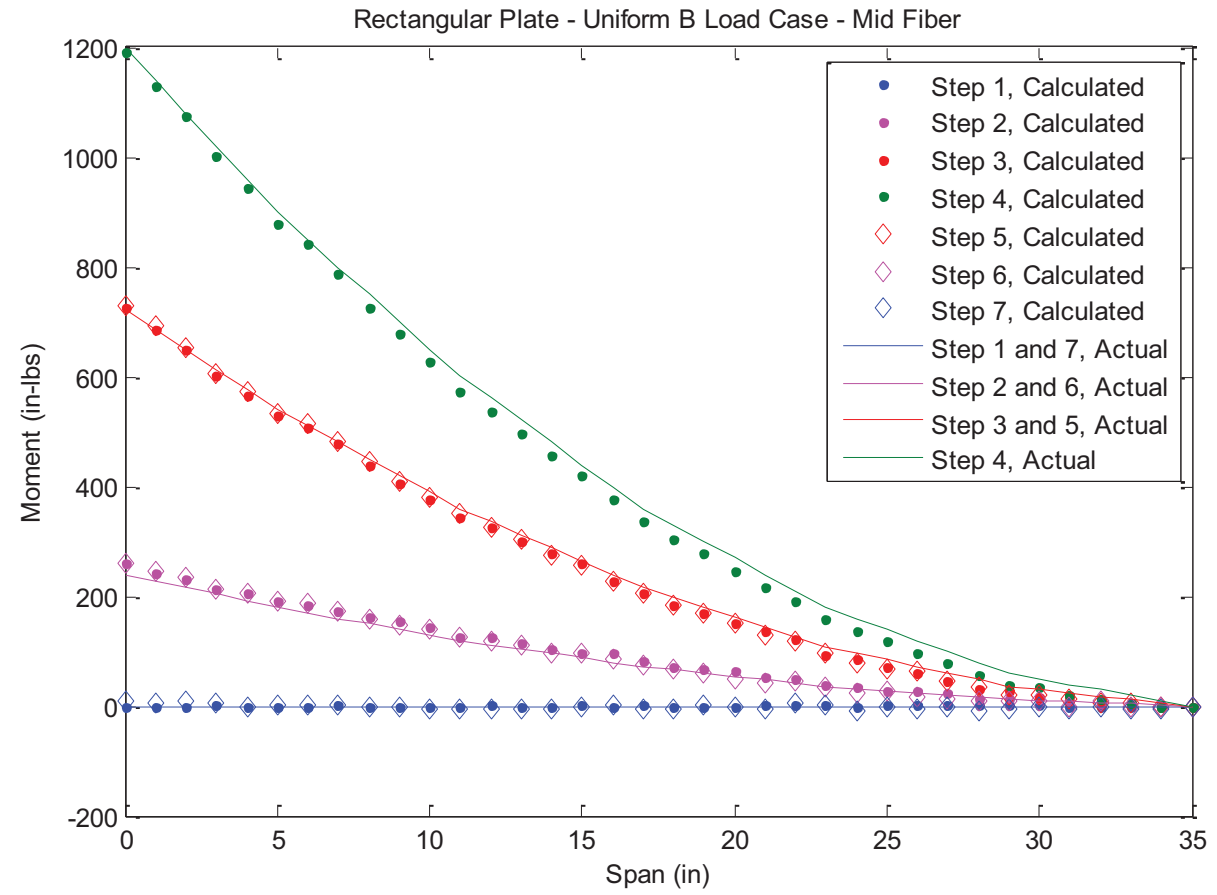

Figure A2_2. Rectangular plate load results for middle fiber during Uniform B load case.

American Institute of Aeronautics and Astronautics 


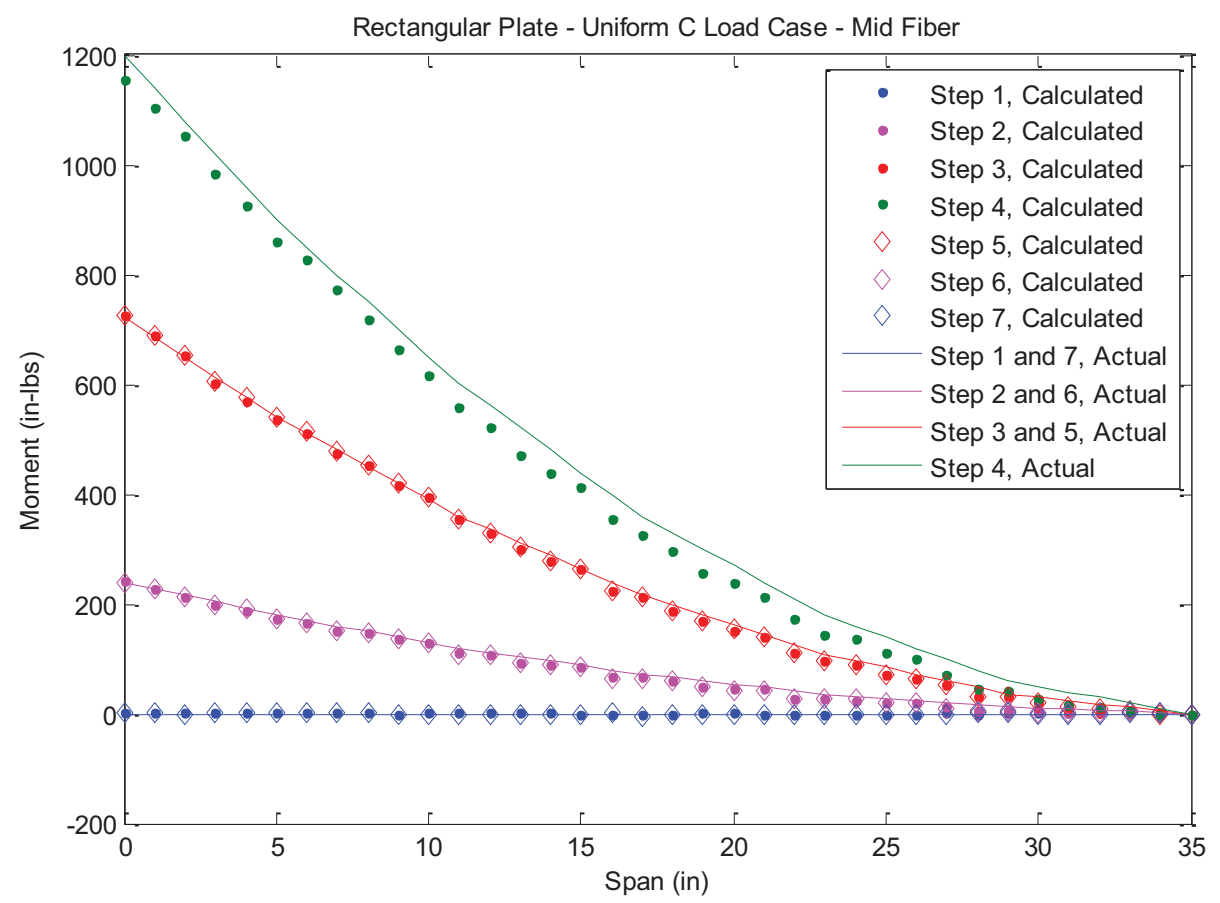

Figure A2_3. Rectangular plate load results for middle fiber during Uniform C load case.

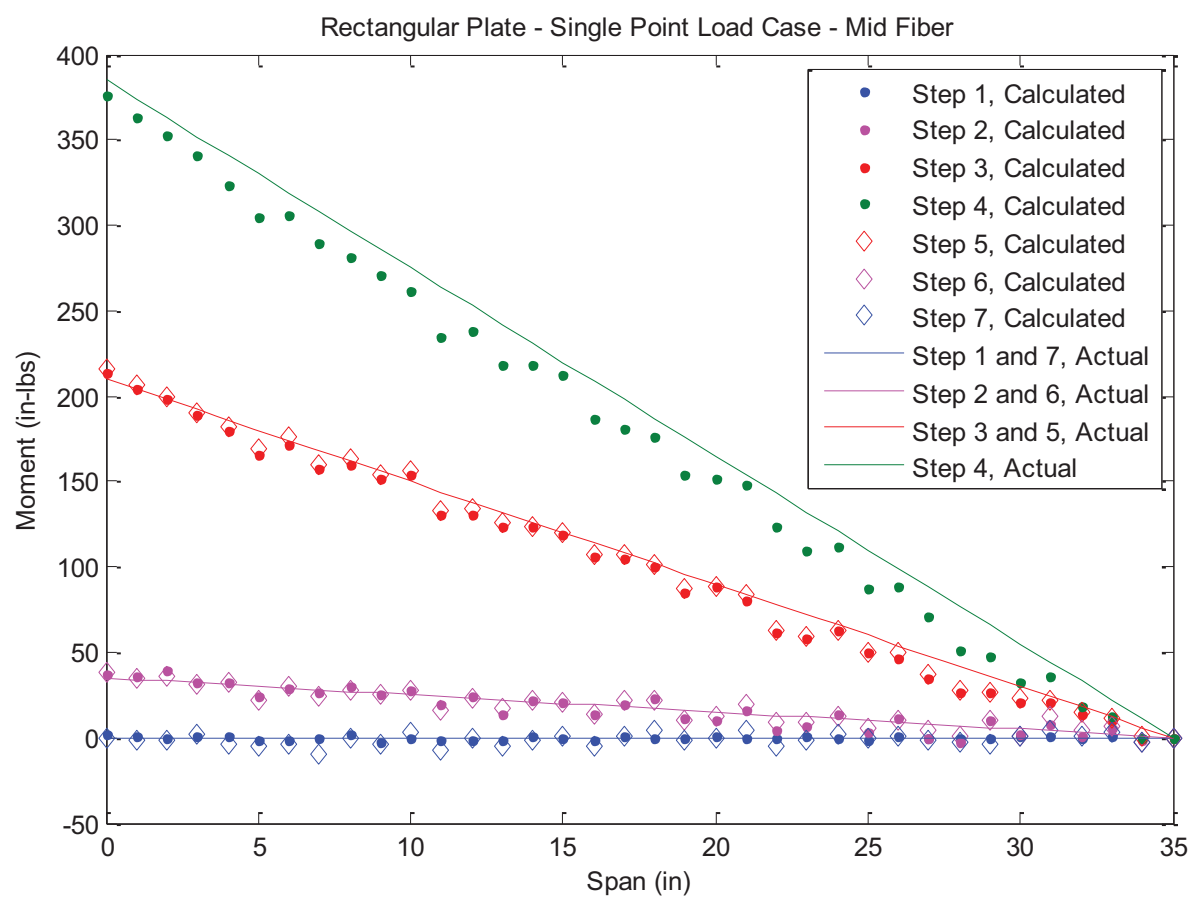

Figure A2_4. Rectangular plate load results for middle fiber during single point load case. 


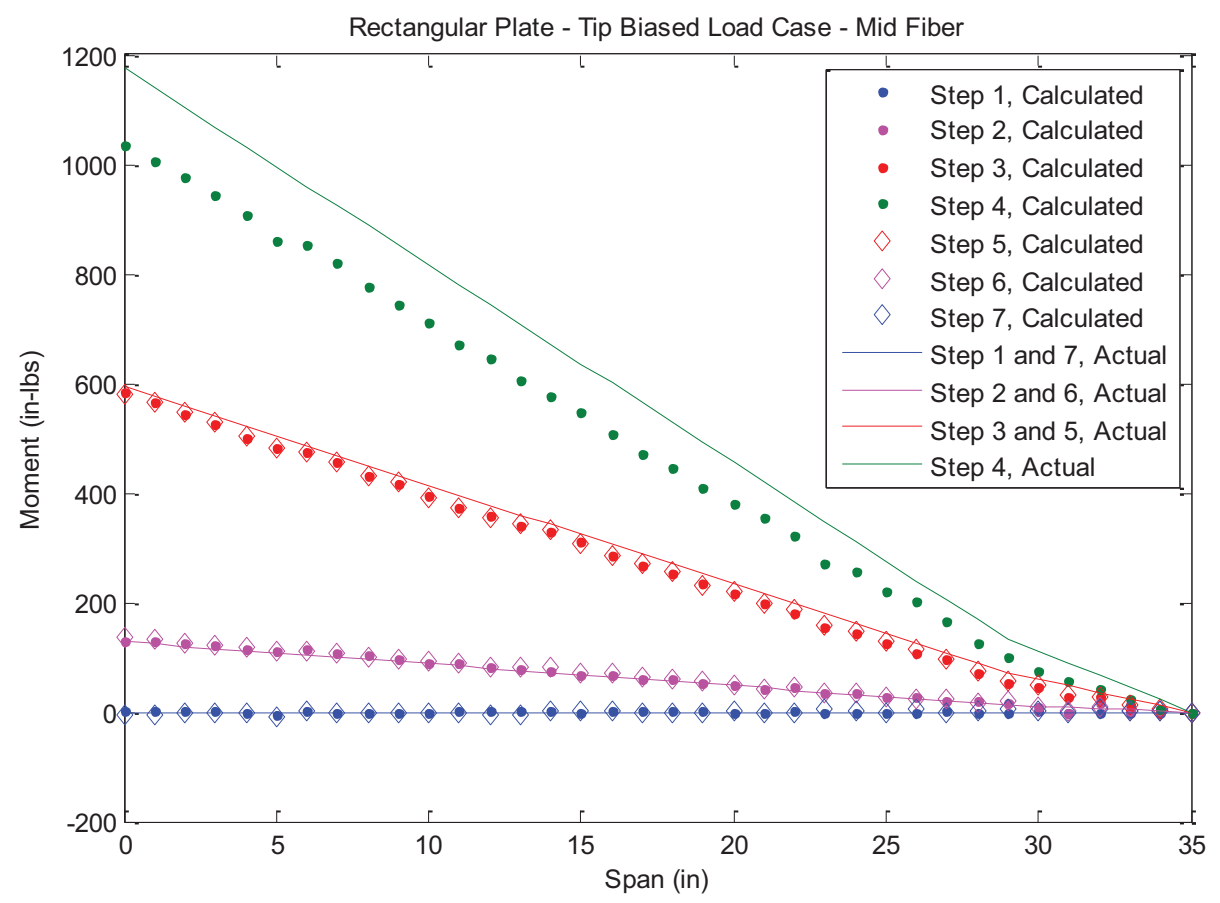

Figure A2_5. Rectangular plate load results for middle fiber during tip-biased load case.

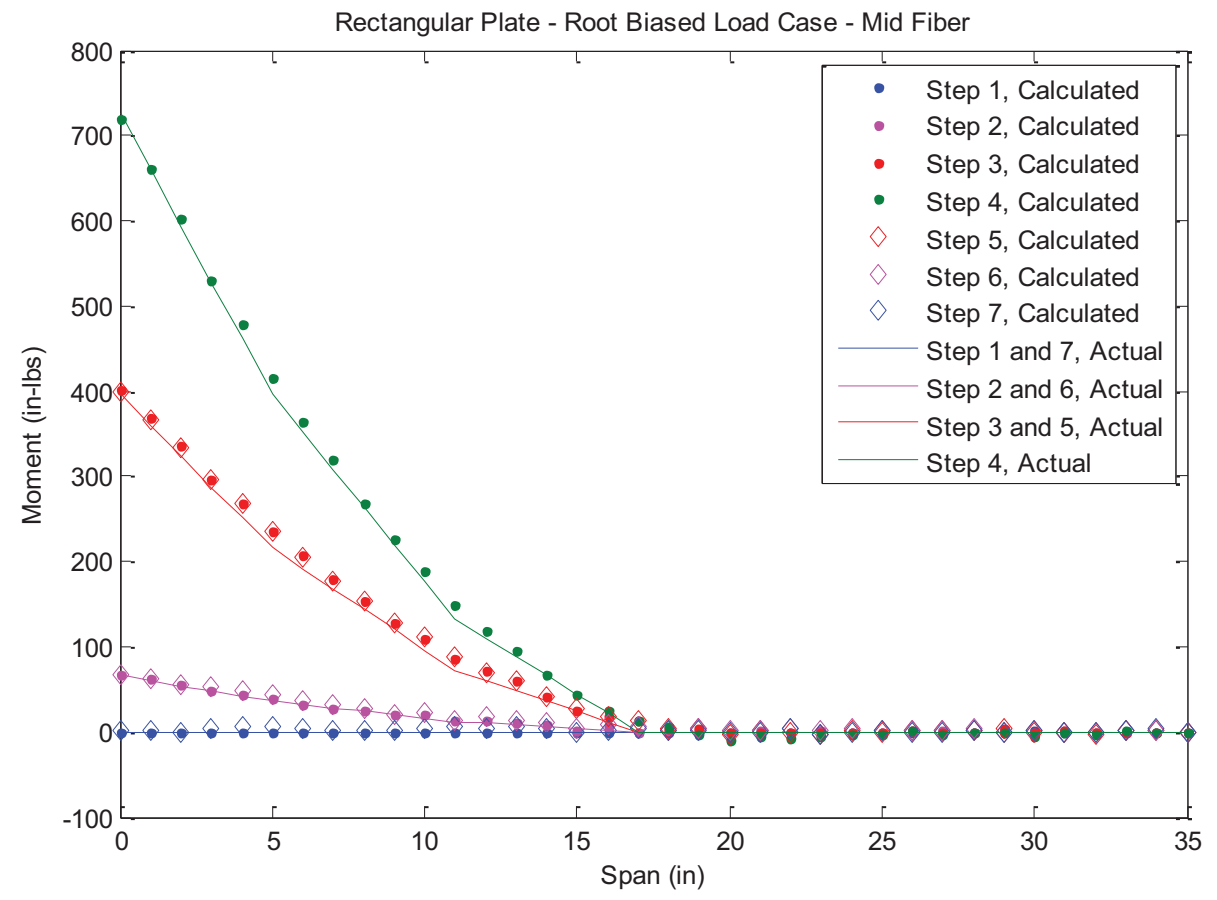

Figure A2_6. Rectangular plate load results for middle fiber during root-biased load case. 


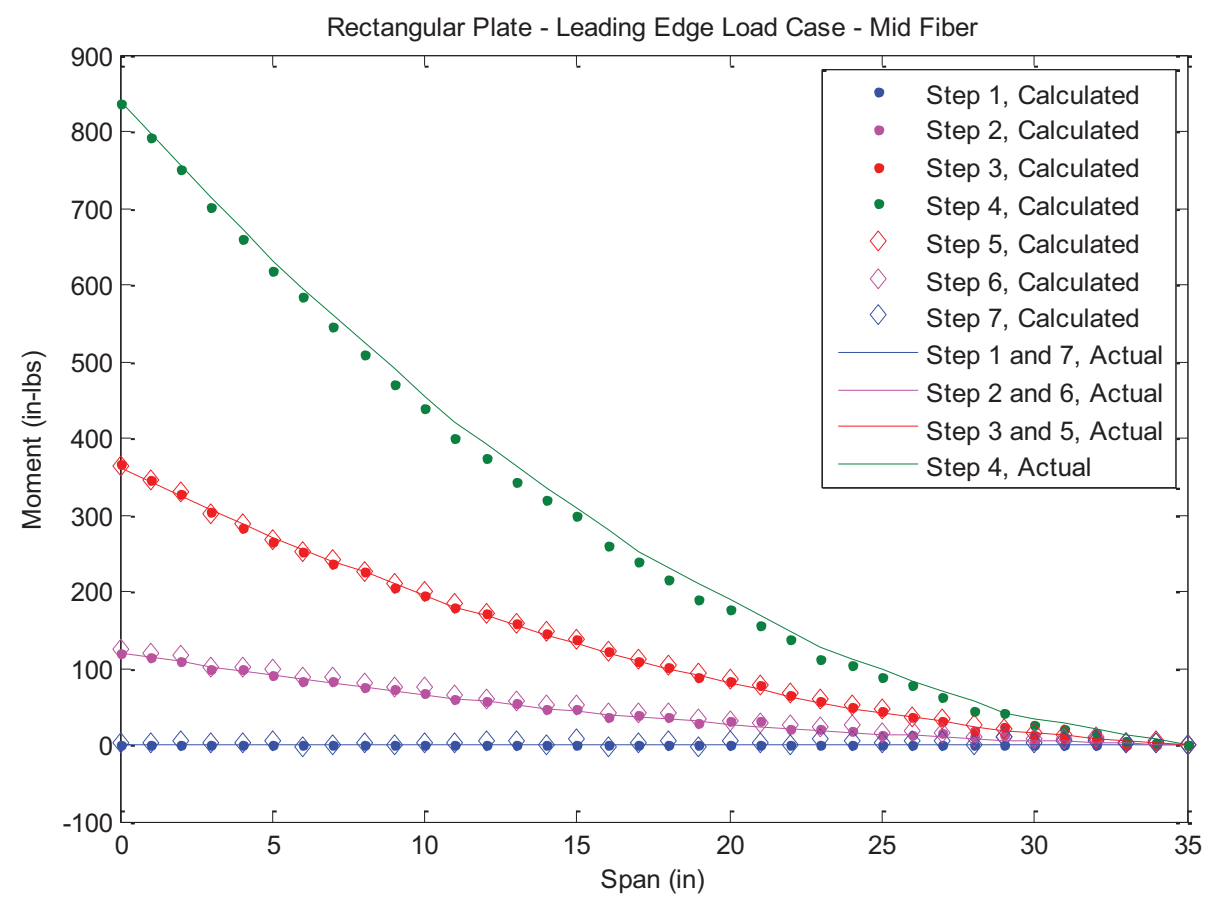

Figure A2_7. Rectangular plate load results for middle fiber during leading edge load case.

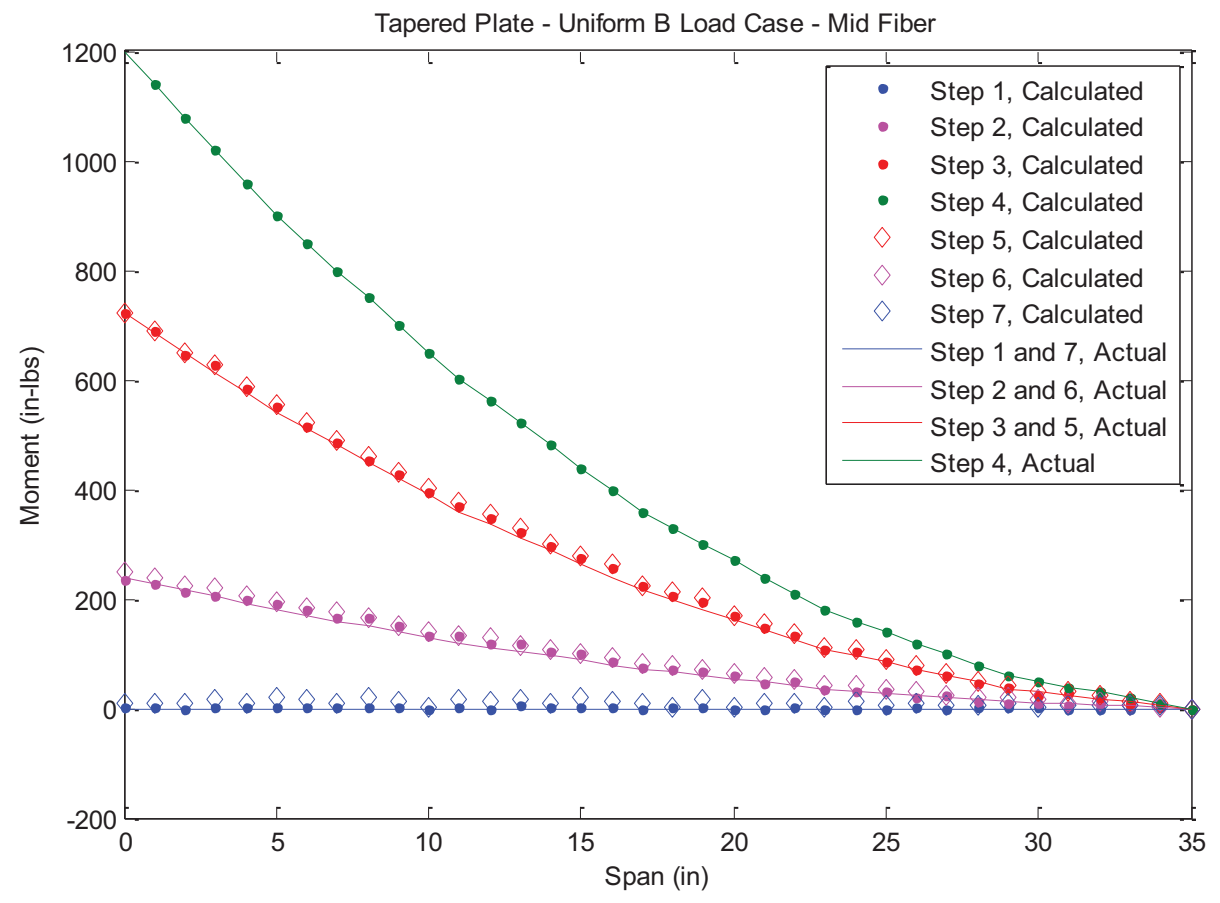

Figure A2_8. Tapered plate load results for middle fiber during Uniform B load case. 


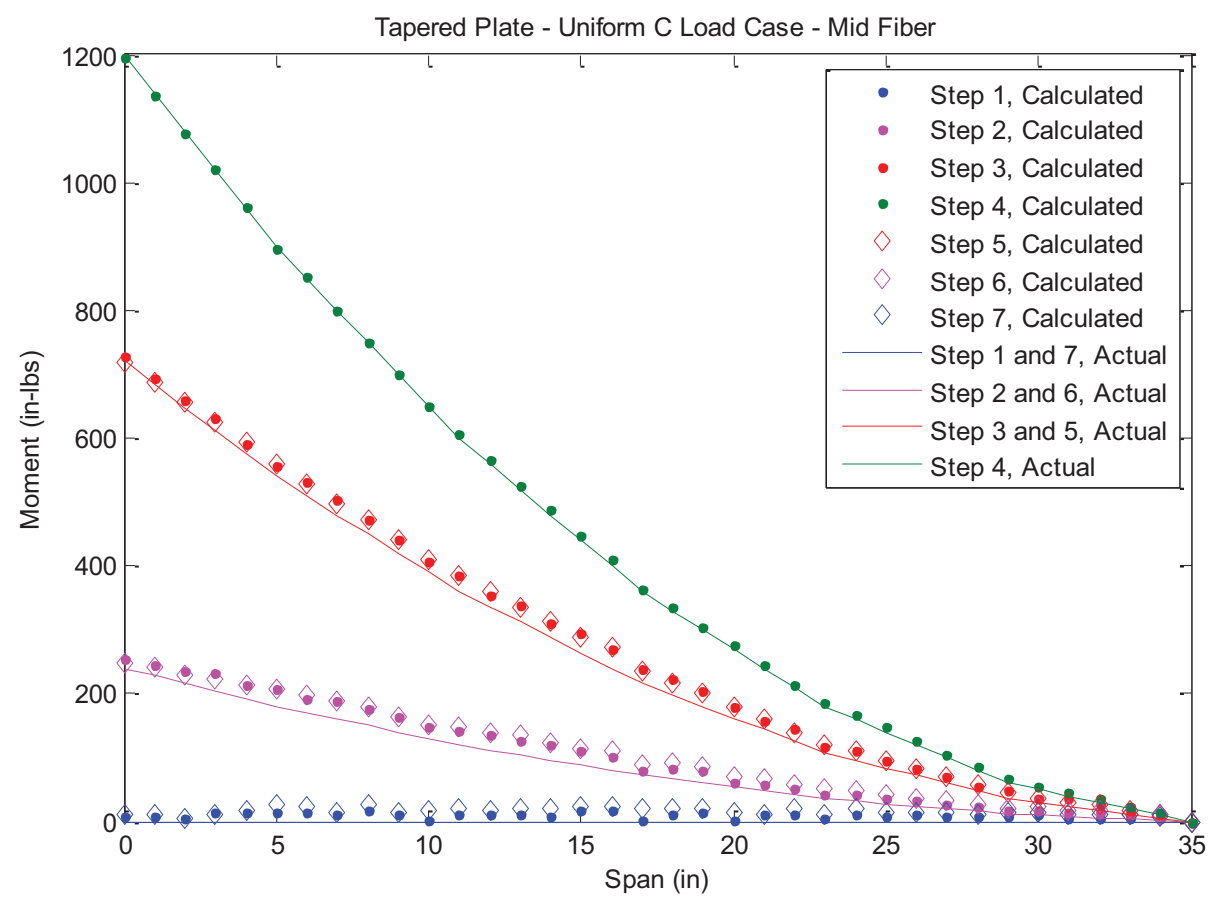

Figure A2_9. Tapered plate load results for middle fiber during Uniform C load case.

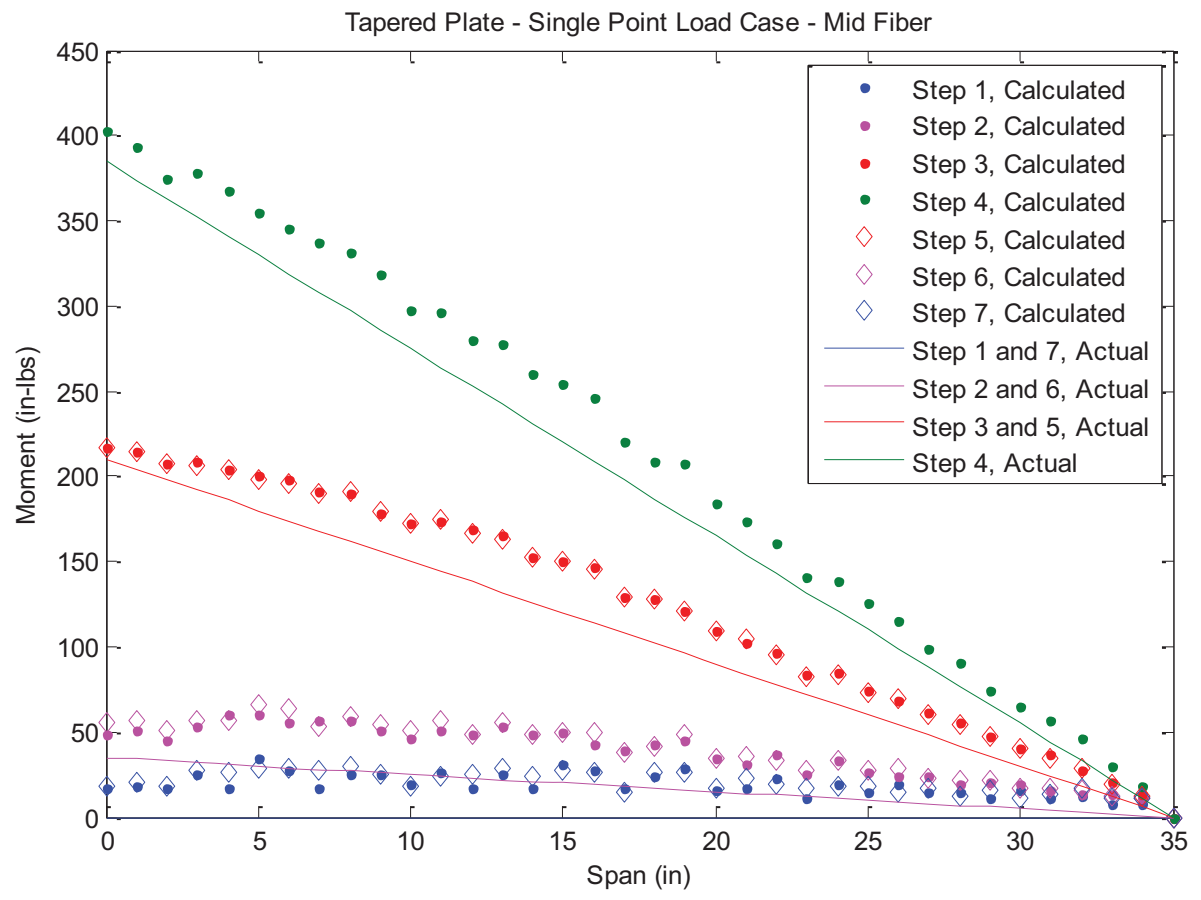

Figure A2_10. Tapered plate load results for middle fiber during single point load case. 


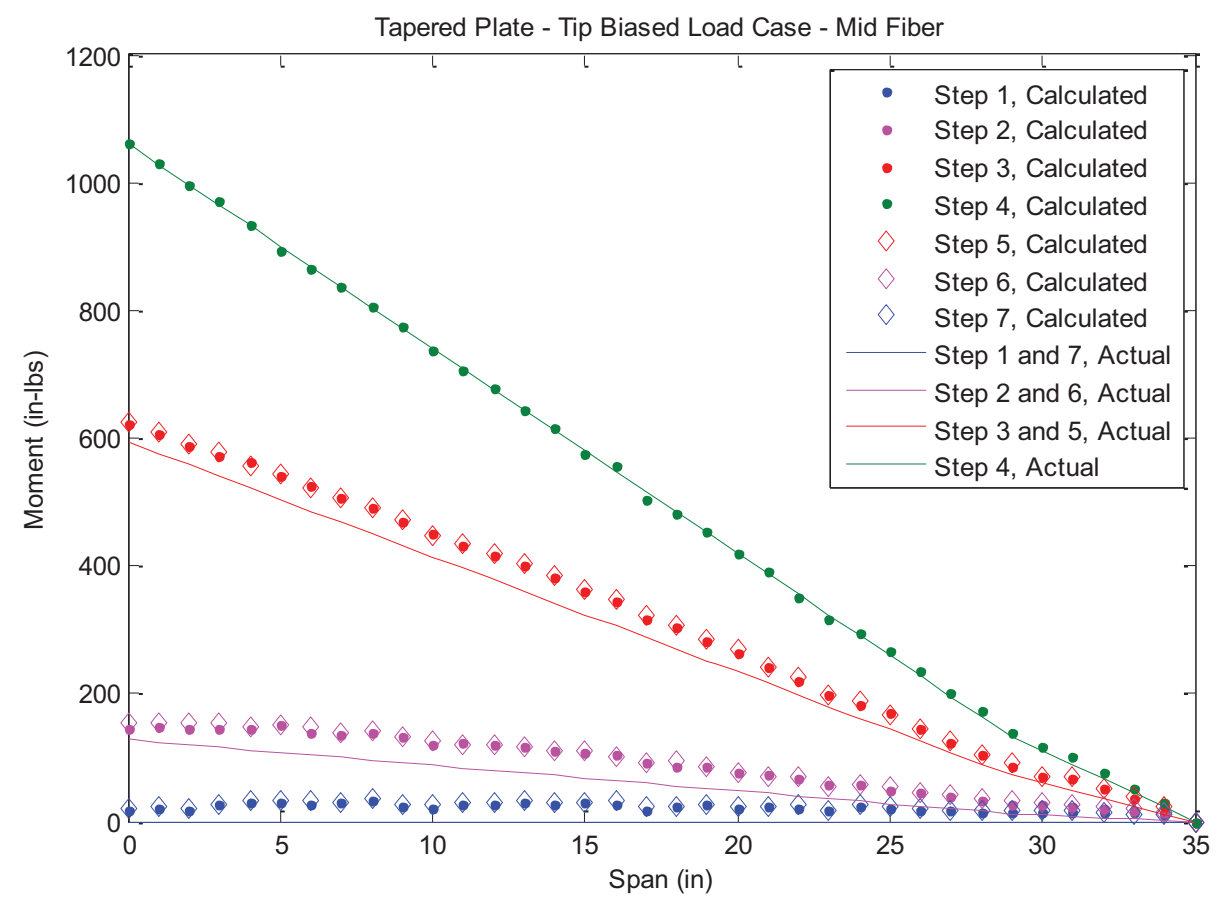

Figure A2_11. Tapered plate load results for middle fiber during tip-biased load case.

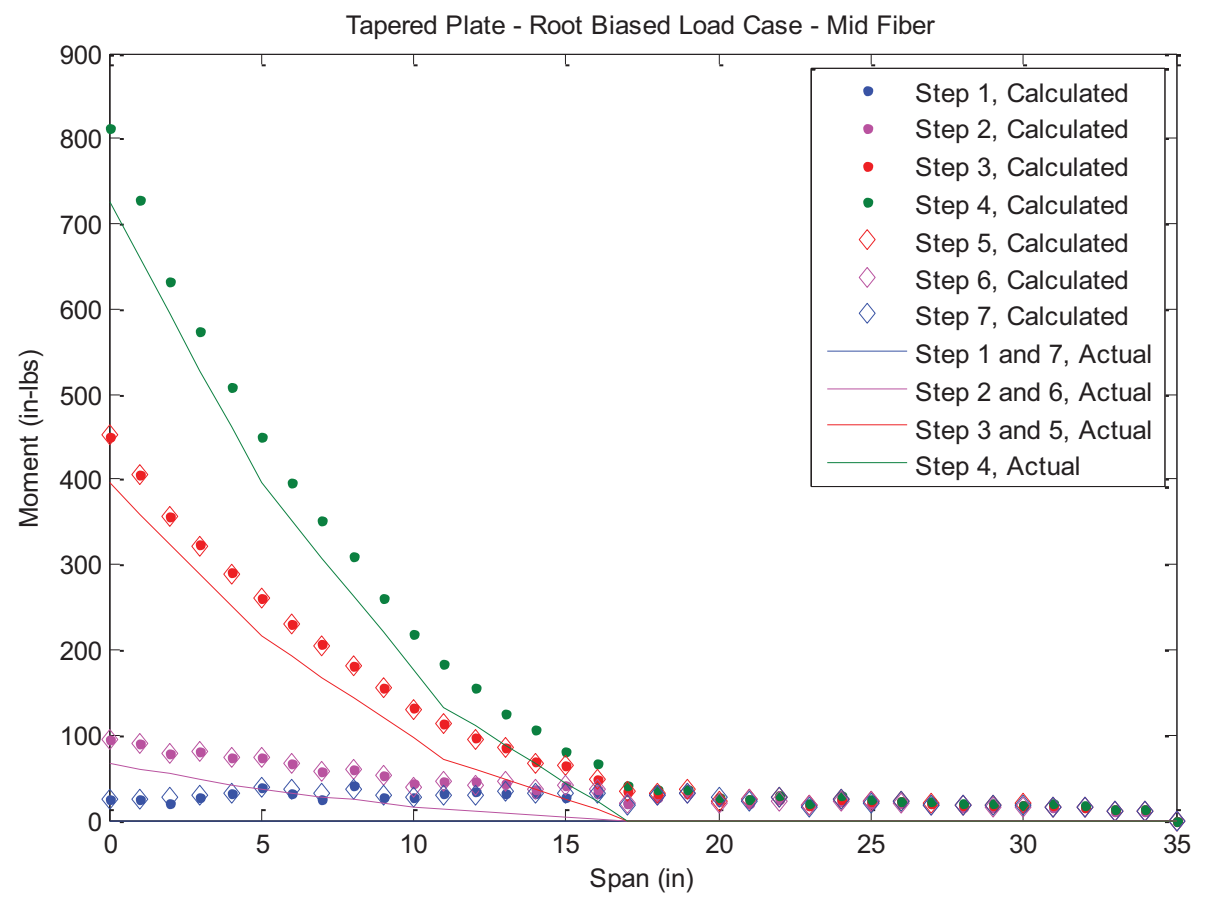

Figure A2_12. Tapered plate load results for middle fiber during root-biased load case.

American Institute of Aeronautics and Astronautics 


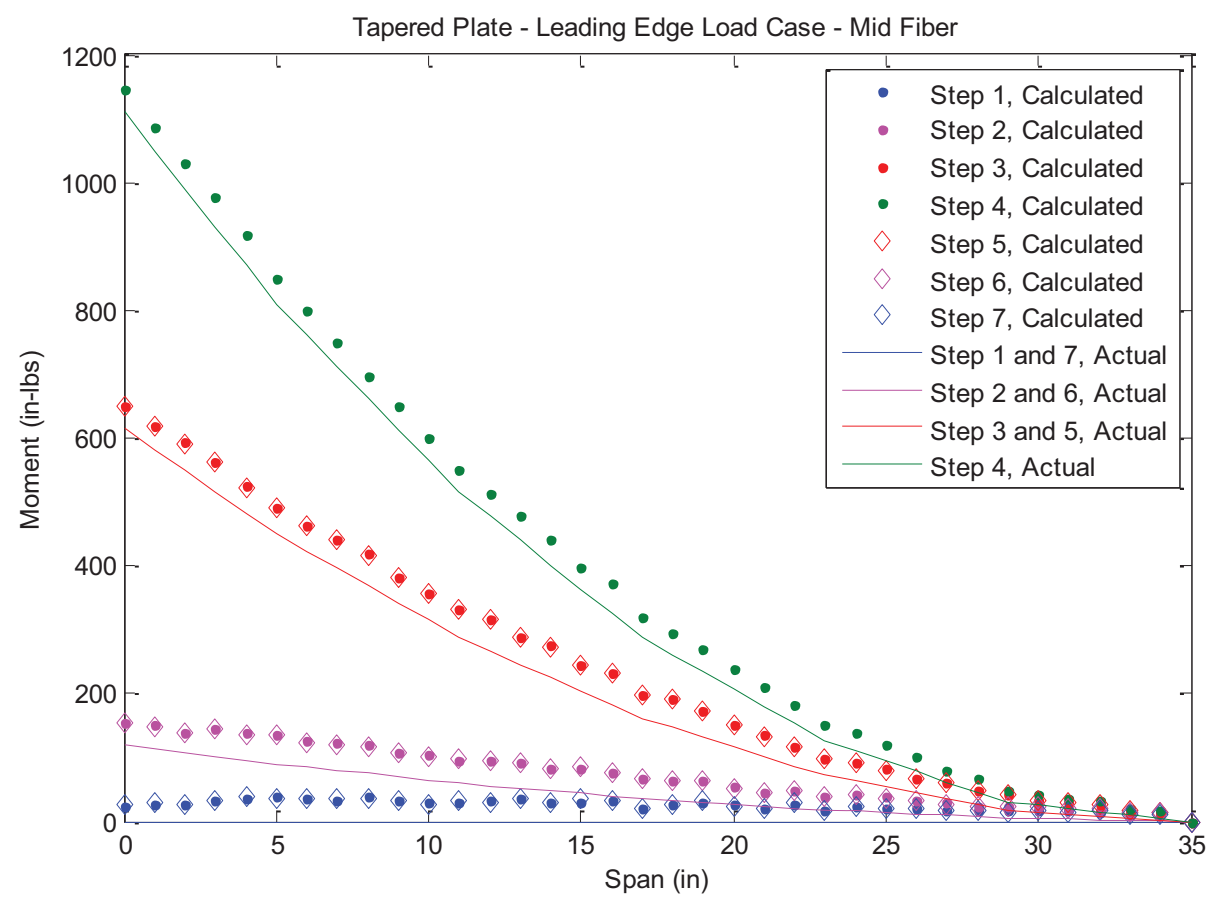

Figure A2_13. Tapered plate load results for middle fiber during leading edge load case.

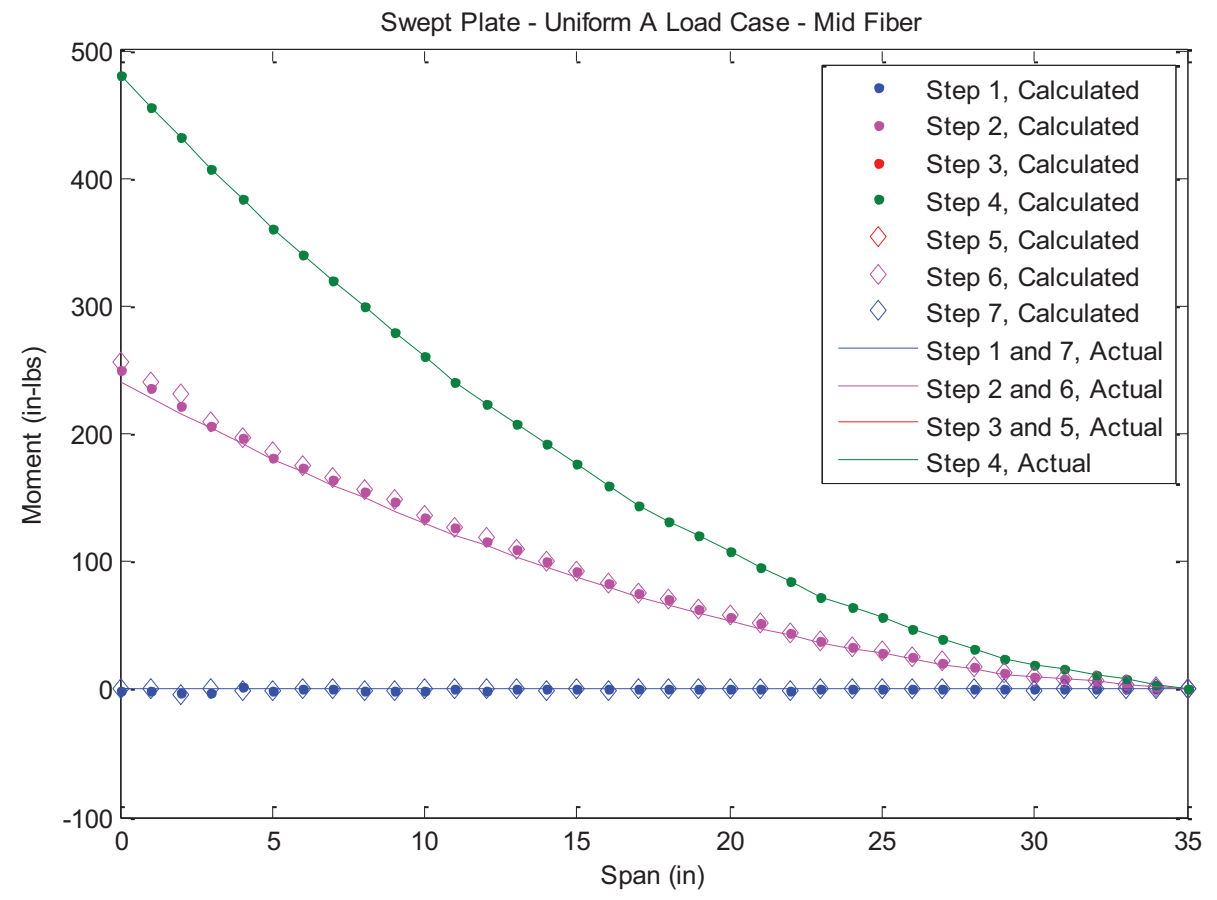

Figure A2_14. Swept plate load results for middle fiber during Uniform A load case. 


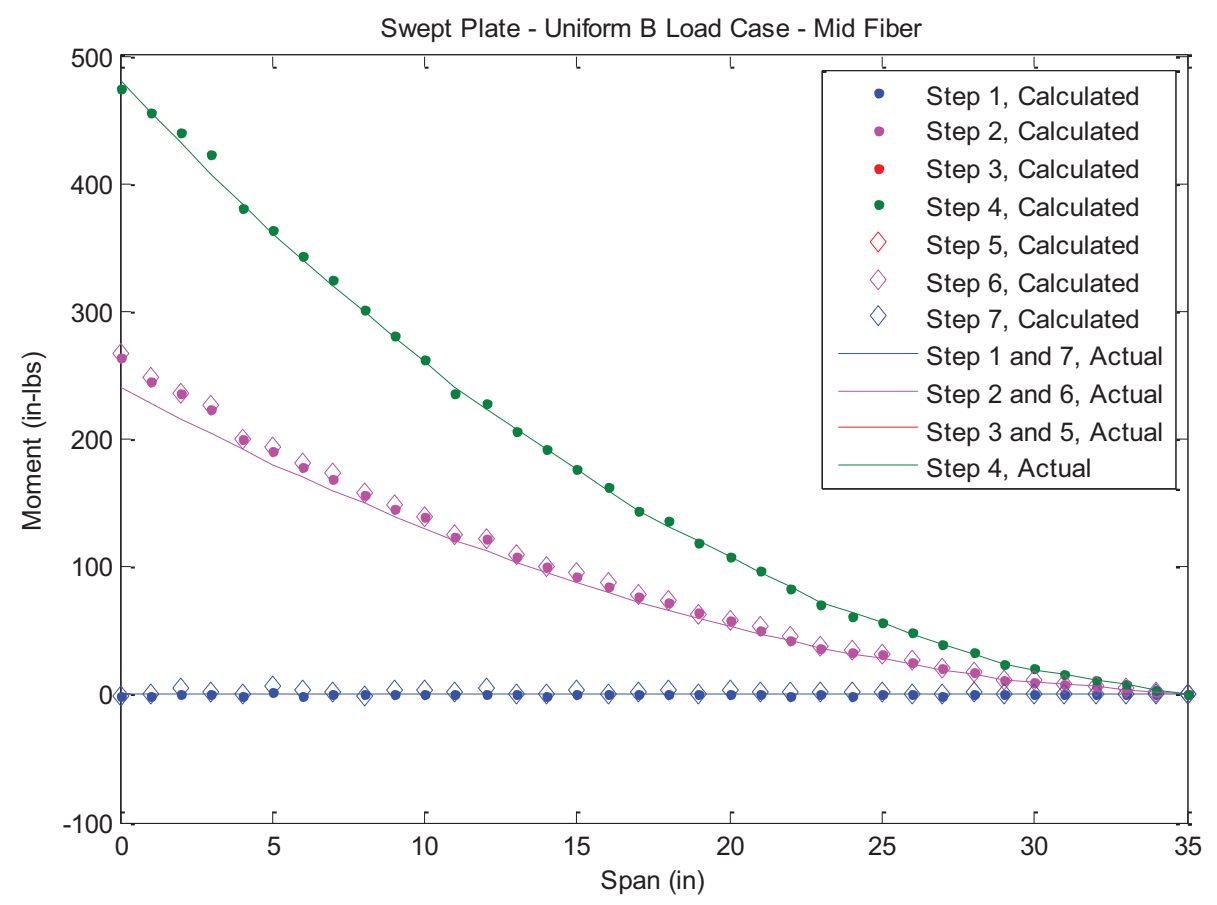

Figure A2_15. Swept plate load results for middle fiber during Uniform B load case.

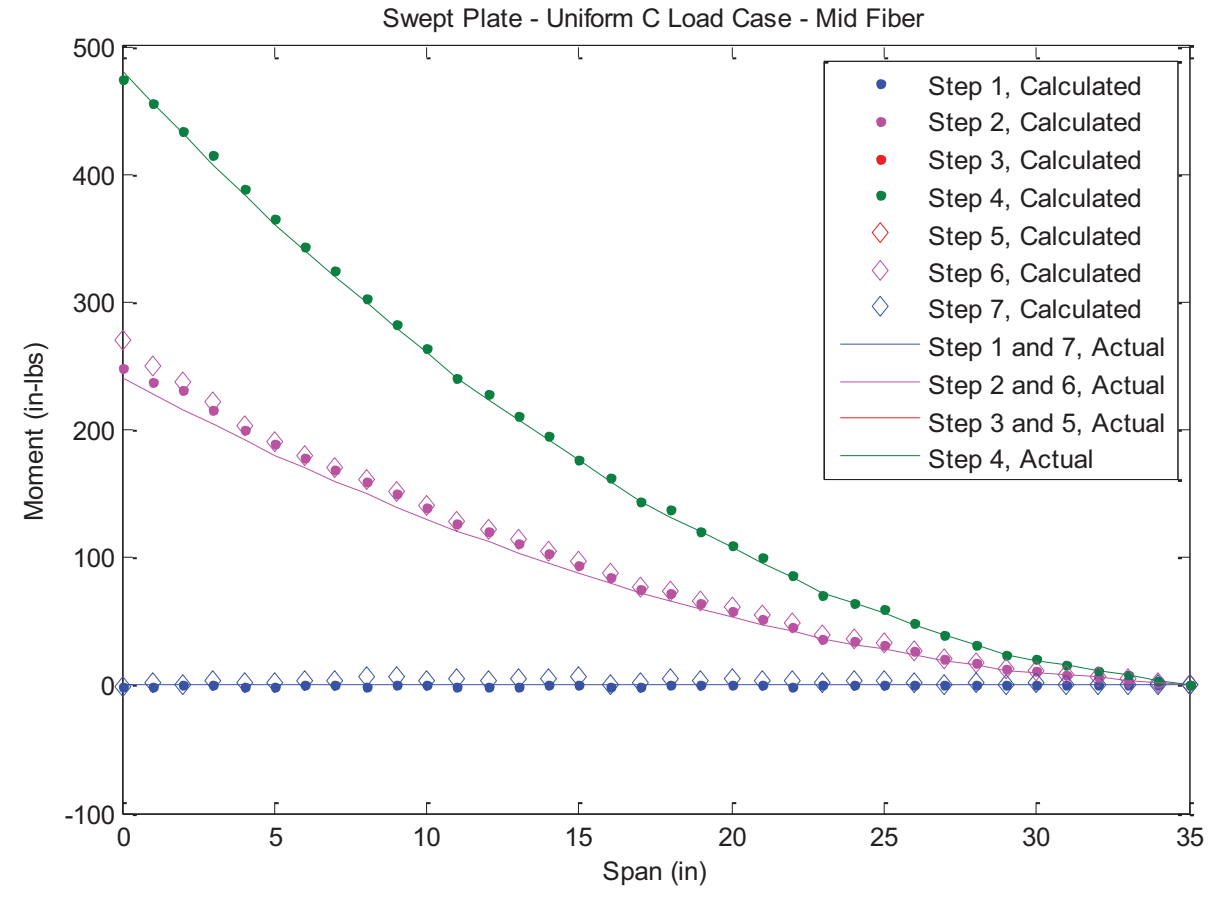

Figure A2_16. Swept plate load results for middle fiber during Uniform C load case. 


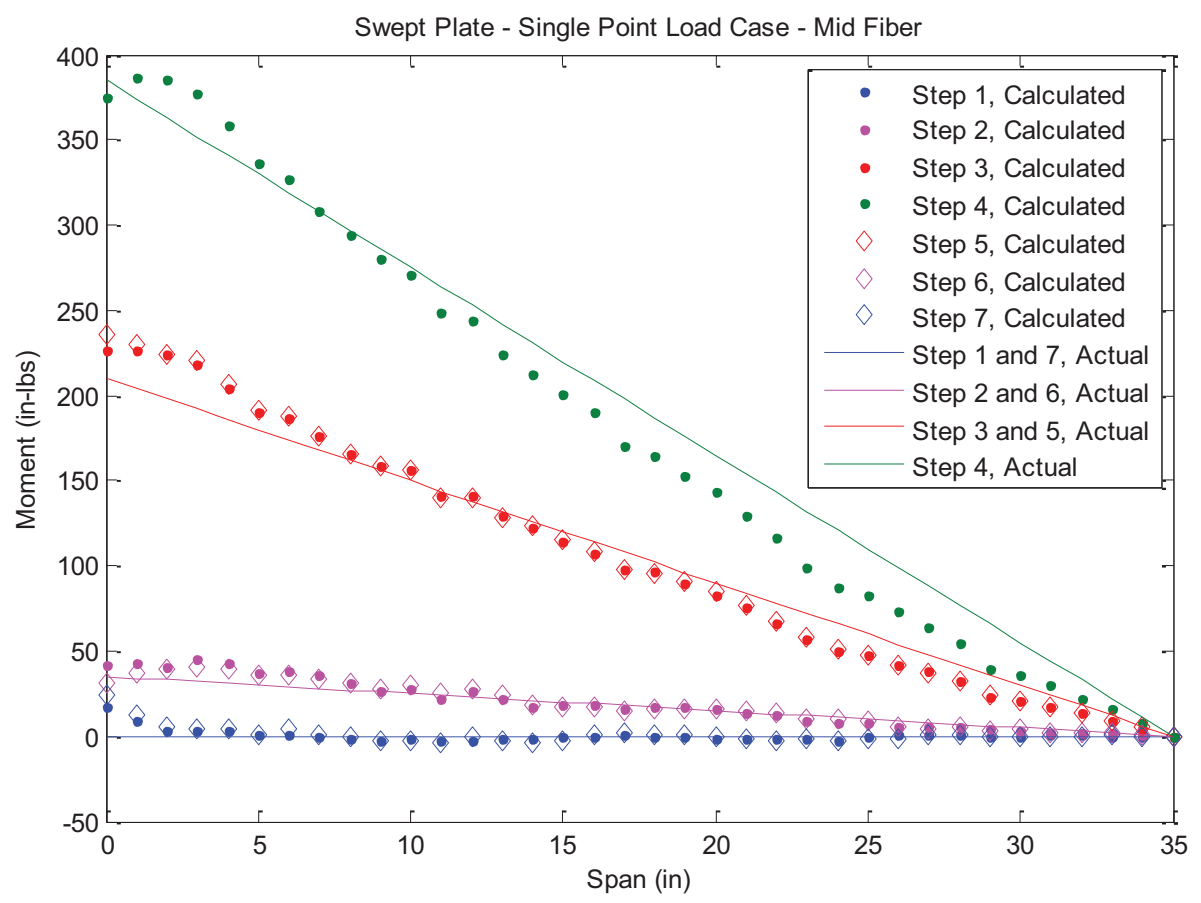

Figure A2_17. Swept plate load results for middle fiber during single point load case.

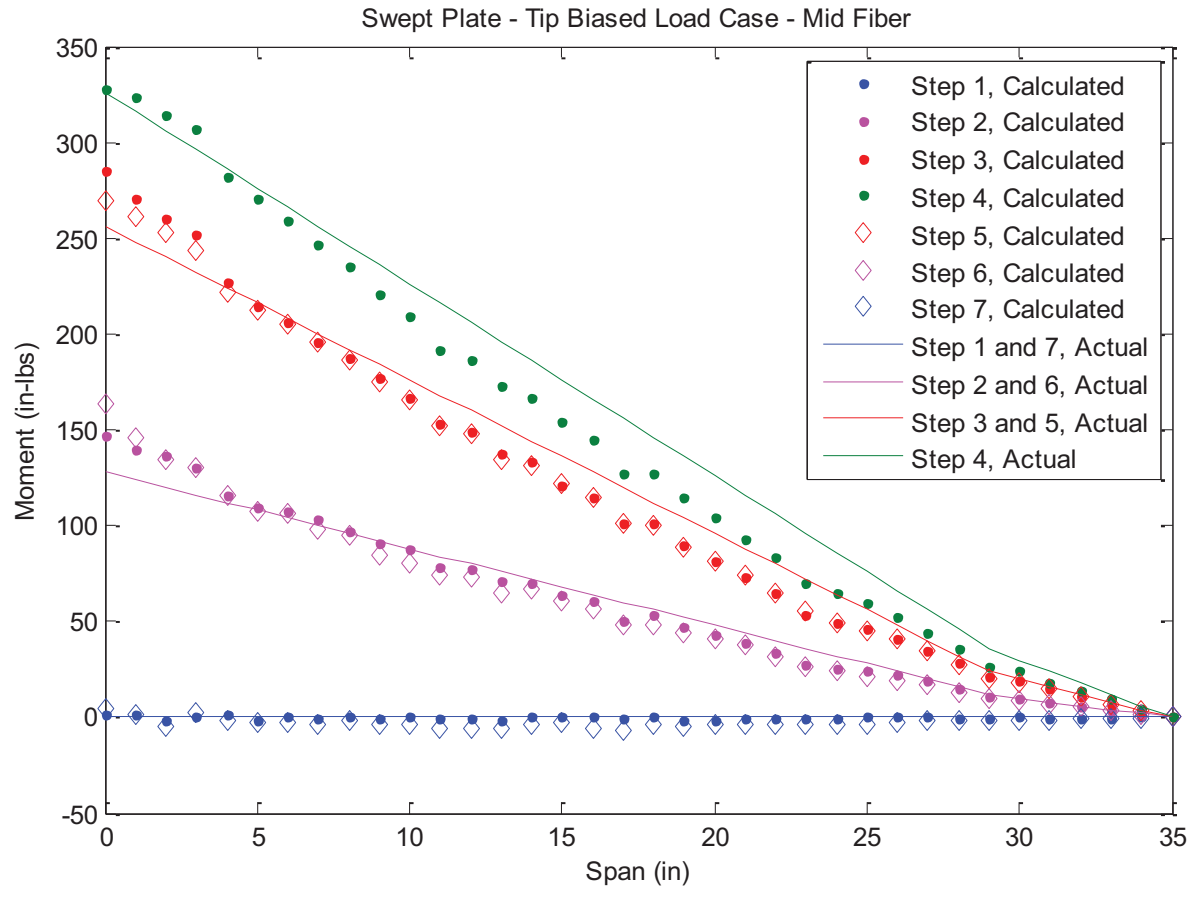

Figure A2_18. Swept plate load results for middle fiber during tip-biased load case. 


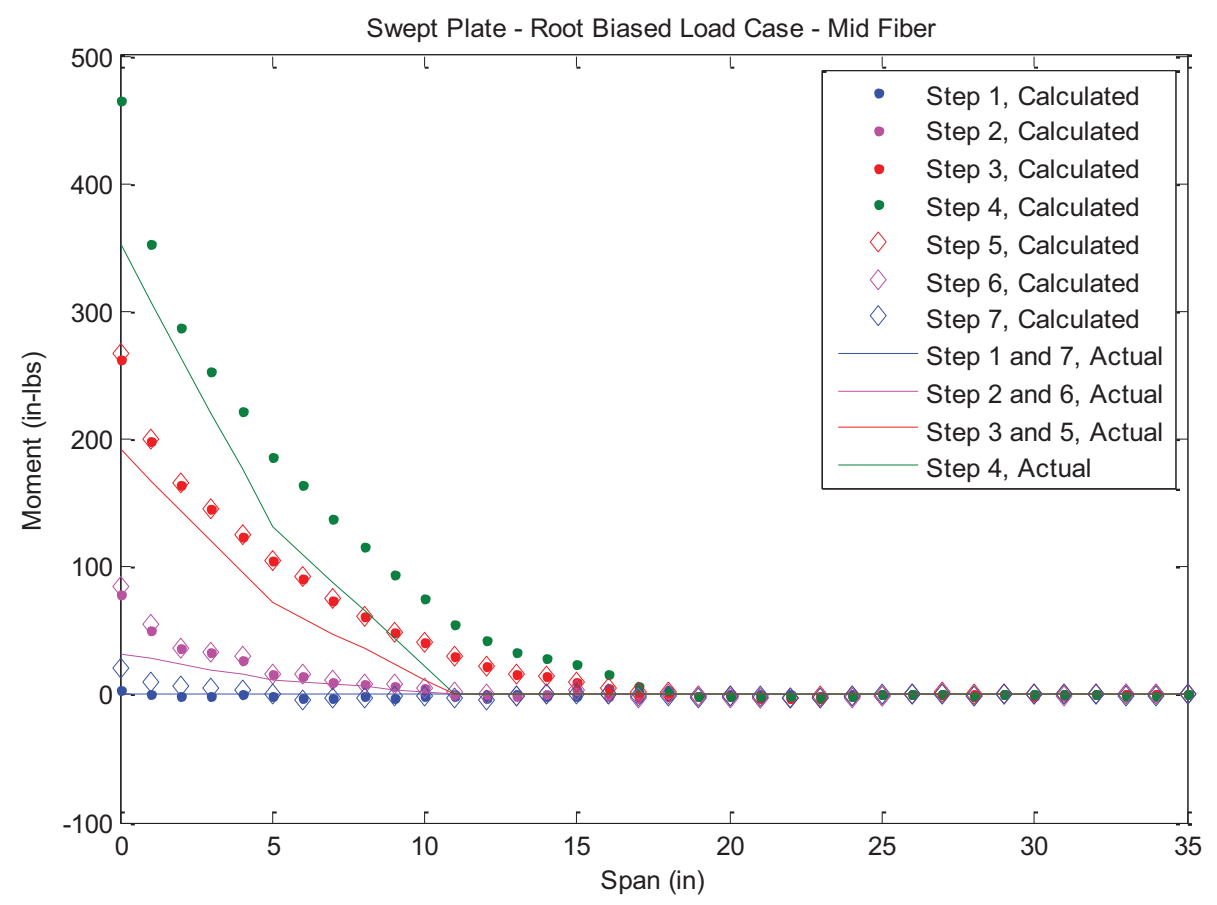

Figure A2_19. Swept plate load results for middle fiber during root-biased load case.

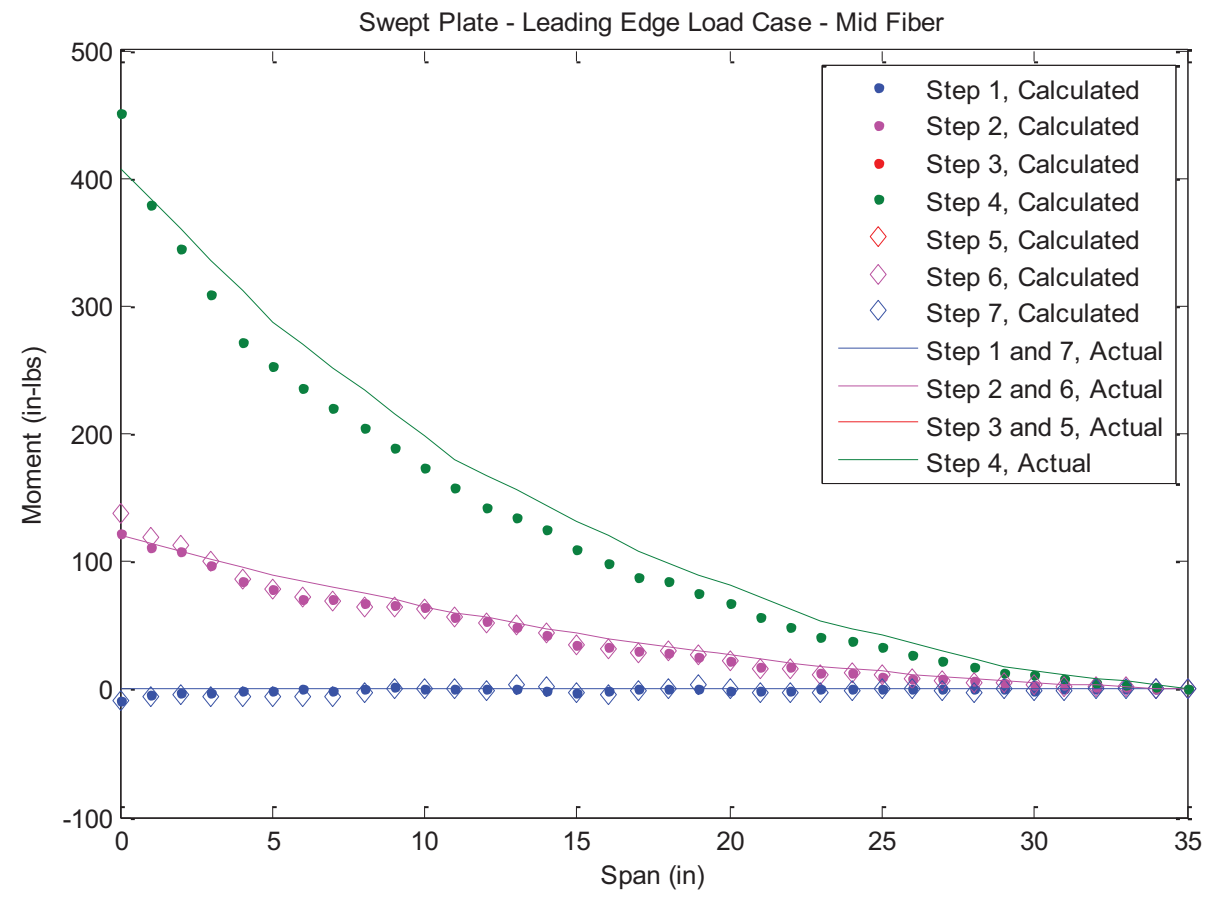

Figure A2_20. Swept plate load results for middle fiber during leading edge load case. 


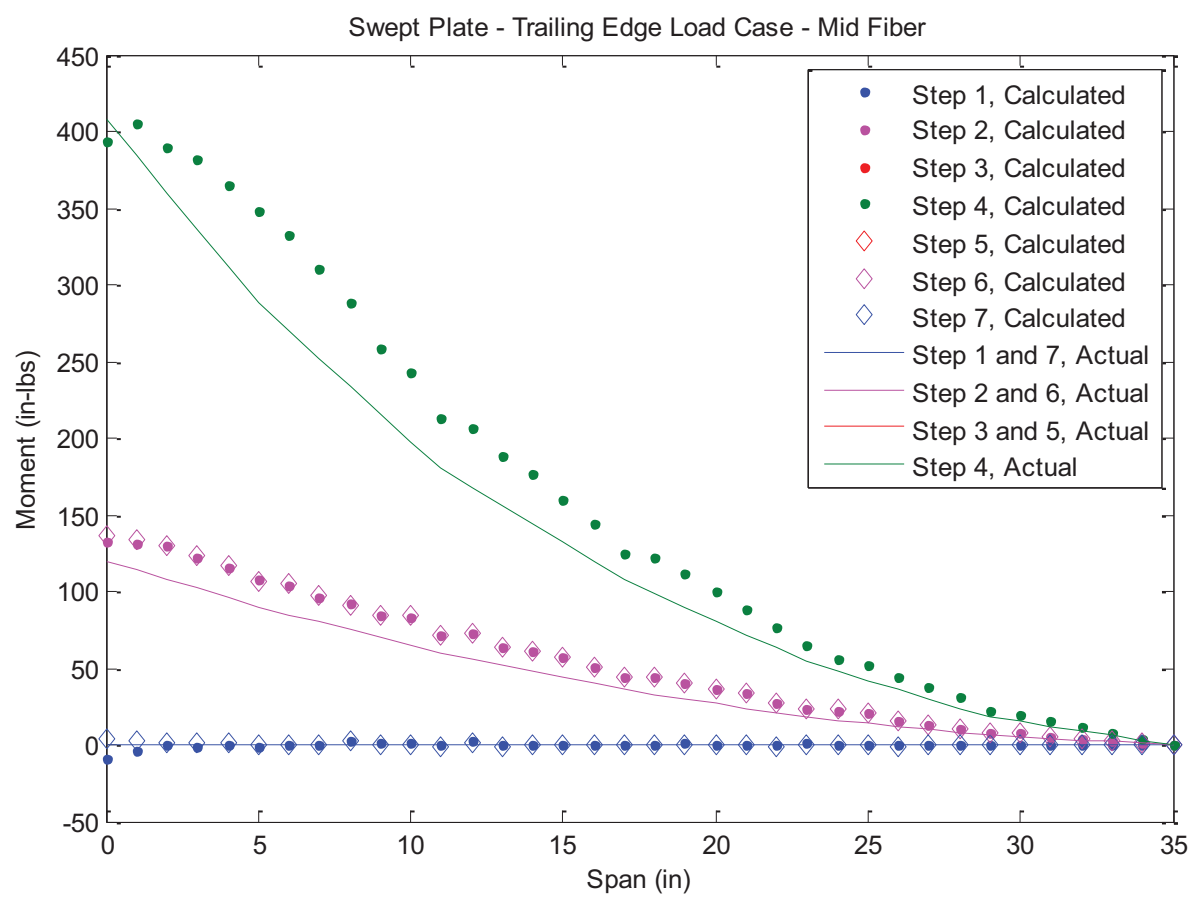

Figure A2_21. Swept plate load results for middle fiber during trailing edge load case.

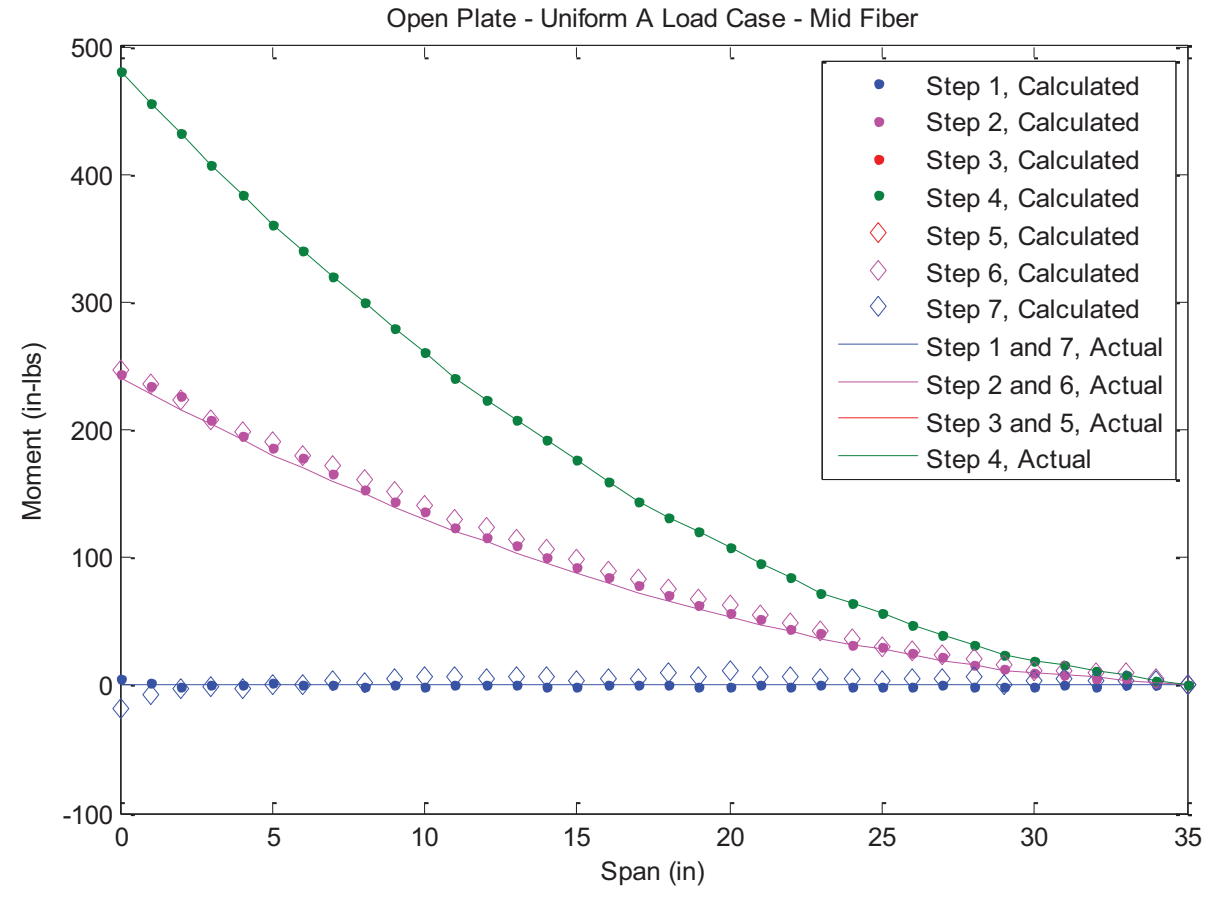

Figure A2_22. Open plate load results for middle fiber during Uniform A load case.

American Institute of Aeronautics and Astronautics 


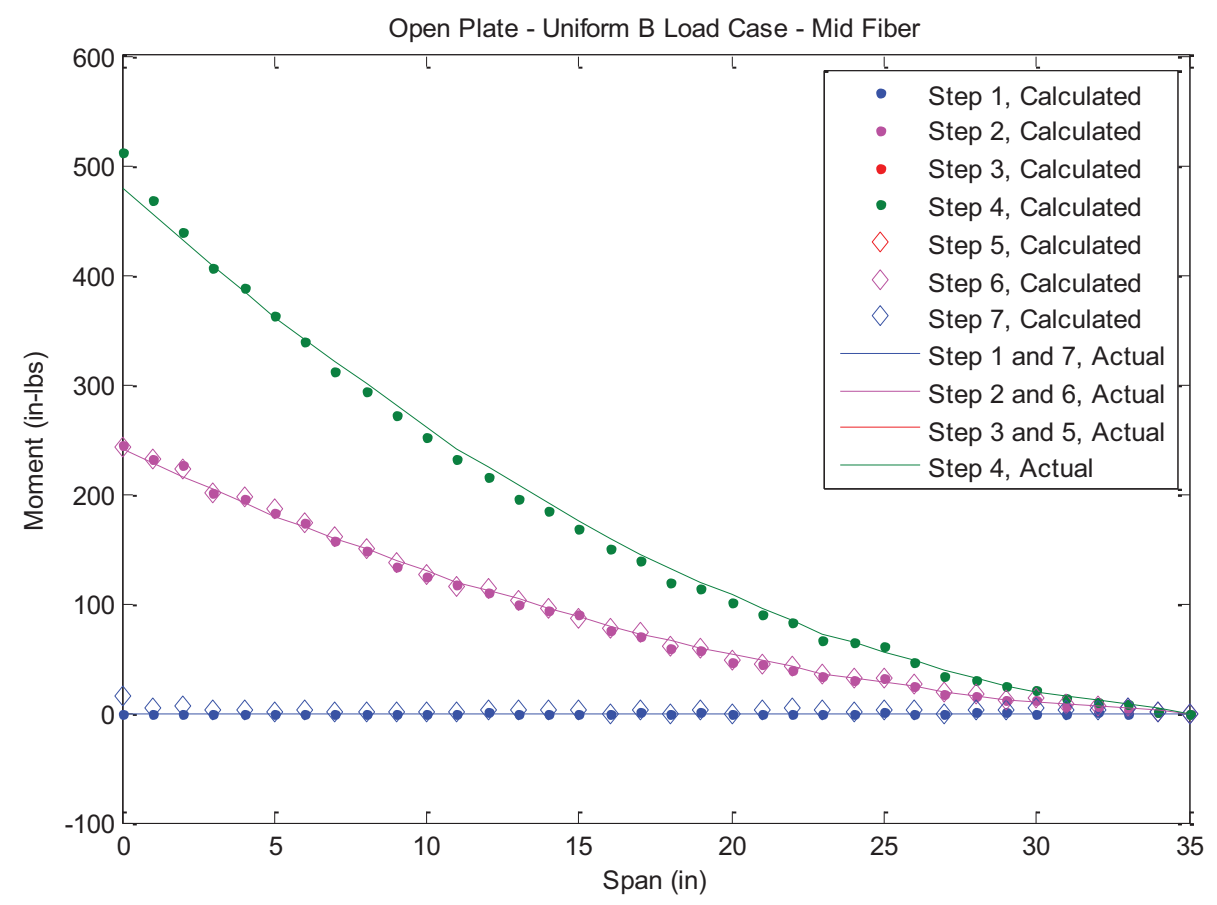

Figure A2_23. Open plate load results for middle fiber during Uniform B load case.

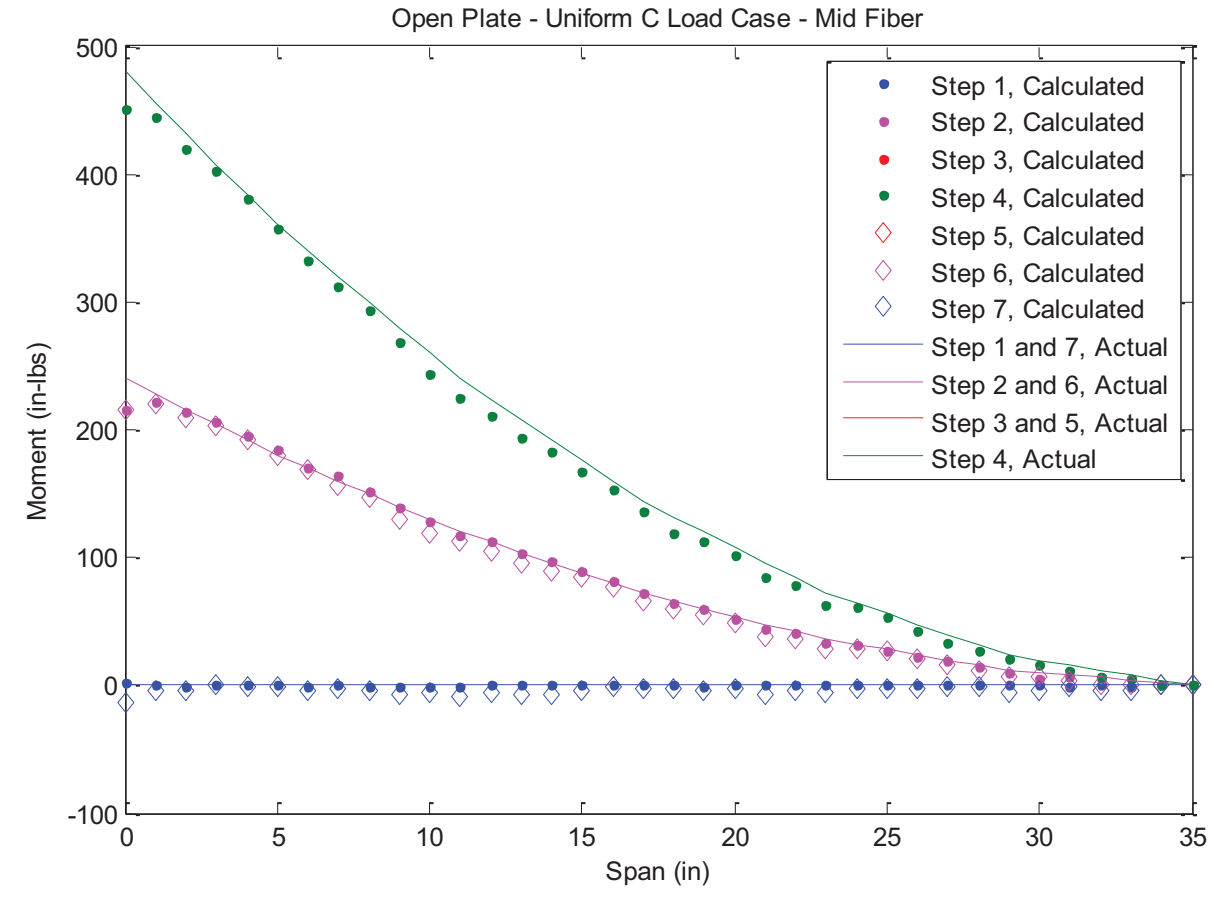

Figure A2_24. Open plate load results for middle fiber during Uniform C load case. 


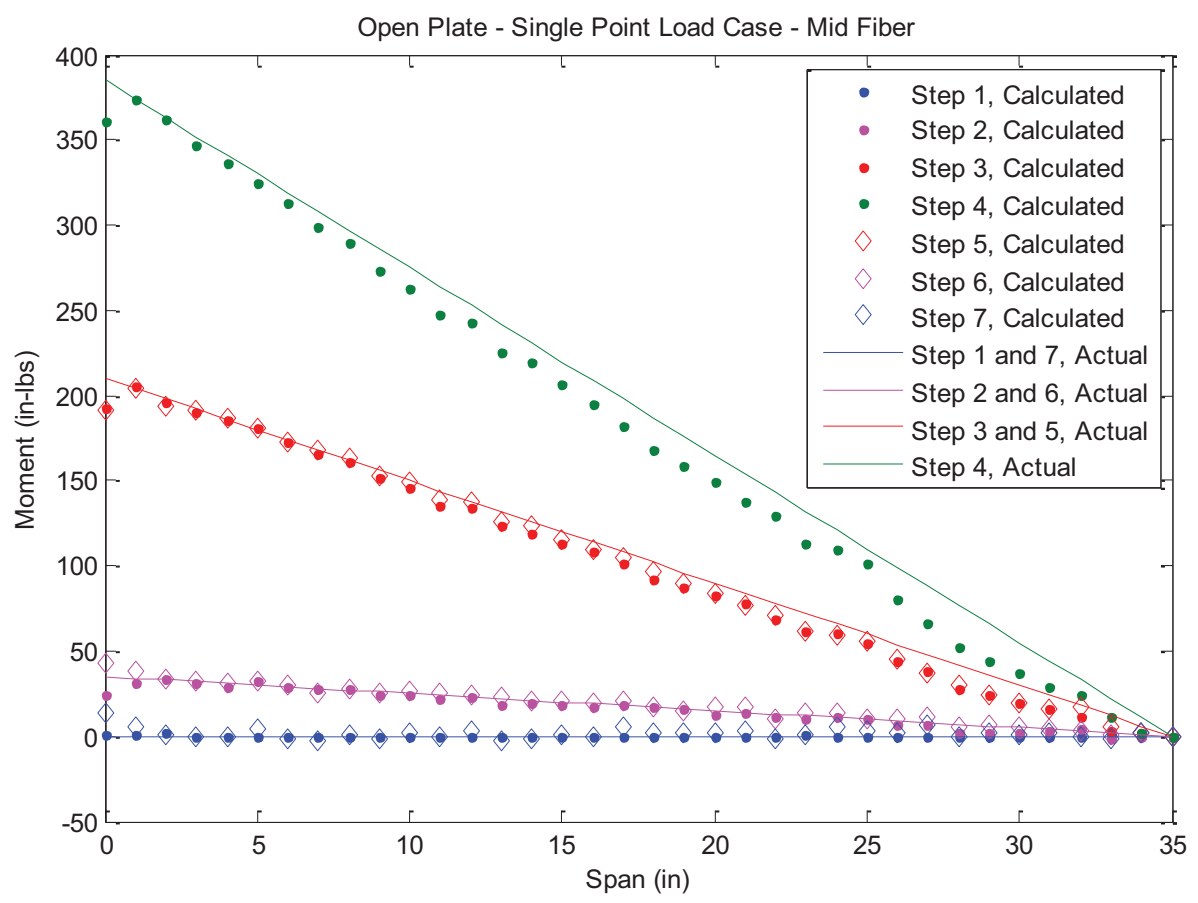

Figure A2_25. Open plate load results for middle fiber during single point load case.

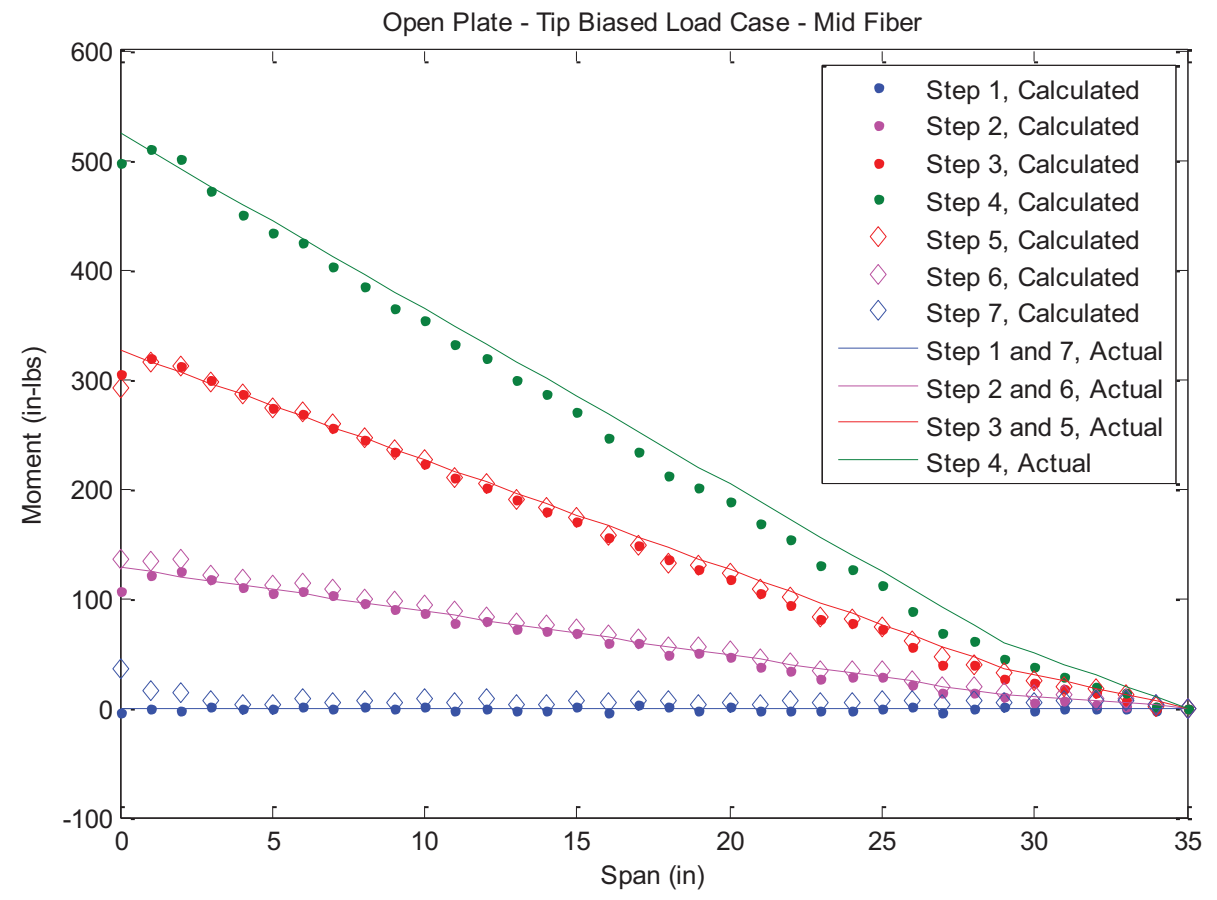

Figure A2_26. Open plate load results for middle fiber during tip-biased load case. 


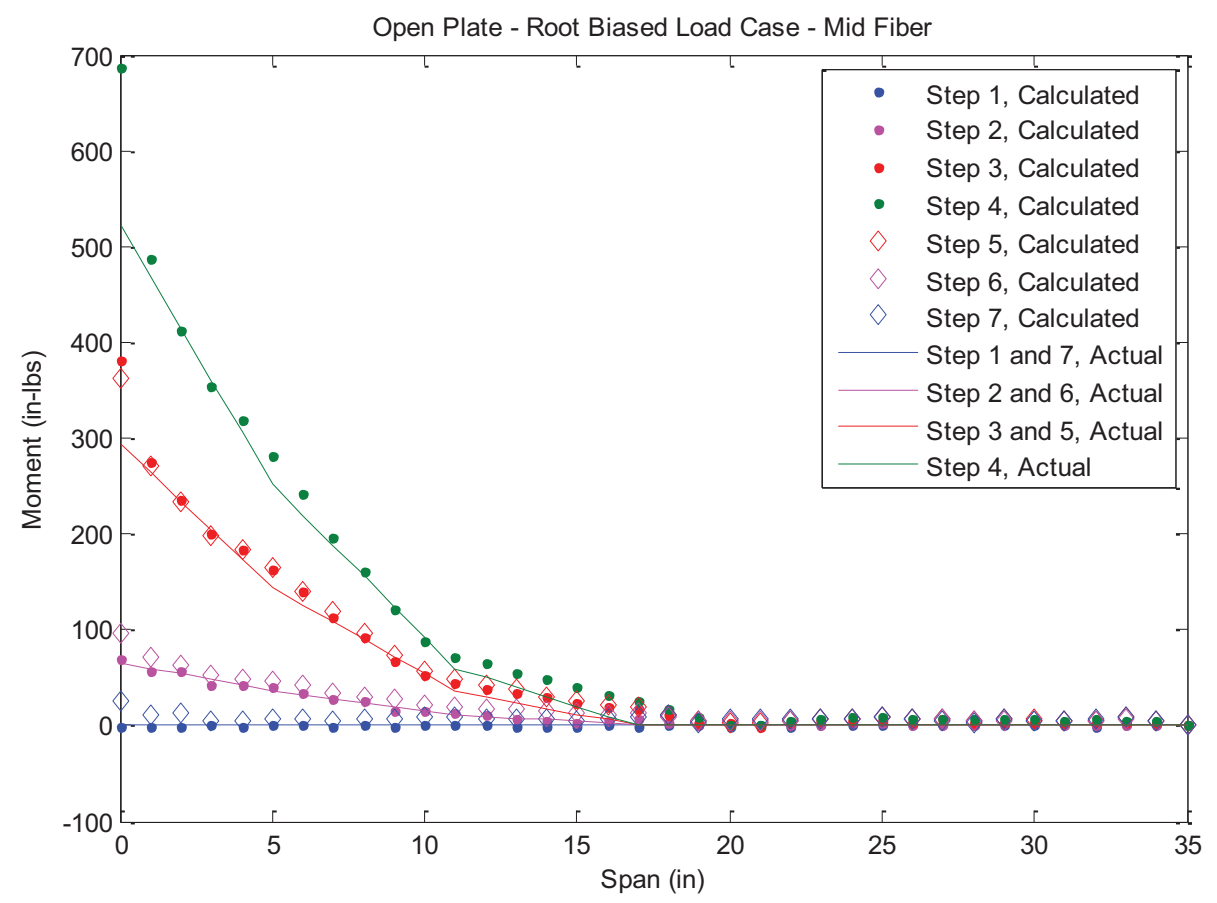

Figure A2_27. Open plate load results for middle fiber during root-biased load case.

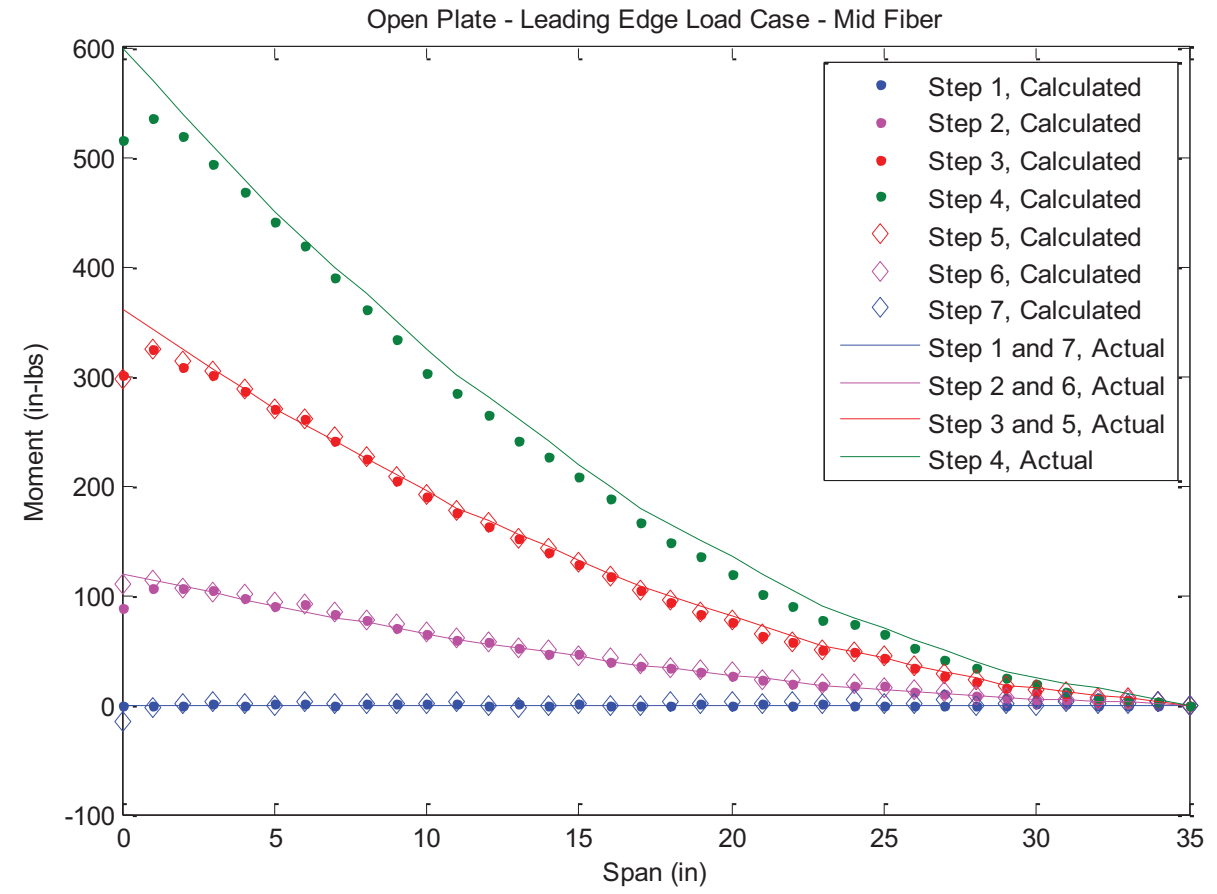

Figure A2_28. Open plate load results for middle fiber during leading edge load case. 


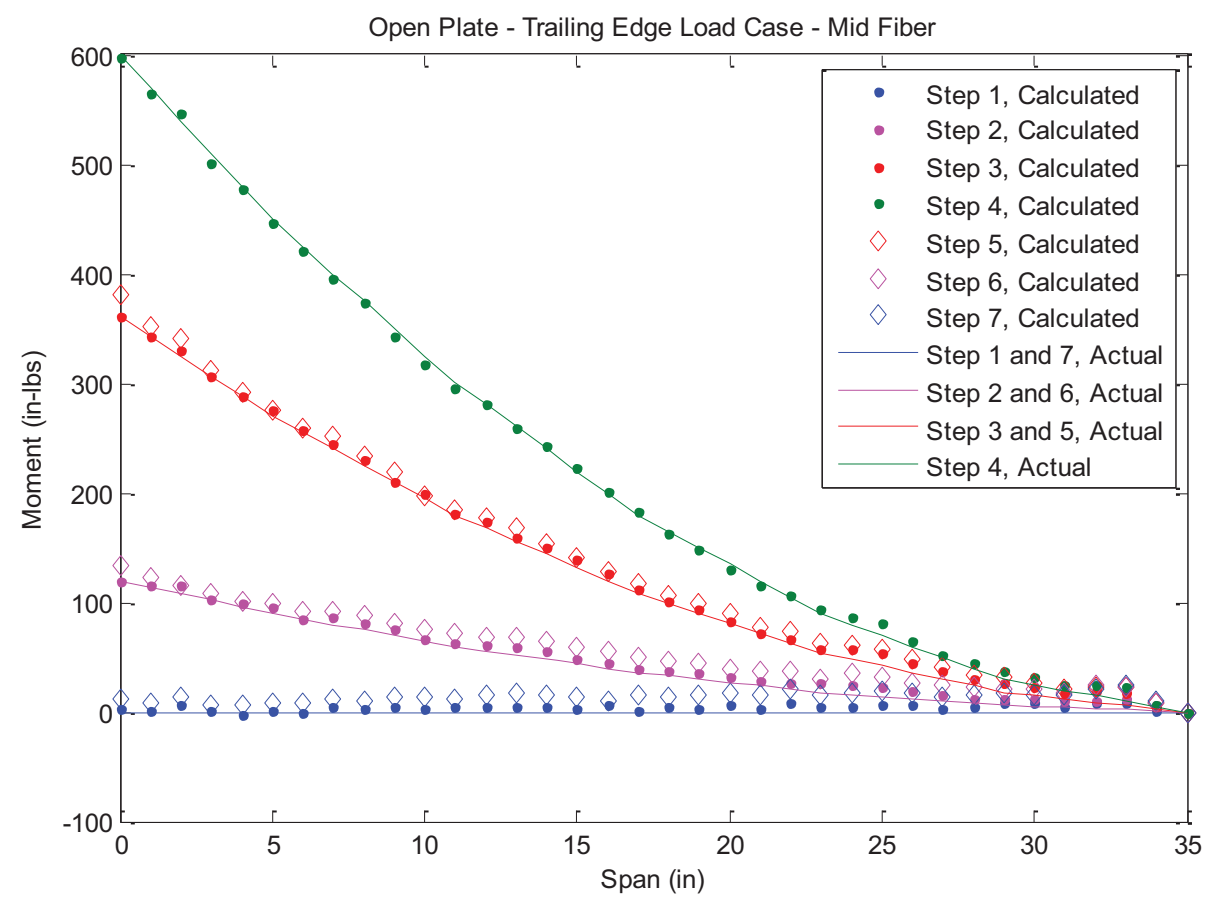

Figure A2_29. Open plate load results for middle fiber during trailing edge load case. 